\begin{abstract}
Universidade de São Paulo
Escola Politécnica

Departamento de Engenharia Metalúrgica e de Materiais
\end{abstract}

Mariane Yuka Tsubaki Oide

\title{
SISTEMAS POLIMÉRICOS SEMICONDUTORES PARA APLICAÇÃo COMO CAMADA ATIVA EM LED
}

São Paulo 

Mariane Yuka Tsubaki Oide

\title{
SISTEMAS POLIMÉRICOS SEMICONDUTORES PARA APLICAÇÃO COMO CAMADA ATIVA EM LED
}

\author{
Versão Corrigida
}

Dissertação apresentada ao Departamento de Engenharia Metalúrgica e de Materiais da Escola Politécnica da Universidade de São Paulo para obtenção do título de Mestre em Ciências.

Área de concentração:

Engenharia Metalúrgica e de Materiais

Orientadora: Profa ${ }^{\mathrm{a}}$. Dra‥ Wang Shu Hui

São Paulo 
Autorizo a reprodução e divulgação total ou parcial deste trabalho, por qualquer meio convencional ou eletrônico, para fins de estudo e pesquisa, desde que citada a fonte.

Este exemplar foi revisado e alterado em relação à versão original, sob responsabilidade única do autor e com a anuência de seu orientador.

São Paulo, de de 2019.

Assinatura do autor

Assinatura do orientador

Catalogação-na-publicação

Oide, Mariane Yuka Tsubaki

Sistemas poliméricos semicondutores para aplicação como camada ativa em LED / M. Y. T. Oide -- versão corr. -- São Paulo, 2019. $119 \mathrm{p}$.

Dissertação (Mestrado) - Escola Politécnica da Universidade de São Paulo. Departamento de Engenharia Metalúrgica e de Materiais.

1.POLÍMEROS (MATERIAIS) 2.SEMICONDUTORES 3.FILMES FINOS 4.OPTOELETRÔNICA ver ÓPTICA ELETRÔNICA I.Universidade de São Paulo. Escola Politécnica. Departamento de Engenharia Metalúrgica e de Materiais II.t. 
Nome: OIDE, Mariane Yuka Tsubaki

Título: Sistemas poliméricos semicondutores para aplicação como camada ativa em LED

Dissertação apresentada à Escola Politécnica da Universidade de São Paulo para a obtenção do título de Mestre em Ciências

Aprovado em:

Banca Examinadora

Profa. Dra.

Instituição:

Julgamento:

Prof. Dr.

Instituição:

Julgamento:

Prof. Dr.

Instituição:

Julgamento: 



\section{Agradecimentos}

Ao Departamento de Engenharia Metalúrgica e de Materiais da Escola Politécnica da Universidade de São Paulo pela oportunidade de realização do curso de mestrado.

Ao Conselho Nacional de Desenvolvimento Científico e Tecnológico pela concessão da bolsa de mestrado para o desenvolvimento dessa pesquisa.

À Prof ${ }^{a}$. Dr ${ }^{a}$. Wang Shu Hui pelos ensinamentos, pela dedicação nos momentos mais adversos e pela orientação.

Aos Prof. Dr. Roberto Koji Onmori e Prof. Dr. Fernando Josepetti Fonseca por disponibilizarem o Laboratório do Grupo de Eletrônica Molecular do Departamento de Engenharia de Sistemas Eletrônicos da Escola Politécnica da Universidade de São Paulo.

Aos meus colegas do Laboratório de Engenharia de Macromoléculas: Dr. Emerson Roberto Santos, Me. Satoru Yoshida e Me. Katia Yabunaka Sakaguti pelo companheirismo e pela ajuda no desenvolvimento de ideias e soluções acerca do trabalho de pesquisa desenvolvido. 

"Cada sonho que você deixa para trás, é um pedaço do seu futuro que deixa de existir."

(Steve Jobs) 



\section{Resumo}

Diodos poliméricos emissores de luz (PLEDs) foram produzidos utilizando poli(vinil-carbazol) (PVK), poli(2,7-(9,9-dioctilfluoreno)) (PFO) e poli((1,4-fenileno-2flúor)-alt-2,7-(9,9-dioctilfluoreno)) ( $\left.\mathrm{PF}_{\mathrm{PF}}\right)$ dopados com diferentes concentrações de dopante fosforescente tris(2-fenilpiridinato) de irídio(III) $\left[\operatorname{Ir}(\mathrm{ppy})_{3}\right]$ como camada ativa. Os resultados mostraram que o dispositivo a base de PFO dopado com $4 \%$ em massa de $\operatorname{Ir}(\mathrm{ppy})_{3}$ apresentou as maiores eficiências de corrente e de potência luminosa e o espectro eletromagnético do PLED a base de PVK puro apresentou emissão em $540 \mathrm{~nm}$, sugerindo um desbalanceamento de cargas e emissão do óxido de zinco dopado com alumínio (AZO), camada injetora. Assim, estudos da influência da massa molar média do PVK e de sistemas híbridos PVK:AZO nas propriedades elétricas e ópticas dos PLEDs foram elaborados. Resultados mostraram que o AZO possui propriedades foto/eletroluminescentes e é responsável pela emissão larga na região do visível. Os dispositivos híbridos apresentaram emissão próxima ao branco puro, atingindo-se uma pureza de 0,19.

Palavras-chave: $\operatorname{Ir}(\mathrm{ppy})_{3}$, Polifluoreno, PVK, AZO, WPLED. 



\begin{abstract}
Polymer light emiting diodes (PLEDs) were manufactured using poly(9vinylcarbazole) (PVK), poly(9,9-dioctylfluorene) (PFO) and poly(9,9-dioctylfluorenealt-1,4-fluorphenylene) (PF $\left.F_{P F}\right)$ doped with different concentrations of tris-(2phenylpyridinate) iridium(III) [Ir(ppy) 3$]$,a phosphorescent dye, as the active layer. Results showed that PFO based devices doped with 4 wt. \% of $\operatorname{Ir}(\mathrm{ppy})_{3}$ presented the highest current and power efficiencies, and the PVK based devices' electroluminescence spectrum showed an emission centered at $540 \mathrm{~nm}$, suggesting that a charge unbalance and light emission from the injection layer of aluminum doped zinc oxide (AZO) occurred. Therefore, studies based on the PVK:AZO system and different PVK's average molar masses were elaborated to observe the PLEDs' electrical and optical properties. Results showed that $A Z O$ is $a$ photo/electroluminescent material and it is responsible for the broad emission in the visible range. The hybrid device showed near pure white light emission and its purity reached 0.19 .
\end{abstract}

Key-words: Ir(ppy) ${ }_{3}$, Polyfluorene, PVK, AZO, WPLED. 



\section{Lista de Figuras}

Figura 1 - Esquematização de uma estrutura básica de um OLED. ................7

Figura 2 - Diagrama de energia de um OLED típica contendo múltiplas camadas.

Figura 3 - Esquematização de um PLED.................................................

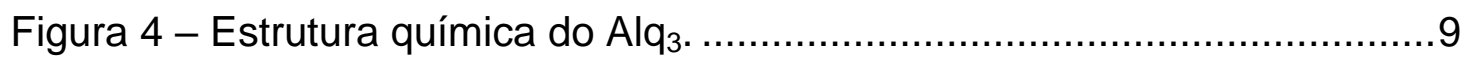

Figura 5 - Estrutura química do PEDOT e do PSS. ....................................

Figura 6 - Estrutura conjugada do acetileno. ............................................10

Figura 7 - Combinação entre dois átomos que possuem um orbital 1s na camada de valência. 10

Figura 8 - Diagrama de níveis de energia para a formação dos orbitais ligante e antiligante a partir de dois orbitais $1 \mathrm{~s}$. 11

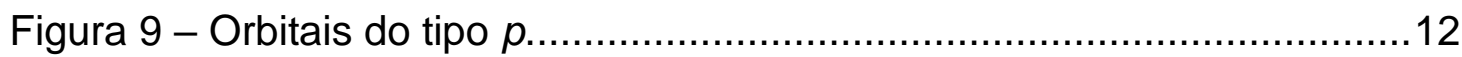

Figura 10 - Orbital molecular ligante e antiligante: a) Formação ligação $\sigma$ e b) Formação da ligação m. 12

Figura 11 - Distribuição eletrônica do átomo de carbono...............................13

Figura 12 - Hibridização $\mathrm{sp}^{2}$ para a formação do eteno. ...............................13

Figura 13 - Diagrama de níveis de energia para a formação do orbital ligante e antiligante no etileno. .14

Figura 14 - Formação de bandas de energia em polímeros conjugados. ......15

Figura 15 - Diagrama de bandas para condutores, semicondutores e isolantes. 16

Figura 16 - Esquematização das principais etapas na eletroluminescência. .16

Figura 17 - Estados dos spins na formação de um éxciton...........................17

Figura 18 - Diagrama de Jablonski. ...................................................18

Figura 19 - Esquematização do processo de formação de éxcitons na eletroluminescência 19

Figura 20 - Diagrama de energia do hospedeiro e do dopante. 20 
Figura 21 - Mecanismos envolvidos na fosforescência de sistemas hospedeiro/dopante.

Figura 22 - Esquematização de uma lâmina contendo 4 dispositivos montados no laboratório: a) Vista superior e b) Vista lateral.

Figura 23 - Esquematização da lâmina de vidro com ITO antes e depois da corrosão. 27

Figura 24 - Esquematização do processo de preparação das soluções. …... 28

Figura 25 - Esquematização da técnica de spin-coating para a formação de filmes finos. 31

Figura 26 - Esquematização do processo de deposição dos filmes poliméricos e de AZO: a) Substrato com as 4 trilhas de ITO; b) Deposição do PEDOT:PSS; c) Deposição da camada emissora e d) Deposição da camada de AZO. 32

Figura 27 - Esquematização do posicionamento da máscara mecânica em relação à lâmina contendo todos os filmes depositados por via úmida. 33

Figura 28 - Esquematização da câmara de evaporação para a deposição de alumínio. 34

Figura 29 - Esquematização da lâmina final contendo 4 dispositivos com área emissiva de $9 \mathrm{~mm}^{2}$ destacado em vermelho. 35

Figura 30 - Fonte de tensão programável Keithley, modelo 2400. 36

Figura 31 - Equipamento da Konica Minolta, modelo CS-200 capaz de medir a luminância e determinar as coordenadas de cromaticidade dos dispositivos eletroluminescentes. 36

Figura 32 - Diagrama de cromaticidade CIE 1931 37

Figura 33 - Espectrorradiômetro da Luzchem, modelo SPR-03 utilizado para a obtenção dos espectros eletroluminescentes. 38

Figura 34 - Influência da polarização na curva $\mathrm{J} \times \mathrm{V}$ do dispositivo contendo apenas o PVK como a camada emissora. 40

Figura 35 - Influência da polarização na curva $\mathrm{J} \times \mathrm{V}$ do dispositivo contendo apenas o PFO como a camada emissora. 40 
Figura 36 - Influência da polarização na curva $\mathrm{J} \times \mathrm{V}$ do dispositivo contendo apenas o $\mathrm{PF}_{\mathrm{PF}}$ como a camada emissora.

Figura 37 - Curvas $\mathrm{J}$ x V dos dispositivos baseados no PVK contendo a curva ampliada da proporção Polímero: Dopante 95:5.

Figura 38 - Diagrama das bandas de energias dos dispositivos baseados no PVK. 43

Figura 39 - Curva $\mathrm{J}$ x V dos dispositivos baseados no PFO. .44

Figura 40 - Diagrama das bandas de energias dos dispositivos baseados no PFO. .45

Figura 41 - Curva $\mathrm{J}$ x V para os dispositivos baseados no $\mathrm{PF}_{\mathrm{PF}}$. .46

Figura 42 - Eficiência de corrente em função da tensão aplicada para os dispositivos baseados em: a) PVK, b) PFO e c) PF $\mathrm{PF}_{\text {. }}$ .48

Figura 43 - Eficiência luminosa em função da tensão aplicada para os dispositivos baseados em: a) PVK, b) PFO e c) $\mathrm{PF}_{\mathrm{PF}}$. 49

Figura 44 - Fotografias tiradas dos dispositivos acesos contendo: a) PVK, b)

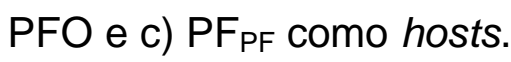

Figura 45 - Diagrama de cromaticidade dos dispositivos a base de PVK polarizados a: 1) $7 \mathrm{~V}$, 2) $10 \mathrm{~V} \mathrm{e} \mathrm{3)} 13 \mathrm{~V}$. .53

Figura 46 - Diagrama de cromaticidade dos dispositivos a base de PFO polarizados a: 1) $7 \mathrm{~V}$, 2) $10 \mathrm{~V} \mathrm{e} \mathrm{3)} 13 \mathrm{~V}$. .54

Figura 47 - Diagrama de cromaticidade dos dispositivos a base de $\mathrm{PF}_{\mathrm{PF}}$ polarizados a: 1) $7 \mathrm{~V}$, 2) $10 \mathrm{~V}$ e 3) $13 \mathrm{~V}$. .54

Figura 48 - Espectros de eletroluminescência dos dispositivos a base de: a) PVK a 6 V, b) PFO a 6 V e c) $P_{P F F}$ a 7 V. .59

Figura 49 - Espectros de eletroluminescência normalizados para os dispositivos baseados em PVK a 6 V.

Figura 50 - Deconvolução dos espectros de eletroluminescência para a proporção PVK:Ir(ppy) ${ }_{3}$ de: a) 100:0; b) 95:5; c) 90:10 e d) 85:15 a 6 V. 62 
Figura 51 - Espectros de eletroluminescência normalizados para os dispositivos baseados em PFO a 6 V. 64

Figura 52 - Deconvolução dos espectros de eletroluminescência para a proporção PFO:Ir(ppy) ${ }_{3}$ de: a) 100:0; b) 98:2; c) 96:4 e d) 93:7 a 6 V. .65

Figura 53 - Espectros de eletroluminescência normalizados para os dispositivos baseados em $\mathrm{PF}_{\mathrm{PF}}$ a $7 \mathrm{~V}$. 67

Figura 54 - Deconvolução dos espectros de eletroluminescência para a proporção $P F_{P F}: \operatorname{Ir}(p p y)_{3}$ de: a) 100:0; b) 98:2; c) 96:4 e d) 93:7 a 7 V. 68

Figura 55 - Curva J x V da quarta polarização dos dispositivos TI, TII e TIII. 70

Figura 56 - Fotografias dos dispositivos acesos: a) TI, b) TII e c) TIII. 71

Figura 57 - Deconvolução dos espectros eletromagnéticos a $7 \vee$ obtidos dos dispositivos TI, TII e TIII. 71

Figura 58 - Esquematização dos níveis de energia e do mecanismo de eletroluminescência dos dispositivos TI e TII. 73

Figura 59 - Esquematização dos níveis de energia e do mecanismo de eletroluminescência dos dispositivos TIII. 75

Figura 60 - Espectros de eletroluminescência normalizados para todos os dispositivos à base de PVK puro a 7 V (TI, TII e TIII) e a 6 V (PVK utilizado na Seção 6.1.) 76

Figura 61 - Curva J x V e fotografias dos dispositivos contendo (a) PVK:AZO e (b) PVK como camada ativa e suas respectivas tensões de limiar.

Figura 62 - Luminância e eficiência de corrente em função da tensão aplicada dos dispositivos contendo PVK e PVK:AZO como camada ativa. 78

Figura 63 - Espectro de eletroluminescência normalizado e o diagrama de cromaticidade CIE 1931 dos dispositivos a base de PVK e PVK:AZO a $10 \mathrm{~V}$. 79

Figura 64 - Espectros de eletroluminescência a $10 \mathrm{~V}$ normalizados e respectivas componentes de Gauss para: a) PVK e b) PVK:AZO. 80

Figura 65 - Espectro de absorção da solução de AZO diluído em clorofórmio contendo a curva ampliada entre $325 \mathrm{~nm}$ e $550 \mathrm{~nm}$. 
Figura 66 - Solução diluída de AZO em clorofórmio excitado em 320 nm (filtro de $360 \mathrm{~nm})$.

Figura 67 - Espectros de fotoluminescência das soluções de AZO: a) concentrado e b) diluído em clorofórmio excitado em diferentes comprimentos de onda.

Figura 68 - Espectros de fotoluminescência do AZO diluído em clorofórmio deconvoluídos em componentes Gaussianos excitados em: a) 320 nm e b) 380 nm.

Figura 69 - Diagrama sugerido dos mecanismos das emissões observadas experimentalmente. .86

Figura 70 - Espectro de absorção na região UV-Vis do AZO, PVK e PVK:AZO diluídos em clorofórmio.

Figura 71 - Esquematização do processo de excitação em 320 nm, 370 nm e $400 \mathrm{~nm}$ do sistema híbrido PVK:AZO. .88

Figura 72 - Espectro de fotoluminescência (original e normalizada) à temperatura ambiente das soluções diluídas de PVK, AZO e PVK:AZO em clorofórmio excitados em: a) $320 \mathrm{~nm}$, b) $370 \mathrm{~nm}$ e c) $400 \mathrm{~nm}$. .90

Figura 73 - Espectro de absorção do AZO diluído em clorofórmio e espectro fotoluminescente da solução diluída de PVK em clorofórmio excitado em 320 nm...91

Figura 74 - Esquematização do mecanismo sugerido para a transferência de energia entre PVK e AZO. .92

Figura 75 - Fotografias de diferentes dispositivos PVK:AZO acesos na mesma lâmina 1 durante a polarização. .92

Figura 76 - Fotografias de diferentes dispositivos PVK:AZO acesos na mesma lâmina 2 durante a polarização. .93

Figura 77 - Influência da tensão aplicada no espectro de eletroluminescência no mesmo dispositivo da: a) lâmina 1 e b) lâmina 2 .94

Figura 78 - Deconvolução dos espectros de eletroluminescência a: a) 12,5 V; b) $13,5 \mathrm{~V}$ e c) $14 \mathrm{~V}$ para o mesmo dispositivo da lâmina 1. .95 
Figura 79 - Deconvolução dos espectros de eletroluminescência a: a) $11 \mathrm{~V}$ e b) $12 \mathrm{~V}$ para o mesmo dispositivo da lâmina 2 .

Figura 80 - Esquematização dos níveis de energia e do mecanismo de eletroluminescência dos dispositivos de PVK:AZO. 98

Figura 81 - Curva $\mathrm{J} \times \mathrm{V}$ da quarta polarização e fotografia obtida do dispositivo aceso contendo PMMA:AZO como camada emissora. 99

Figura 82 - Esquematização dos níveis de energia e do mecanismo de eletroluminescência dos dispositivos de PMMA:AZO. 100

Figura 83 - Influência da polarização na curva $\mathrm{J} \times \mathrm{V}$ do dispositivo de PVK com adição de $5 \%$ em massa de dopante.

Figura 84 - Influência da polarização na curva $\mathrm{J} \times \mathrm{V}$ do dispositivo de PVK com adição de $10 \%$ em massa de dopante.

Figura 85 - Influência da polarização na curva $\mathrm{J}$ x V do dispositivo de PVK com adição de $15 \%$ em massa de dopante.

Figura 86 - Influência da polarização na curva $\mathrm{J}$ x V do dispositivo de PFO com adição de $2 \%$ em massa de dopante.

Figura 87 - Influência da polarização na curva $\mathrm{J} \times \mathrm{V}$ do dispositivo de PFO com adição de $4 \%$ em massa de dopante. 113

Figura 88 - Influência da polarização na curva $\mathrm{J} \times \mathrm{V}$ do dispositivo de PFO com adição de $7 \%$ em massa de dopante.

Figura 89 - Influência da polarização na curva $\mathrm{J} \times \mathrm{V}$ do dispositivo de PF com adição de $2 \%$ em massa de dopante.

Figura 90 - Influência da polarização na curva $\mathrm{J} \times \mathrm{V}$ do dispositivo de PF $\mathrm{PF}$ com adição de $4 \%$ em massa de dopante.

Figura 91 - Influência da polarização na curva $\mathrm{J} \times \mathrm{V}$ do dispositivo de PF com adição de $7 \%$ em massa de dopante. 116

Figura 92 - Influência da polarização na curva $\mathrm{J}$ x V do dispositivo de TI. .. 117

Figura 93 - Influência da polarização na curva J x V do dispositivo TII. ...... 117

Figura 94 - Influência da polarização na curva $\mathrm{J}$ x V do dispositivo TIII. ..... 118 
Figura 95 - Influência da polarização na curva $\mathrm{J}$ x $\mathrm{V}$ do dispositivo PVK:AZO. 119 



\section{Lista de Tabelas}

Tabela 1 - Tempo de vida e eficiência para diferentes tecnologias de iluminação.

Tabela 2 - Posicionamento e origens propostas para a fotoluminescência do $\mathrm{ZnO}$

Tabela 3 - Materiais utilizados durante o trabalho e suas respectivas funções e fabricantes.

Tabela 4 - HOMO e LUMO dos materiais utilizados na montagem dos PLEDs.

Tabela 5 - Concentrações mássicas das soluções iniciais preparadas para a dopagem.

Tabela 6 - Proporções mássicas Polímero: $\operatorname{Ir}(\mathrm{ppy})_{3}$ das soluções preparadas para a deposição dos filmes finos da camada emissora.

Tabela 7 - Concentrações das soluções utilizadas para a deposição dos filmes poliméricos à base de PVK.

Tabela 8 - Parâmetros utilizados no processo de spin-coating e o solvente utilizado para a decapagem para cada tipo de filme.

Tabela 9 - Influência no número de polarizações na tensão de limiar dos dispositivos de PVK, PFO e PFPF puros.

Tabela 10 - Tensões de limiar para os dispositivos baseados em PVK, PFO e $\mathrm{PF}_{\mathrm{PF}}$ .46

Tabela 11 - Máxima luminância, eficiência de corrente e eficiência de potência luminosa atingida pelos dispositivos de PVK .50

Tabela 12 - Máxima luminância, eficiência de corrente e eficiência de potência luminosa atingida pelos dispositivos de PFO.

Tabela 13 - Máxima luminância, eficiência de corrente e eficiência de potência luminosa atingida pelos dispositivos de PF $F_{P F}$. .52

Tabela 14 - Influência da tensão na pureza e do comprimento de onda dominante $\left(\lambda_{\text {dom }}\right)$ nos dispositivos de PVK. .56 
Tabela 15 - Influência da tensão na pureza e do comprimento de onda dominante $\left(\lambda_{\text {dom }}\right)$ nos dispositivos de PFO.

Tabela 16 - Influência da tensão na pureza e do comprimento de onda dominante $\left(\lambda_{\text {dom }}\right)$ nos dispositivos de $\mathrm{PF}_{\mathrm{PF}}$. 58

Tabela 17 - Picos dos espectros eletroluminescentes dos dispositivos de PVK a $6 \mathrm{~V}$.

Tabela 18 - Picos dos espectros eletroluminescentes dos dispositivos de PFO a 6 V. 66

Tabela 19 - Picos dos espectros eletroluminescentes dos dispositivos de $\mathrm{PF}_{\mathrm{PF}}$ a $7 \mathrm{~V}$. 69

Tabela 20 - Origem sugerido para cada componente Gaussiano observado na lâmina 1 . 96

Tabela 21 - Origem sugerido para cada componente Gaussiano observado na lâmina 2.

Tabela 22 - Influência da polarização na tensão de limiar dos dispositivos de PVK. 112

Tabela 23 - Influência da polarização na tensão de limiar dos dispositivos de PFO. 114

Tabela 24 - Influência da polarização na tensão de limiar dos dispositivos de PF $\mathrm{PF}$. 116

Tabela 25 - Influência da polarização na tensão de limiar dos dispositivos de PVK puro (TI, TII e TIII). 118 


\section{Lista de Equações}

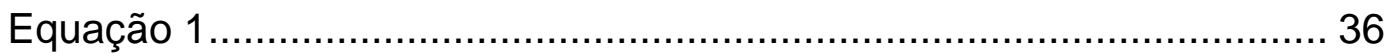

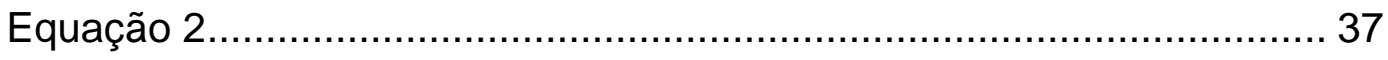

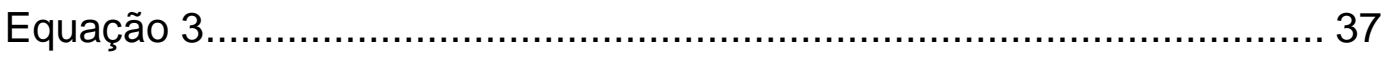





\section{Lista de Siglas}
A
Ampère
Al
Alumínio
$\mathrm{Alq}_{3}$
Tris(8-hidroxiquinolina) de Alumínio
AZO
Óxido de Zinco Dopado com Alumínio
CB
Conduction Band - Banda de Condução
$\mathrm{cd}$
Candela
$\mathrm{cm}$
Centímetro
$\mathrm{EBL}$
Electron Blocking Layer
EIL
Electron Injection Layer
EML
Emissive Layer - Camada ativa
ETL
Electron transport layer - Camada transportadora de elétron
$\mathrm{eV}$
Elétron-Volt
GEM
Grupo de Eletrônica Molecular do PSI/POLI
$\mathrm{HBL}$
Hole Blocking Layer- Camada Bloqueadora de Lacunas
$\mathrm{HCl}$
Ácido Clorídrico
HIL
Hole Injection Layer - Camada Injetora de Lacunas
HOMO
Highest Occupied Molecular Orbital
HTL
Hole Transport Layer - Camada Transportadora de Buraco
Ir
Irídio
$\operatorname{Ir}(\text { ppy })_{3}$
Tris(2-Fenilpiridinato) de Irídio (III)
ISC
Intersystem Crossing - Cruzamento Intersistema
ITO
Indium Tin Oxide - Óxido de Índio-Estanho
$\mathrm{J}$
Densidade de Corrente
LED
Light Emitting Diode
Li Lítio
Im Lúmen
LUMO Lowest Unoccupied Molecular Orbital
$\mathrm{mA} \quad$ Miliampère
$\mathrm{M}_{\mathrm{w}}$
Massa Molar Média Ponderada
$\mathrm{mg}$
Miligramas 


\begin{tabular}{|c|c|}
\hline $\mathrm{mL}$ & Mililitros \\
\hline $\mathrm{mm}$ & Milímetros \\
\hline $\mathrm{ms}$ & Milissegundos \\
\hline$\mu \mathrm{L}$ & Microlitros \\
\hline$\mu \mathrm{m}$ & Micrômetros \\
\hline $\mathrm{nm}$ & Nanometros \\
\hline ns & Nanossegundos \\
\hline $\mathrm{O}_{\mathrm{i}}$ & Oxigênio Intersticial \\
\hline OLED & Organic Light Emitting Diode \\
\hline Os & Ósmio \\
\hline $\mathrm{O}_{\mathrm{Zn}}$ & Antisítio de Oxigênio \\
\hline PEDOT:PSS & Poli(3,4-etilenodioxitiofeno): Poli(4-sulfonato-estireno) \\
\hline PFO & Poli(2,7-(9,9-Dioctilfluoreno)) \\
\hline $\mathrm{PF}_{\mathrm{PF}}$ & Poli((1,4-Fenileno-2-Flúor)-alt-2,7-(9,9-Dioctilfluoreno)) \\
\hline PhLED & Phosphorescent Light Emitting Diode \\
\hline PLED & Polymer Light Emitting Diode \\
\hline PMMA & Poli(metacrilato de metila) \\
\hline $\mathrm{Pt}$ & Platina \\
\hline PTFE & Politetrafluoroetileno \\
\hline PtOEP & Octaetilporfirina de Platina (II) \\
\hline PVK & Poli(9-Vinilcarbazol) \\
\hline $\mathrm{Ru}$ & Rutênio \\
\hline $\mathrm{S}_{0}$ & Estado Fundamental Singleto \\
\hline $\mathrm{S}_{1}$ & Estado Excitado Singleto de Menor Energia \\
\hline$S_{n}$ & Estado Excitado Singleto \\
\hline $\mathrm{T}_{1}$ & Estado Excitado Tripleto de Menor Energia \\
\hline$T_{n}$ & Estado Excitado Tripleto \\
\hline USP & Universidade de São Paulo \\
\hline UV & Ultravioleta \\
\hline UV-Vis & Ultravioleta-Visível \\
\hline V & Volts \\
\hline VB & Valence Band-Banda de Valência \\
\hline$v_{0}$ & Vacância de Oxigênio \\
\hline
\end{tabular}




$\begin{array}{ll}\mathrm{V}_{0}^{+} & \text {Vacância de Oxigênio Monovalente } \\ \mathrm{V}_{0}{ }^{2+} & \text { Vacância de Oxigênio Bivalente } \\ \mathrm{V}_{\mathrm{Zn}} & \text { Vacância de Zinco } \\ \mathrm{W} & \text { Watt } \\ \text { WPLED } & \text { White Polymer Light Emitting Diode } \\ \mathrm{Zn}_{\mathrm{i}} & \text { Zinco Intersticial } \\ \mathrm{Zn}_{\mathrm{i}}{ }^{-} & \text {Zinco Intersticial Monovalente } \\ \mathrm{Zn}_{\mathrm{i}}{ }^{2-} & \text { Zinco Intersticial Bivalente } \\ \mathrm{ZnO} & \text { Óxido de Zinco } \\ \mathrm{Zn}_{\circ} & \text { Antisítio de Zinco }\end{array}$





\section{Lista de Símbolos}

$\begin{array}{ll}\lambda_{\text {dom }} & \text { Comprimento de Onda Dominante } \\ \lambda_{\text {onset }} & \text { Comprimento de Onda de Onset } \\ \pi & \text { Orbital Molecular Ligante "Pi" } \\ \sigma & \text { Orbital Molecular Ligante "Sigma" } \\ \pi^{*} & \text { Orbital Molecular Antigante "Pi" } \\ \sigma^{*} & \text { Orbital Molecular Antigante "Sigma" } \\ E_{g} & \text { Band Gap Energy - Energia de Gap } \\ \eta_{c} & \text { Eficiência de Corrente } \\ \eta_{P} & \text { Eficiência de Potência Luminosa } \\ L & \text { Luminância } \\ V & \text { Tensão } \\ \Omega & \text { Ohm }\end{array}$





\section{Sumário}

1 Objetivo

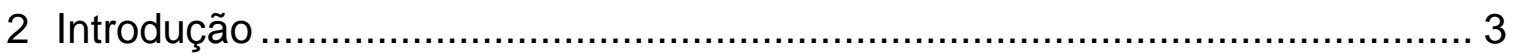

3 Revisão Bibliográfica...................................................................... 7

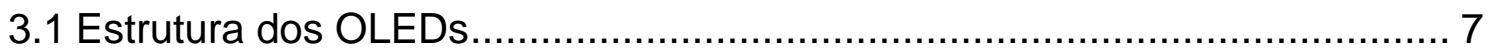

3.2 Condução de Cargas em Polímeros Conjugados .................................... 10

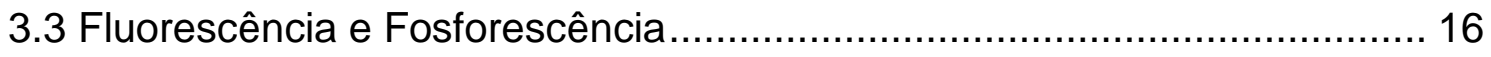

3.4 Sistema polímero hospedeiro e dopante fosforescente …....................... 19

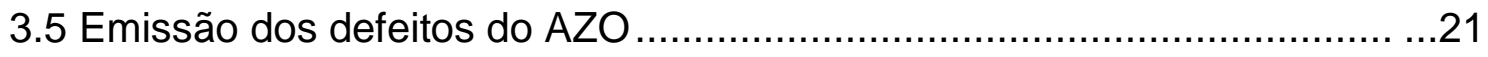

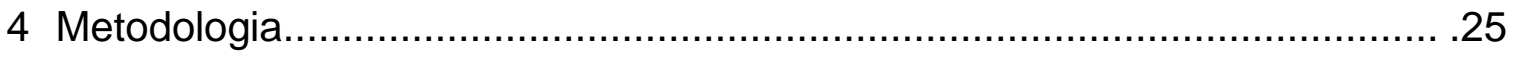

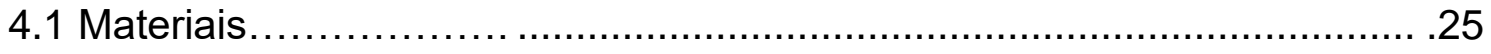

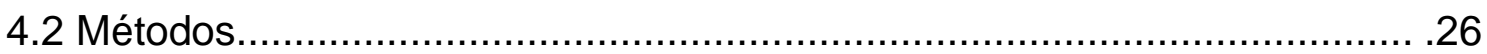

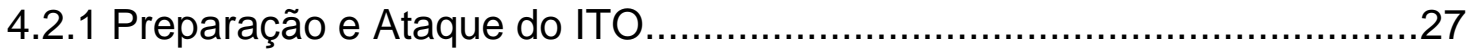

4.2.2 Preparação das soluções para a formação da camada emissora............28

4.2.3 Deposição dos filmes finos poliméricos e do AZO..................................31

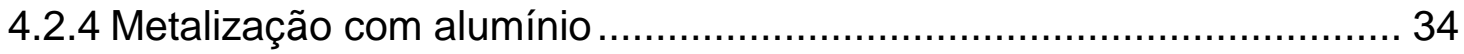

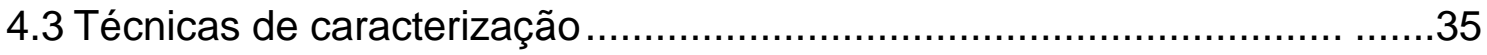

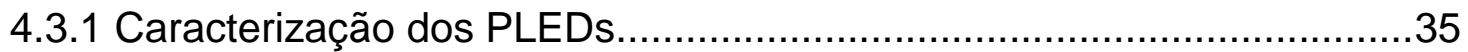

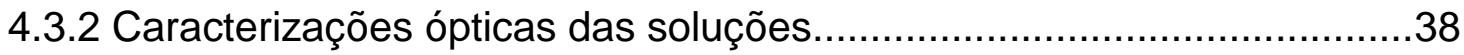

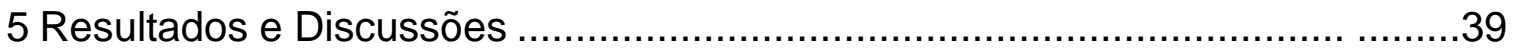

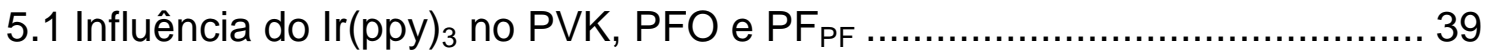

5.1.1 Influência do número de polarizações nas curvas $\mathrm{J}$ x V .........................39

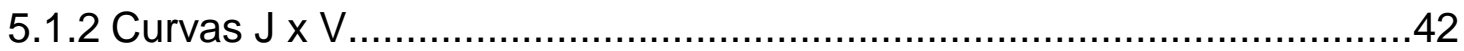

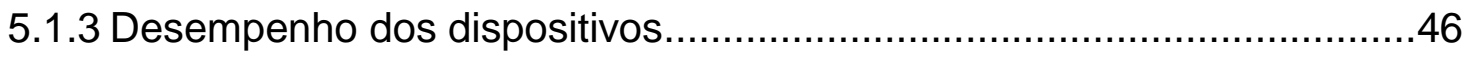

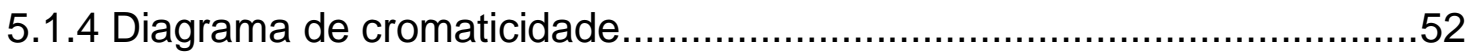

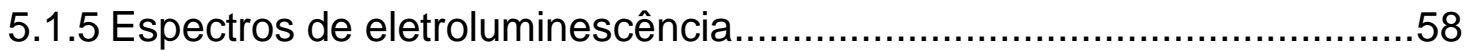

5.2 Estudo da massa molar de dispositivos a base de PVK ............................ 69

5.3 Comparação entre os dispositivos de PVK e PVK:AZO ............................ 76

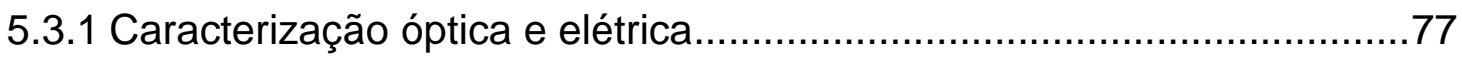

5.4 Espectros de Absorção e Fotoluminescência do AZO …........................... 80

5.5 UV-Vis e Fluorescência do sistema PVK:AZO ……................................. 87

5.6 Eletroluminescência do sistema PVK:AZO ……..................................... 92

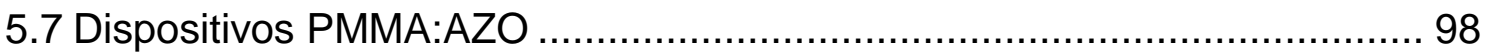




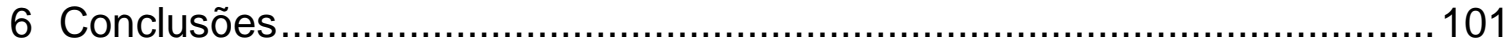

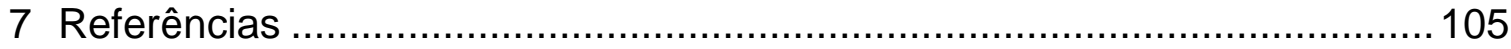

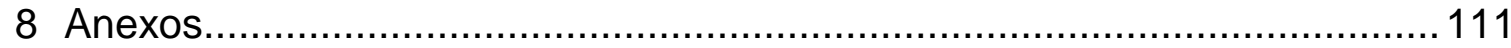

8.1 Curvas J x V para diferentes números de polarizações .............................111 


\section{Objetivo}

O objetivo deste trabalho é estudar diferentes sistemas poliméricos como camada ativa em PLEDs para entender os mecanismos envolvidos na interação dos componentes com diferentes níveis de energia de banda e de banda proibida (band gap energy).

Inicialmente, camadas emissoras (EML) foram dopadas para estudar a influência do tris(2-fenilpiridinato) de irídio (III) [Ir(ppy) $)_{3}$, cuja fosforescência ocorre na região verde do espectro eletromagnético, nas propriedades elétricas e eletroluminescentes de três polímeros distintos: $\mathrm{PVK}$, PFO e $\mathrm{PF}_{\mathrm{PF}}$, todos com emissão na região azul do espectro eletromagnético.

Além disso, dispositivos a base de PVK, com duas massas molares diferentes, e dispositivos com PVK:AZO (óxido de zinco dopado com alumínio) como camada emissora foram produzidos com o intuito de estudar a influência da emissão da camada injetora de elétrons (AZO) em PLEDs a base de PVK. 


\section{Introdução}

Em 1880, Thomas A. Edison introduziu o bulbo incandescente constituída por algodão carbonizado no seu interior sob vácuo, um grande avanço tecnológico na época, trazendo uma nova concepção de energia, em que eletricidade é convertida em luz, e conforto para as pessoas [1]. Desde então, a demanda por energia vem crescendo rapidamente, sendo necessário estudar soluções eficientes ou aplicações para diminuir o gasto de energia em processos de alto consumo energético [1].

Atualmente, cerca de $30 \%$ da eletricidade é utilizada em sistemas de iluminação, dentre eles estão os bulbos incandescentes de filamento de tungstênio, que possuem alto consumo de energia uma vez que apenas $15 \%$ da energia elétrica é transformada em luz e baixo tempo de vida (1000 h - 2000 h); as lâmpadas fluorescentes, que surgiram como uma alternativa para as lâmpadas incandescentes, que são basicamente um tubo de vidro recoberto por um material fosforescente cuja função é absorver a radiação ultravioleta (UV), emitida pelo vapor de mercúrio em baixa pressão, e emitir luz na região do visível; os diodos emissores de luz (LED) que possuem uma banda estreita de emissão e podem durar de $40000 \mathrm{~h}$ a 100000 h, dependendo da cor; e os diodos emissores de luz orgânicos (OLED) que vem sendo muito estudado e promete ser um forte candidato a dominar o sistema de iluminação devido à possibilidade de desenvolvimento de dispositivos de grande área ativa, baixo consumo energético e ecologicamente sustentável uma vez que não é utilizado materiais prejudiciais à saúde e ao meio ambiente, como o mercúrio [2-3]. A Tabela 1 mostra um resumo dos principais sistemas de iluminação atuais com seus respectivos tempo de vida e eficiência. 
Tabela 1 - Tempo de vida e eficiência para diferentes tecnologias de iluminação.

\begin{tabular}{ccc}
\hline Tecnologia & Tempo de Vida (h) & Eficiência (Im/W) \\
\hline Lâmpada Incandescente & $750-1500$ & $12-18$ \\
Lâmpada Halógena & $2000-4000$ & $16-29$ \\
$\begin{array}{c}\text { Lâmpada Linear } \\
\text { Fluorescente } \\
\text { Lâmpada Compacta } \\
\text { Fluorescente }\end{array}$ & 20000 & $80-100$ \\
LED & $6000-10000$ & $60-70$ \\
PLEDs Brancos & $>60000$ & $>100$ \\
\hline
\end{tabular}

Fonte: [3] Adaptado de Thejokalyani e Dhoble (2014, p. 450) e de [5].

A eletroluminescência, geração de luz pela injeção de cargas, em materiais orgânicos foi primeiramente observada nos anos 60 em monocristais de antraceno [4]. Apesar de estes materiais apresentarem alta eficiência quântica, necessitavam de altas tensões para serem acesas o que não possibilitou a sua aplicação [6]. Entretanto, o seu estudo permitiu o entendimento dos processos envolvidos na eletroluminescência dos materiais orgânicos e o desenvolvimento de estruturas eficientes para maximizar este fenômeno. Assim, em 1987, Tang e Van Slyke da Kodak desenvolveram OLEDs eficientes e com baixa tensão de operação por meio da evaporação sucessiva de filmes finos orgânicos [6]. Estes dispositivos consistiram em uma heteroestrutura $p$ - $n$ contendo uma camada transportadora de lacunas de diamina aromática, uma camada emissiva de tris-hidroxiquinolato de alumínio ( $\left.\mathrm{Alq}_{3}\right)$, ânodo de óxido de índio dopado com estanho (ITO) e um cátodo de uma liga de magnésio-prata [4]. Em 1990, Friend e colaboradores da Universidade de Cambridge desenvolveram diodos emissores de luz poliméricos (PLEDs) baseados em poli(vinileno-fenileno), que é um polímero conjugado, preparados por deposição via úmida [7].

Os OLEDs comerciais baseados em pequenas moléculas disponíveis atualmente são fabricados por deposição térmica em alto vácuo, tornando-os caros [8]. Assim, para que estes dispositivos sejam comercialmente competitivos, novas 
técnicas de deposição de baixo custo e de grande escala devem ser desenvolvidas [8].

Os PLEDs vêm sendo muito estudados como uma promessa de trazer esta versatilidade no processo de deposição dos filmes finos uma vez que as principais técnicas envolvidas são de baixo custo e de baixo consumo de energia, pois são baseadas em soluções como, por exemplo, ink-jet printing, spin coating, blade coating e assim por diante [2]. Entretanto, estes dispositivos apresentam baixa eficiência luminosa e curto tempo operacional de vida, principalmente, os PLEDs com emissão azul comparado aos PLEDs com emissão no vermelho e verde, dificultando a comercialização de full color displays e sistemas de iluminação [8]. Assim, compostos organometálicos fosforescentes baseados, principalmente, em complexos de metais de transição pesados, vêm sendo desenvolvidos para a obtenção de PLEDs de alta eficiência, também conhecidos como PhPLEDs [9]. Em 1998, Forrest e colaboradores reportaram pela primeira vez a eletrofosforescência em octaetilporfirina de prata(II) (PtOEP). Desde então, novos compostos com esta propriedade vêm sendo estudados, dentre eles, complexos de metais pesados como Os(II), Pt(II), Ru(II) e, principalmente, os complexos de $\operatorname{Ir}(\mathrm{III})$ devido à sua alta estabilidade, alta eficiência quântica de fotoluminescência e alta colimação espectral [9]. 


\section{Revisão Bibliográfica}

\subsection{Estrutura dos OLEDs}

Os OLEDs são dispositivos emissores de luz constituídos basicamente por sucessivas deposições de filmes finos orgânicos semicondutores situados entre dois eletrodos (cátodo e ânodo). Os primeiros dispositivos eram formados basicamente por uma estrutura simples contendo uma monocamada de material emissor (EML) conforme mostrado na Figura 1 [6]. Nos anos 60's, esta estrutura foi muito utilizada para o estudo da eletroluminescência no antraceno.

Figura 1 - Esquematização de uma estrutura básica de um OLED.

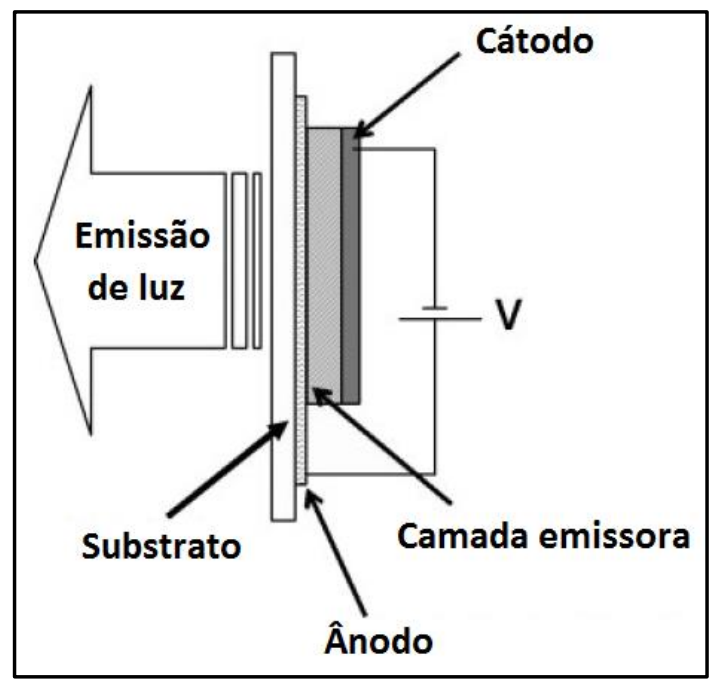

Fonte: [6] Geffroy, Le Roy e Prat (2006, p. 573).

Com o avanço dos estudos, novas camadas com funções especializadas foram introduzidas para aumentar a eficiência destes dispositivos (Figura 2), sendo elas: HIL (hole injection layer); HTL (hole transport layer); EBL (electron blocking layer); HBL (hole blocking layer); ETL (electron transport layer) e EIL (electron injection layer). 
Figura 2 - Diagrama de energia de um OLED típica contendo múltiplas camadas.

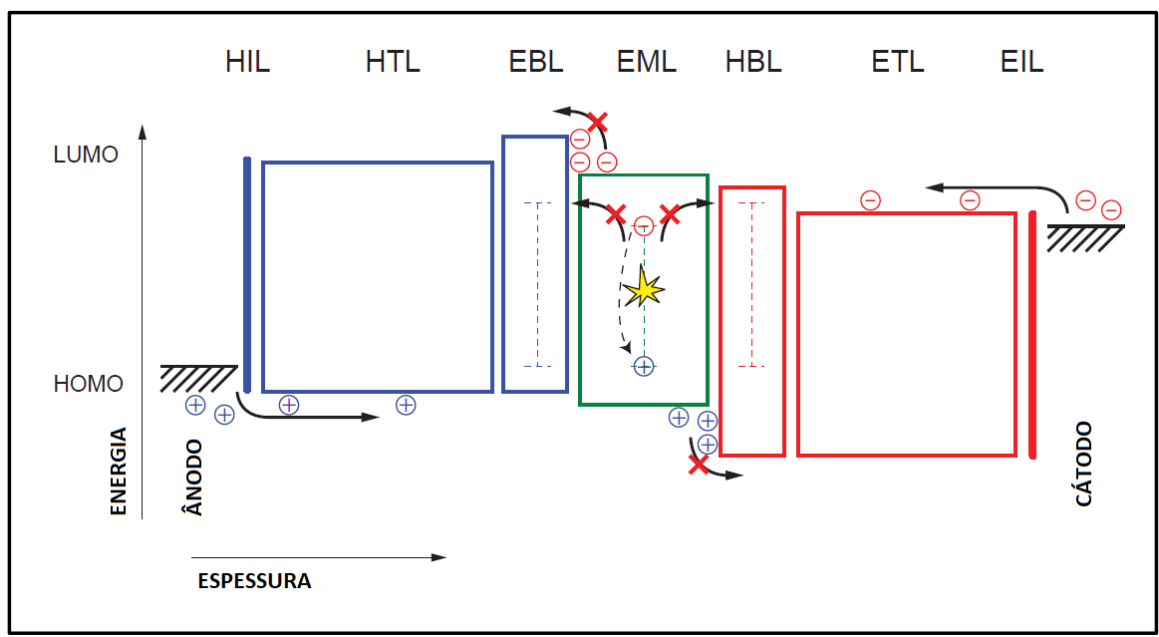

Fonte: [1] Reineke et. al. (2013, p.4).

O princípio de funcionamento dos OLEDs se baseia na injeção e transporte de elétrons e lacunas pelos seus respectivos eletrodos para o interior da camada emissora (material orgânico semicondutor) conforme mostrado na Figura 3. Quando estas cargas se encontram no interior do semicondutor, elas podem se recombinar, gerando luz e este fenômeno é denominado eletroluminescência.

Figura 3 - Esquematização de um OLED.

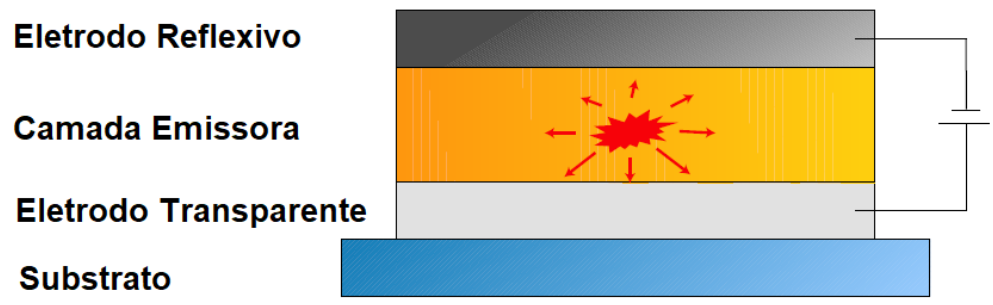

Fonte: [1] Reineke et. al. (2013, p. 3)

Para que essa injeção de carga ocorra de forma eficiente, o ânodo deve ser um metal com alta função trabalho (entre 4,5 e 5,1 eV), geralmente o óxido de estanho-índio (ITO), para a injeção de lacunas, enquanto que o cátodo deve ser um metal com baixa função trabalho (entre 2,9 e 4,0 eV), geralmente metais como alumínio, lítio, cálcio e magnésio. 
As camadas injetoras tanto de elétrons quanto de lacunas são responsáveis por facilitar a injeção de elétrons e lacunas do cátodo e do ânodo, respectivamente, para o interior da camada emissora. Estes materiais possuem alta mobilidade de cargas e alta temperatura de transição vítrea [3].

As camadas transportadoras de elétrons possuem boa capacidade de transportar elétrons, possuem alta afinidade eletrônica combinada com alto potencial de ionização, como o $\mathrm{Alq}_{3}$ (Figura 4) [3]. Enquanto que as camadas transportadoras de lacunas possuem baixo potencial de ionização combinado com baixa afinidade eletrônica, responsável por aceitar e transportar lacunas [3], sendo que o poli(3,4etilenodioxitiofeno) dopado com poli(estireno-4-sulfonato) (PEDOT:PSS) (Figura 5) é o mais utilizado. Na ausência de camadas bloqueadoras de elétrons e/ou lacunas, as camadas transportadoras devem ter também alto LUMO para bloquear os elétrons, enquanto que para bloquear as lacunas, elas devem ter baixo HOMO conforme mostrado na Figura 2.

Figura 4 - Estrutura química do $\mathrm{Alq}_{3}$.

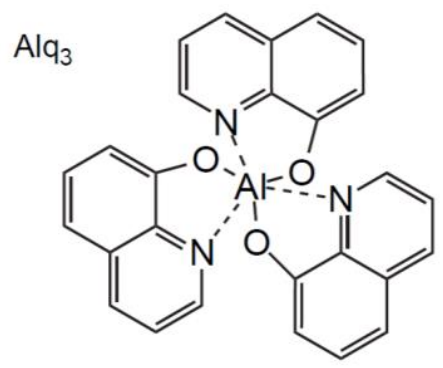

Fonte: [4] Friend (1999, p.121).

Figura 5 - Estrutura química do PEDOT e do PSS.<smiles>Cc1sc(C(C)(C)C)c2c1OCCO2</smiles>

PEDOT<smiles>CCC(C)C(c1ccc(S(=O)(=O)O)cc1)C(C)(C)C</smiles>

PSS

Fonte: [4] Friend (1999, p.122). 


\subsection{Condução de Cargas em Polímeros Conjugados}

O principal responsável pela condução elétrica em polímeros são os grandes sistemas conjugados, conforme mostrado na Figura 6 para o poliacetileno.

Figura 6 - Estrutura conjugada do acetileno.

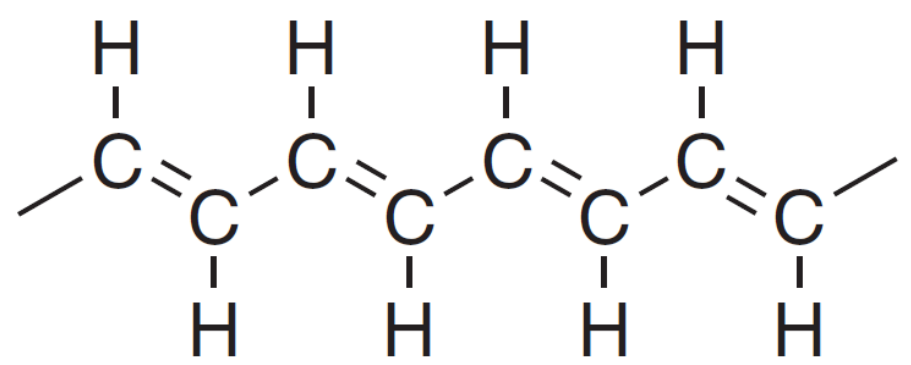

Fonte: [10] Geoghegan e Hadziioannou (2013, p. 3).

Assim, para se entender os principais mecanismos envolvidos, deve-se primeiramente entender a estrutura eletrônica formada quando átomos de carbono fazem ligações químicas entre si.

Quando átomos se ligam para formar moléculas, ligações químicas são formadas pela superposição dos orbitais atômicos da camada de valência, levando à formação dos orbitais moleculares, que podem ser ligantes (funções de onda dos orbitais atômicos em fase) ou anti-ligantes (funções de onda dos orbitais atômicos fora de fase) [11].

Figura 7 - Combinação entre dois átomos que possuem um orbital 1s na camada de valência.

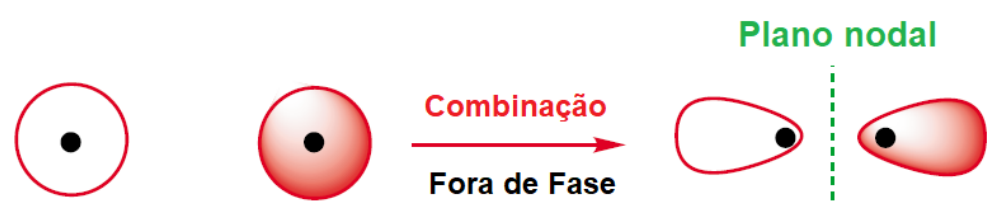

Dois orbitais 1s se combinam fora de fase para a formação de um orbital antiligante

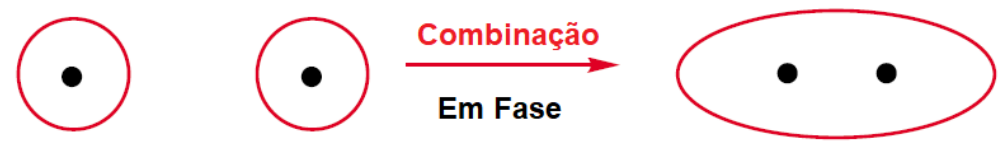

Dois orbitais 1s se combinam fora de fase para a formação de um orbital ligante

Fonte: [12] London (2002, p. 96). 
Os orbitais moleculares ligantes são caracterizados por possuírem energia inferior à energia dos orbitais atômicos, ou seja, qualquer elétron que ocupar este orbital possuirá energia inferior aos átomos isolados devido à existência de uma densidade de elétrons entre os núcleos que favorece a formação das ligações químicas. Enquanto que os orbitais moleculares antiligantes são caracterizados por possuírem um plano nodal entre os núcleos conforme mostrado na Figura 7 , resultado das interferências destrutivas entre as funções de onda dos orbitais atômicos. Assim, os elétrons que ocupam este orbital sofrem repulsão e, por consequência, a sua energia é superior à energia dos orbitais atômicos, tornando-o desfavorável. A Figura 8 mostra o diagrama de níveis de energia para a formação do orbital ligante e antiligante quando dois átomos de orbital 1s na camada de valência se combinam. Conforme se pode observar, o orbital ligante possui menor energia e, por consequência, os elétrons da banda de valência o ocupa para a formação de ligações estáveis.

Figura 8 - Diagrama de níveis de energia para a formação dos orbitais ligante e antiligante a partir de dois orbitais $1 \mathrm{~s}$.

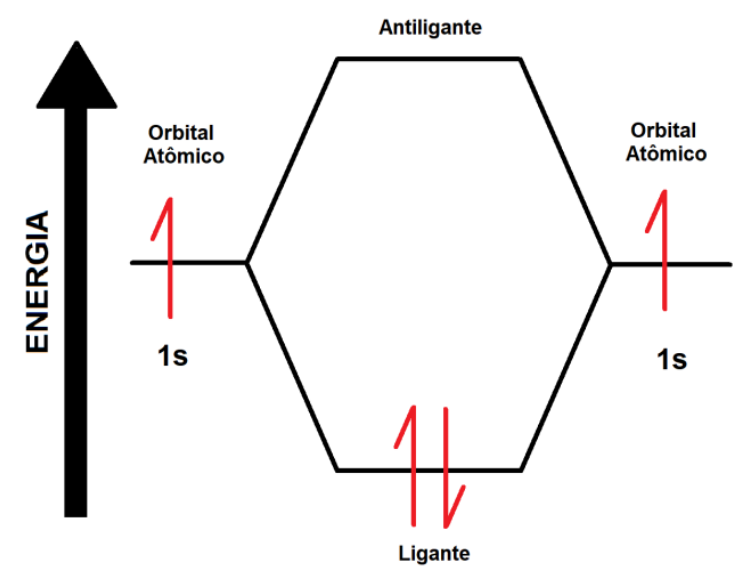

Fonte: Autoria própria.

No caso em que as ligações são formadas por meio da interação entre os orbitais $p$, também ocorre a formação de orbitais moleculares ligante e antiligante. Entretanto, o orbital do tipo $p$ possui maiores possibilidades de combinações uma vez que possui uma orientação no espaço conforme mostrado na Figura 9. 
Figura 9 - Orbitais do tipo $p$.

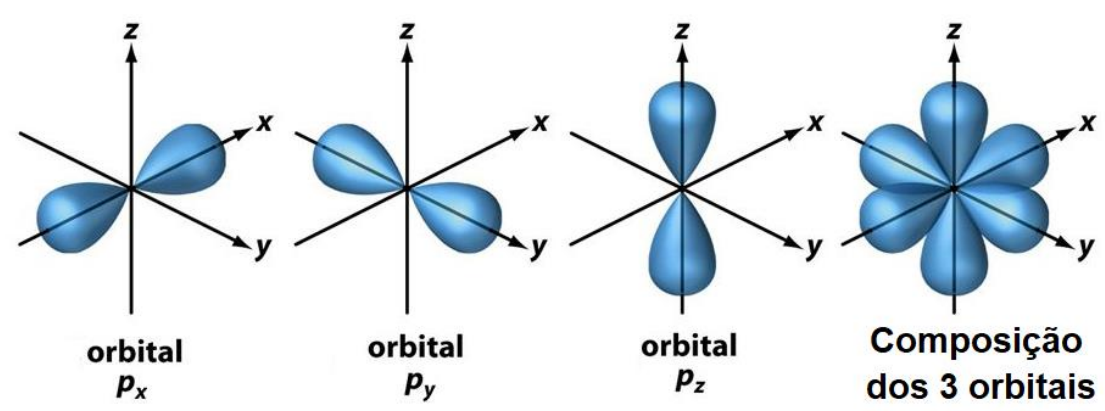

Fonte: [15].

Assim, quando dois orbitais $p$ se unem "frente-a-frente" conforme mostrado na Figura 10 a), ocorre a formação de um orbital molecular com simetria rotacional em torno do eixo que contem os dois núcleos dos átomos combinados, denominada de ligação $\sigma$ (sigma). Enquanto que as ligações $\pi$ (pi), que são mais fracas comparadas às ligações $\sigma$, são formadas quando a combinação leva à formação de um orbital molecular ausente de simetria de rotação conforme mostrado na Figura 10 b).

Figura 10 - Orbital molecular ligante e antiligante: a) Formação ligação $\sigma$ e b) Formação da ligação m.

a)

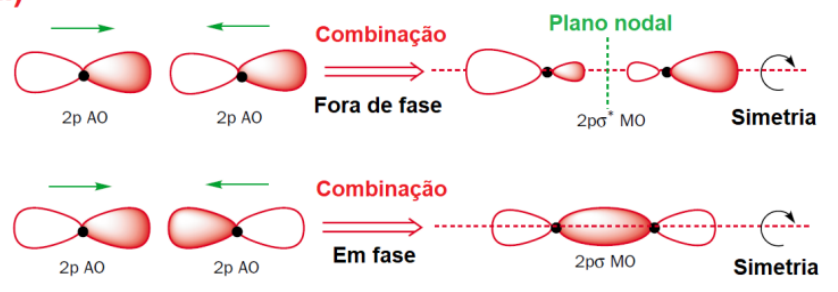

b)

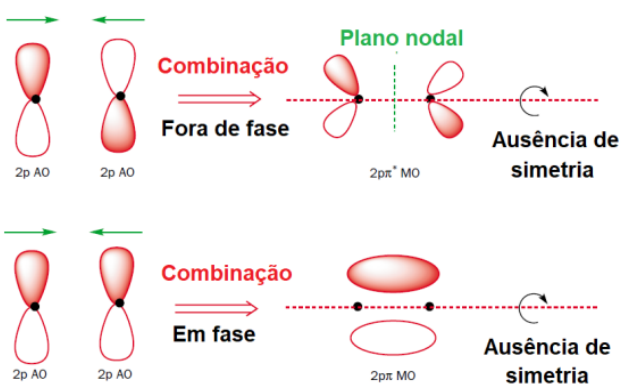

Fonte: [12] Adaptado de London (2002, p. 99).

No caso do carbono, o átomo de carbono possui seis elétrons no total, sendo que dois pertencem ao orbital atômico $1 \mathrm{~s}$ e os outros quatro, aos orbitais atômicos $2 s$ e $2 p$ conforme mostrado na Figura 11. 
Figura 11 - Distribuição eletrônica do átomo de carbono.

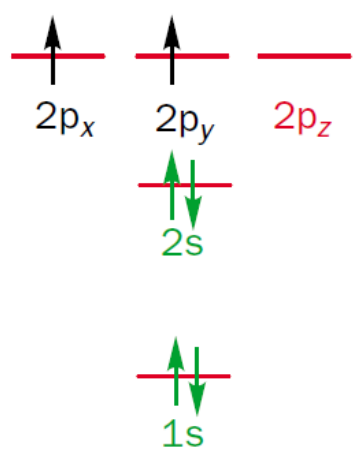

Fonte: [12] London (2002, p.94)

Assim, o átomo de carbono possui dois átomos aptos a fazer ligações químicas, mas sabe-se que ele contribui com quatro elétrons. Neste caso, o carbono pode formar ligações químicas através da hibridização dos orbitais $2 s$ e $2 p$ [10]. A hibridização $s p^{2}$ é a responsável pelas características semicondutoras dos polímeros conjugados.

$\mathrm{Na}$ hibridização $s p^{2}$, o orbital esférico $2 s$ forma uma superposição com os orbitais $2 p_{x}$ e $2 p_{y}$. Assim, cada átomo de carbono faz três ligações, doando um elétron para cada ligação. Entretanto, o carbono possui quatro elétrons na camada de valência $e$, por consequência, o quarto elétron fica no orbital $2 p_{z}$ (nãohibridizado). Portanto, quando dois átomos de carbono hibridizados $s p^{2}$ se aproximam para fazer uma ligação química, os orbitais $2 p_{z}$ se sobrepõem, formando uma ligação $\pi$ entre estes dois átomos, enquanto que os três orbitais $s p^{2}$ são responsáveis pela formação de três ligações $\sigma$ [10]. A Figura 12 mostra a formação do eteno, que é formado pela hibridização $s p^{2}$ do carbono.

Figura 12 - Hibridização $s p^{2}$ para a formação do eteno.

(H)

(1)

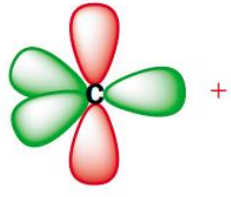

$\mathbb{H}$

$\boxplus$

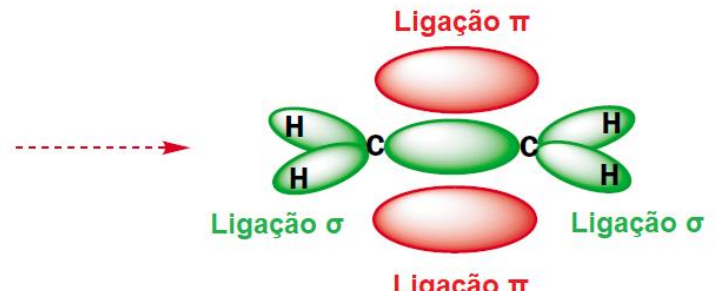

Ligação $\pi$

Fonte: [12] London (2002, p. 106) 
A Figura 13 mostra o diagrama de níveis de energia para a formação de orbital $\pi$ ligante $(\pi)$ e $\pi$ antiligante $\left(\pi^{*}\right)$ a partir de dois átomos de carbono para a formação do etileno. Neste caso, a ligação $\pi$ possui dois elétrons e, portanto, este orbital molecular está completamente ocupado, enquanto que a ligação $\pi^{*}$ está vazia. Assim, as ligações $\pi$ também são conhecidas como Lowest Unoccupied Molecular Orbital (LUMO) e as ligações $\pi^{*}$ como Highest Occupied Molecular Orbital (HOMO) e o band gap é dada pela diferença entre as energias LUMO e HOMO [10]. O etileno não é um semicondutor uma vez que o band gap destes materiais é de 7,6 $\mathrm{eV}[10]$.

Figura 13 - Diagrama de níveis de energia para a formação do orbital ligante e antiligante no etileno.

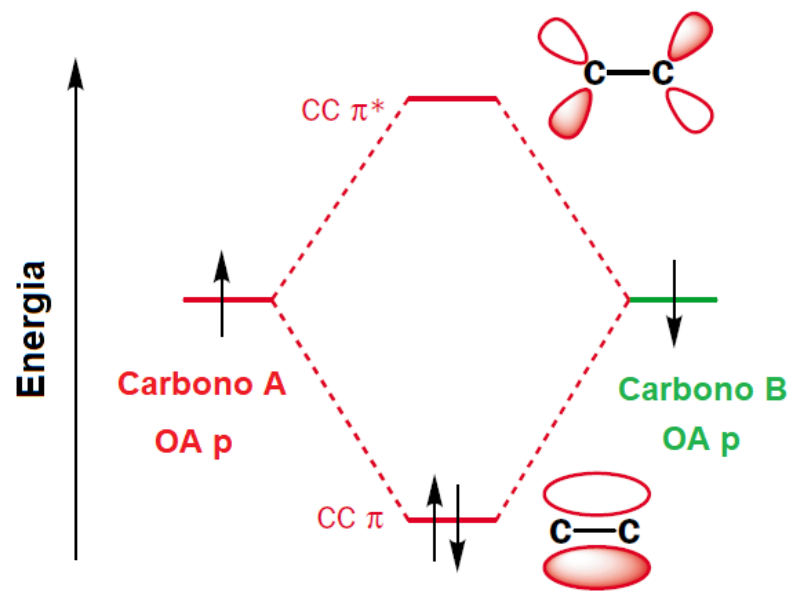

Fonte: [12] London (2002, p. 103)

Entretanto, quando se adiciona unidades $\left(\mathrm{CH}_{2}\right)$ dentro da cadeia para a formação de polímeros conjugados, níveis de energia extras são adicionados tanto no LUMO quanto no HOMO conforme mostrado na Figura 14. Estes níveis de energia extras adicionados no LUMO possuem valores superior e inferior à energia do LUMO de moléculas menores e isto também ocorre para o HOMO [10]. Assim, os níveis LUMO e HOMO vão ficando cada vez mais próximos, formando bandas contínuas denominadas de banda de condução (CB) e banda de valência (VB) conforme a Figura 14, separada por band gaps cada vez menores. 
Figura 14 - Formação de bandas de energia em polímeros conjugados.

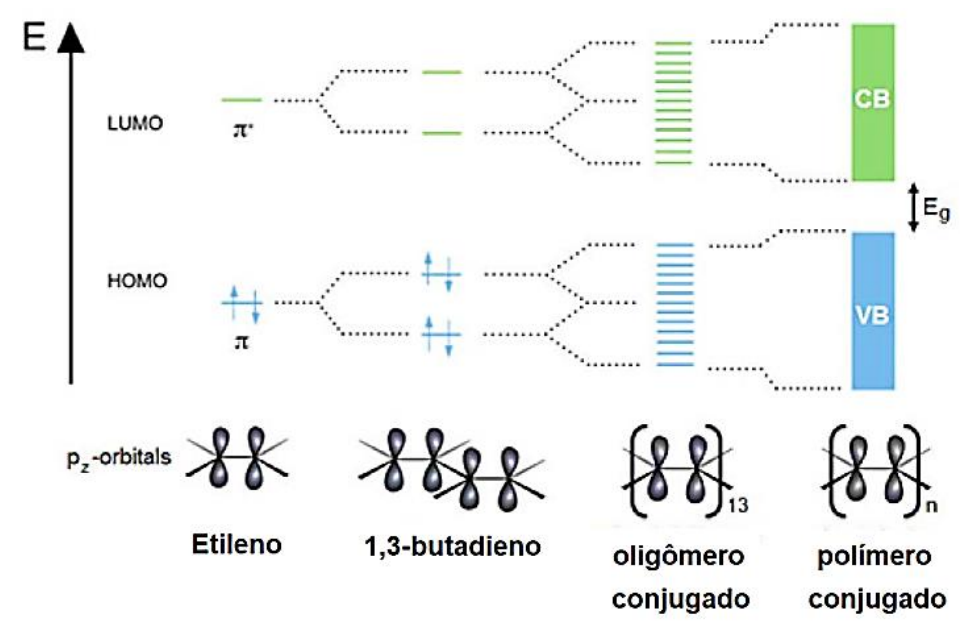

Fonte: [13] Banerji, Tausch e Scherf (2013, p. 2).

Dependendo do tamanho do band gap, o material (orgânico ou inorgânico) pode ser considerado condutor, semicondutor ou isolante. A Figura 15 mostra o diagrama de bandas para as três categorias de materiais. Os condutores são caracterizados por possuírem uma justaposição ou sobreposição entre a banda de condução e a banda de valência. Assim, os elétrons possuem grande disponibilidade de estados permitidos, possibilitando a sua livre movimentação pelo cristal na presença de um campo elétrico. Enquanto que nos semicondutores e isolantes, existe uma barreira energética entre as bandas de condução e de valência (band gap). Apesar dos dois materiais possuírem a mesma estrutura de bandas, existe uma diferença no tamanho do gap deles: os semicondutores possuem um band gap menor que a dos isolantes. Geralmente, materiais com band gap entre 0,7 e $3 \mathrm{eV}$ são considerados semicondutores enquanto que materiais com band gap superiores a $3 \mathrm{eV}$, como isolantes [10]. Assim, como o band gap dos semicondutores é relativamente baixa, é possível que ocorra a excitação de elétrons da banda de valência para a banda de condução através da energia térmica e óptica o que não ocorre com os isolantes [14]. 
Figura 15 - Diagrama de bandas para condutores, semicondutores e isolantes.

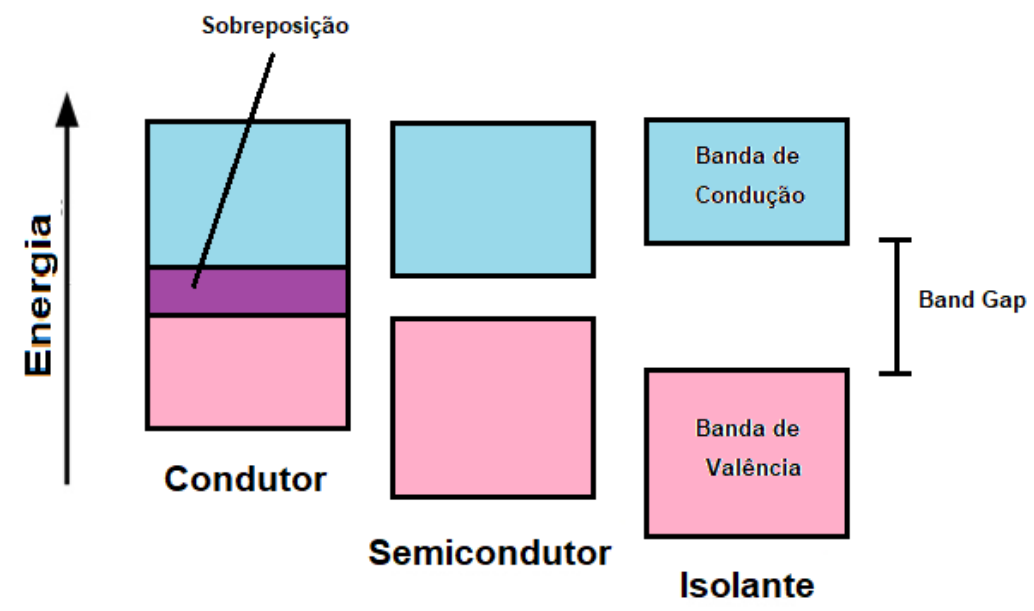

Fonte: Autoria própria.

\subsection{Fluorescência e Fosforescência}

A luminescência é a emissão de luz por qualquer material que provém de estados eletronicamente excitados [16]. No caso da eletroluminescência, esta excitação ocorre pela injeção de cargas no material conforme apresentado na Figura 16. Quando se aplica uma diferença de potencial, cargas são injetadas pelos eletrodos no interior da camada emissiva (semicondutor orgânico) (1), em seguida, estas cargas são transportadas (2), quando um elétron encontra uma lacuna, ocorre a recombinação e formação de éxcitons (3) e, por fim, ocorre o decaimento radiativo do éxciton com emissão de luz (4).

Figura 16 - Esquematização das principais etapas na eletroluminescência.

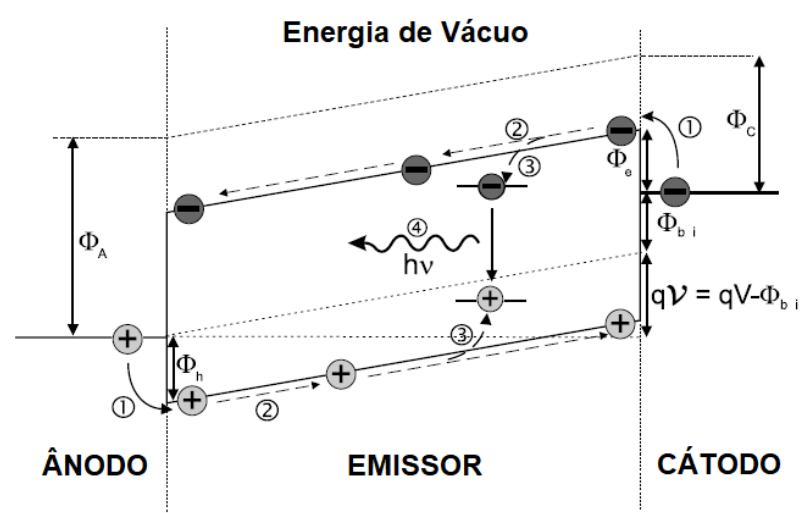

$\Phi_{\mathrm{A}}$ : Função de trabalho do ânodo

$\Phi_{\mathrm{C}}$ : Função de trabalho do cátodo

$\Phi_{\mathrm{h}}$ : Barreira para injeção de lacunas

$\Phi_{\mathrm{e}}$ : Barreira para injeção de elétrons

$\Phi_{\text {bi }}$ : Built-in Potential

$V$ : Tensão aplicada

$\mathscr{V}$ : Tensão efetiva na camada orgânica

$q$ : Carga elementar

Fonte: [17] Brütting, Berleb, Mückl (2001, p.3). 
A eletroluminescência é resultado da recombinação entre cargas com sinais opostos e formação de éxcitons, que decaem radiativamente com emissão de luz fluorescente ou fosforescente, dependendo do estado excitado envolvido [17].

O éxciton é um par elétron-lacuna com suas respectivas massas efetivas atraídas por uma força de Coulomb [18] e podem ser formadas em dois estados de energia: singleto e tripleto dependendo dos spins do elétron e da lacuna emparelhados [10]. Nos estados excitados singletos, o elétron pertencente ao orbital excitado possui spin oposto ao elétron pertencente ao orbital do estado fundamental conforme mostrado na Figura 17 a). Portanto, a transição do estado excitado $S_{1}$ para o estado fundamental $S_{0}$ é permitido e ocorre rapidamente, com altas taxas de emissão de fóton que possuem curtos tempos de vida e duram alguns nanosegundos (ns) [16]. Esta emissão é denominada fluorescência. Entretanto, nos estados excitados tripletos, o elétron pertencente ao orbital excitado possui spin com a mesma orientação do spin de elétron que está no estado fundamental $\mathrm{S}_{0}$ (Figura 17 b) [16]. Assim, a transição eletrônica é proibida e, por consequência, a sua emissão é lenta e possui um tempo de vida longo, tipicamente milissegundos (ms) ou até alguns segundos (s), caracterizando a emissão fosforescente [16].

Figura 17 - Estados dos spins na formação de um éxciton.

a)

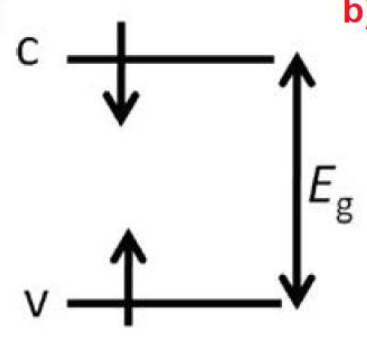

Singleto b)

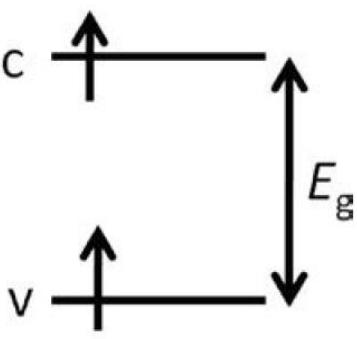

Tripleto

Fonte: [18] Meng (2013, p. 12).

A Figura 18 contem os principais fenômenos observados quando ocorre a excitação de elétrons em um composto. Quando uma molécula orgânica absorve um fóton, ela pode ser excitada do estado fundamental $\left(\mathrm{S}_{0}\right)$ para algum estado excitado singleto $\left(S_{n}\right.$, sendo $n$ um número inteiro e maior que 1$)$. Em seguida, este estado 
excitado decai por meio de relaxações vibracionais e conversões internas para o estado excitado singleto de menor energia $\left(S_{1}\right)$. Em moléculas com alto acoplamento spin-órbita, o estado excitado $S_{1}$ pode ser transferido por Cruzamento Intersistema (ISC) para algum estado excitado tripleto $\left(T_{n}\right.$, sendo $n$ um número inteiro e maior que 1) e este decai por meio de relaxações vibracionais e conversões internas para 0 estado excitado tripleto de menor energia $\left(T_{1}\right)[7,9]$. Por fim, a emissão ocorre pelo decaimento de um estado excitado $S_{1}$ para o estado fundamental $S_{0}$ (fluorescência) e/ou pelo decaimento de um estado excitado $T_{1}$ (fosforescência) [9].

Figura 18 - Diagrama de Jablonski.

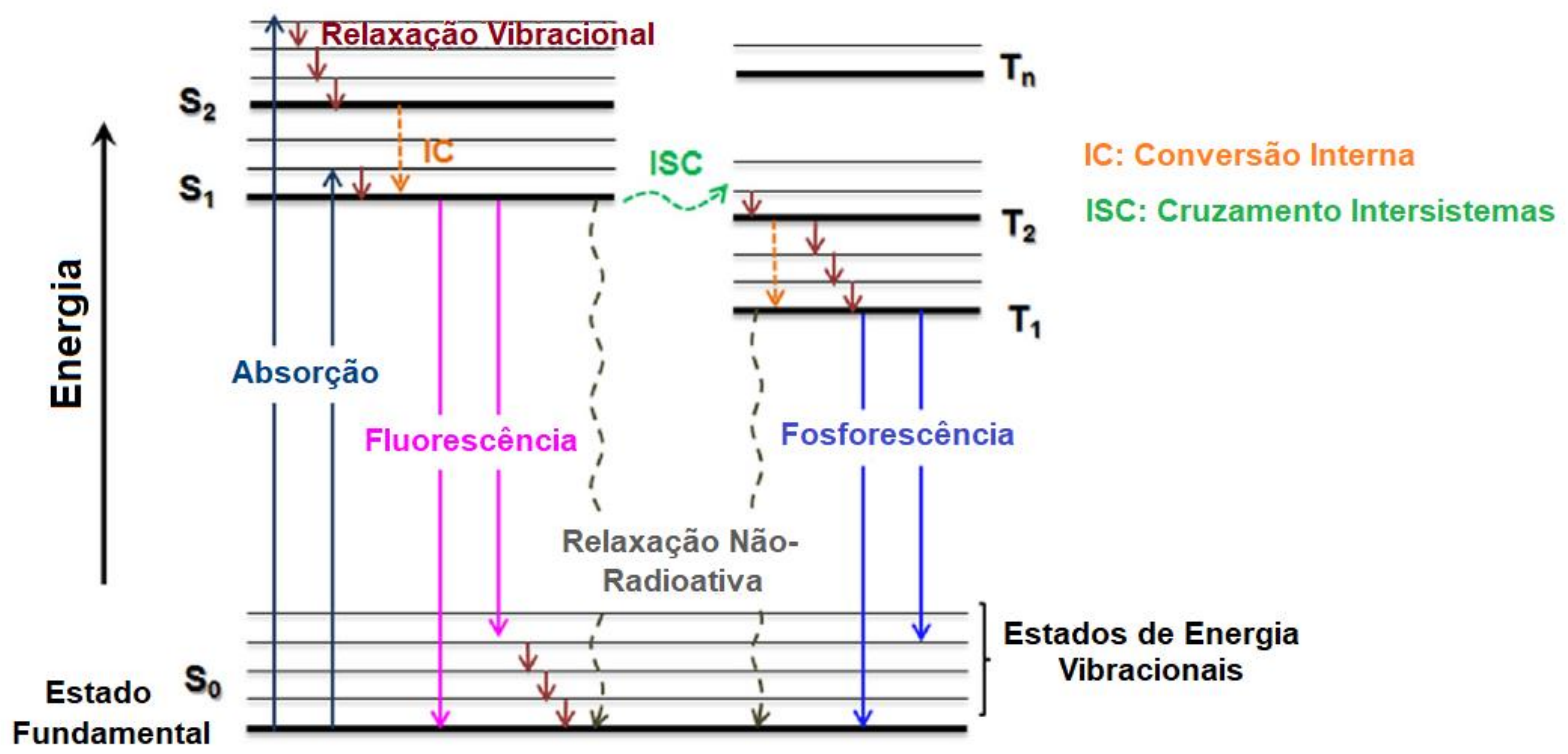

Fonte: [9] Xu et. al. (2015, p. 95).

Quando moléculas orgânicas são excitadas por um campo elétrico, ocorre a formação de éxcitons, sendo que um quarto são singletos e os três quartos restantes, tripletos conforme mostrado na Figura 19. 
Figura 19 - Esquematização do processo de formação de éxcitons na eletroluminescência.

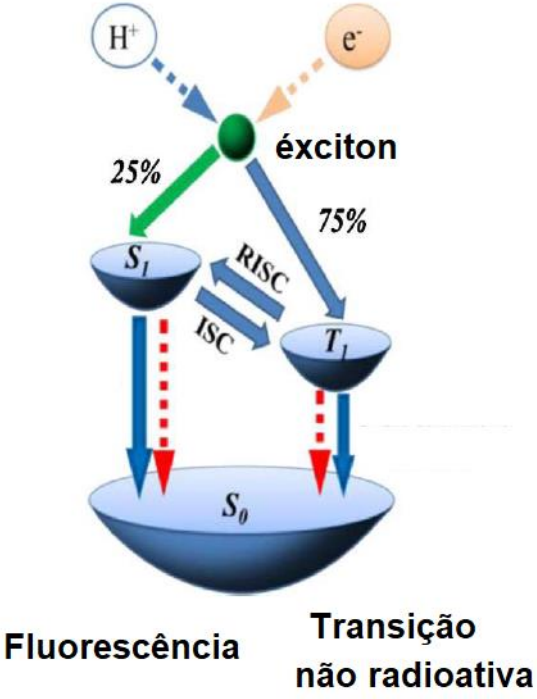

ISC: Cruzamento Intersistemas

RISC: Cruzamento Intersistemas Reversa

Fonte: [7] Wang et. al. (2013, p. 72).

Em OLEDs, em que a camada emissiva consiste em apenas materiais fluorescentes, os singletos formados decaem radiativamente para o estado fundamental, emitindo luz enquanto que os tripletos decaem de forma não radiativa levando a perda de sua energia [9]. Assim, a eficiência na emissão é limitada em apenas $25 \%$ [9]. Porém, pequenas perturbações na simetria do spin dos tripletos podem levar ao decaimento radiativo, produzindo-se a fosforescência que apesar de ser ineficiente, podem ser aumentadas com a presença de átomos de metais pesados, como o irídio, platina, paládio, etc, uma vez que eles aumentam significativamente o acoplamento spin-órbita [1,9], permitindo a emissão de tanto dos singletos quanto dos tripletos, possibilitando uma eficiência interna quântica de quase $100 \%$ [9].

\subsection{Sistema polímero hospedeiro e dopante fosforescente}

Conforme mencionado anteriormente, a adição de complexos organometálicos de metais pesados no polímero pode aumentar a eficiência dos PLEDs. Entretanto, para que estas altas eficiências sejam atingidas, o polímero hospedeiro que forma a camada emissiva precisa satisfazer algumas propriedades que levam em consideração o tipo de dopante e as propriedades das camadas adjacentes [19]. 
Os HOMOs e LUMOs do polímero hospedeiro e do dopante fosforescente devem ser selecionados de tal forma que os éxcitons formados na camada emissiva fiquem confinados nela [19]. Assim, é necessário que o band gap do polímero hospedeiro seja largo o suficiente para que a sua transferência de energia (Figura 20) com o dopante seja eficiente, mas não induza desativação de carga por armadilhas [19]. Além disso, o dopante deve estar muito bem disperso no interior do hospedeiro para que processos de extinção de éxcitons não ocorram e ainda, as mobilidades de elétrons e de lacunas do hospedeiro devem ser próximas para que a recombinação seja eficiente [19].

Figura 20 - Diagrama de energia do hospedeiro e do dopante.

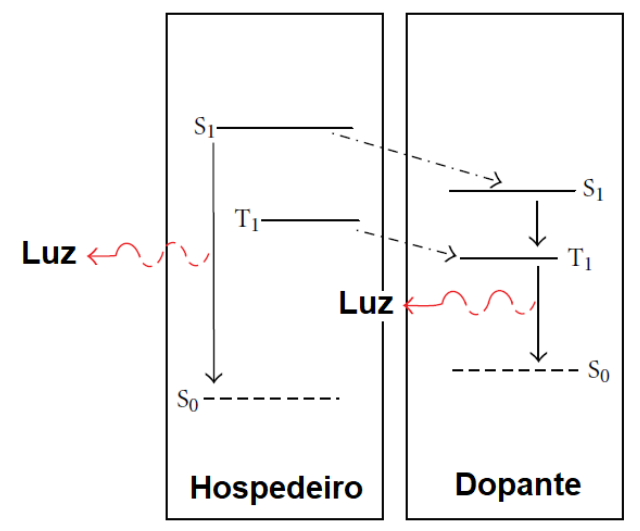

Fonte: [19] Diouf et. al. (2012, p. 2).

Os princípios da fosforescência em sistemas contendo um polímero hospedeiro e um dopante fosforescente podem ser divididos em três mecanismos (Figura 21), sendo eles: transferência de energia de Föster ou de Dexter; transferência de energia de Dexter; e injeção e recombinação de cargas diretamente no dopante.

A transferência energia de Föster é uma interação de Coulomb do tipo dipolodipolo entre o dopante e o hospedeiro. Esta transferência é caracterizada por ser rápida (na ordem de $10^{-12} \mathrm{~s}$ ) e de relativamente longo alcance (acima de $10 \mathrm{~nm}$ ), enquanto que a transferência de energia de Dexter é de curto alcance $(1 \mathrm{~nm})$ onde éxcitons se difundem de sítios doadores para sítios aceitadores [9, 20].

Sendo assim, o primeiro mecanismo envolve a transferência dos éxcitons do polímero hospedeiro com estado singleto $S_{1}$ para o estado excitado $S_{1}$ do dopante 
por meio da transferência de energia de Föster ou de Dexter. E então, o éxciton do dopante com o estado excitado $S_{1}$ é transferido para o estado tripleto $T_{1}$ do próprio dopante por meio do ICS e por fim, a fosforescência ocorre pelo decaimento do estado excitado $T_{1}$ para o estado fundamental $S_{0}[7,9]$. O segundo envolve a transferência de éxcitons do hospedeiro com estado excitado $T_{1}$ para o estado excitado $T_{1}$ do dopante por meio da transferência de energia de Dexter, resultando em fosforescência [9]. E por fim, a fosforescência ocorre por meio do aprisionamento de cargas pelo dopante em que os estados excitados $S_{1}$ são transferidos por ISC para o estado excitado $T_{1}$ e este decai radiativamente, enquanto que os estados excitados $T_{1}$ formados na recombinação decaem diretamente para o estado fundamental com emissão de luz fosforescente [9].

Figura 21 - Mecanismos envolvidos na fosforescência de sistemas hospedeiro/dopante.

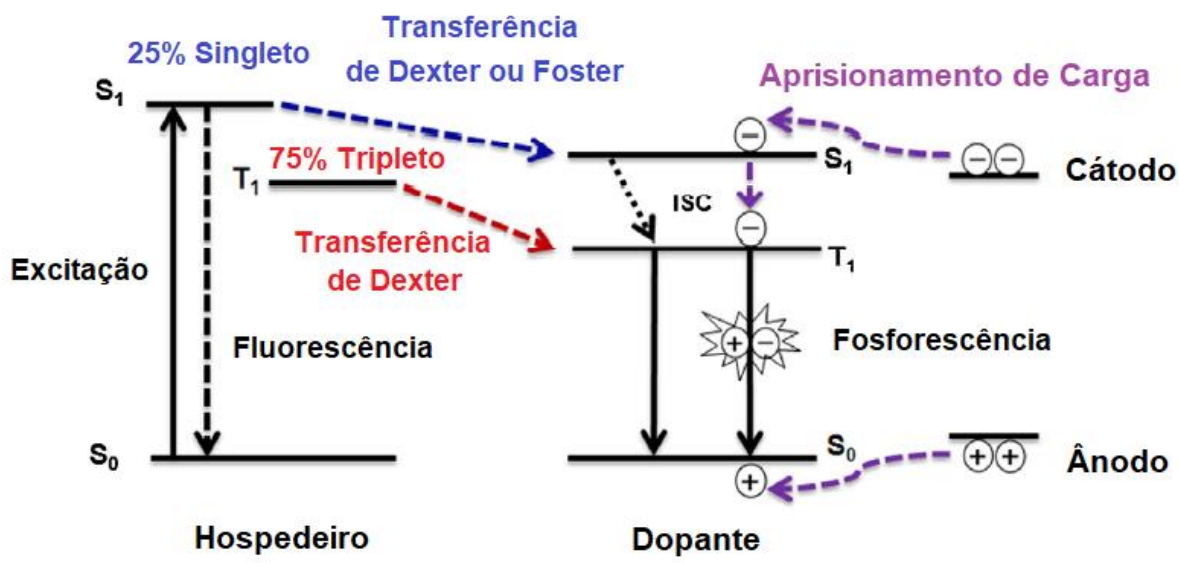

Fonte: [9] Xu et. al. (2015, p. 95).

\subsection{Emissão dos defeitos do AZO}

O óxido de zinco dopado com alumínio (AZO) é uma dopagem do tipo-n que resulta em uma material com condutividade superior a do óxido de zinco $(\mathrm{ZnO})$ e possui propriedades fotoluminescentes. Apesar de estes materiais apresentarem um band gap de 3,4 eV (região UV), análises de fotoluminescência mostram uma banda larga de emissão na região do visível que está relacionada aos defeitos intrínsecos e extrínsecos do material que criam estados no interior do band gap [21-23].

Os principais defeitos citados em trabalhos incluem vacâncias de oxigênio e de zinco $\left(V_{o}\right.$ e $\left.V_{Z n}\right)$; oxigênio e zinco intersticiais $\left(O_{i}\right.$ e $\left.Z n_{i}\right)$ e antisítios de oxigênio e 
de zinco $\left(\mathrm{Zn}_{\mathrm{O}}\right.$ e $\left.\mathrm{O}_{\mathrm{Zn}}\right)$ [24], sendo que $\mathrm{V}_{0}, \mathrm{Zn}_{\mathrm{o}}$ e $\mathrm{Zn}_{\mathrm{i}}$ possuem caráter doador de elétrons enquanto que $\mathrm{V}_{\mathrm{Zn}}, \mathrm{O}_{i}$ e $\mathrm{O}_{\mathrm{Zn}}$, possuem caráter aceitador de elétrons [24].

Atualmente, existem diversos trabalhos teóricos cujos principais objetivos são estudar os mecanismos responsáveis por cada emissão e calcular os níveis de energia para diferentes tipos de defeitos [25]. Entretanto, não existe um consenso sobre a origem dessas emissões uma vez que diferentes estudos preveem diferentes níveis de energia para o mesmo tipo de defeito, portanto, não é possível ainda identificá-la de forma conclusiva pela simples observação entre 0 posicionamento do pico e o nível de energia teórico [25]. A Tabela 2 mostra o posicionamento e as origens propostas para a fotoluminescência do $\mathrm{ZnO}$.

Tabela 2 - Posicionamento e origens propostas para a fotoluminescência do $\mathrm{ZnO}$.

\begin{tabular}{|c|c|}
\hline Posição do Pico (nm) & Origem Proposta \\
\hline $373-390$ & NBE \\
\hline 402 (77 K) & $\mathrm{O}_{\mathrm{Zn}}$ \\
\hline$\sim 446$ & $\mathrm{~V}_{\mathrm{o}}$ \\
\hline$\sim 459$ & $\mathrm{Zn}_{\mathrm{i}}$ \\
\hline$\sim 495$ & $\mathrm{~V}_{\mathrm{o}}$ \\
\hline$\sim 500 / 510$ & $\mathrm{Cu}^{+} / \mathrm{Cu}^{2+}$ \\
\hline$\sim 510$ & $\begin{array}{l}\text { Defeitos de superfície; defeitos } \\
\text { complexos; } \mathrm{V}_{0}^{+}\end{array}$ \\
\hline$\sim 520$ & $\mathrm{~V}_{\mathrm{Zn}} ; \mathrm{O}_{\mathrm{Zn}} ; \mathrm{V}_{\mathrm{o}} ; \mathrm{Zn}_{\mathrm{i}}$ \\
\hline$\sim 540$ & $\mathrm{~V}_{0}^{2+}$ \\
\hline$\sim 560$ & Defeitos de superfície \\
\hline$\sim 580$ & $\mathrm{O}_{\mathrm{i}}$; impurezas de lítio (Li) \\
\hline$\sim 590$ & Grupos hidroxilas \\
\hline$\sim 626$ & $\mathrm{O}_{\mathrm{i}}$ \\
\hline$\sim 750$ & Defeitos relativos ao oxigênio; Zn \\
\hline
\end{tabular}

Fonte: [25] Adaptado de Djurisic (2010, p. 206). Sendo NBE (near band edge); $\mathrm{O}_{\mathrm{Zn}}$ (vacância de zinco); $\mathrm{V}_{\mathrm{o}}$ (vacância de oxigênio); $\mathrm{V}_{0}^{+}$(vacância de oxigênio monovalente); $\mathrm{Zn}_{\mathrm{i}}$ (zinco intersticial); $\mathrm{O}_{\mathrm{Zn}}$ (antisítio de oxigênio); $V_{0}{ }^{2+}$ (vacância de oxigênio bivalente) e $O_{i}$ (oxigênio intersticial).

Além disso, trabalhos envolvendo estudos termodinâmicos de formação de defeitos mostram que certos defeitos necessitam de altas energias de formação e 
podem ser instáveis, levando à sua desativação. Por exemplo, estudos teóricos demonstram que o $\mathrm{Zn}_{\mathrm{i}}$ é um shallow donor defect, entretanto, ele é instável e necessitam altas energias de formação [23]. Apesar disso, muitos autores reportam este defeito como o responsável pela emissão na região violeta-azul do espectro eletromagnético [26-28].

Outro fator que influencia fortemente na formação de defeitos são a rota e os parâmetros utilizados na síntese do AZO e do ZnO. Síntese em atmosfera rica em oxigênio, por exemplo, favorece a formação de defeitos aceitadores de elétrons como vacância de zinco, oxigênio intersticial e antisítios de oxigênio. Por outro lado, excesso de zinco favorece a formação de defeitos doadores como vacância de oxigênio, zinco intersticial e antisítio de zinco [23].

Para o estudo da origem da eletroluminescência neste trabalho, utilizou-se os valores de níveis de energia e posicionamento dos picos observados na fotoluminescência do $\mathrm{ZnO}$ uma vez que os defeitos envolvidos neste material e no AZO são os mesmos e ainda, pela maior densidade de trabalhos existentes. 


\section{Metodologia}

Este capítulo tem como objetivo apresentar os materiais utilizados para a produção dos PLEDs, assim como as etapas de sua fabricação e as técnicas de caracterização utilizadas para o estudo do desempenho destes dispositivos.

\subsection{Materiais}

Os materiais que foram utilizados e suas respectivas funções e fabricantes para a produção dos dispositivos orgânicos emissores de luz estão apresentados na Tabela 3.

Tabela 3 - Materiais utilizados durante o trabalho e suas respectivas funções e fabricantes.

\begin{tabular}{|c|c|c|}
\hline Material & Função & Fabricante \\
\hline PEDOT:PSS & HTL & $\begin{array}{l}\text { Sigma Aldrich, 1,3 \% em } \\
\text { massa, dispersão em água }\end{array}$ \\
\hline PVK & EML & $\begin{array}{c}\text { Sigma Aldrich, } 98 \%, M_{W}= \\
1100000 \mathrm{~g} / \mathrm{mol}\end{array}$ \\
\hline PVK & EML & $\begin{array}{l}\text { Sintetizado no Laboratório, } \\
\qquad \mathrm{M}_{\mathrm{W}}=50000 \mathrm{~g} / \mathrm{mol}\end{array}$ \\
\hline PFO & EML & Sintetizado no Laboratório \\
\hline$P F_{P F}$ & EML & Sintetizado no Laboratório \\
\hline $\operatorname{Ir}(\text { ppy })_{3}$ & Dopante & Sigma Aldrich, 99\% \\
\hline $\begin{array}{l}\text { PMMA (Poli(metacrilato de } \\
\text { metila)) }\end{array}$ & EML & $\begin{array}{l}\text { Aldrich Chemical Company, } \\
\text { Inc., } M_{w}=120000 \mathrm{~g} / \mathrm{mol}\end{array}$ \\
\hline AZO & EIL & $\begin{array}{l}\text { Sigma Aldrich, } 2,5 \% \text { em } \\
\text { massa, dispersão em } \\
\text { isopropanol }\end{array}$ \\
\hline Clorofórmio & Solvente & $\begin{array}{c}\text { Tedia, grau } \\
\text { espectroscópico }\end{array}$ \\
\hline ITO (sobre vidro) & Ânodo & Diamond Coatings \\
\hline
\end{tabular}

Fonte: Autoria própria.

A Tabela 4 mostra os valores dos níveis de energia HOMO e LUMO dos materiais utilizados no trabalho e suas respectivas referências. 
Tabela 4 - HOMO e LUMO dos materiais utilizados na montagem dos PLEDs.

\begin{tabular}{cccc}
\hline Material & HOMO & LUMO & Referência \\
\hline ITO (função trabalho) & 5,0 & - & {$[29]$} \\
PEDOT:PSS & 5,1 & 2,0 & {$[30]$} \\
PVK & 5,8 & 2,2 & {$[31]$} \\
PFO & 5,8 & 2,6 & {$[32]$} \\
Ir(ppy) & 5,6 & 3,0 & Sigma Aldrich \\
AZO & 4,3 & 7,7 & Sigma Aldrich, \\
Al (função trabalho) & - & $4,3]$ & {$[29]$} \\
\hline
\end{tabular}

Fonte: Autoria própria.

\subsection{Métodos}

Os PLEDs foram produzidos por meio de deposições sucessivas de filmes finos poliméricos e de alumínio em uma lâmina de vidro contendo 4 trilhas de óxido de índio e estanho (ITO) através das técnicas de spin-coating e evaporação térmica a vácuo, respectivamente. A estrutura do PLED consistiu basicamente em ITO/ PEDOT:PSS (56 nm)/ EML (45 - $65 \mathrm{~nm}) /$ AZO (93 nm)/ Al (100 nm) como mostrado na Figura 22, cada lâmina contendo 4 dispositivos com área emissiva de $9 \mathrm{~mm}^{2}$. A preparação destes dispositivos foi efetuada em quatro etapas: (1) preparação e ataque do ITO; (2) preparação das soluções de polímeros emissores; (3) deposição dos filmes finos poliméricos e (4) metalização, sendo que as etapas (1) - (3) foram conduzidas no Laboratório de Engenharia de Macromoléculas do Departamento de Engenharia Metalúrgica e de Materiais da Escola Politécnica da Universidade de São Paulo (USP), enquanto que a etapa (4), no Laboratório do Grupo de Eletrônica Molecular (GEM) do Departamento de Engenharia de Sistemas Eletrônicos da Escola Politécnica da (USP). Por fim, as caracterizações ópticas e elétricas dos dispositivos produzidos foram realizadas no Laboratório de Engenharia de Macromoléculas (USP). 
Figura 22 - Esquematização de uma lâmina contendo 4 dispositivos montados no laboratório: a) Vista superior e b) Vista lateral.

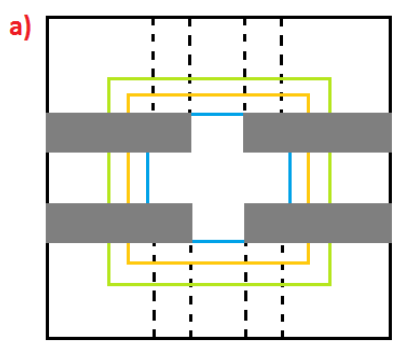

b)

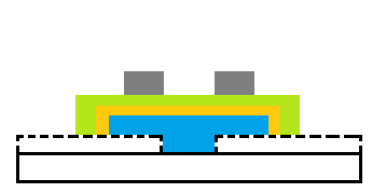

LEGENDA

$\square$ vidro

I.-. ITO

$\square$ PEDOT:PSS

Emissor

AZO

Alumínio

Fonte: Autoria própria.

\subsubsection{Preparação e Ataque do ITO}

O substrato para a montagem do dispositivo consiste em uma lâmina de vidro de dimensões $50 \times 75 \times 1(\mathrm{~mm})$ recoberta por uma fina camada de ITO cuja espessura e resistência de folha são de, aproximadamente, $135 \mathrm{~nm}$ e $12 \Omega / \mathrm{cm}^{2}$, respectivamente.

Esta lâmina é cortada em dimensões de $25 \times 25(\mathrm{~mm})$ e em seguida, passa por um processo de ataque para evitar o contato entre os eletrodos (cátodo e ânodo) que pode levar ao curto circuito da camada polimérica.

A trilha, formada por quatro retângulos de dimensões $3 \times 10(\mathrm{~mm})$, é criada protegendo-se a camada de ITO que não deve ser atacada com fita adesiva (fita mágica da 3M). Em seguida, a parte exposta é friccionada com algodão umedecido em ácido clorídrico $(\mathrm{HCl})$ contendo pó de zinco, lavada em água destilada e por fim, a fita adesiva é retirada, criando-se a estrutura final representada na Figura 23.

Figura 23 - Esquematização da lâmina de vidro com ITO antes e depois da corrosão.

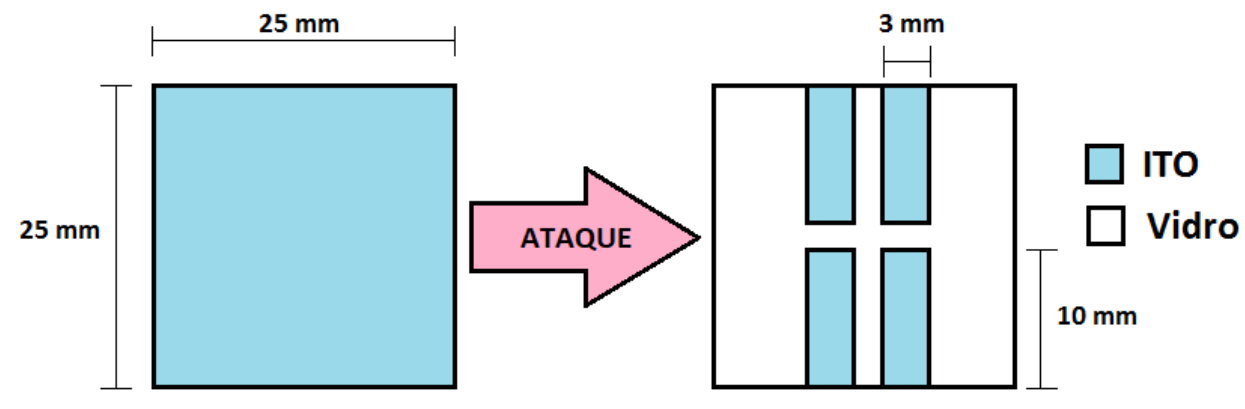

Fonte: Autoria própria. 
Após a etapa de ataque, as lâminas devem passar por uma etapa de limpeza rigorosa com o objetivo de eliminar os resíduos do último processo e outros contaminantes. Neste trabalho, utilizou-se o produto comercial de limpeza AquaBrilho que, em estudos prévios do grupo, mostrou-se ser bastante eficiente e ainda, melhorou a qualidade do filme depositado sobre a lâmina de ITO.

\subsubsection{Preparação das soluções para a formação da camada emissora}

\subsubsection{PVK, PFO e PF $F_{P F}$ dopados com $\operatorname{Ir}(\text { ppy })_{3}$}

A dopagem foi realizada pela mistura física entre o polímero hospedeiro (host) e $\operatorname{Ir}(\mathrm{ppy})_{3}$ em diferentes proporções dissolvidos em clorofórmio espectroscópico conforme mostrado na Figura 24.

Figura 24 - Esquematização do processo de preparação das soluções.

1) Soluções são preparadas separadamente.

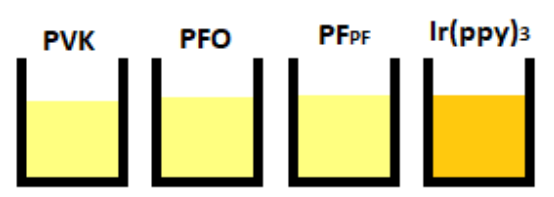

2) Solução do polímero é misturado com a solução do dopante.

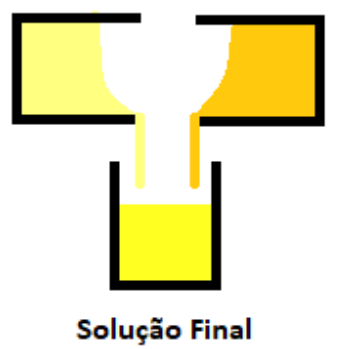

Fonte: Autoria própria.

Primeiramente, as soluções dos polímeros e do complexo de irídio foram preparadas separadamente com concentrações mássicas apresentadas na Tabela 5. Com o auxílio de um equipamento de banho ultrassônico Unique, modelo USC 1800 A, cada solução preparada passou por um processo de homogeneização durante 30 minutos. 
Tabela 5 - Concentrações mássicas das soluções iniciais preparadas para a dopagem.

Composto

$\operatorname{Ir}(\mathrm{ppy})_{3}$

PVK

PFO

$\mathrm{PF}$ PF
Concentração Inicial $(\mathrm{mg} / \mathrm{mL})$

0,7

8

10

10

Fonte: Autoria própria.

Em seguida, estas soluções foram misturadas para a preparação de $2 \mathrm{~mL}$ de solução contendo proporções mássicas, Polímero:Ir(ppy $)_{3}$, conforme descritas na Tabela 6, sendo que as concentrações finais das soluções de PVK, PFO e PFPF foram, respectivamente, $2 \mathrm{mg} / \mathrm{mL}, 5 \mathrm{mg} / \mathrm{mL}$ e $5 \mathrm{mg} / \mathrm{mL}$. Em seguida, estas soluções passaram por um processo de homogeneização em banho ultrassônico durante 30 minutos e, por fim, por um processo de filtragem por filtros de PTFE (politetrafluoroetileno) Millipore de porosidade 0,22 $\mu \mathrm{m}$.

Tabela 6 - Proporções mássicas Polímero: $\operatorname{Ir}(\mathrm{ppy})_{3}$ das soluções preparadas para a deposição dos filmes finos da camada emissora.

\begin{tabular}{ccc}
\hline PVK:Ir(ppy) & PFO:Ir(ppy $)_{3}$ & PF $_{\text {PF }}: \operatorname{Ir}(\text { ppy })_{3}$ \\
\hline $100: 0$ & $100: 0$ & $100: 0$ \\
$95: 5$ & $98: 2$ & $98: 2$ \\
$90: 10$ & $96: 4$ & $96: 4$ \\
$85: 15$ & $93: 7$ & $93: 7$ \\
\hline
\end{tabular}

Fonte: Autoria própria. 


\subsubsection{PVK puro}

Nesta etapa, foram preparadas três soluções distintas de $1,5 \mathrm{~mL}$ em clorofórmio espectroscópico: (TI) PVK, $M_{w}=1100000 \mathrm{~g} / \mathrm{mol}$, cuja concentração foi de $5 \mathrm{mg} / \mathrm{mL}$; (TII) PVK, $M_{w}=1100000 \mathrm{~g} / \mathrm{mol}$, cuja concentração foi de $2 \mathrm{mg} / \mathrm{mL}$ e (TIII) PVK, $M_{w}=50000 \mathrm{~g} / \mathrm{mol}$, cuja concentração foi de $5 \mathrm{mg} / \mathrm{mL}$. A Tabela 7 mostra um resumo das soluções preparadas para a deposição do filme fino polimérico.

Tabela 7 - Concentrações das soluções utilizadas para a deposição dos filmes poliméricos à base de PVK.

\begin{tabular}{ccc}
\hline Dispositivo & Massa Molar $(\mathbf{g} / \mathbf{m o l})$ & Concentração $(\mathbf{m g} / \mathbf{m L})$ \\
\hline TI & 1100000 & 5 \\
TII & 1100000 & 2 \\
TIII & 50000 & 5 \\
\hline
\end{tabular}

Fonte: Autoria própria.

\subsubsection{PVK:AZO}

Para a preparação da solução de PVK:AZO, primeiramente, $32 \mathrm{mg}$ de PVK $\left(\mathrm{M}_{\mathrm{w}}=1100000 \mathrm{~g} / \mathrm{mol}\right)$ foram dissolvidos em $1 \mathrm{~mL}$ de clorofórmio espectroscópico e adicionou-se $20 \mu \mathrm{L}$ de AZO. Em seguida, a solução resultante foi homogeneizada durante 1 hora com o auxílio de um equipamento de banho ultrassônico Unique, modelo USC - 1800 A. Após este processo, separou-se $125 \mu \mathrm{L}$ da solução final e adicionou-se $875 \mu \mathrm{L}$ de clorofórmio espectroscópico para a produção de $1 \mathrm{~mL}$ de solução. Por fim, esta solução foi novamente homogeneizada durante 1 hora com 0 auxílio do equipamento de banho ultrassônico.

\subsubsection{PMMA:AZO}

Para a preparação da solução de PMMA:AZO, primeiramente, 2 mg de PMMA foram dissolvidos em $1 \mathrm{~mL}$ de clorofórmio espectroscópico. Separadamente, $25 \mu \mathrm{L}$ de AZO foram dispersos em $1 \mathrm{~mL}$ de clorofórmio espectroscópico e a dispersão resultante foi homogeneizado em banho ultrassônico (Unique, modelo USC - 1800 A) durante 1 hora. Em seguida, separou-se $50 \mu \mathrm{L}$ da dispersão de AZO e adicionou- 
se na solução de PMMA. A solução resultante foi homogeneizada durante 1 hora em banho ultrassônico Unique, modelo USC - 1800 A.

\subsubsection{Deposição dos filmes finos poliméricos e do AZO}

As deposições dos filmes finos poliméricos e do AZO foram feitas pela técnica de spin-coating (Figura 25) em uma glovebox, onde nitrogênio foi injetado constantemente para manter o ambiente inerte e umidade relativa interna inferior a $20 \%$. As espessuras da camada emissora variaram entre $45-65 \mathrm{~nm}$.

Figura 25 - Esquematização da técnica de spin-coating para a formação de filmes finos.

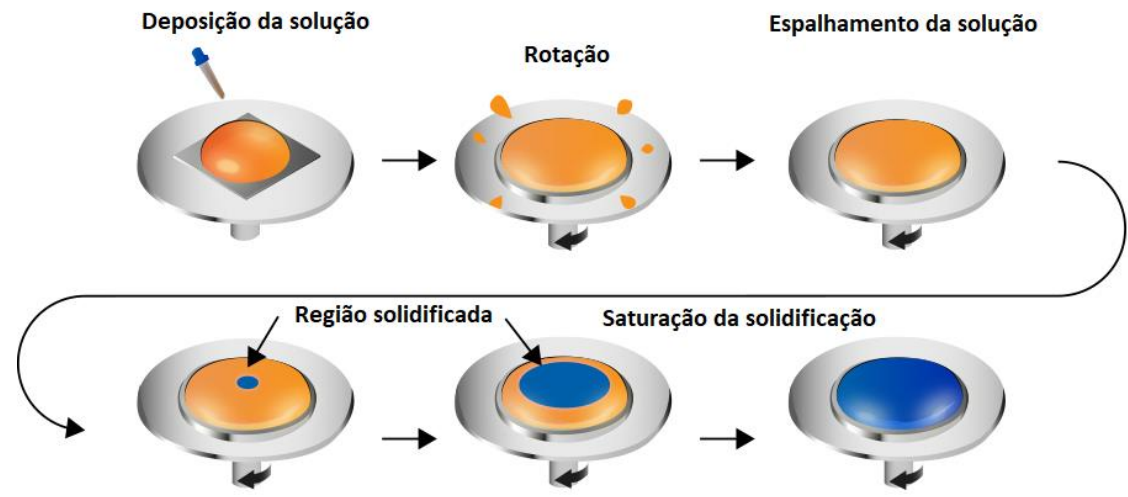

Fonte: [34].

A ordem de deposição dos filmes está apresentada na Figura 26. O substrato limpo contendo a trilha de ITO foi posicionado e fixado com uma fita dupla face sobre o prato do spinner caseiro que foi montado a partir de um motor de disco rígido de computador. Em seguida, $150 \mu \mathrm{L}$ de PEDOT:PSS foi depositado no centro do substrato e, então, o prato foi submetido a uma rotação de 3000 rpm durante 1 minuto. Este processo foi repetido mais uma vez para minimizar os defeitos do primeiro filme polimérico formado. Após a deposição do HTL, a lâmina passou por um processo de decapagem, conforme mostrado na Figura 26 b), e secagem a 50 ${ }^{\circ} \mathrm{C}$ durante 5 minutos com o auxílio de um secador TAIFF. A decapagem constituiu na retirada do filme das bordas da lâmina com intuito de retirar o excesso de polímero dos eletrodos com o auxílio de um cotonete e de um solvente do polímero, que neste caso, foi água destilada. 
Após a deposição do filme de PEDOT:PSS iniciou-se a deposição do filme da camada emissora. Para os dispositivos à base de $\mathrm{PVK}, \mathrm{PFO}$ e $\mathrm{PF}_{\mathrm{PF}}$, o processo e os parâmetros envolvidos foram os mesmos descritos anteriormente exceto no processo de decapagem, que foi feita conforme a Figura $26 \mathrm{c}$ ), em que foi utilizado 0 clorofórmio para a retirada do excesso de filme. Para os dispositivos cuja camada emissora foi de PVK:AZO, a deposição do filme foi feita uma única vez, utilizando os mesmos parâmetros na deposição do PEDOT:PSS. A decapagem também foi feita com clorofórmio conforme a Figura 26 c).

Por fim, o AZO foi depositado sobre a estrutura anterior pelo mesmo processo e parâmetros utilizados na deposição dos filmes poliméricos. Entretanto, o volume de AZO utilizado foi de $100 \mu \mathrm{L}$, a deposição por spin-coating foi feita uma única vez e o processo de decapagem foi feito de acordo com a Figura 26 d) utilizando o clorofórmio.

Figura 26 - Esquematização do processo de deposição dos filmes poliméricos e de AZO: a) Substrato com as 4 trilhas de ITO; b) Deposição do PEDOT:PSS; c) Deposição da camada emissora e d) Deposição da camada de AZO.

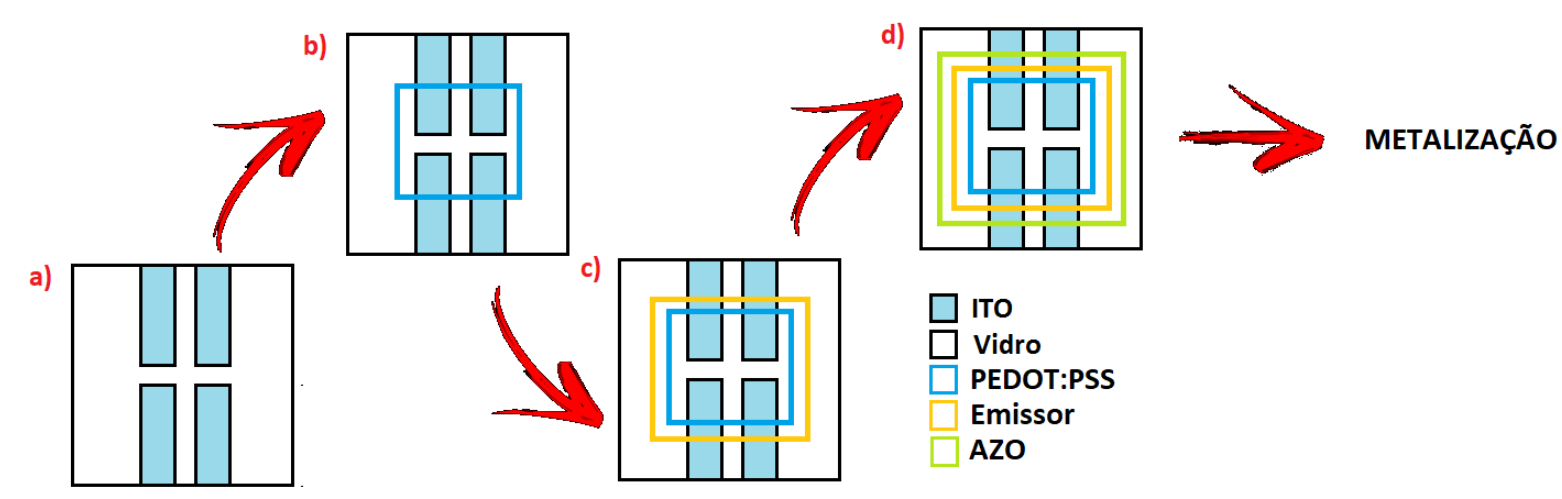

Fonte: Autoria própria.

A Tabela 8 mostra os parâmetros utilizados na técnica de spin-coating e os solventes utilizados para a decapagem de cada tipo de filme depositado. 
Tabela 8 - Parâmetros utilizados no processo de spin-coating e o solvente utilizado para a decapagem para cada tipo de filme.

\begin{tabular}{cccccc}
\hline Material & $\begin{array}{c}\text { Volume } \\
\text { Depositado } \\
(\mu \mathrm{L})\end{array}$ & $\begin{array}{c}\text { Número de } \\
\text { Deposição }\end{array}$ & $\begin{array}{c}\text { Velocidade de } \\
\text { Rotação }(\mathrm{rpm})\end{array}$ & $\begin{array}{c}\text { Tempo } \\
(\text { minutos })\end{array}$ & Decapagem \\
\hline $\begin{array}{c}\text { PEDOT:PSS } \\
150\end{array}$ & 2 & 3000 & 1 & Água \\
$\begin{array}{c}\text { Polímero: } \\
\text { Ir(ppy) }\end{array}$ & 150 & 2 & 3000 & 1 & Clorofórmio \\
PVK:AZO & 150 & 1 & 3000 & 1 & Clorofórmio \\
PMMA:AZO & 150 & 1 & 3000 & 1 & Clorofórmio \\
AZO & 100 & 1 & 3000 & 1 & Clorofórmio \\
\hline
\end{tabular}

Fonte: Autoria própria.

Ao final desta etapa, as lâminas resultantes foram posicionadas em suportes específicos junto às máscaras mecânicas, que são responsáveis pela deposição seletiva do cátodo, de tal forma que as 4 aberturas de dimensões $3 \times 10(\mathrm{~mm})$ cada, por onde o alumínio foi depositado, ficasse perpendicular às trilhas de ITO conforme ilustrado na Figura 27.

Figura 27 - Esquematização do posicionamento da máscara mecânica em relação à lâmina contendo todos os filmes depositados por via úmida.

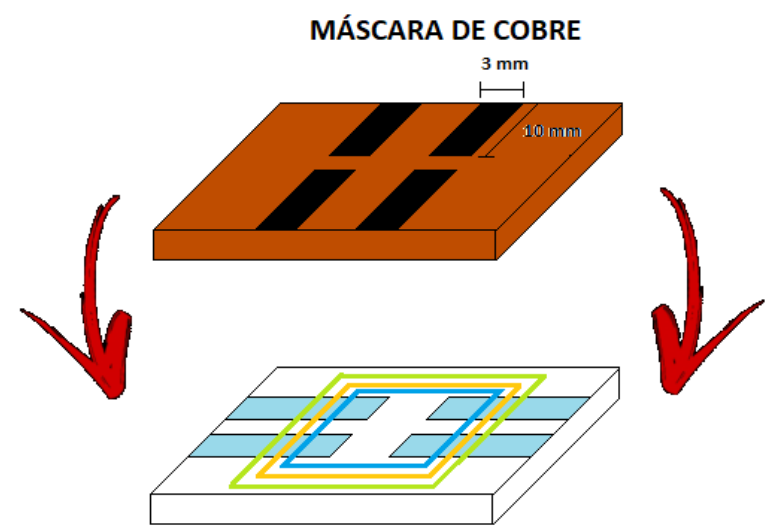

Fonte: Autoria própria. 


\subsubsection{Metalização com alumínio}

Nesta etapa, os suportes com as máscaras contendo as lâminas do processo anterior foram colocadas sobre o planetário situado no interior da metalizadora, onde ocorre a deposição de alumínio por evaporação térmica. O planetário consiste em um suporte giratório, que permite a deposição de filmes homogêneos, capaz de comportar até 25 amostras. Em seguida, fez-se o vácuo até atingir uma pressão interna de $10^{-5} \mathrm{mbar}$ e, então, o alumínio que fica situado sobre um filamento de tungstênio é aquecido até a sua evaporação e condensação sobre as amostras (Figura 28). A taxa de evaporação foi de $10 \mathrm{~nm} / \mathrm{s}$ e a espessura do filme obtido foi de $100 \mathrm{~nm}$ a $200 \mathrm{~nm}$.

Figura 28 - Esquematização da câmara de evaporação para a deposição de alumínio.

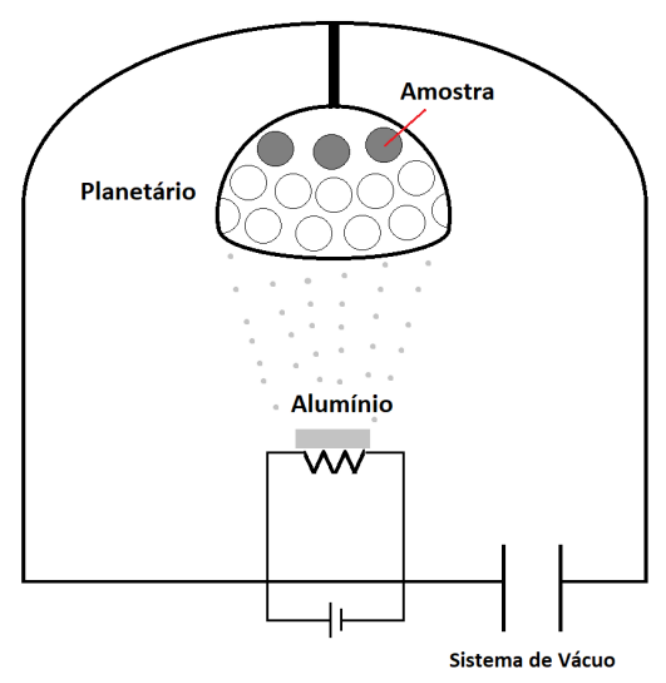

Fonte: Autoria própria.

Assim, ao final deste processo, obteve-se 4 dispositivos por lâmina com uma área emissiva de $9 \mathrm{~mm}^{2}$ (em vermelho) conforme ilustrado na Figura 29. 
Figura 29 - Esquematização da lâmina final contendo 4 dispositivos com área emissiva de 9 mm² destacado em vermelho.

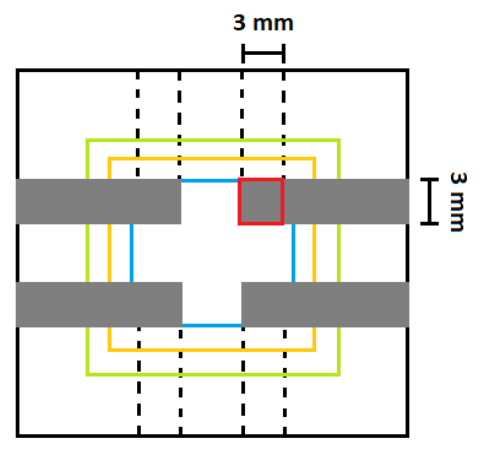

Fonte: Autoria própria.

\subsection{Técnicas de caracterização}

\subsubsection{Caracterização dos PLEDs}

Os PLEDs produzidos foram caracterizados eletricamente a partir do levantamento das curvas de densidade de corrente em função da tensão aplicada (curvas $\mathrm{J} \times \mathrm{V}$ ), e também, opticamente obtendo-se os espectros de eletroluminescência, coordenadas de cromaticidade e a luminância dos dispositivos, quando possível.

\subsubsection{Caracterização elétrica}

As curvas $\mathrm{J} \times \mathrm{V}$ foram obtidas utilizando-se uma fonte de tensão programável, Keithley série 2400 (Figura 30) servido pelo programa LabTracer 2.0 com passo 0,1 $\mathrm{V} / \mathrm{s}$ e com estabelecimento de uma corrente máxima de $50 \mathrm{~mA}$. O PLED é conectado aos terminais da fonte programável de tal forma que a corrente fluísse do ITO para o alumínio. Para cada tensão aplicada, o equipamento colheu uma resposta em corrente, obtendo-se a curva da corrente em função da tensão. Para adquirir a curva $\mathrm{J} \times \mathrm{V}$, a corrente medida foi dividida pela área emissiva, que neste caso, foi de $9 \mathrm{~mm}^{2}$.

A partir das curvas $\mathrm{J} \times \mathrm{V}$ obtidas, estimou-se a tensão de limiar dos dispositivos como sendo a intersecção entre as tangentes das curvas nos limites inferior (região de baixa densidade de corrente) e superior (região de alta densidade de corrente). 
Figura 30 - Fonte de tensão programável Keithley, modelo 2400.

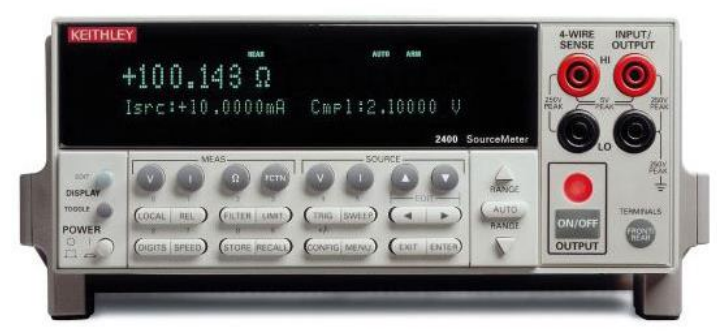

Fonte: [35].

\subsubsection{Caracterização óptica}

As coordenadas de cromaticidade e a luminância dos dispositivos montados foram determinadas com o auxílio de uma fonte de corrente e tensão (Faíscas) e um equipamento da Konica Minolta, modelo CS-200 (Figura 31). O dispositivo, em ambiente inerte contendo atmosfera de nitrogênio, foi polarizado diretamente em uma tensão constante e, em seguida, o equipamento foi posicionado e focado na área ativa de tal forma a permitir a medição dos valores das coordenadas de cromaticidade e luminância.

Figura 31 - Equipamento da Konica Minolta, modelo CS-200 capaz de medir a luminância e determinar as coordenadas de cromaticidade dos dispositivos eletroluminescentes.

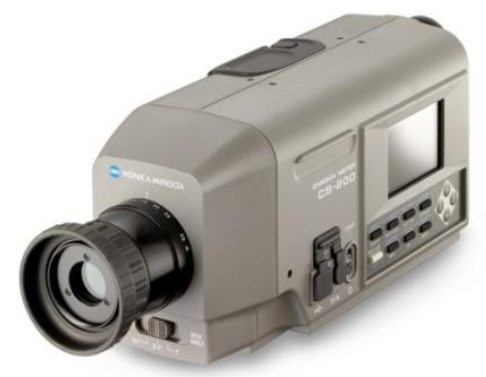

Fonte: [36].

A partir dos valores de luminância obtidos e da corrente observada para uma determinada tensão aplicada, foi possível calcular tanto a eficiência de corrente quanto a eficiência de potência dos dispositivos de acordo com a Equação 1 e Equação 2 [1].

$$
\eta_{c}=\frac{L}{J} \quad[\mathrm{~cd} / \mathrm{A}]
$$




$$
\boldsymbol{\eta}_{p}=\boldsymbol{\eta}_{c} \frac{\pi}{V} \quad[\mathrm{~lm} / \mathrm{W}]
$$

Onde $\eta_{c}$ é a eficiência de corrente; $L$ é a luminância; $J$ é a densidade de corrente; $\eta_{p}$ é a eficiência de potência e $V$ é a tensão aplicada.

A partir dos valores das coordenadas de cromaticidade, montaram-se os diagramas de cromaticidade dos dispositivos produzidos - CIE 1931 (International Committee of Illumination 1931). E ainda, calculou-se a pureza ou saturação dos dispositivos segundo a Equação 3, utilizando o D65 e as coordenadas $(0,33 ; 0,33)$ como os iluminantes padrões e foi obtido o comprimento de onda dominante $\left(\lambda_{\text {dom }}\right)$ conforme mostrado na Figura 32.

$$
\text { Pureza }=\frac{a}{a+b}
$$

Onde a e b estão apresentados na Figura 32.

Figura 32 - Diagrama de cromaticidade CIE 1931.

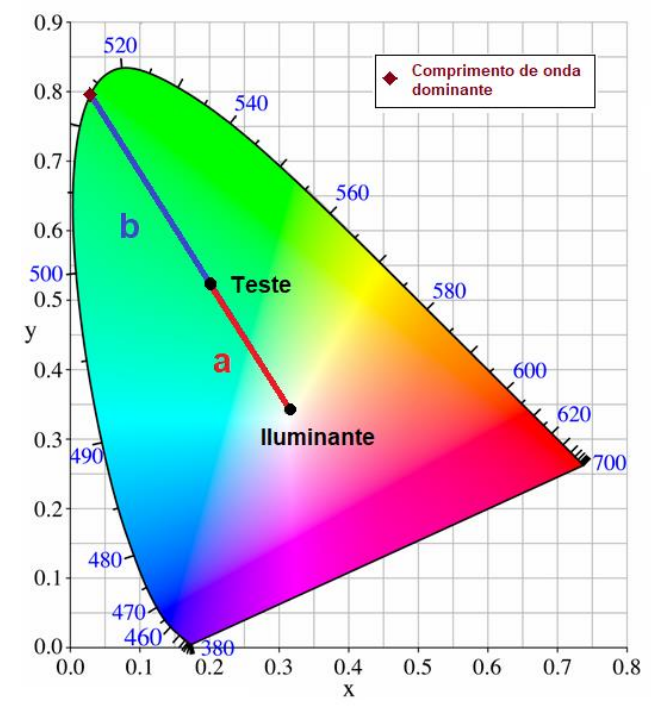

Fonte: Adaptado de [38].

Além das coordenadas de cromaticidade e da luminância, foram também obtidos os espectros de eletroluminescência com o espectrorradiômetro da Luzchem, modelo SPR-03 (Figura 33) - equipamento emprestado pelo Instituto de Física da USP - e com o auxílio de uma fonte de corrente e tensão (Faíscas). O dispositivo foi polarizado diretamente a uma determinada tensão constante e em 
seguida, posicionou-se a fibra óptica do espectrorradiômetro sobre a área ativa para a obtenção do espectro.

Figura 33 - Espectrorradiômetro da Luzchem, modelo SPR-03 utilizado para a obtenção dos espectros eletroluminescentes.

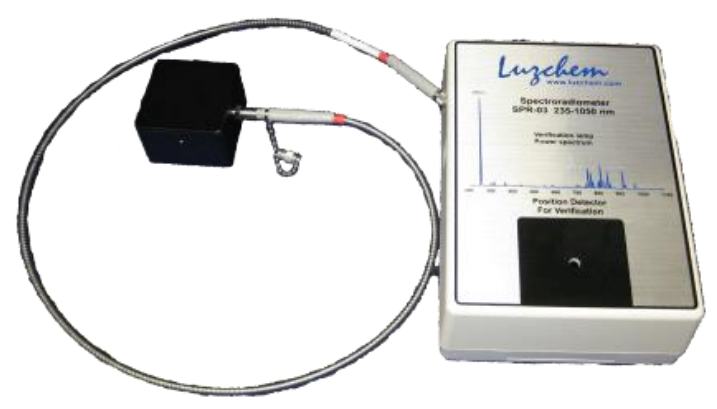

Fonte: [40].

\subsubsection{Caracterizações ópticas das soluções}

Espectros de absorção e de fotoluminescência das soluções de PVK, AZO e PVK:AZO diluídas em clorofórmio espectroscópico a temperatura ambiente foram obtidos com o auxílio dos espectrofotômetros Varian Cary 50 Conc e Varian Cary Eclipse, respectivamente.

As concentrações utilizadas para a obtenção dos espectros de absorção e de fotoluminescência do PVK, AZO e PVK:AZO foram, respectivamente, $1,33 \mathrm{mg} / \mathrm{mL}$; $5,34 \mathrm{mg} / \mathrm{mL}$ e $1,99 \mathrm{mg} / \mathrm{mL}$ (1,33 mg/mL de PVK e 0,66 mg/mL de AZO). Espectros de fotoluminescência do AZO puro comercial sem nenhuma purificação anterior também foram obtidos.

Filtros de $360 \mathrm{~nm}$ foram utilizados para a obtenção dos espectros de fotoluminescência quando as soluções diluídas foram excitadas em $320 \mathrm{~nm}$, e filtros de $430 \mathrm{~nm}$ para as soluções excitadas em $320 \mathrm{~nm}$ (somente AZO diluído), $370 \mathrm{~nm}$, $380 \mathrm{~nm}, 400 \mathrm{~nm}$ e $420 \mathrm{~nm}$. Os slits de excitação e emissão, respectivamente, utilizados para a solução diluída de AZO foram de $20 \mathrm{~nm}$ e $20 \mathrm{~nm}$; para as solução de PVK e de PVK:AZO foram de $10 \mathrm{~nm}$ e $10 \mathrm{~nm}$ e para a solução concentrada de AZO foram de $20 \mathrm{~nm}$ e $10 \mathrm{~nm}$. 


\section{Resultados e Discussões}

\subsection{Influência do Ir(ppy $)_{3}$ no PVK, PFO e PF}

\subsubsection{Influência do número de polarizações nas curvas $\mathrm{J} \times \mathrm{V}$}

A Figura 34, Figura 35 e Figura 36 mostram, respectivamente, a influência do número de polarizações nas curvas $\mathrm{J} \times \mathrm{V}$ dos dispositivos contendo PVK, PFO e $\mathrm{PF}_{\mathrm{PF}}$ puros como camada emissora de luz. Enquanto que a Tabela 9, mostra a mesma influência, entretanto, nas tensões de limiar dos mesmos. Como pode ser observado, o comportamento das curvas na primeira polarização se difere dos comportamentos observados nas outras polarizações, sendo que esta diferença é minimizada a partir da terceira polarização. Isso também pode ser observado nos valores das tensões de limiar dos dispositivos.

As tensões de limiar dos dispositivos de PVK, PFO e PF puros na primeira polarização foram de $7,0 \mathrm{~V}, 7,0 \mathrm{~V}$ e $9,6 \mathrm{~V}$, respectivamente. Na segunda polarização, estas tensões passaram para os valores de 7,2 V, 7,6 V e 8,6 V o que equivale à redução de 2,8 \%,7,9\% e 10,4 \%, respectivamente. Entretanto, conforme a corrente passa pelo material, esta redução diminui, sendo que da terceira para a quarta polarização esta variação se tornou menos significativa.

Deste modo, sugere-se que este fenômeno ocorre, principalmente, quando a corrente passa pela primeira vez pelo material, pois provoca o relaxamento das tensões internas dos filmes e, por consequência, as cadeias poliméricas se rearranjam, criando-se passagens para a movimentação das cargas. Assim, a partir de um determinado número de polarizações, a corrente flui com maior facilidade e, por consequência, curvas $\mathrm{J} \times \mathrm{V}$ e tensões de limiar mais representativas daquele filme são obtidas. 
Figura 34 - Influência da polarização na curva $\mathrm{J}$ x V do dispositivo contendo apenas o PVK como a camada emissora.

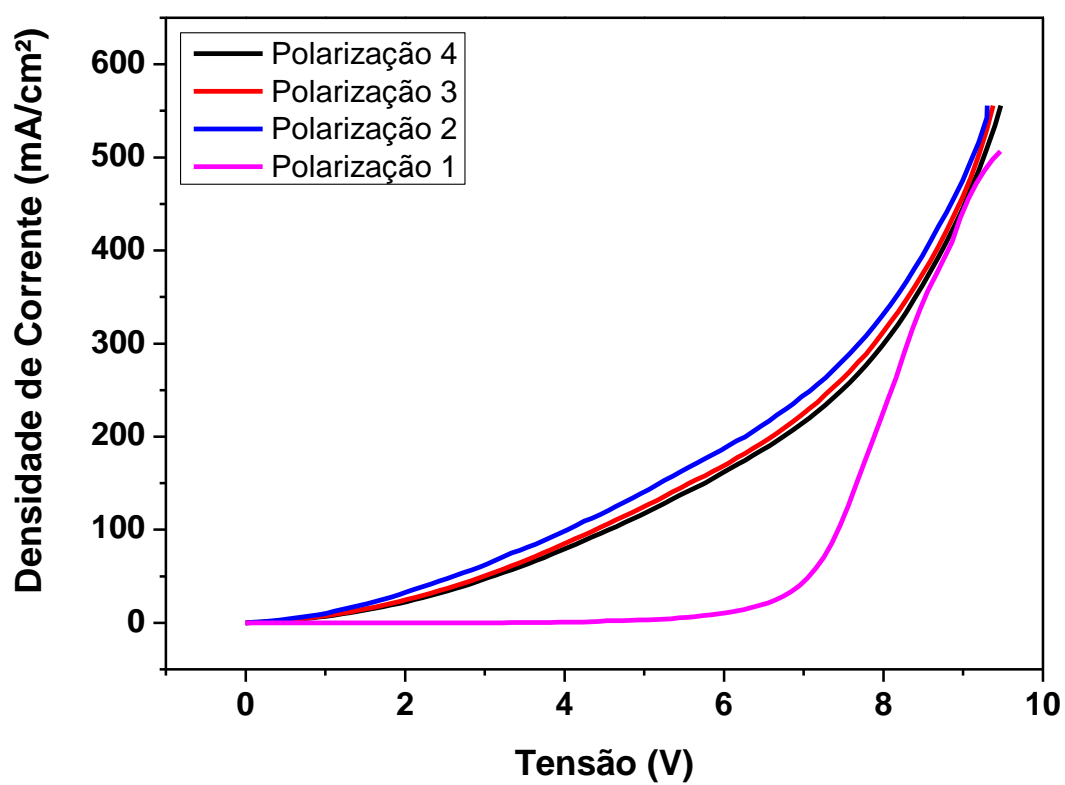

Fonte: Autoria própria.

Figura 35 - Influência da polarização na curva $\mathrm{J}$ x V do dispositivo contendo apenas o PFO como a camada emissora.

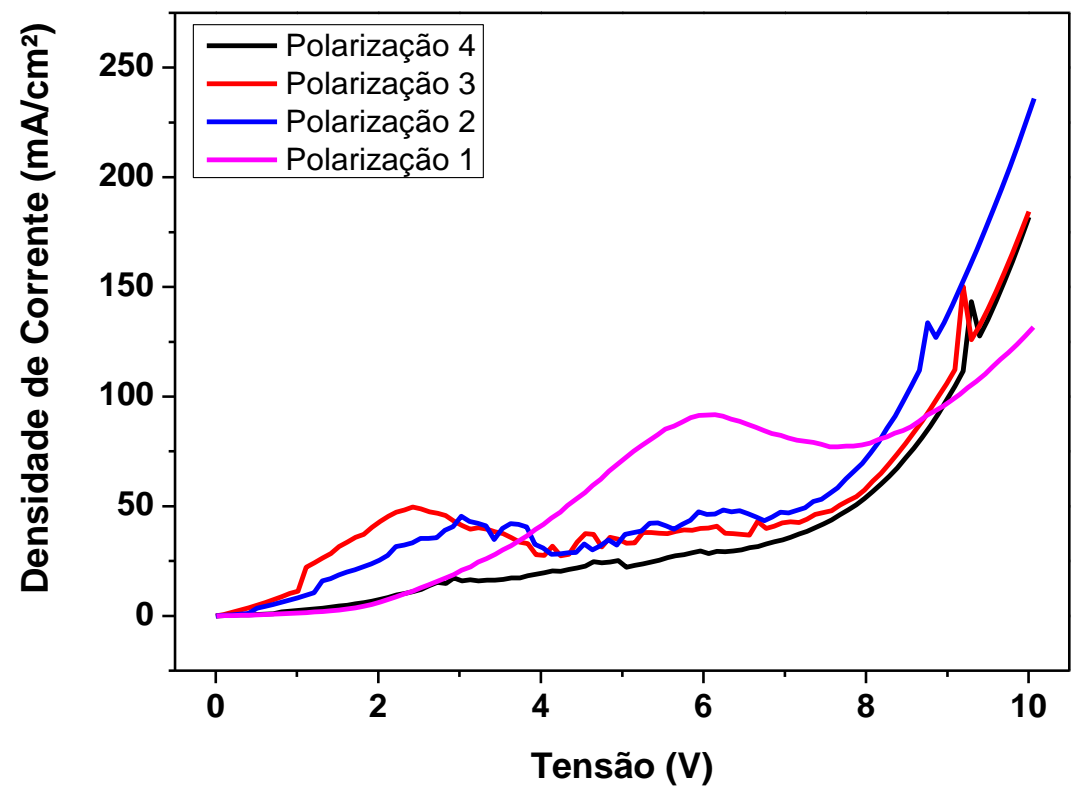

Fonte: Autoria própria. 
Figura 36 - Influência da polarização na curva $\mathrm{J}$ x $\mathrm{V}$ do dispositivo contendo apenas o $\mathrm{PF}_{\mathrm{PF}}$ como a camada emissora.

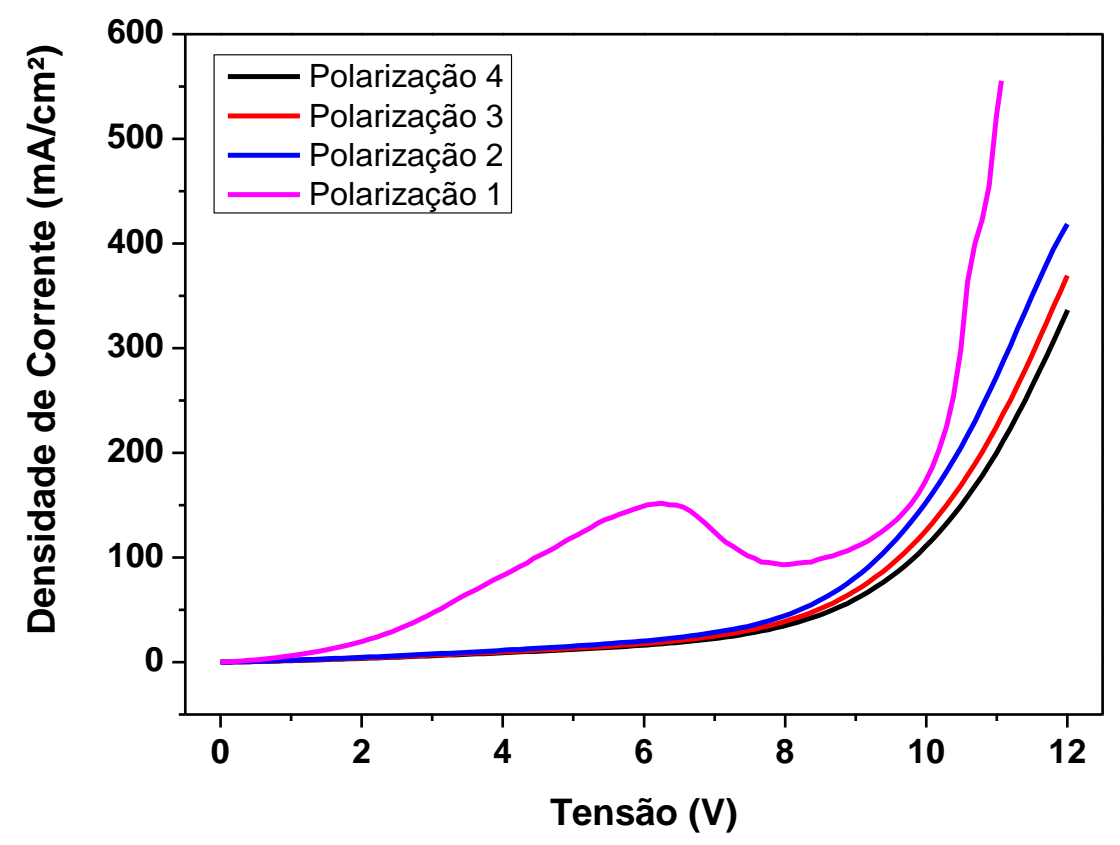

Fonte: Autoria própria.

Tabela 9 - Influência no número de polarizações na tensão de limiar dos dispositivos de PVK, PFO e $\mathrm{PF}_{\mathrm{PF}}$ puros.

\section{Tensão de Limiar (V)}

\begin{tabular}{ccccc}
\hline Emissor & Polarização 1 & Polarização 2 & Polarização 3 & Polarização 4 \\
\hline PVK & 7,0 & 7,2 & 7,7 & 7,7 \\
PFO & 7,0 & 7,6 & 7,8 & 7,8 \\
PF & 9,6 & 8,6 & 8,7 & 8,7 \\
\hline
\end{tabular}

Fonte: Autoria própria.

As curvas $\mathrm{J} x \mathrm{~V}$ e suas respectivas tensões de limiar em função do número de polarizações para os dispositivos contendo a camada emissora dopada com $\operatorname{Ir}(\mathrm{ppy})_{3}$ estão apresentadas na seção 8.1. Este comportamento observado nos dispositivos à base de PVK, PFO e PF $F_{P F}$ puros também estão presentes nos PLEDs dopados. 


\subsubsection{Curvas $\mathrm{J} \times \mathrm{V}$}

Conforme foi mostrado na seção 5.1.1, a partir da terceira polarização, as curvas $\mathrm{J} \times \mathrm{V}$ são muito semelhantes e as tensões de limiar praticamente se mantêm constantes. Logo, estas curvas mais reprodutíveis foram utilizadas para a realização das análises das propriedades elétricas dos dispositivos.

As curvas $\mathrm{J} \times \mathrm{V}$ dos dispositivos baseados em PVK, PFO e $\mathrm{PF}_{\mathrm{PF}}$ estão apresentadas na Figura 37, Figura 39 e Figura 41, respectivamente. Além disso, as tensões de limiar para cada tipo de dispositivo produzido estão exibidas na Tabela 10.

Figura 37 - Curvas $\mathrm{J}$ x V dos dispositivos baseados no PVK contendo a curva ampliada da proporção Polímero: Dopante 95:5.

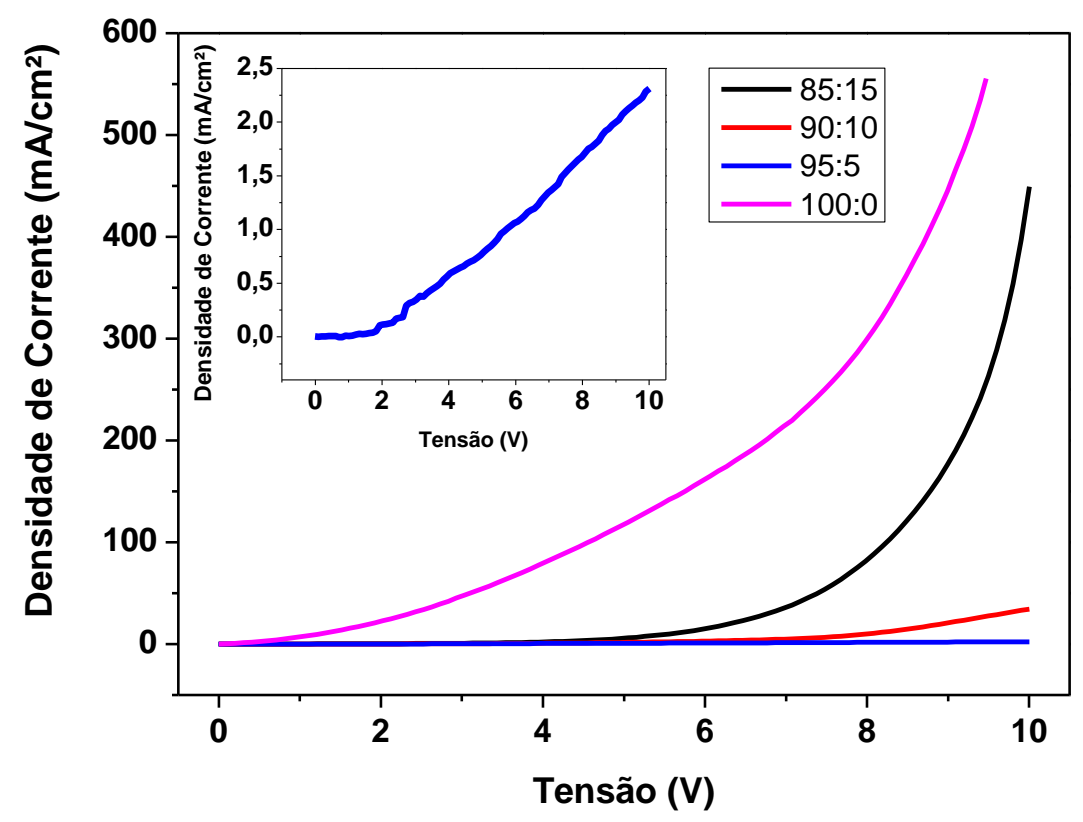

Fonte: Autoria própria.

De acordo com a Figura 37, quando a adição de $\operatorname{Ir}(\mathrm{ppy})_{3}$ no $\mathrm{PVK}$ foi de $5 \%$ em massa, ocorreu uma queda significante na densidade de corrente (menor que 5 $\mathrm{mA} / \mathrm{cm}^{2}$ ). E ainda, apesar de se perceber uma transição a 2,3 $\mathrm{V}$, a curva $\mathrm{J} \times \mathrm{V}$ deste dispositivo não a apresentou com aumento significativo na densidade de corrente $\mathrm{e}$ também, mostrou-se bastante resistivo em tensões superiores a $4 \mathrm{~V}$. Assim, não se pode afirmar com clareza se o dispositivo apresentou características de diodo. Isso 
pode ter ocorrido porque o filme da camada emissora estava espesso ou os filmes da camada transportadora de lacunas/ de elétrons estavam muito finos, provocando um desbalanceamento de cargas.

O aumento da proporção de dopante (10 \% e $15 \%$ em massa) em relação ao host provocou tanto a diminuição da densidade de corrente em relação ao PVK puro quanto da tensão de limiar que passou de 7,7 V para 7,4 V. Estes comportamentos podem ser explicados entendendo-se o mecanismo de transporte e injeção de cargas em filmes orgânicos.

Figura 38 - Diagrama das bandas de energias dos dispositivos baseados no PVK.

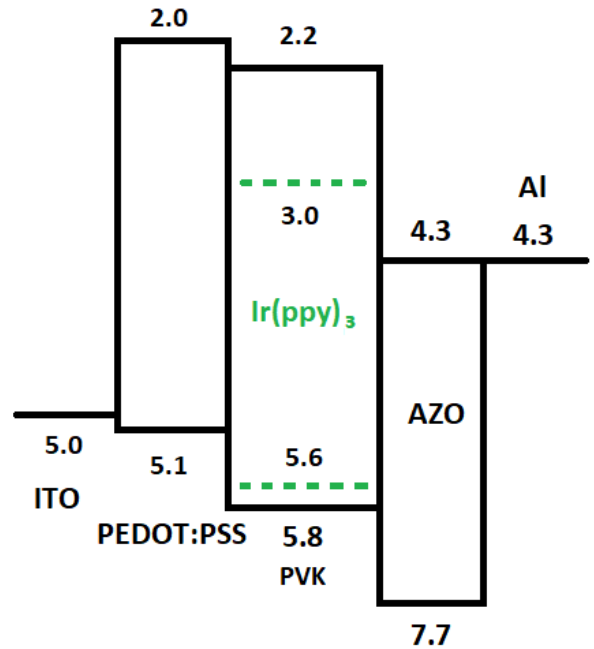

Fonte: Autoria própria.

Segundo o diagrama apresentado (Figura 38), quando as lacunas são transportadas e injetadas pelo HOMO do PEDOT:PSS para o HOMO do PVK, e quando elétrons são transportados e injetados do LUMO do AZO para o LUMO do PVK, existem barreiras energéticas devido à diferença entre as energias dos HOMOs e dos LUMOs dessas duas camadas, cujos valores são de 0,7 eV e 2,1 eV, respectivamente, que devem ser ultrapassadas pelas cargas. Entretanto, a adição do dopante fosforescente, por possuir a energia do HOMO mais próximo da energia do HOMO do PEDOT:PSS e energia do LUMO mais próxima do AZO, diminui essas barreiras para $0,5 \mathrm{eV}$ e $0,7 \mathrm{eV}$, respectivamente, facilitando a entrada de cargas no interior do complexo de irídio e, por consequência, provocando a diminuição na tensão de limiar do dispositivo de 7,7 V (PVK puro) para 7,4 V (10 \% e $15 \%$ em 
massa de dopante) [19]. Além disso, o complexo organometálico age como centro de recombinação uma vez que o PVK possui um band gap largo, diminuindo também a densidade de corrente em relação ao PLED de PVK puro [19]. $\mathrm{Na}$ literatura, sabe-se que este fenômeno também provoca aumentos na tensão de limiar dos dispositivos. Entretanto, apesar deste fenômeno também ser observado, a tensão de limiar decaiu conforme visto anteriormente. Portanto, a adição de $\operatorname{Ir}(\mathrm{ppy})_{3}$ no PVK ao mesmo tempo facilita a injeção de cargas na camada emissora e funciona como centro de recombinação, agindo de formas diferentes sobre a tensão de limiar do dispositivo.

Para os dispositivos baseados no PFO, pode-se observar tanto na Figura 39 quanto na Tabela 9 que a adição de $\operatorname{Ir}(\mathrm{ppy})_{3}$ quase não alterou a densidade de corrente, entretanto, a tensão de limiar dos PLEDs diminuíram em relação ao dispositivo de PFO puro. Assim, sugere-se que o dopante não agiu como centros de recombinações conforme observado no PVK, apenas facilitando a injeção de carga na camada emissora.

Figura 39 - Curva J x V dos dispositivos baseados no PFO.

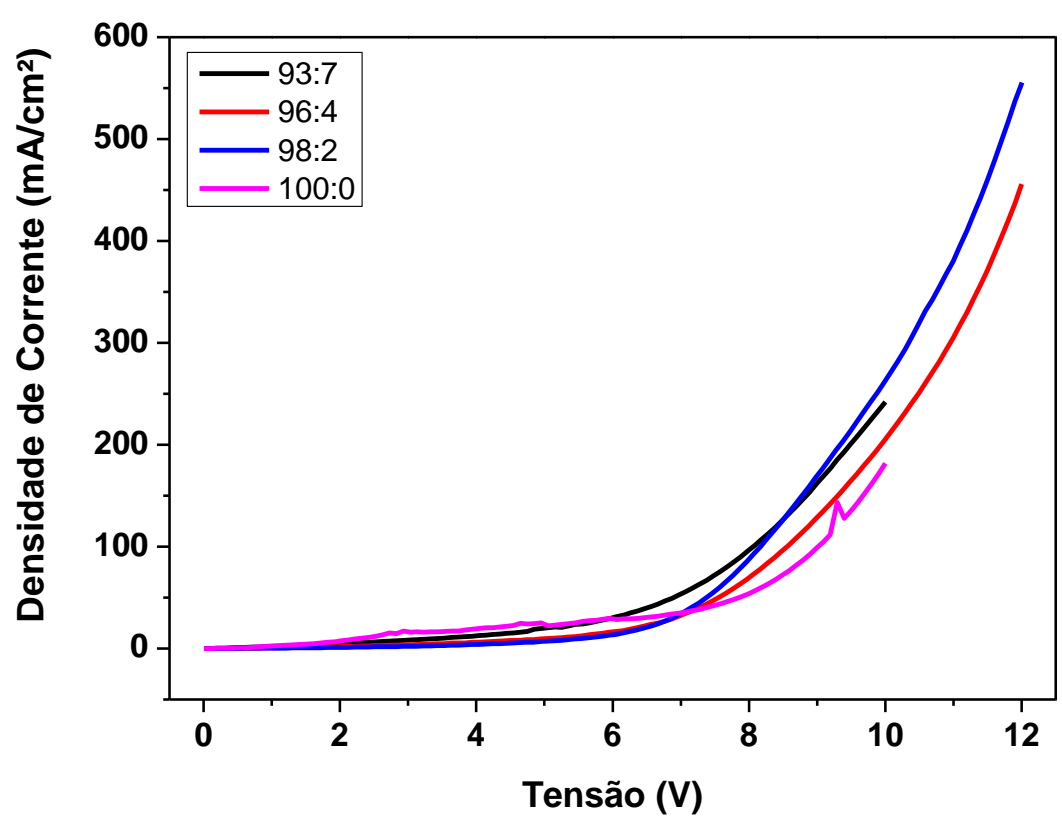

Fonte: Autoria própria.

Analisando-se o diagrama de bandas de energia apresentado na Figura 40, quando lacunas são transportadas e injetadas pelo HOMO do PEDOT:PSS para o 
HOMO do PFO, a barreira energética existente entre as energias do HOMO dessas duas camadas é de $0,7 \mathrm{eV}$, porém a adição do dopante diminui esta barreira para $0,5 \mathrm{eV}$, facilitando a entrada de cargas positivas no interior da camada emissora, assim como foi observado no PVK que possui a mesma energia HOMO que a do PFO. Isso também pode ser observado quando elétrons são transportados do LUMO do AZO para o LUMO do PFO. A barreira energética entre as energias LUMO do AZO e PFO é de 1,7 eV, porém quando se adiciona o complexo de irídio esta barreira cai para 1,3 eV, o que equivale a uma redução de $23 \%$. Quando se adiciona o dopante no PVK, estas mesmas barreiras energéticas variam de 2,1 eV para $0,7 \mathrm{eV}$, que representa uma redução muito mais significativa de $62 \%$. Assim, a adição de $\operatorname{Ir}(\mathrm{ppy})_{3}$ no PFO quase não provocou mudanças significativas na tensão de limiar dos dispositivos dopados conforme no PVK.

Figura 40 - Diagrama das bandas de energias dos dispositivos baseados no PFO.

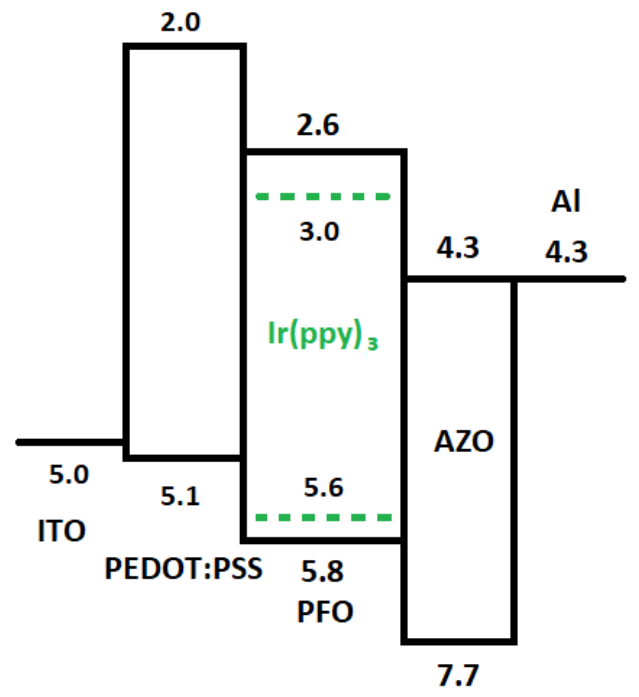

Fonte: Autoria própria.

Por fim, para os dispositivos a base de PF $F_{P F}$, a adição de $2 \%$ em massa de $\operatorname{Ir}(\text { ppy })_{3}$ não provocou variação significativa na densidade de corrente como observado na Figura 41. Entretanto, quando se adicionou 4 \% e 7 \% em massa de dopante, este aumento foi significante. Além disso, todos os dispositivos dopados apresentaram tensões de limiar inferiores ao do dispositivo de PFPF puro, atingindo uma redução de até $28 \%$ quando adicionado $7 \%$ em massa de dopante. Portanto, 
sugere-se que o $\operatorname{Ir}(\text { ppy })_{3}$ não agiu como centro de recombinação, mas apenas facilitando a entrada de carga na camada emissora.

Figura 41 - Curva J x V para os dispositivos baseados no $\mathrm{PF}_{\mathrm{PF}}$.

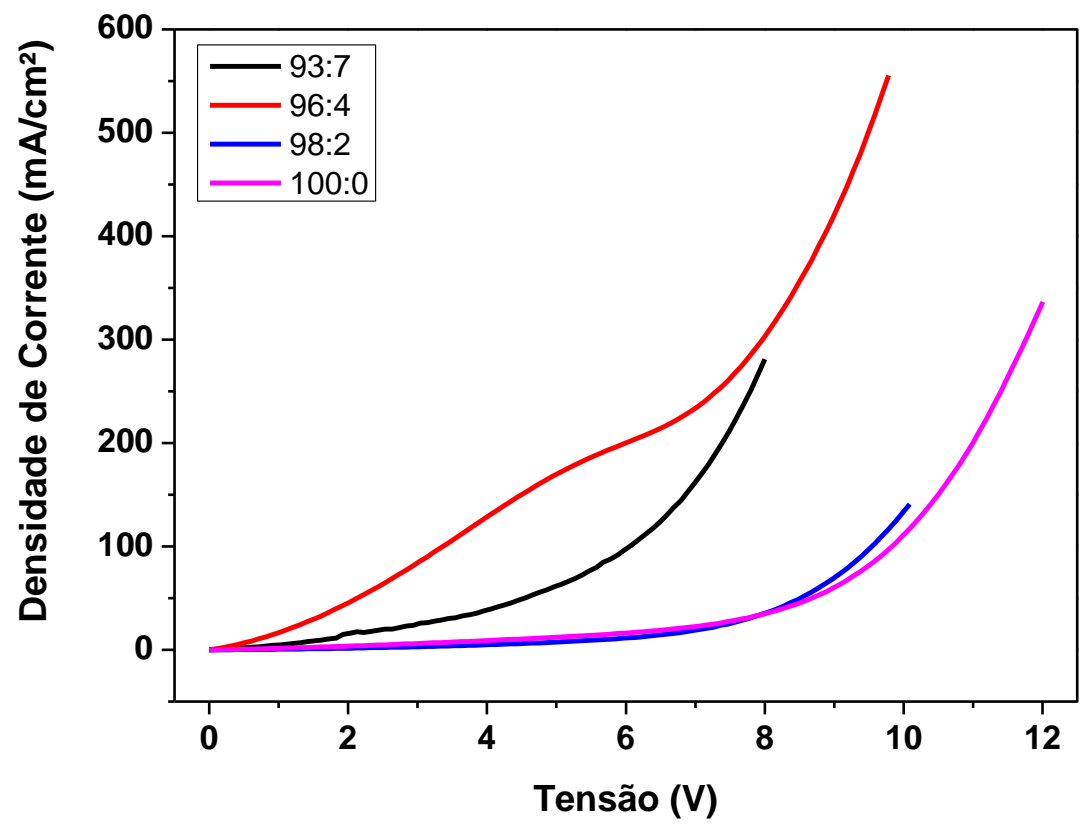

Fonte: Autoria própria.

Tabela 10 - Tensões de limiar para os dispositivos baseados em PVK, PFO e PF PF.

\begin{tabular}{|c|c|c|c|c|c|}
\hline \multicolumn{6}{|c|}{ Tensão de Limiar } \\
\hline \multicolumn{2}{|c|}{ PVK:Ir(ppy $)_{3}$} & \multicolumn{2}{|c|}{ PFO:Ir(ppy) ${ }_{3}$} & \multicolumn{2}{|c|}{$\mathrm{PF}_{\mathrm{PF}}: \operatorname{Ir}(p p y)_{3}$} \\
\hline 100:0 & $7,7 \mathrm{~V}$ & 100:0 & $7,8 \mathrm{~V}$ & 100:0 & $8,7 \mathrm{~V}$ \\
\hline $95: 5$ & $2,3 \mathrm{~V}$ & $98: 2$ & $7,1 \mathrm{~V}$ & $98: 2$ & $7,8 \mathrm{~V}$ \\
\hline $90: 10$ & $7,4 \mathrm{~V}$ & $96: 4$ & $7,1 \mathrm{~V}$ & $96: 4$ & $7,6 \mathrm{~V}$ \\
\hline $85: 5$ & $7,4 \mathrm{~V}$ & $93: 7$ & $6,7 \mathrm{~V}$ & $93: 7$ & $6,3 \mathrm{~V}$ \\
\hline
\end{tabular}

Fonte: Autoria própria.

\subsubsection{Desempenho dos dispositivos}

Para o estudo do desempenho dos dispositivos produzidos, calcularam-se as eficiências de corrente e de potência luminosa, e os gráficos foram montados em função da tensão aplicada de acordo com a Figura 42 e a Figura 43, respectivamente. As eficiências do dispositivo de PVK puro conforme a variação da 
tensão não foi possível de se determinar, pois os PLEDs apresentaram baixa estabilidade e baixa luminância.

Estes dispositivos construídos com PVK apresentam valores baixos de eficiências que permanecem baixos com o aumento da tensão, entretanto os dispositivos contendo $\operatorname{Ir}(\mathrm{ppy})_{3}$ a 5 e $15 \%$ demonstraram aumento significativo (50 a $100 \%$ a tensão de 9-10V. Enfatiza-se que as curvas $\mathrm{J} \times \mathrm{V}$ destes dois dispositivos são muito diferentes, pois os dispositivos contendo $\operatorname{Ir}(\mathrm{ppy})_{3}$ a 5 e $10 \%$ apresentaram valores de densidade de corrente inferior a $5 \mathrm{~mA} / \mathrm{cm}^{2}$.

Além disso, as eficiências dos dispositivos à base de PFO foram, no geral, superiores às eficiências dos dispositivos à base de $\mathrm{PVK}$ e $\mathrm{PF} \mathrm{PF}_{\mathrm{PF}}$. Entretanto, nos três sistemas não foi observada uma correlação direta entre a eficiência, tanto de potência luminosa como de corrente, e a concentração de $\operatorname{Ir}(\mathrm{ppy})_{3}$. Para os sistemas a base de PFO e PF $F_{\mathrm{PF}}$, foi possível observar um aumento inicial da eficiência com aumento da tensão aplicada, coerente com a curva de $\mathrm{J} \times \mathrm{V}$, e valores máximos aparecem a partir de $7 \mathrm{~V}$.

Chen [37] e seus colaboradores realizaram um trabalho em que eles estudaram a transferência de energia e confinamento de éxciton em sistemas poliméricos utilizando PVK e PFO como polímeros hospedeiros, e contendo diferentes dopantes fosforescentes baseados em complexos de irídio com diferentes energias de estado $T_{1}$. $O$ grupo mostrou que os éxcitons podem ser tanto confinados nos sítios do dopante quanto se difundirem para o polímero hospedeiro dependendo da energia do estado $T_{1}$ dos materiais. Segundo eles, como o PFO possui baixa energia do estado $T_{1}$, quando este polímero é dopado com um material cujo estado $T_{1}$ é superior, as energias de excitação fluem do dopante para o estado $T_{1}$ do PFO e, assim, este sofre decaimento não radiativo, provocando a diminuição na eficiência de corrente do dispositivo. Pode-se destacar também que a unidade repetitiva do PFO é não polar enquanto que o $\operatorname{Ir}(\mathrm{ppy})_{3}$ possui alta polaridade. Assim, a separação de fases entre estes materiais pode ocorrer e, por consequência, diminuir a eficiência do dispositivo devido aos fenômenos de aniquilamento de éxcitons nos sítios dos dopantes [37].

Portanto, era esperado que as eficiências observadas nos dispositivos dopados com $\operatorname{Ir}(\mathrm{ppy})_{3}$ à base de PVK fossem superiores ou próximos aos observados nos dispositivos dopados à base de PFO uma vez que os estados $T_{1}$ do 
PFO, PVK e Ir(ppy) 3 são de 2,15 eV, 2,41 eV e 2,50 eV, respectivamente [37]. Contudo, este comportamento não foi observado, provavelmente, devido ao desbalanceamento de cargas nos dispositivos de PVK uma vez que este possui uma baixa mobilidade de lacunas $\left(10^{-7}-10^{-6} \mathrm{~cm}^{2} / \mathrm{Vs}\right)$ em relação ao PFO $\left(10^{-4} \mathrm{~cm}^{2} / \mathrm{Vs}\right)$ e/ou a proporção de $\operatorname{Ir}(\mathrm{ppy})_{3}$ em relação ao PVK utilizada neste trabalho foi alta, favorecendo a agregação de dopantes e, por consequência, diminuindo a eficiência do dispositivo [39, 41].

Figura 42 - Eficiência de corrente em função da tensão aplicada para os dispositivos baseados em:

a) PVK, b) PFO e c) PFPF.
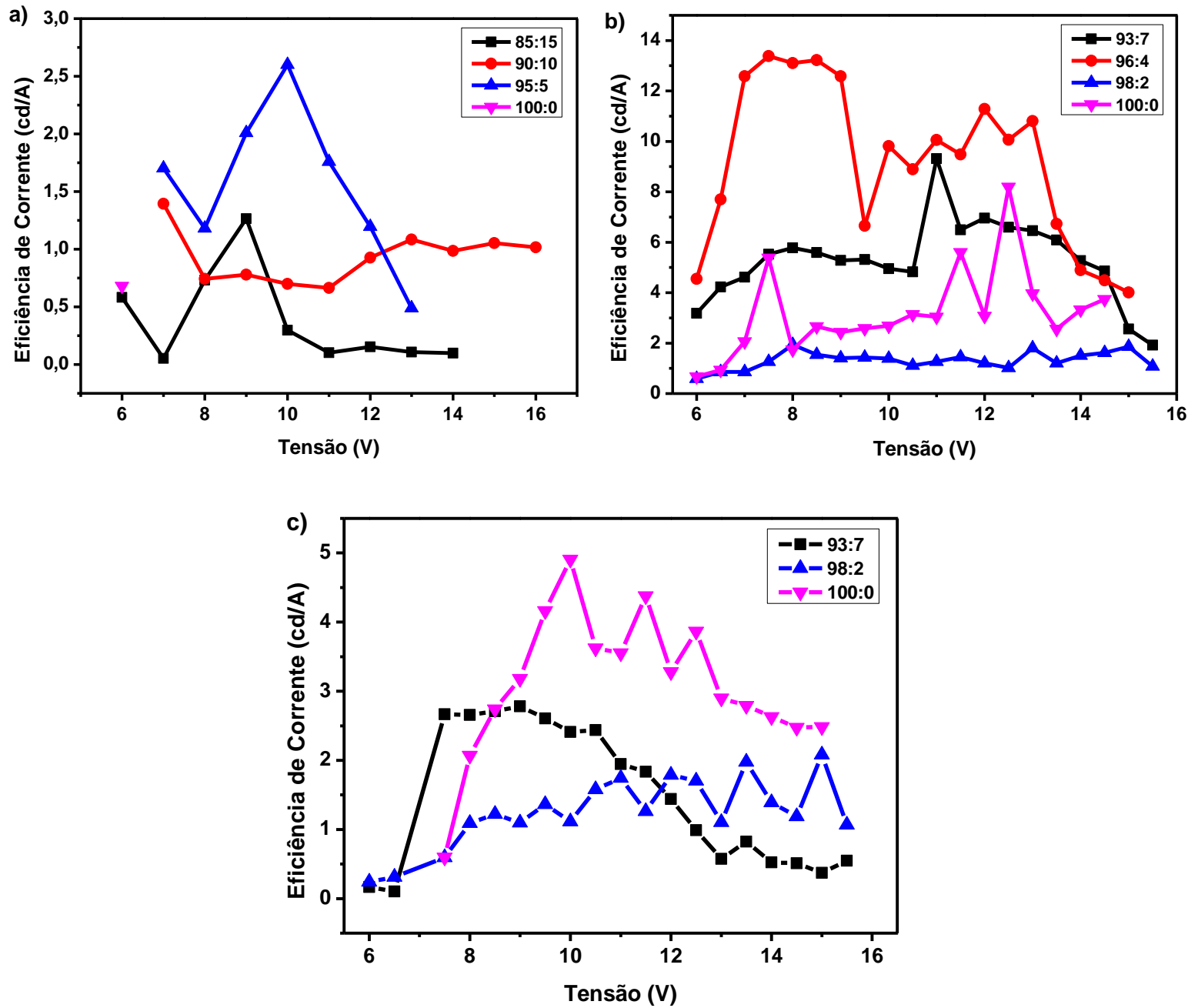

Fonte: Autoria própria. 
Figura 43 - Eficiência luminosa em função da tensão aplicada para os dispositivos baseados em: a) PVK, b) PFO e c) PFPF.
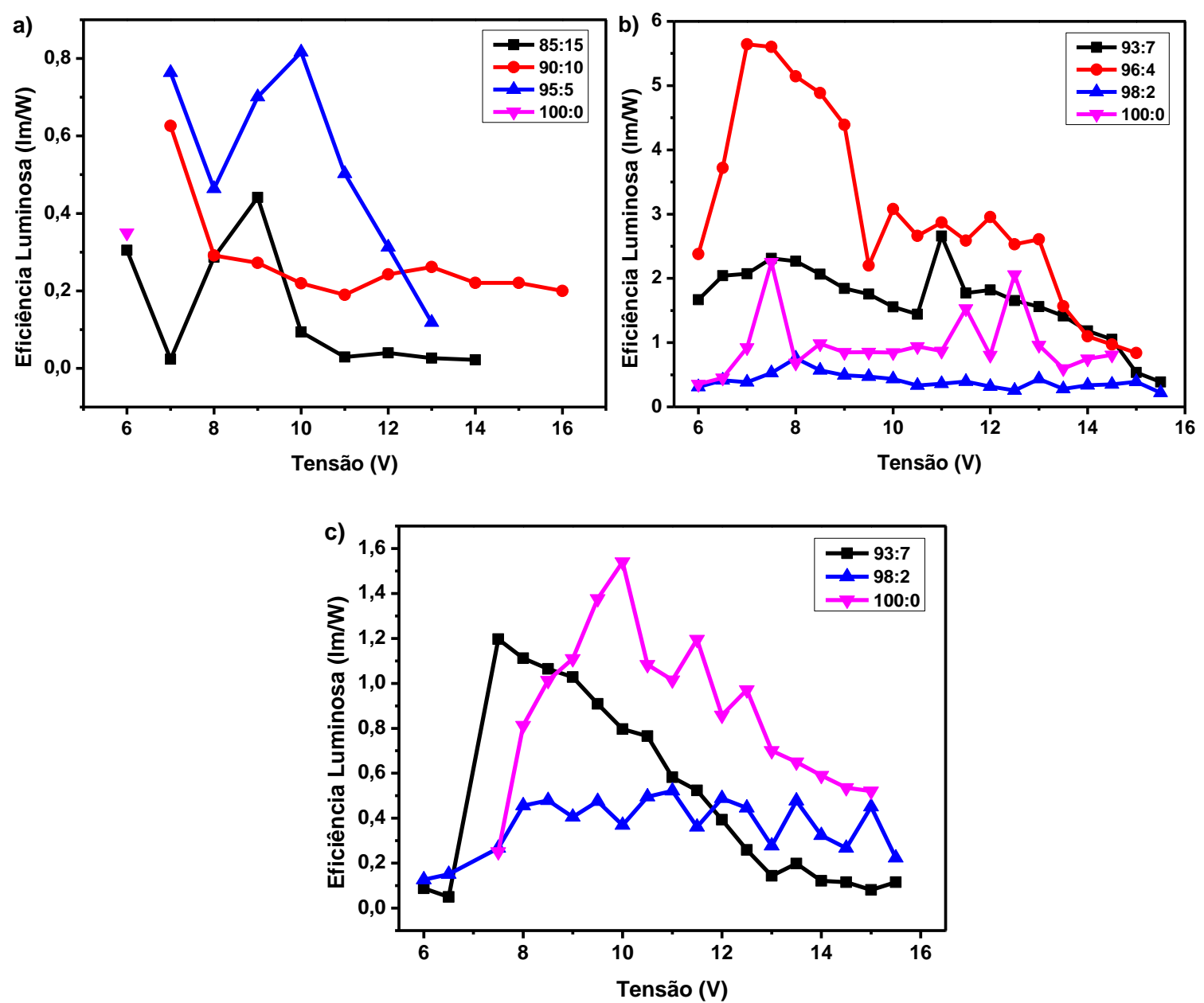

Fonte: Autoria própria.

A Tabela 11, a Tabela 12 e a Tabela 13 mostram a máxima luminância, eficiência de corrente e de potência luminosa dos dispositivos baseados em PVK, $\mathrm{PFO}$ e $\mathrm{PF}_{\mathrm{PF}}$, respectivamente.

Segundo a Tabela 11, pode-se observar que, para os dispositivos a base de PVK, a máxima luminância foi atingida quando se adicionou $15 \%$ em massa de $\operatorname{Ir}(\text { ppy })_{3}$ cujo valor foi de $37,9 \mathrm{~cd} / \mathrm{m}^{2}$ a $9 \mathrm{~V}$ e que representou um ganho de $565 \%$ em relação ao dispositivo de PVK puro (máxima luminância de $5,7 \mathrm{~cd} / \mathrm{m}^{2}$ ). Entretanto, as eficiências de corrente e luminosa correspondentes (1,26 cd/A e 0,44 Im/W) não foram as máximas eficiências obtidas para os dispositivos a base de PVK, sendo que o melhor desempenho foi atingido quando se adicionou $5 \%$ em massa de 
dopante fosforescente conforme mostrado na Tabela 11, sendo os seus valores de $2,6 \mathrm{~cd} / \mathrm{A}$ e $0,82 \mathrm{Im} / \mathrm{W}$ a $10 \mathrm{~V}$.

De acordo com a Figura 43, dentre os dispositivos de PVK, as maiores eficiências foram obtidas quando se adicionou $5 \%$ em massa de $\operatorname{Ir}(\mathrm{ppy})_{3}$. Entretanto, a adição de dopante acima desta proporção provocou a diminuição nas eficiências, sendo que os valores máximos atingidos foram $1,4 \mathrm{~cd} / \mathrm{A}$ e $0,63 \mathrm{Im} / \mathrm{W}$ a $7 \mathrm{~V}$ e 1,26 $\mathrm{cd} / \mathrm{A}$ e $0,44 \mathrm{~lm} / \mathrm{W}$ a $9 \mathrm{~V}$ para os dispositivos contendo $10 \%$ e $15 \%$ em massa de $\operatorname{Ir}(\mathrm{ppy})_{3}$, respectivamente conforme mostrado na Tabela 11. Este comportamento pode ser explicado pelo fato de que altas concentrações de $\operatorname{Ir}(\mathrm{ppy})_{3}$ favorecem a transferência de energia entre as suas moléculas, porém concomitantemente ocorre o processo de agregação de dopantes que aumenta os mecanismos de "autoaniquilamento" dos éxcitons e, por consequência, diminui a eficiência do PLED [19]. Portanto, é necessário adicionar uma quantidade ótima de $\operatorname{Ir}(\mathrm{ppy})_{3}$ para que 0 dispositivo tenha um bom desempenho uma vez que baixas concentrações do mesmo limita a transferência de energia que poderia ser utilizada para a recombinação radioativa nos sítios do dopante e, por consequência, a energia não poderá ser utilizada de forma eficiente [42].

Tabela 11 - Máxima luminância, eficiência de corrente e eficiência de potência luminosa atingida pelos dispositivos de PVK.

\begin{tabular}{cccc}
\hline PVK:Ir(ppy) & $\begin{array}{c}\text { Máxima Luminância } \\
\left(\mathbf{c d} / \mathbf{m}^{2}\right)\end{array}$ & $\begin{array}{c}\text { Máxima Eficiência de } \\
\text { Corrente (cd/A) }\end{array}$ & $\begin{array}{c}\text { Máxima Eficiência } \\
\text { Luminosa }(\mathbf{I m} / \mathrm{W})\end{array}$ \\
\hline $100: 0$ & 5,7 & 0,68 & 0,35 \\
$95: 5$ & 35,4 & 2,60 & 0,82 \\
$90: 10$ & 11,2 & 1,40 & 0,63 \\
$85: 15$ & 37,9 & 1,26 & 0,44 \\
\hline
\end{tabular}

Fonte: Autoria própria.

Observando-se a Tabela 12 para os dispositivos baseados em PFO, a máxima luminância atingida foi de $648,13 \mathrm{~cd} / \mathrm{m}^{2}$ a $13 \mathrm{~V}$ o que corresponde a um aumento de 154 \% em relação a luminância máxima do dispositivo de PFO puro 
$(254,92 \mathrm{~cd} / \mathrm{A}$ a $12,5 \mathrm{~V})$. Entretanto, as eficiências de corrente e luminosa correspondentes (10,80 cd/A e 2,61 Im/W) não foram as máximas eficiências obtidas para os dispositivos a base de PFO, sendo que a quantidade ótima foi de $4 \% \mathrm{em}$ massa de dopante, atingindo-se os valores máximos de eficiência de corrente de $13,4 \mathrm{~cd} / \mathrm{A}$ a $7,5 \mathrm{~V}$ e de eficiência luminosa de $5,64 \mathrm{Im} / \mathrm{W}$ a $7 \mathrm{~V}$.

A adição de 2 \% em massa de $\operatorname{Ir}(\mathrm{ppy})_{3}$ provocou uma redução nas eficiências em que os seus valores máximos foram de 1,93 cd/A e 2,27 Im/W a $8 \mathrm{~V}$ e a máxima eficiência de corrente e luminosa atingida pelo dispositivo de PFO puro foi de 8,2 $\mathrm{cd} / \mathrm{A}$ a $12,5 \mathrm{~V}$ e $2,15 \mathrm{Im} / \mathrm{W}$ a $7,5 \mathrm{~V}$. Entretanto, quando se adicionou quantidades superiores a $2 \%$ em massa, ocorreu um aumento na eficiência de corrente dos dispositivos de tal forma que a quantidade ótima foi de $4 \%$ em massa de dopante. Adicionando-se 7 \% em massa de $\operatorname{Ir}(\mathrm{ppy})_{3}$, em média, as eficiências de corrente diminuíram em relação à última proporção, sendo que os máximos valores atingidos foram de 9,31 cd/A e 2,66 Im/W a $11 \mathrm{~V}$ que, porém permaneceram superiores às eficiências de corrente do PFO puro.

Tabela 12 - Máxima luminância, eficiência de corrente e eficiência de potência luminosa atingida pelos dispositivos de PFO.

\begin{tabular}{cccc}
\hline PFO:Ir(ppy) ${ }_{3}$ & $\begin{array}{c}\text { Máxima Luminância } \\
\left(\mathbf{c d} / \mathbf{m}^{2}\right)\end{array}$ & $\begin{array}{c}\text { Máxima Eficiência de } \\
\text { Corrente }(\mathbf{c d} / \mathbf{A})\end{array}$ & $\begin{array}{c}\text { Máxima Eficiência } \\
\text { Luminosa }(\mathbf{I m} / \mathbf{W})\end{array}$ \\
\hline $100: 0$ & 254,92 & 8,20 & 2,25 \\
$98: 2$ & 150,95 & 1,93 & 0,76 \\
$96: 4$ & 648,13 & 13,39 & 5,64 \\
$93: 7$ & 422,6 & 9,32 & 2,66 \\
\hline
\end{tabular}

Fonte: Autoria própria.

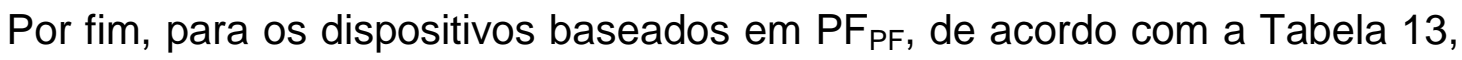
a máxima luminância atingida foi para o dispositivo contendo apenas o filme polimérico não dopado cujo valor foi de $112,51 \mathrm{~cd} / \mathrm{m}^{2}$ a $12,5 \mathrm{~V}$, o que corresponde a uma eficiência de corrente e luminosa de $3,86 \mathrm{~cd} / \mathrm{A}$ e $0,97 \mathrm{Im} / \mathrm{W}$, respectivamente. 
Entretanto, as máximas eficiências de corrente e luminosa foram de 4,91 cd/A a 10 $\mathrm{V}$ e de $1,54 \mathrm{~lm} / \mathrm{W}$ a $10 \mathrm{~V}$ para o mesmo tipo de dispositivo. Portanto, os melhores desempenhos foram atingidos para o dispositivo de $\mathrm{PF}_{\mathrm{PF}}$ puro.

Em média, a adição de $\operatorname{Ir}(\mathrm{ppy})_{3}$ provocou a diminuição nas eficiências do dispositivo, sendo que para tensões entre $7,5 \vee$ e $11,5 \vee$ as eficiências dos dispositivos contendo $7 \%$ em massa de dopante foram superiores em relação aos dispositivos contendo $4 \%$ em massa e para tensões superiores a $11,5 \mathrm{~V}$, este comportamento é invertido. Assim, conforme observado nas curvas $\mathrm{J} \times \mathrm{V}$ e nos gráficos das figuras Figura 42 e Figura 43, sugere-se que não ocorreu um confinamento eficiente dos éxcitons na camada emissora uma vez que se observou o aumento na densidade de corrente com a adição do complexo de irídio e baixas eficiências.

Tabela 13 - Máxima luminância, eficiência de corrente e eficiência de potência luminosa atingida pelos dispositivos de $\mathrm{PF}_{\mathrm{PF}}$.

\begin{tabular}{cccc}
\hline $\mathrm{PF}_{\mathrm{PF}}: \mathrm{Ir}(\mathrm{ppy})_{3}$ & $\begin{array}{c}\text { Máxima Luminância } \\
\left(\mathbf{c d} / \mathrm{m}^{2}\right)\end{array}$ & $\begin{array}{c}\text { Máxima Eficiência de } \\
\text { Corrente }(\mathbf{c d} / \mathbf{A})\end{array}$ & $\begin{array}{c}\text { Máxima Eficiência } \\
\text { Luminosa }(\mathrm{Im} / \mathrm{W})\end{array}$ \\
\hline $100: 0$ & 112,51 & 4,91 & 1,54 \\
$98: 2$ & 145,72 & 2,08 & 0,50 \\
$93: 7$ & 196,36 & 2,78 & 1,20 \\
\hline
\end{tabular}

Fonte: Autoria própria.

\subsubsection{Diagrama de cromaticidade}

A Figura 44 mostra as fotografias dos dispositivos acesos. Conforme se pode observar a olho nu, os dispositivos de PVK mostraram emissão esverdeada enquanto que os dispositivos de PFO e PFPF, azulada. Entretanto, o olho humano não consegue perceber nuances entre as cores da luz emitida e, por consequência, não se pode utilizá-los para a caracterização. Assim, os diagramas de cromaticidade apresentados na Figura 45, Figura 46 e Figura 47 foram montados de acordo com o CIE 1931 (International Committee of Illumination 1931). 
Figura 44 - Fotografias tiradas dos dispositivos acesos contendo: a) PVK, b) PFO e c) PF $\mathrm{PF}_{\text {como }}$ hosts.

a)

b)

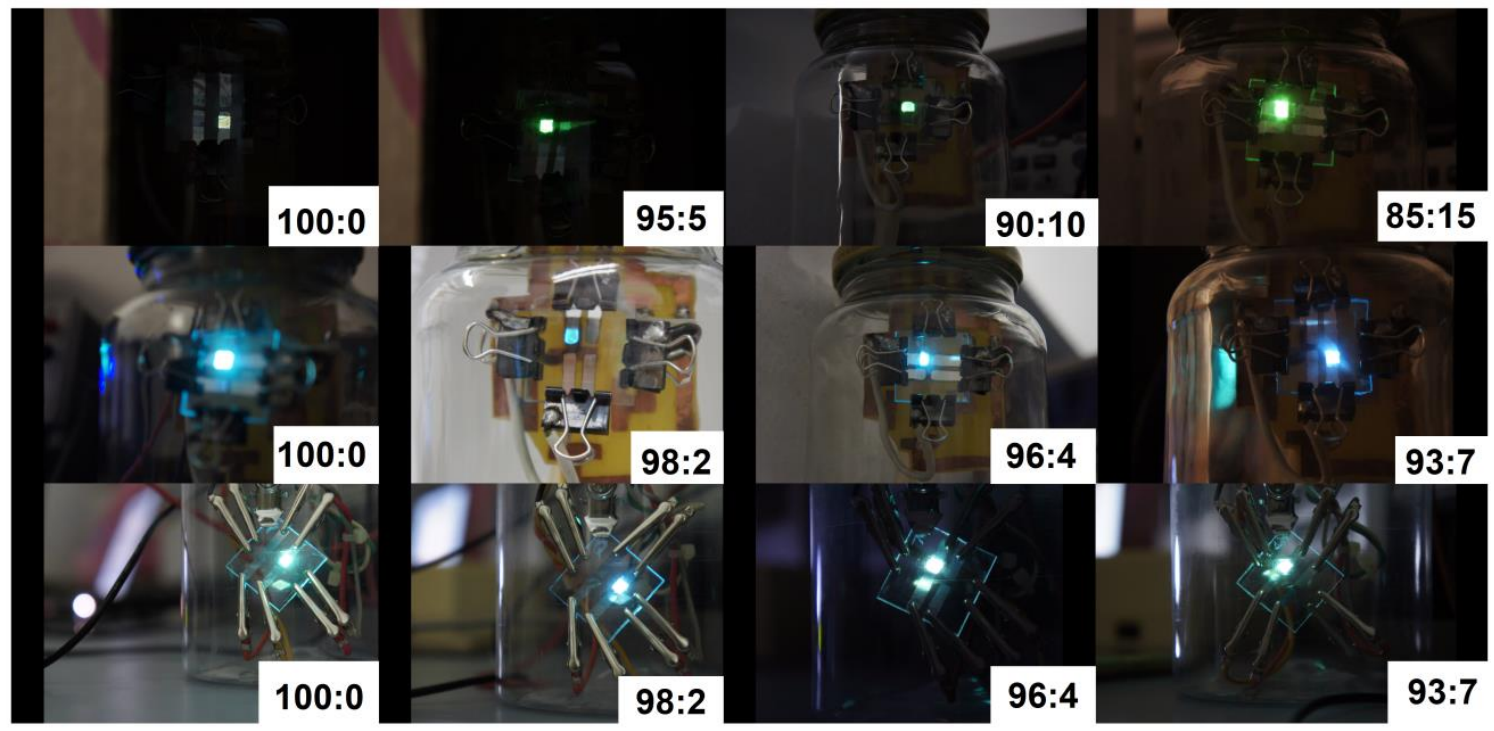

Fonte: Autoria própria.

Figura 45 - Diagrama de cromaticidade dos dispositivos a base de PVK polarizados a: 1) 7 V, 2) 10 V e 3) $13 \mathrm{~V}$.

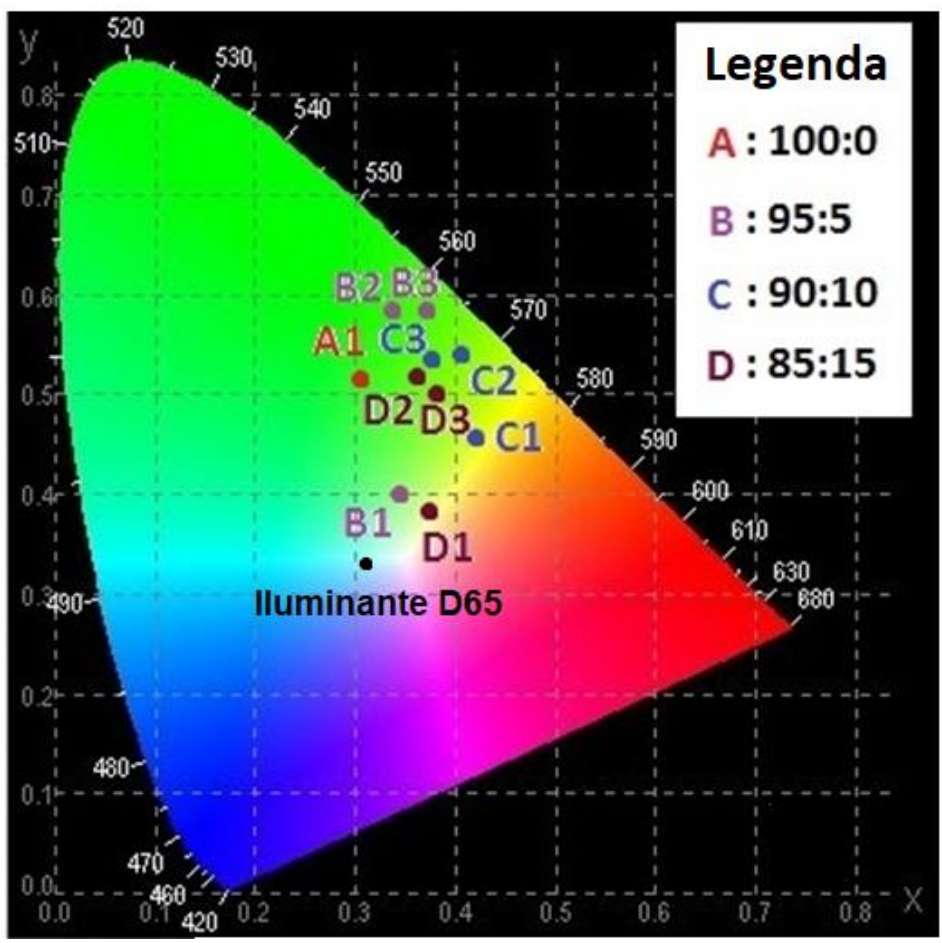

Fonte: Adaptado de [43] 
Figura 46 - Diagrama de cromaticidade dos dispositivos a base de PFO polarizados a: 1) $7 \mathrm{~V}$, 2) $10 \mathrm{~V}$ e 3) $13 \mathrm{~V}$.

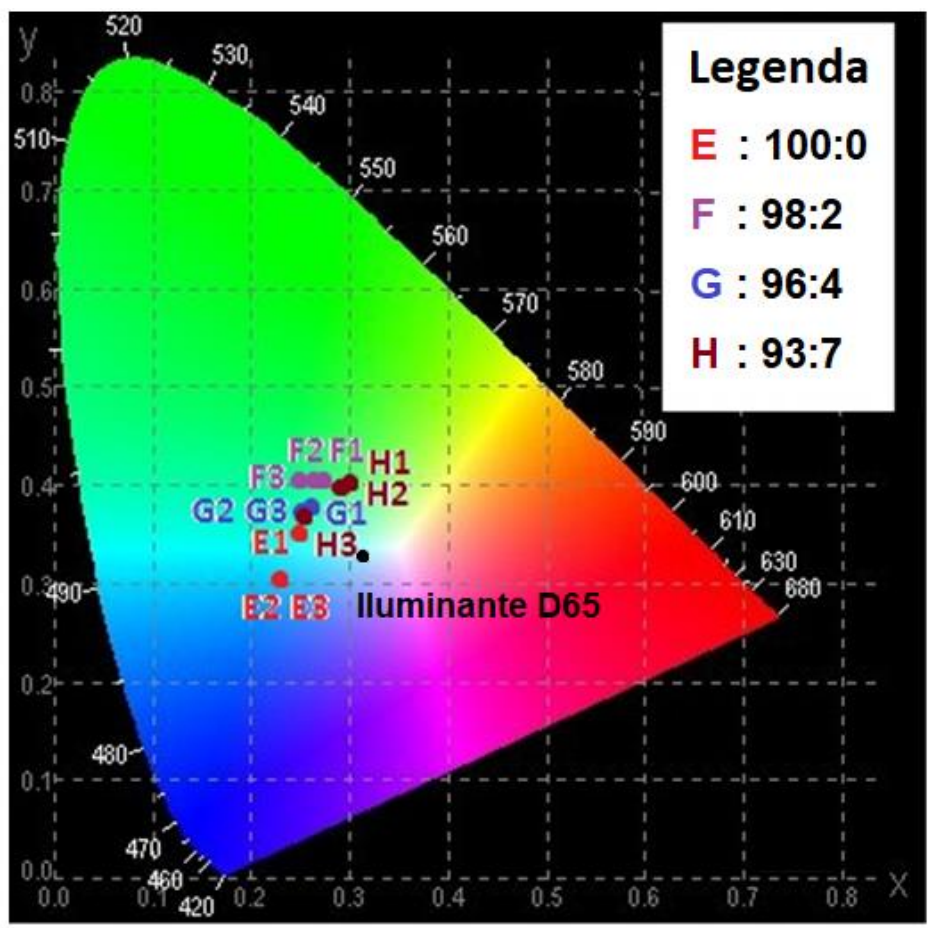

Fonte: Adaptado de [43]

Figura 47 - Diagrama de cromaticidade dos dispositivos a base de $\mathrm{PF}_{\mathrm{PF}}$ polarizados a: 1) $7 \mathrm{~V}$, 2) $10 \mathrm{~V}$ e 3) $13 \mathrm{~V}$.

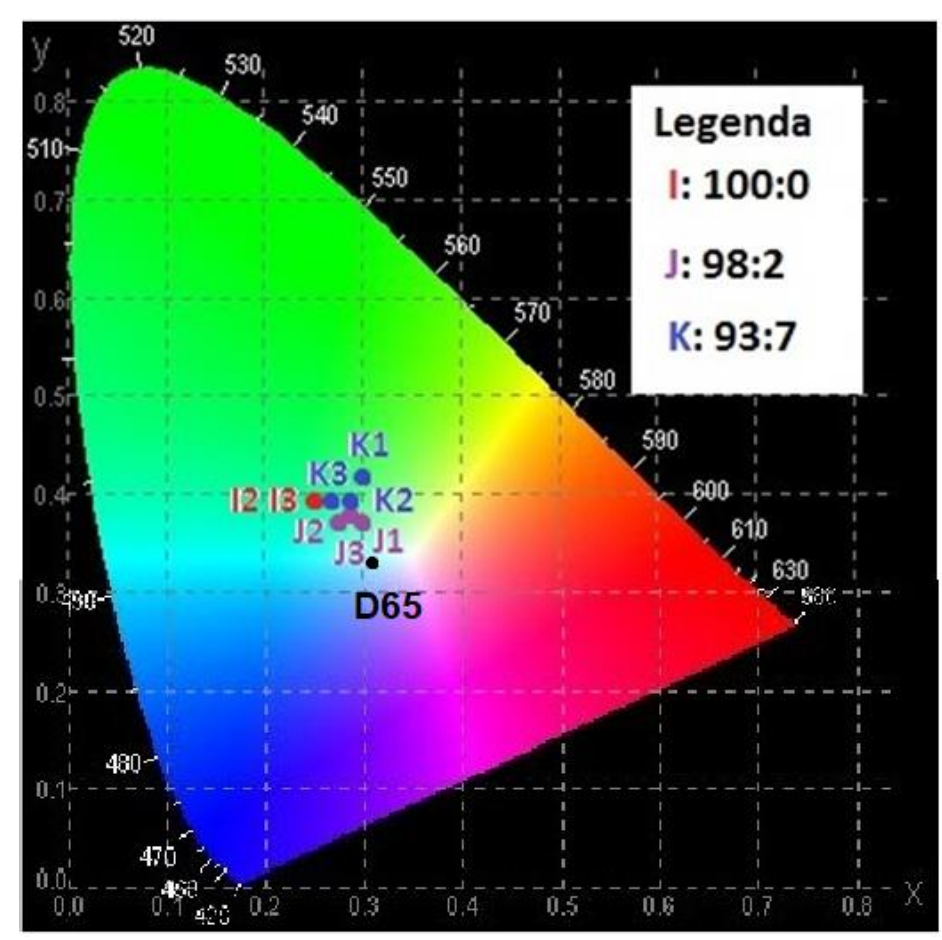

Fonte: Adaptado de [43] 
Observando-se a Figura 45, nota-se que os dispositivos baseados no PVK apresentaram emissão na região verde do diagrama de cromaticidade o que não condiz com a literatura. Enquanto que os dispositivos baseados no PFO e PF região entre o azul e o verde conforme foi percebido pela observação direta das fotografias.

Com o auxílio da Tabela 14, pode-se perceber que a diferença de potencial aplicada influencia fortemente na cromaticidade dos dispositivos de PVK, sendo que, a pureza obtida quando se aplicou uma tensão de $7 \mathrm{~V}$ foi inferior à pureza de quando estas tensões foram de $10 \mathrm{~V}$ e $13 \mathrm{~V}$, atingindo variações de até 103,5 \% (13 V), $32 \%$ (10 V) e 51,5 \% (10 V e 13 V) para os dispositivo com adição de $5 \%, 10 \%$ e $15 \%$ em massa de $\operatorname{Ir}(\text { ppy })_{3}$, respectivamente. E ainda, a maior pureza obtida foi quando se adicionou $10 \%$ em massa de dopante $(0,66$ a $7 \mathrm{~V}$ e 0,87 a $10 \mathrm{~V})$, entretanto, aplicando-se uma tensão de $13 \mathrm{~V}$ a maior pureza foi obtida quando a adição foi de $5 \%$ em massa de dopante $(0,85)$. Pode-se notar também que os comprimentos de onda dominantes variaram entre $549 \mathrm{~nm}$ (verde) e $580 \mathrm{~nm}$ (amarelo) e ainda, os seus valores reduziram sucessivamente com o aumento da tensão aplicada para a mesma proporção PVK:Ir(ppy $)_{3}$ e com a adição de dopante fosforescente, ocorreu uma redução em seus valores conforme o aumento de sua proporção em relação ao polímero hospedeiro. Portanto, segundo o diagrama de cromaticidade, o aumento da tensão provocou o aumento na sensação de emissão da cor verde, enquanto que a adição de $\operatorname{Ir}(\mathrm{ppy})_{3}$, aumentou a sensação de emissão da cor amarela. 
Tabela 14 - Influência da tensão na pureza e do comprimento de onda dominante $\left(\lambda_{\text {dom }}\right)$ nos dispositivos de PVK.

\begin{tabular}{|c|c|c|c|c|c|c|}
\hline \multirow{2}{*}{ PVK:Ir(ppy) 3} & \multicolumn{3}{|c|}{$7 \mathrm{~V}$} & \multicolumn{2}{|l|}{$10 \mathrm{~V}$} & $13 \mathrm{~V}$ \\
\hline & Pureza & $\lambda_{\text {dom }}(\mathrm{nm})$ & Pureza & $\Lambda_{\mathrm{dom}}(\mathrm{nm})$ & Pureza & $\lambda_{\text {dom }}(\mathrm{nm})$ \\
\hline $100: 0$ & 0,51 & 549 & - & - & - & - \\
\hline $95: 5$ & 0,28 & 567 & 0,77 & 556 & 0,85 & 560 \\
\hline $90: 10$ & 0,66 & 575 & 0,87 & 567 & 0,72 & 563 \\
\hline $85: 15$ & 0,32 & 580 & 0,66 & 562 & 0,66 & 566 \\
\hline
\end{tabular}

Fonte: Autoria própria.

Para os dispositivos baseados no PFO, conforme se pode observar na Figura 46 e na Tabela 15, a pureza de todos os dispositivos aumenta conforme o aumento da tensão aplicada. Entretanto, estas variações, em valores absolutos, foram inferiores às dos dispositivos baseados no PVK (no máximo de 0,12 para o PFO puro quando se aplicou de $7 \mathrm{~V}$ para $13 \vee$ e 0,57 para o PVK contendo $5 \%$ de dopante quando a tensão passou de $7 \mathrm{~V}$ para $13 \mathrm{~V}$ ), sendo que as maiores variações obtidas foram de $60 \%$ (10 V e $13 \mathrm{~V}), 38 \%$ (13 V), $24 \%(10 \mathrm{~V}$ e $13 \mathrm{~V}) \mathrm{e}$ $18 \%$ (13 V) quando se adicionou $2 \%, 4 \%$ e $7 \%$ em massa de $\operatorname{Ir}(\mathrm{ppy})_{3}$, respectivamente. Além disso, em média, a pureza dos dispositivos de PVK foram superiores em relação à pureza dos dispositivos de PFO. A menor pureza obtida pelo dispositivo de PVK foi de 0,28 a $7 \mathrm{~V}$ com adição de $5 \%$ em massa de dopante, o que é superior à maioria dos valores de pureza obtidos pelos dispositivos de PFO, exceto quando se aplica tensões de $10 \mathrm{~V}$ e $13 \mathrm{~V}$ no PLED de PFO puro. Nota-se também que os comprimentos de onda dominantes variaram entre $488 \mathrm{~nm}$ (azul) e $540 \mathrm{~nm}$ (verde), e ainda, seus valores diminuíram com o aumento da tensão aplicada. Contudo, a adição de $\operatorname{Ir}(\mathrm{ppy})_{3}$ provocou um aumento no comprimento de onda dominante. Estes comportamentos também foram observados nos dispositivos de PVK. Portanto, o aumento da tensão provocou o aumento na sensação de emissão da cor azul, enquanto que a adição de $\operatorname{Ir}(\mathrm{ppy})_{3}$, aumentou a sensação de emissão da cor verde. Pode-se destacar que todos os dispositivos dopados obtiveram purezas inferiores ao do polímero puro para as 3 tensão aplicadas. 
Tabela 15 - Influência da tensão na pureza e do comprimento de onda dominante $\left(\lambda_{\text {dom }}\right)$ nos dispositivos de PFO.

\begin{tabular}{ccccccc}
\hline & \multicolumn{2}{c}{7 V } & \multicolumn{2}{c}{$10 \mathrm{~V}$} & \multicolumn{2}{c}{$13 \mathrm{~V}$} \\
\cline { 2 - 7 } PFO:Ir(ppy) 3 & Pureza & $\lambda_{\text {dom }}(\mathbf{n m})$ & Pureza & $\lambda_{\text {dom }}(\mathbf{n m})$ & Pureza & $\lambda_{\text {dom }}(\mathbf{n m})$ \\
\hline $100: 0$ & 0,20 & 496 & 0,32 & 488 & 0,32 & 488 \\
$98: 2$ & 0,16 & 515 & 0,18 & 512 & 0,22 & 507 \\
$96: 4$ & 0,17 & 504 & 0,21 & 501 & 0,21 & 501 \\
$93: 7$ & 0,17 & 540 & 0,14 & 530 & 0,20 & 500 \\
\hline
\end{tabular}

Fonte: Autoria própria.

Por fim, para os dispositivos de $\mathrm{PF}_{\mathrm{PF}}$, analisando-se a Figura 47 e a Tabela 16, ao contrário do observado com os dispositivos anteriores, a pureza diminuiu quando se variou a tensão aplicada de $7 \mathrm{~V}$ para $10 \mathrm{~V}$. Entretanto, quando a tensão aplicada passou para $13 \mathrm{~V}$, ocorreu um aumento na pureza da cor emitida. E ainda, em média, a pureza destes dispositivos foi próxima a dos dispositivos de PFO, mostrando-se pequenas variações, em valores absolutos, com a tensão aplicada (no máximo de 0,11 para o $\mathrm{PF}_{\mathrm{PF}}$ puro quando se aplicou de $10 \mathrm{~V}$ para $13 \mathrm{~V}$ ). Pode-se destacar também que os comprimentos de onda dominantes variaram entre $505 \mathrm{~nm}$ (verde) e $545 \mathrm{~nm}$ (verde), sendo que o seus valores aumentaram com o aumento da tensão e diminuíram com a adição de dopante, diferentemente, do verificado com os dispositivos a base de PVK e PFO. 
Tabela 16 - Influência da tensão na pureza e do comprimento de onda dominante $\left(\lambda_{\text {dom }}\right)$ nos dispositivos de $\mathrm{PF}_{\mathrm{PF}}$.

\begin{tabular}{ccccccc}
\hline \multirow{2}{*}{ PF $_{\mathrm{PF}}: \operatorname{Ir}(\mathbf{p p y})_{3}$} & \multicolumn{2}{c}{$7 \mathrm{~V}$} & \multicolumn{2}{c}{$10 \mathrm{~V}$} & \multicolumn{2}{c}{$13 \mathrm{~V}$} \\
\cline { 2 - 7 } & Pureza & $\boldsymbol{\lambda}_{\text {dom }}(\mathbf{n m})$ & Pureza & $\boldsymbol{\lambda}_{\text {dom }}(\mathbf{n m})$ & Pureza & $\boldsymbol{\lambda}_{\text {dom }}(\mathbf{n m})$ \\
\hline $100: 0$ & - & - & 0,10 & 537 & 0,21 & 545 \\
$98: 2$ & 0,19 & 505 & 0,13 & 507 & 0,15 & 511 \\
$96: 4$ & - & - & - & - & - & - \\
$93: 7$ & 0,19 & 505 & 0,10 & 518 & 0,14 & 528 \\
\hline
\end{tabular}

Fonte: Autoria própria.

\subsubsection{Espectros de eletroluminescência}

\subsubsection{Influência do host no espectro de eletroluminescência}

Os espectros de eletroluminescência a $6 \mathrm{~V}$ (PVK e PFO) e 7 V (PF $\left.F_{\mathrm{PF}}\right)$ estão apresentados na Figura 48 e seus picos, na Tabela 17, Tabela 18 e Tabela 19, respectivamente. Comparando-se os espectros da Figura 48, os maiores aumentos na intensidade de emissão ocorreram quando a adição de $\operatorname{Ir}(\mathrm{ppy})_{3}$ no PVK, PFO e $\mathrm{PF}_{\mathrm{PF}}$ foi, respectivamente, de $15 \%, 7 \%$ e $7 \%$ em massa, sendo que os aumentos em relação ao polímero puro relativos à maior intensidade foram de 4, 50 e 2 vezes, respectivamente. Estes resultados sugerem que o dopante facilita a injeção de carga no interior da camada emissora e, por consequência, aumenta a taxa de recombinação em seu interior. 
Figura 48 - Espectros de eletroluminescência dos dispositivos a base de: a) PVK a 6 V, b) PFO a 6 V e c) $\mathrm{PF}_{\mathrm{PF}}$ a $7 \mathrm{~V}$.
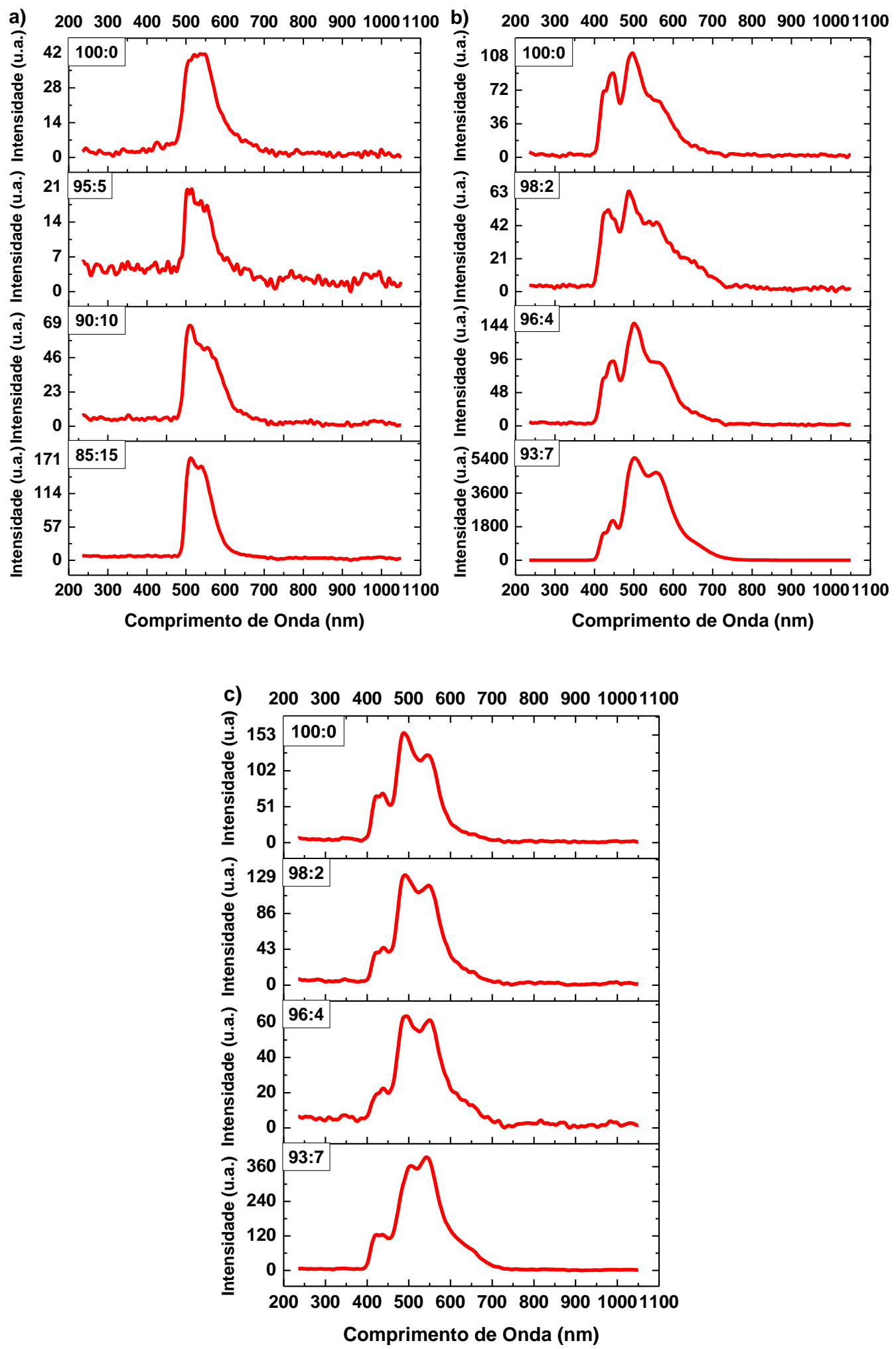

Fonte: Autoria própria. 
Os dispositivos contendo apenas o PVK como camada emissora (Figura 49) mostraram uma emissão larga entre $470 \mathrm{~nm}$ e $720 \mathrm{~nm}$, com pico em torno de 530 $\mathrm{nm}$, região verde do espectro eletromagnético, o que não está de acordo com o observado na literatura. O PVK possui um band gap de 3,5 eV, cujo pico do espectro de fotoluminescência ocorre em torno de $420 \mathrm{~nm}$ o que corresponde à emissão na região violeta-azul, que é atribuído ao excímero formado no decaimento do estado $\mathrm{S}_{1}$, a temperatura ambiente. Na eletroluminescência, este pico sofre um redshift para $445 \mathrm{~nm}$ e podem existir outros pontos de máximo em torno de $512 \mathrm{~nm}$ e $604 \mathrm{~nm}$ conforme observado por Ma e seus colaboradores em um dispositivo cuja estrutura foi ITO/PEDOT:PSS/PVK/CsF/Ca/Al. Segundo eles, o pico relativo a $512 \mathrm{~nm}$ está relacionado com a fosforescência do PVK enquanto que o pico relativo a $604 \mathrm{~nm}$ está relacionado com a formação de eletrômeros. [43, 45-49] O eletrômero é uma espécie emissora eletricamente excitada formada por um par de moléculas de mesma espécie estatisticamente independentes $(M)$, sendo que uma delas possui um caráter doador e a outra, um caráter aceitador $\left(\left(\mathrm{M}^{+} \mathrm{M}^{-}\right)^{*}\right)$ [50]. Assim, Ma e seus colaboradores atribuiu o pico em $604 \mathrm{~nm}$ à formação dos pares $\left(\mathrm{PVK}^{+} \mathrm{PVK}\right)^{*}$.

Com o intuito de identificar a emissão do PVK em torno de $445 \mathrm{~nm}$, foi necessário fazer a deconvolução dos espectros eletromagnéticos experimentais. A Figura 50 mostra os componentes gaussianos de cada espectro de eletroluminescência obtidos para cada proporção PVK:Ir(ppy $)_{3}$ utilizada. Assim, foi possível identificar um componente gaussiano em $441 \mathrm{~nm}$ de baixa intensidade para o dispositivo não dopado que, provavelmente, corresponde à emissão do PVK. Entretanto, a maior parte dos componentes gaussianos apresentou comprimento de onda que correspondem à região verde-amarelo do espectro eletromagnético. Assim, sugere-se que o espectro obtido não pertence unicamente ao PVK. Portanto, propõe-se que esta emissão ocorre devido ao desbalanceamento de cargas, a emissão pode ter ocorrido na interface entre o PVK e a camada injetora de elétrons (AZO) ou o fato do PVK possuir alta massa molar, poderia ter provocado um redshift no espectro de eletroluminescência deste dispositivo, pois quanto maior a massa molar do polímero, maior será a quantidade de grupos carbazoles empilhados, formando-se uma estrutura mais compacta e, por consequência, as interações intermoleculares entre estes grupos diminuem [49]. Para se entender melhor o fenômeno observado, produziu-se dispositivos contendo como camada emissora 
PVK puro com diferentes massas molares e também PVK:AZO (Seção 5.2 e 5.3). Adicionando-se $\operatorname{Ir}(\mathrm{ppy})_{3}$, foi possível notar o surgimento de dois novos máximos locais em torno de $510 \mathrm{~nm}$ e $540 \mathrm{~nm}$, correspondentes ao $\operatorname{Ir}(\mathrm{ppy})_{3}$ com emissão na cor verde [51]. E ainda, de acordo com a Figura 50, o componente gaussiano em $441 \mathrm{~nm}$ observado para o dispositivo de PVK puro não esteve presente nos dispositivos dopados. Portanto, sugere-se que a transferência de energia entre 0 polímero hospedeiro e o dopante ocorreu de forma eficiente, aumentando a eficiência dos dispositivos dopados conforme observado na Seção 5.1.3 e na literatura.

Figura 49 - Espectros de eletroluminescência normalizados para os dispositivos baseados em PVK a $6 \mathrm{~V}$.

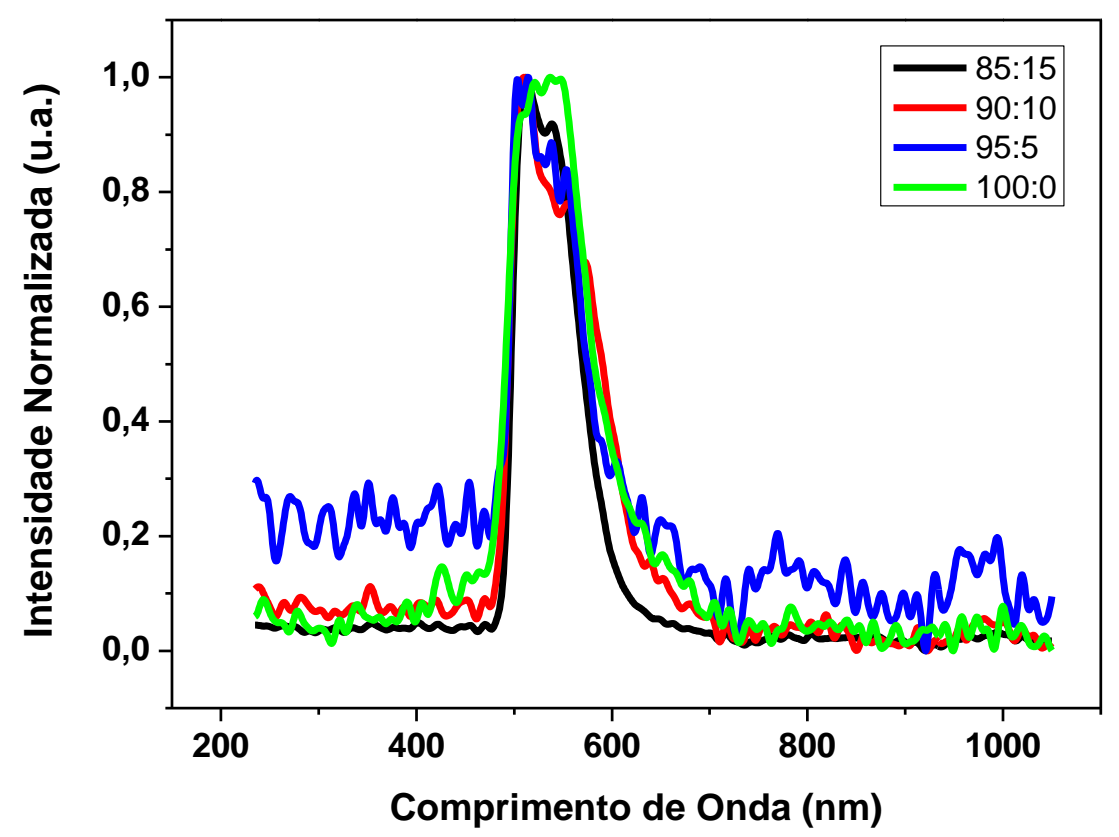

Fonte: Autoria própria. 
Figura 50 - Deconvolução dos espectros de eletroluminescência para a proporção $P V K: \operatorname{Ir}(\mathrm{ppy})_{3}$ de: a) 100:0; b) 95:5; c) 90:10 e d) 85:15 a 6 V.
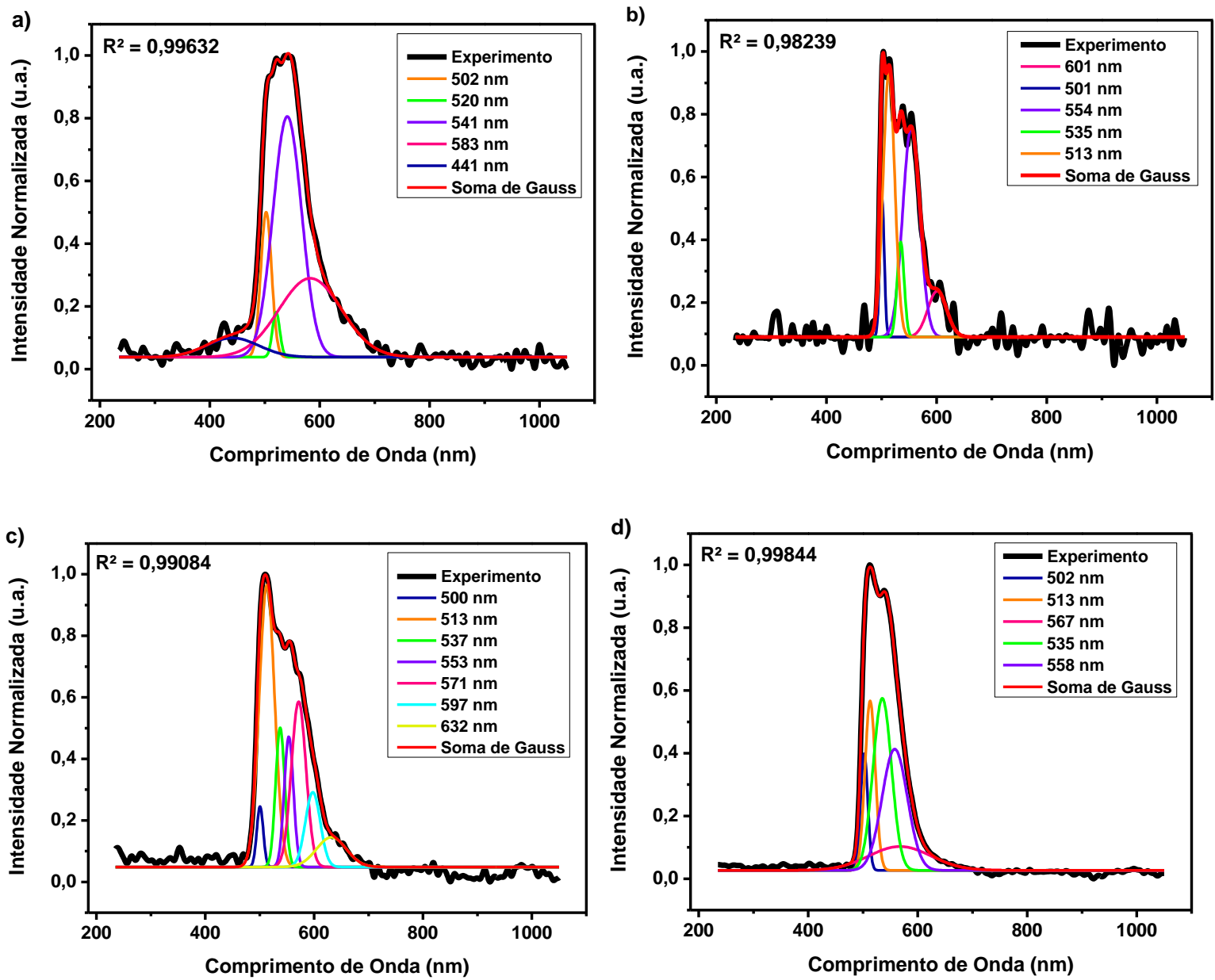

Fonte: Autoria própria.

As emissões de maior intensidade do dispositivo a base de PVK sem $\operatorname{Ir}(\mathrm{ppy})_{3}$ apresentam os máximos nos comprimentos de onda $540 \mathrm{~nm}$ e $580 \mathrm{~nm}$, enquanto a emissão de maior intensidade do $\operatorname{Ir}(\mathrm{ppy})_{3}$ ocorre $510 \mathrm{~nm}$, de acordo com a literatura. Nos sistemas estudados a concentração de $\operatorname{Ir}(\mathrm{ppy})_{3}$ variou de 5 a $15 \%$ e estes espectros apresentaram aumento da intensidade relativa da banda a $510 \mathrm{~nm}$ e desaparecimento das bandas a $580 \mathrm{~nm}$ e $440 \mathrm{~nm}$. 
Tabela 17 - Picos dos espectros eletroluminescentes dos dispositivos de PVK a 6 V.

\begin{tabular}{cccc}
\hline PVK:Ir(ppy) & \multicolumn{2}{c}{ Picos $(\mathbf{n m})$} & Intensidade relativa $\mathbf{I}_{\mathbf{5 1 0}} / \mathbf{I}_{\mathbf{5 4 0}}$ \\
\hline $\mathbf{1 0 0 : 0}$ & - & 540 & 0 \\
$95: 5$ & 509 & 539 & 1,4 \\
$90: 10$ & 507 & 539 & 2 \\
$85: 15$ & 513 & 541 & 1 \\
\hline
\end{tabular}

Fonte: Autoria própria.

Os espectros eletromagnéticos (Figura 51) dos dispositivos baseados no PFO apresentaram emissão ampla entre $400 \mathrm{~nm}$ e $750 \mathrm{~nm}$. O dispositivo de PFO puro apresentou três picos na região azul do espectro eletromagnético com máximos a 425 nm, 445 nm e 495 nm (Tabela 18) o que estão de acordo com o observado na literatura [52]. Foi também possível observar um pico em torno de 558 nm, região amarelo-laranja do espectro eletromagnético, relacionado à emissão dos keto defects (grupos cetona) que agem como armadilhas de carga e que, possivelmente, foram introduzidos durante a síntese do polímero ou pela degradação eletrooxidativa [32, 53].

A adição do dopante provocou a diminuição gradativa na intensidade de emissão relativa das bandas em torno de $433 \mathrm{~nm}$ e $446 \mathrm{~nm}$ para o PFO dopado com $2 \%$ em massa de $\operatorname{Ir}(\mathrm{ppy})_{3}, 423 \mathrm{~nm}$ e $445 \mathrm{~nm}$ para o PFO dopado com $4 \%$ em massa de $\operatorname{Ir}(\mathrm{ppy})_{3}$ e $423 \mathrm{~nm}$ e $446 \mathrm{~nm}$ para o PFO dopado com $7 \%$ em massa de $\operatorname{Ir}(\mathrm{ppy})_{3}$ que correspondem às emissões na região azul do espectro eletromagnético pelo PFO. E, ao mesmo tempo, provocou o aumento na intensidade de emissão relativa da banda em torno de $558 \mathrm{~nm}$ para as proporções PFO:Ir(ppy $)_{3}$ 100:0, 98:2 e 96:4 e $557 \mathrm{~nm}$ para a proporção 93:7 de tal forma que as intensidades relativas foram de $57 \%, 70 \%, 62 \%$ e $86 \%$, respectivamente. Pode-se destacar também que para os dispositivos dopados com $4 \%$ e $7 \%$ em massa de $\operatorname{Ir}(\mathrm{ppy})_{3}$, os comprimentos de onda relativos à maior intensidade sofreram um redshift em relação ao do dispositivo não dopado. 
Figura 51 - Espectros de eletroluminescência normalizados para os dispositivos baseados em PFO a $6 \mathrm{~V}$.

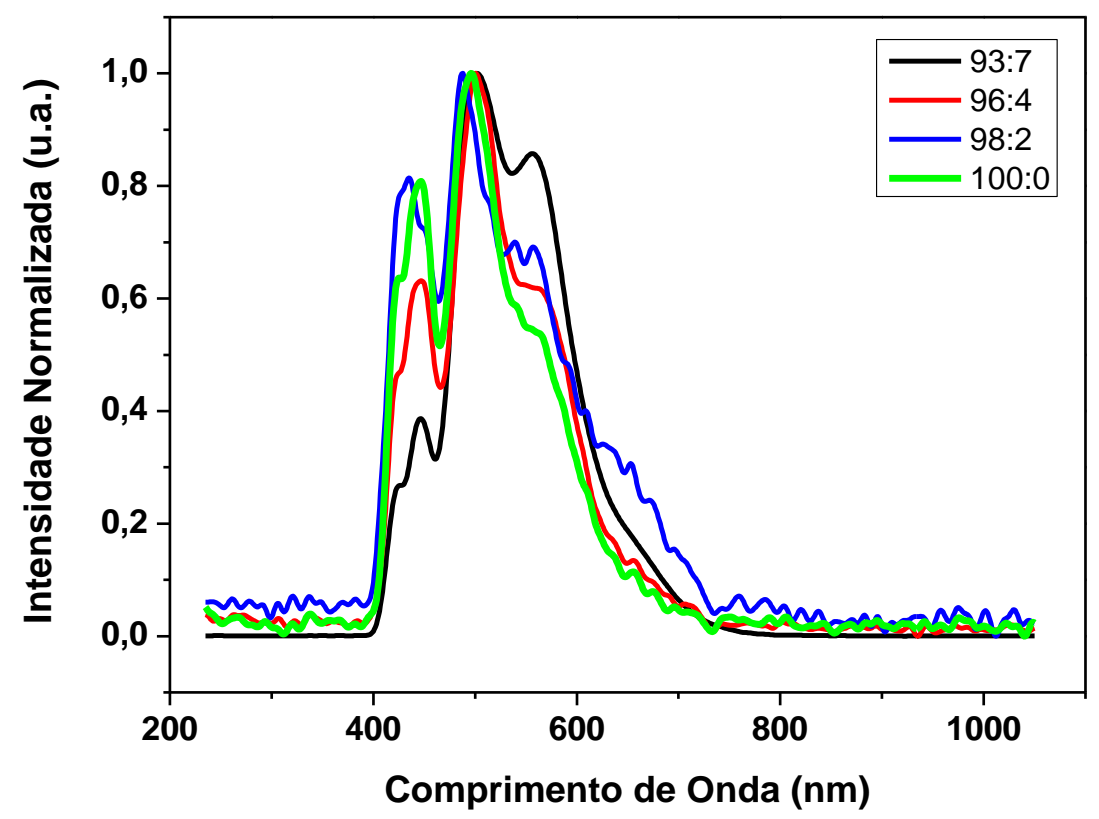

Fonte: Autoria própria.

E ainda, de acordo com os espectros mostrados na Figura 51, os dispositivos contendo PFO dopado como camada emissora não apresentaram picos de emissão referente ao $\operatorname{Ir}(\mathrm{ppy})_{3}$ conforme observado nos dispositivos a base de PVK dopado. Assim, os espectros de eletroluminescência foram deconvoluídos em oito componentes gaussianos conforme mostrado na Figura 52 com o objetivo de identificar a emissão relativa ao dopante. A partir deles, pode-se notar a existência de um componente gaussiano em torno de 506 - $511 \mathrm{~nm}$ para os dispositivos de PFO dopado que, possivelmente corresponde à emissão do $\operatorname{Ir}(\mathrm{ppy})_{3}$. 
Figura 52 - Deconvolução dos espectros de eletroluminescência para a proporção PFO:Ir(ppy $)_{3}$ de: a) 100:0; b) 98:2; c) 96:4 e d) 93:7 a 6 V.
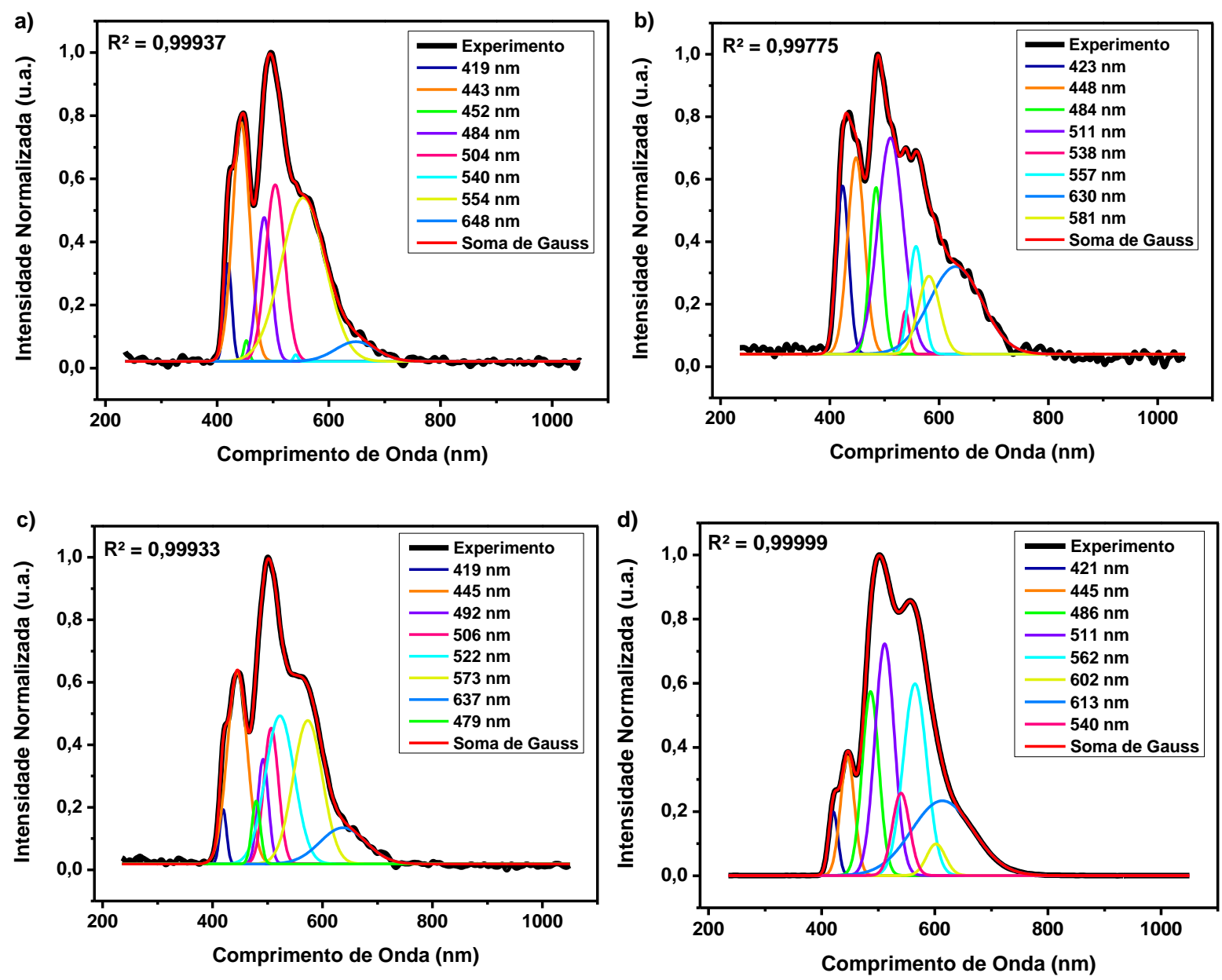

Fonte: Autoria própria.

Portanto, como foi possível observar a emissão do PFO independentemente da dopagem e, através da deconvolução dos espectros de eletroluminescência, foi possível também identificar um componente gaussiano cujo máximo localiza-se, aproximadamente, em 506 - $511 \mathrm{~nm}$ para os dispositivos dopados que, provavelmente, correspondem à emissão do $\operatorname{Ir}(\mathrm{ppy})_{3}$, sugere-se que a transferência de energia entre o PFO e o $\operatorname{Ir}(\mathrm{ppy})_{3}$ não foi eficiente devido ao estado $T_{1}$ do PFO ser maior que ao estado $T_{1}$ do dopante fosforescente conforme discutido na Seção 5.1.3. 
Tabela 18 - Picos dos espectros eletroluminescentes dos dispositivos de PFO a 6 V.

\begin{tabular}{ccccc}
\hline PFO:Ir(ppy) ${ }_{3}$ & \multicolumn{4}{c}{ Picos (nm) } \\
\hline 100:0 & 425 & 445 & 495 & 558 \\
$98: 2$ & 433 & 446 & 490 & 558 \\
$96: 4$ & 423 & 445 & 503 & 558 \\
$93: 7$ & 423 & 446 & 504 & 557 \\
\hline
\end{tabular}

Fonte: Autoria própria.

Para os dispositivos cuja camada emissora é baseada no $\mathrm{PF}_{\mathrm{PF}}$, os espectros eletromagnéticos apresentaram emissão ampla entre $400 \mathrm{~nm}$ e $700 \mathrm{~nm}$ conforme mostrado na Figura 53. Observou-se que os espectros obtidos apresentaram o mesmo aspecto, entretanto, o posicionamento dos picos sofreram pequenas variações conforme a adição de $\operatorname{Ir}(\mathrm{ppy})_{3}$ para a mesma tensão aplicada de $7 \mathrm{~V}$ (Tabela 19).

A Figura 53 mostra os espectros eletroluminescentes normalizados dos dispositivos baseados em PF PF 7 V. Pode-se observar que a adição do dopante fosforescente provocou a diminuição sucessiva nas intensidades de emissão relativas à maior intensidade, correspondentes ao comprimento de onda em torno de $425 \mathrm{~nm}$ e $438 \mathrm{~nm}$ para o $\mathrm{PF}_{\mathrm{PF}}$ puro. Adicionalmente, para os dispositivos dopados $\mathrm{PF}_{\mathrm{PF}}: \operatorname{Ir}(\mathrm{ppy})_{3}$, estes comprimentos de onda são equivalentes a $421 \mathrm{~nm}$ e $437 \mathrm{~nm}$ para a proporção 98:2, $420 \mathrm{~nm}$ e $442 \mathrm{~nm}$ para a proporção 96:4 e 422 nm e $436 \mathrm{~nm}$ para a proporção 93:7. Nota-se também, que ao mesmo tempo, ocorreu o aumento na intensidade de emissão relativa correspondente ao comprimento de onda em torno de $543 \mathrm{~nm}$ para o $\mathrm{PF}_{\mathrm{PF}}$ puro, sendo que quando se adicionou $7 \%$ em massa de dopante o máximo da banda permaneceu em $543 \mathrm{~nm}$. 
Figura 53 - Espectros de eletroluminescência normalizados para os dispositivos baseados em $\mathrm{PF}_{\mathrm{PF}} \mathrm{a}$ $7 \mathrm{~V}$.

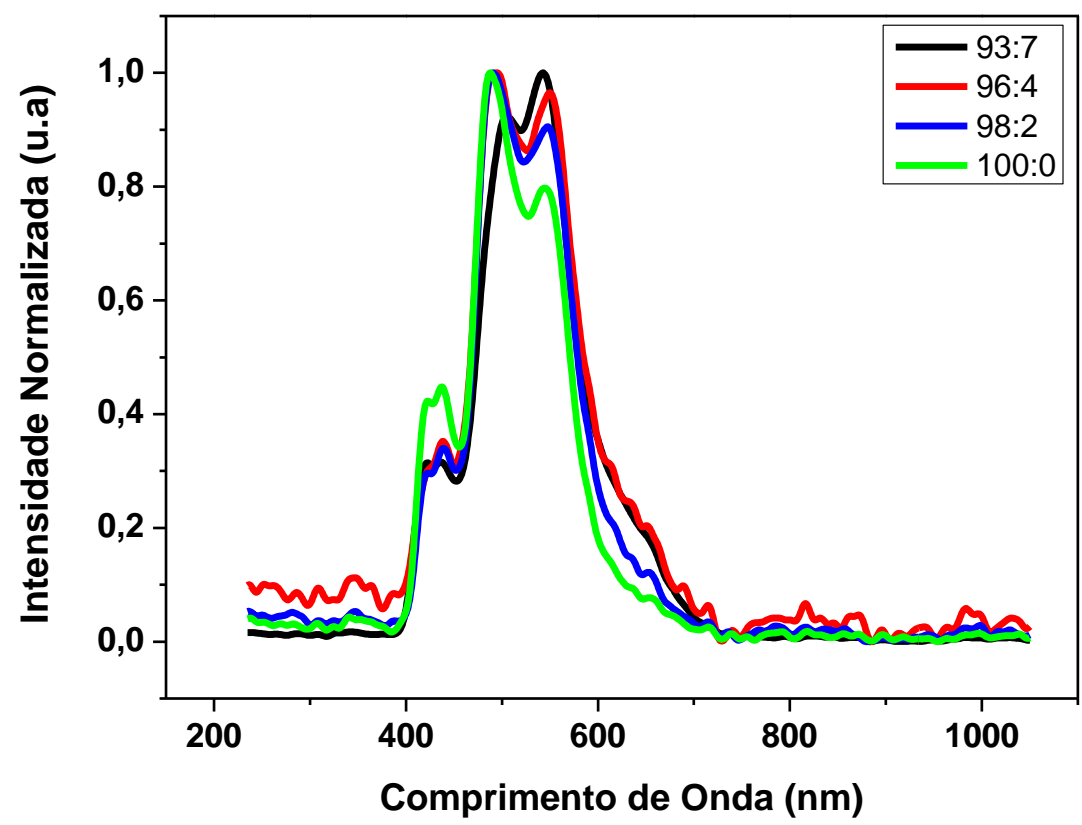

Fonte: Autoria própria.

A Figura 54 mostra a deconvolução dos espectros de eletroluminescência obtidos a uma tensão aplicada de $7 \mathrm{~V}$ dos dispositivos baseados no PF $F_{\mathrm{PF}}$ com 0 intuito de identificar a emissão do dopante fosforescente uma vez que não foi possível observá-la diretamente pelo espectro experimental. O espectro de eletroluminescência relativo à emissão do dispositivo de $\mathrm{PF}_{\mathrm{PF}}$ puro foi deconvoluído em cinco componentes gaussianos, enquanto que os dispositivos dopados, em seis componentes. De acordo com a Figura 54, não foi possível observar os componentes gaussianos cujo comprimento de onda fosse compatível com a emissão do $\operatorname{Ir}(\mathrm{ppy})_{3}$ nos dispositivos contendo a camada emissora dopada. Sabe-se que a emissão fosforescente pode ocorrer tanto pela transferência de energia do polímero hospedeiro para o dopante quanto pela recombinação direta no próprio dopante [9, 37]. Assim, sugere-se que $0 \operatorname{Ir}(\mathrm{ppy})_{3}$ não funcionou como centros de recombinação o que é condizente com o observado na Seção 5.1.2. E ainda, podese concluir que a transferência de energia entre $\circ \operatorname{Ir}(\mathrm{ppy})_{3}$ e $\circ \mathrm{PF}_{\mathrm{PF}}$ não foi eficiente uma vez que foi possível verificar a emissão de luz na região azul do espectro eletromagnético independentemente das proporções $\mathrm{PF}_{\mathrm{PF}}: \operatorname{Ir}(\mathrm{ppy})_{3}$ utilizadas. É possível observar mudanças na estrutura vibracional do espectro com aumento da 
intensidade da banda no comprimento de onda $540 \mathrm{~nm}$ com a concentração de $\operatorname{Ir}(\mathrm{ppy})_{3}$, mas não foi possível separar uma banda específica.

Figura 54 - Deconvolução dos espectros de eletroluminescência para a proporção $\mathrm{PF}_{\mathrm{PF}}: \operatorname{Ir}(\mathrm{ppy})_{3}$ de: a) 100:0; b) 98:2; c) 96:4 e d) 93:7 a 7 V.
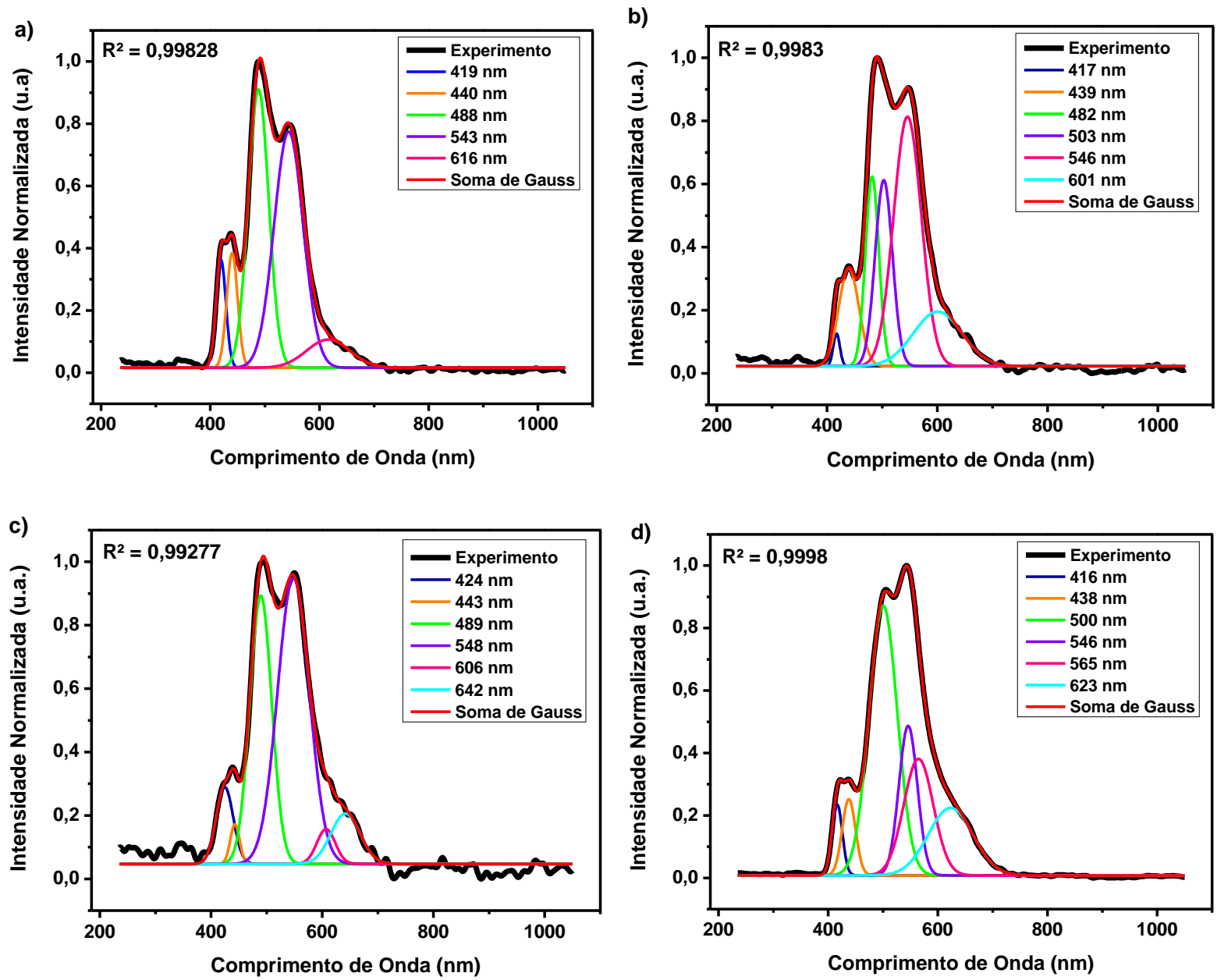

Fonte: Autoria própria. 
Tabela 19 - Picos dos espectros eletroluminescentes dos dispositivos de $\mathrm{PF}_{\mathrm{PF}}$ a $7 \mathrm{~V}$.

\begin{tabular}{ccccc}
\hline PF $_{\mathrm{PF}: I r(p p y)_{3}}$ & \multicolumn{4}{c}{ Picos (nm) } \\
\hline 100:0 & 425 & 438 & 490 & 543 \\
$98: 2$ & 421 & 437 & 491 & 547 \\
$96: 4$ & 420 & 442 & 496 & 551 \\
$93: 7$ & 422 & 436 & 505 & 543 \\
\hline
\end{tabular}

Fonte: Autoria própria.

\subsection{Estudo da massa molar de dispositivos a base de PVK}

A fim de se estudar a influência da massa molar do PVK na eletroluminescência, foram produzidas 3 lâminas contendo 4 dispositivos cada conforme foi descrito na Tabela 7, sendo que o dispositivo TII foi produzido com a mesma estrutura, parâmetros de deposição e materiais do dispositivo de PVK puro estudado na Seção 5.1 .

A Figura 55 mostra as curvas $\mathrm{J} \times \mathrm{V}$ obtidas na quarta polarização dos dispositivos a base de PVK puro. As tensões de limiar estimadas foram de 8,2 V, 4,2 $\mathrm{V}$ e 4,7 V para os dispositivos TI, TII e TIII, respectivamente. Assim, as menores densidades de corrente e a maior tensão de limiar foi obtida para o dispositivo $\mathrm{TI}$. Comparando-se as características das curvas $\mathrm{J}$ x V dos PLEDs TI $\left(\mathrm{M}_{\mathrm{w}}=1100000\right.$ $\mathrm{g} / \mathrm{mol})$ e TIII $\left(\mathrm{M}_{\mathrm{w}}=50000 \mathrm{~g} / \mathrm{mol}\right)$, observou-se que as densidades de corrente do dispositivo $\mathrm{Tl}$ foram menores enquanto que a sua tensão de limiar foi maior que as do dispositivo TIII apesar da concentração de PVK utilizada para a formação dos filmes da camada emissora nestes dois dispositivos ser igual. Assim, a massa molar média do polímero utilizado influencia fortemente nas propriedades elétricas dos PLEDs. Isso pode ser explicado pelo fato de que altas massas molares médias melhoram a capacidade de formação de filmes por spin-coating, aumentando a espessura média da camada em questão. Assim, as cargas possuem maior dificuldade em atravessar a camada ativa, tornando-o mais resistivo. Este comportamento também pode ser observado quando são utilizadas altas concentrações de PVK durante a deposição conforme observado nos dispositivos $\mathrm{TI}$ (5 mg/mL) e TIl (2 mg/mL). Altas concentrações aumentam a espessura média do 
filme, dificultando a passagem de cargas pela camada emissora e, por consequência, diminui a densidade de corrente e aumenta a tensão de limiar do PLED.

Figura 55 - Curva J x V da quarta polarização dos dispositivos TI, TII e TIII.

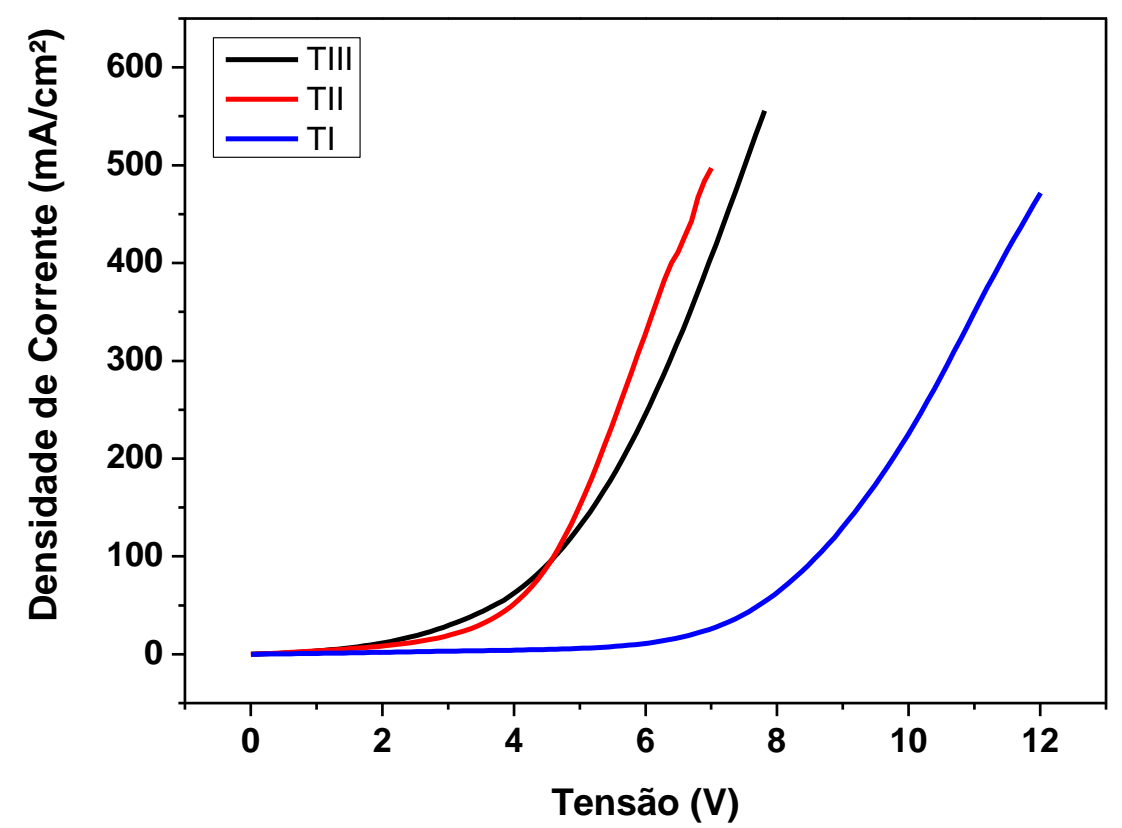

Fonte: Autoria própria.

A Figura 56 mostra as fotografias dos dispositivos à base de PVK acesos. Pode-se perceber a olho nu que os três tipos de dispositivos apresentaram emissão na região laranja (TI e TII) e vermelho (TIII) do espectro eletromagnético. Assim, apesar do dispositivo TII possuir a mesma estrutura com mesmos parâmetros de deposição, apresentou cor de emissão diferente do observado no dispositivo de PVK puro apresentado inicialmente (Figura 44). 
Figura 56 - Fotografias dos dispositivos acesos: a) TI, b) TII e c) TIII.

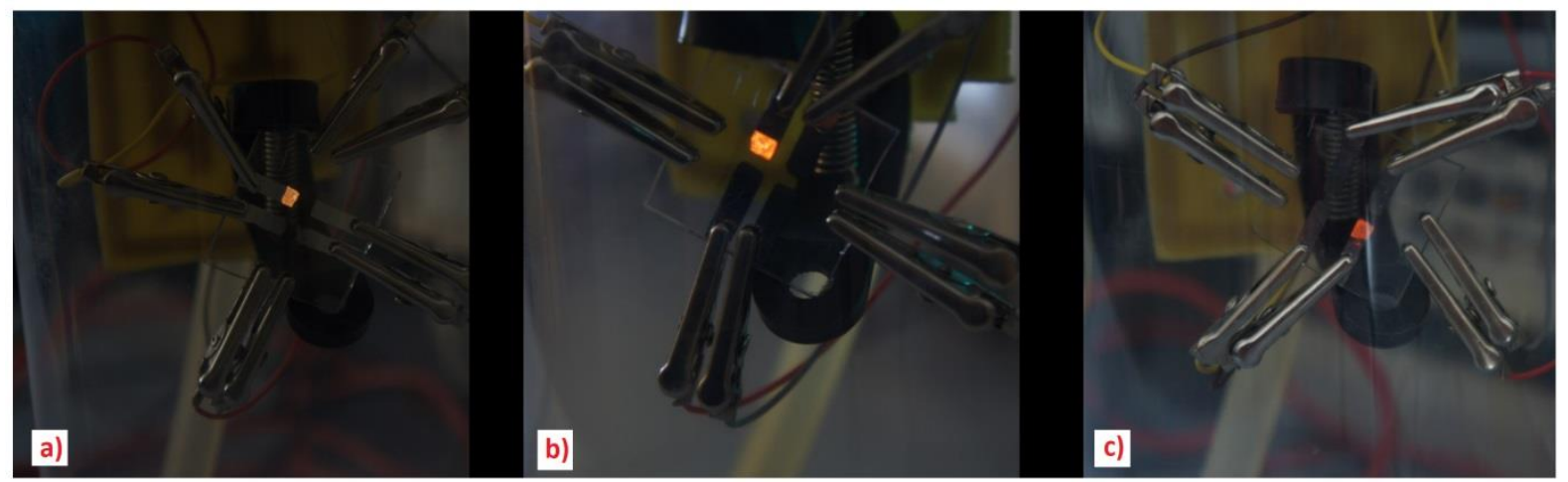

Fonte: Autoria própria.

Os espectros de eletroluminescência obtidos a $7 \mathrm{~V}$ dos dispositivos TI, TII e TIII estão ilustrados na Figura 57. Pode-se observar que os espectros de eletroluminescência apresentaram uma banda de emissão larga entre 400 nm e 800 $\mathrm{nm}$. Além disso, os dispositivos TI e TIl apresentaram um único pico bem definido nos comprimentos de onda $655 \mathrm{~nm}$ e $648 \mathrm{~nm}$, respectivamente, enquanto que o dispositivo TIII, apresentou um pico em $537 \mathrm{~nm}$ com dois ombros em, aproximadamente, $441 \mathrm{~nm}$ e $609 \mathrm{~nm}$.

Figura 57 - Deconvolução dos espectros eletromagnéticos a $7 \mathrm{~V}$ obtidos dos dispositivos $\mathrm{TI}$, TII e TIII.
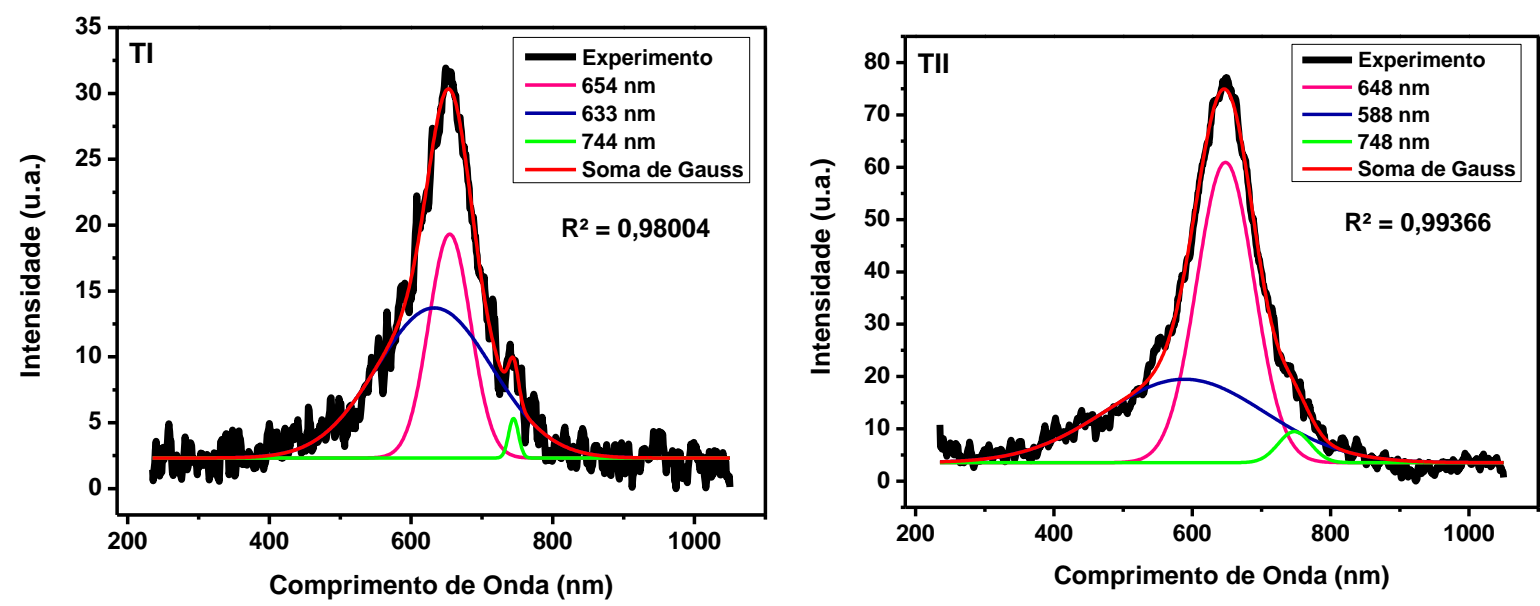


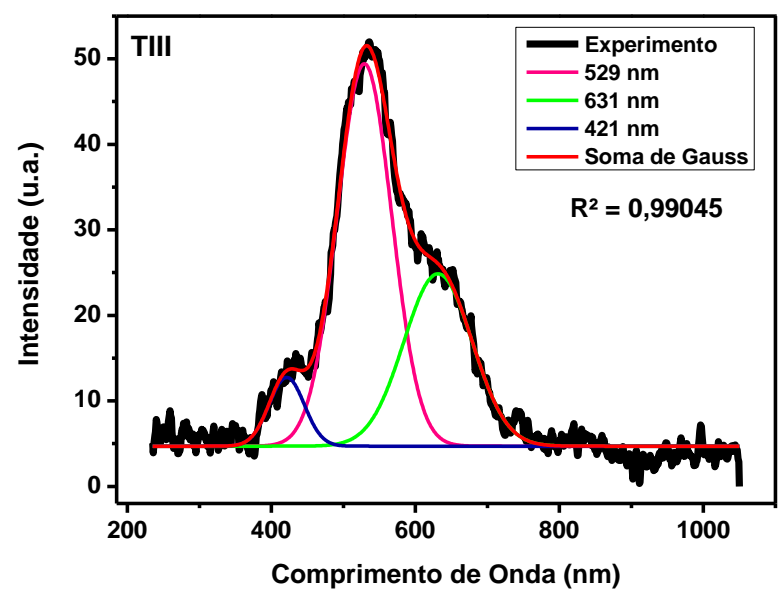

Fonte: Autoria própria.

Para a identificação das origens responsáveis pela emissão eletroluminescente larga, fez-se a deconvolução Gaussiana dos espectros que também estão apresentados na Figura 57. A deconvolução possibilitou a observação de três componentes gaussianos em 633 nm, 654 nm e $744 \mathrm{~nm}$ para os dispositivos TI e $588 \mathrm{~nm}, 648 \mathrm{~nm}$ e $748 \mathrm{~nm}$ para os dispositivos TII, mostrando que a emissão do PVK não ocorreu. Por outro lado, os dispositivos TIII apresentaram componentes gaussianos em $421 \mathrm{~nm}$, que corresponde à emissão do PVK, e mais dois componentes em $529 \mathrm{~nm}$ e $631 \mathrm{~nm}$. A partir destes resultados, pode-se inferir que 0 processo de recombinação de cargas ocorreu em regiões distintas do dispositivo.

$\mathrm{Na}$ literatura, em geral, os estudos da emissão do ZnO na região laranjavermelho (1,9 eV - 2,28 eV) é atribuída ao excesso de oxigênio durante a síntese do ZnO e está relacionada com transições de níveis de energia de defeitos doadores de elétrons, criados próximos à energia da banda de condução, conhecidas como shallow donor defect, para os níveis de energia dos $\mathrm{O}_{i}$, que são considerados como defeitos aceitadores de elétrons cujo nível de energia está mais próximo da energia de Fermi (1,09 eV acima da banda de valência [54] ou 2,28 eV abaixo da banda de condução [55], dependendo do estudo teórico), também conhecido como deep acceptor defect [56-58]. Assim, sugere-se que os componentes gaussianos observados nos três dispositivos em 633 nm e 654 nm (TI), 588 nm e 648 nm (TII) e $631 \mathrm{~nm}$ (TIII) estão relacionados a estes defeitos, apesar dos defeitos $\mathrm{O}_{i}$ possuírem altas energias de formação. 
A Figura 58 mostra o mecanismo proposto pela emissão na região laranjavermelho dos dispositivos TI e TII. Os shallow donor defects, que podem ser tanto o $\mathrm{Zn}_{\mathrm{i}}(0,22$ eV abaixo da banda de condução) [59] quanto uma impureza de alumínio, criam estados de energia no interior do band gap do $\mathrm{AZO}$, próxima à banda de condução. Enquanto que os oxigênio intersticiais criam estados de energia em torno de 1,09 eV acima da banda de valência [54]. Quando se aplica uma determinada tensão no dispositivo, o $\mathrm{O}_{i}$ captura as lacunas provindas do HOMO do PVK uma vez que a barreira energética que as cargas positivas devem ultrapassar é menor $(0,78$ eV ou 0,81 eV) que a barreira existente entre os HOMOs do PVK e do AZO (1,9 eV). Ao mesmo tempo, elétrons são injetados pelo alumínio no interior da camada injetora, que são capturados pelos defeitos doadores e se acumulam na interface PVK/AZO devido à alta barreira energética entre os LUMOs destes dois materiais $(2,1 \mathrm{eV})$. Assim, a recombinação pode ocorrer entre o elétron injetado na banda de condução e/ou no nível de energia dos defeitos doadores do $\mathrm{ZnO}$ com a lacuna injetada no nível de energia do defeito aceitador $\left(\mathrm{O}_{\mathrm{i}}\right)$, emitindo luz na região laranja vermelho do espectro eletromagnético. Como não foi possível observar a emissão do PVK, provavelmente, as cargas foram praticamente barrados na interface entre o polímero e o AZO.

Figura 58 - Esquematização dos níveis de energia e do mecanismo de eletroluminescência dos dispositivos TI e TII.

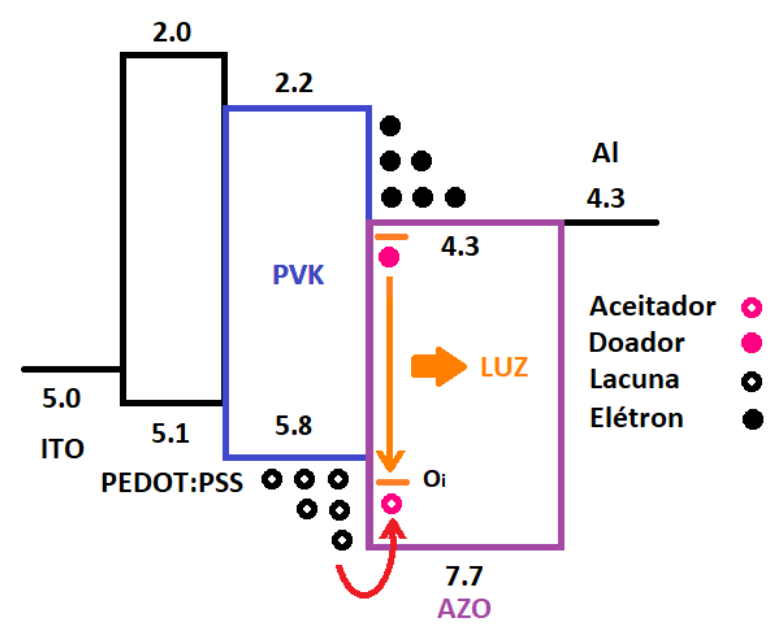

Fonte: Autoria própria. 
Para o dispositivo TIII, além da banda em $631 \mathrm{~nm}$, também foi observado o componente de Gauss em 529 nm cuja emissão ocorre na região verde do espectro eletromagnético. Na literatura, a luminescência na região do verde é a emissão mais comum observada em amostras de ZnO nanoestruturados, entretanto, também é a mais controversa [25]. Geralmente, esta emissão é atribuída à transição eletrônica do nível de energia $V_{\text {o }}$ para a banda de valência [23, 25, 60]. Entretanto, existem autores que acreditam que impurezas de cobre (deep acceptor defect), transições eletrônicas entre um shallow donor/banda de condução para o estado $V_{Z n}$ [23], $O_{Z n}$, defeitos superficiais, complexos $V_{0} Z n_{i}$ e entre outros podem ser responsáveis por esta emissão [61].

Como estudos termodinâmicos mostram que as energias de formação de $\mathrm{V}_{0} \mathrm{e}$ $V_{\mathrm{Zn}}$ são baixas, provavelmente, estes defeitos são os principais responsáveis pela emissão na região verde do espectro eletromagnético [23]. Entretanto, em um trabalho conduzido pelo grupo de Srinatha, a emissão em torno de $530 \mathrm{~nm}$ de filmes finos de AZO depositados por spin-coating foi atribuída à transição eletrônica entre 0 estado criado pelo complexo $V_{0} Z n_{i}$ para a banda de valência [62]. Este mesmo resultado foi obtido pelo grupo de Spadoni, onde ele observou a emissão em $521 \mathrm{~nm}$ quando estudou filmes de AZO depositado por RF sputtering (radio frequency sputtering) [63]. Sugerindo, assim, que a banda em $529 \mathrm{~nm}$ observada na eletroluminescência deve-se a este complexo.

A Figura 59 mostra o mecanismo proposto para a emissão de luz nos dispositivos TIII. Tanto o $\mathrm{O}_{i}$ quanto o complexo $\mathrm{V}_{0} Z_{n_{i}}$ criam estados de energia no interior do band gap do AZO. A aplicação de tensão provoca o deslocamento das cargas. Assim, as cargas são injetadas pelos seus respectivos eletrodos e se acumulam na interface entre o PVK e o AZO devido à existência das barreiras energéticas. Os shallow donor defects e os complexos $V_{0} Z n_{i}$ capturam os elétrons injetados pelo AZO e se recombinam com as lacunas capturadas pelo $\mathrm{O}_{i}$ e com as lacunas da banda de valência, respectivamente, emitindo luz na região laranjavermelho e verde do espectro eletromagnético, sendo que o comprimento de onda emitido depende das transições envolvidas. Como a emissão do PVK foi observada, provavelmente, parte dos elétrons e lacunas ultrapassaram as barreiras energéticas existentes devido ao não alinhamento entre os LUMOs e HOMOs do polímero e das 
camadas injetoras, respectivamente, possibilitando a emissão de luz na região azul em $421 \mathrm{~nm}$.

Figura 59 - Esquematização dos níveis de energia e do mecanismo de eletroluminescência dos dispositivos TIII.

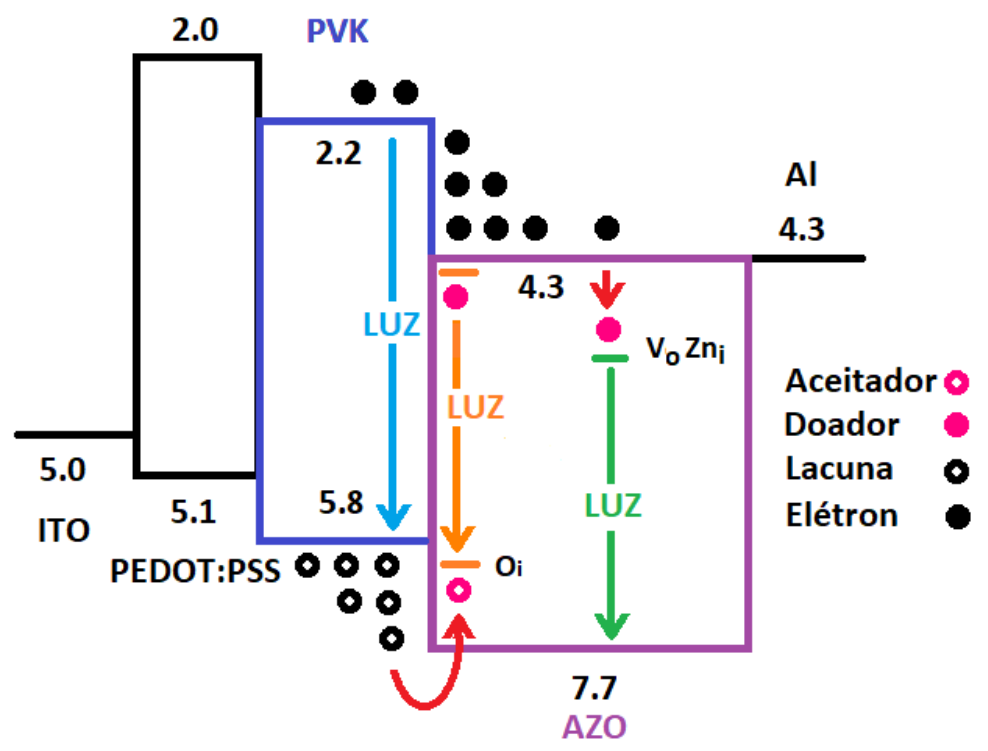

Fonte: Autoria própria.

Comparando-se os quatro espectros de eletroluminescência normalizados dos dispositivos TI, TII e TIII a 7 V e dos dispositivos estudados na Seção 5.1 a 6 V mostrados na Figura 60, pode-se perceber que os dispositivos TI e TII, e os dispositivos TIII e de PVK puro da Seção 6.1 apresentaram espectros muito semelhantes, em que foi observada uma banda entre $490 \mathrm{~nm}$ e $575 \mathrm{~nm}$ em comum, o que indica similitude no mecanismo de emissão. Assim, os dispositivos estudados na Seção 5.1 também apresentou emissão relativa aos defeitos do AZO, confirmando o desbalanço de carga na estrutura utilizada. Pode-se destacar também que o dispositivo TIII, além da banda, apresentou também dois ombros em $441 \mathrm{~nm}$ e 609 nm que não foram observados no dispositivo de PVK puro da Seção 5.1. 
Figura 60 - Espectros de eletroluminescência normalizados para todos os dispositivos à base de PVK puro a 7 V (TI, TII e TIII) e a 6 V (PVK utilizado na Seção 6.1.)

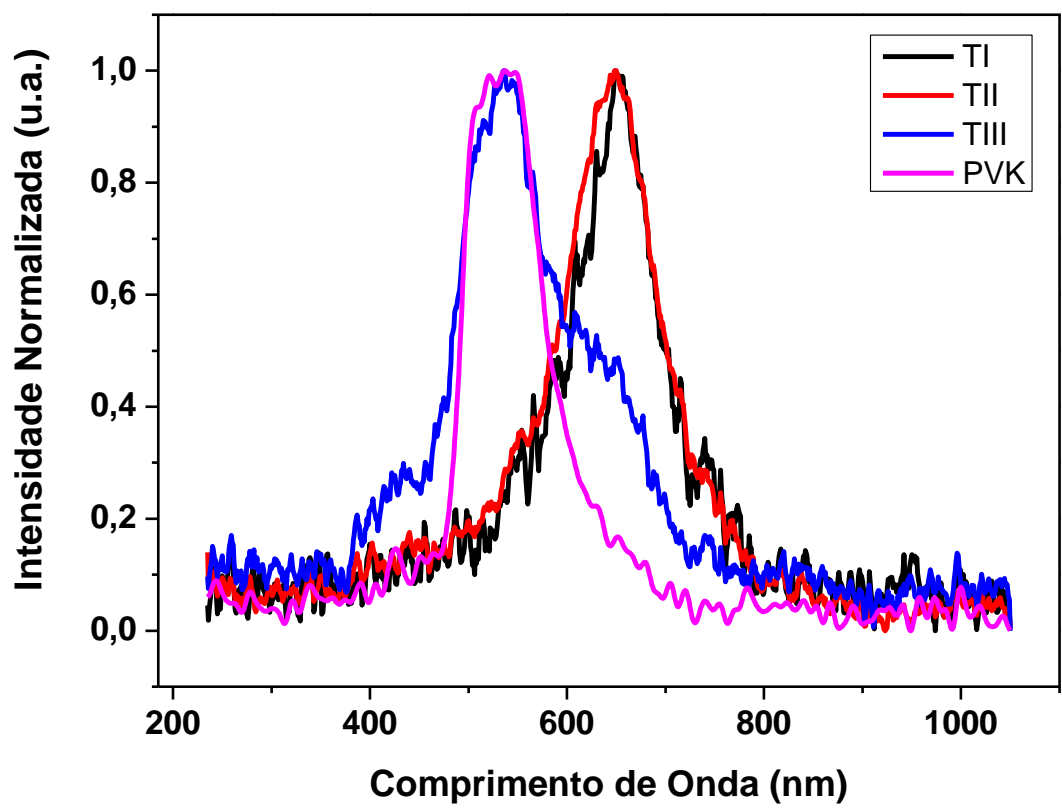

Fonte: Autoria própria.

Essas diferenças nos espectros eletroluminescentes podem ser causadas por diversos fatores como, por exemplo, formação de filmes poliméricos com espessuras heterogêneas, em que filmes mais finos podem facilitar o transporte de cargas para o interior do AZO, aumentando a sua emissão ou até mesmo as variações nos parâmetros de síntese do AZO adquirido podem ter influenciado nos resultados obtidos.

\subsection{Comparação entre os dispositivos de PVK e PVK:AZO}

Conforme mostrado anteriormente, o dispositivo contendo PVK puro como camada emissora mostrou emissão nas regiões verde e laranja do espectro eletromagnético o que não está de acordo com o observado na literatura, indicando um desbalanceamento de cargas. Este comportamento também foi observado quando PVK de diferentes massas molares médias foram utilizadas. Deste modo, sugeriu-se que a emissão poderia ter ocorrido na camada injetora de elétrons (AZO) uma vez que este material possui propriedades fotoluminescentes [52]. Com o objetivo de aumentar a injeção de carga no PVK, sistema híbrido contendo PVK:AZO como camada emissora foi produzido. Neste tópico, as propriedades 
elétricas e ópticas dos dispositivos de PVK puro e de PVK:AZO foram estudadas e comparadas.

\subsubsection{Caracterização óptica e elétrica}

A Figura 61 mostra as curvas $\mathrm{J} \times \mathrm{V}$ dos dispositivos a base de PVK e PVK:AZO na quarta polarização e as suas respectivas tensões de limiar, e as fotografias dos dispositivos acesos. A adição de AZO no interior do PVK provocou o aumento na densidade de corrente e a diminuição da tensão de limiar de $8,1 \mathrm{~V}$ para $7,5 \vee$ o que equivale a uma redução de $7,4 \%$ devido ao fato de que as nanopartículas criam passagens preferenciais para a movimentação de cargas e aumentando a área de contato entre o eletrodo e a camada ativa, facilitando a entrada de carga em seu interior [64]. Além disso, como o PVK é um polímero eletroluminescente não-conjugado, a movimentação de cargas pela sua cadeia ocorre exclusivamente entre os grupos carbazoles pelo processo de hopping. Portanto, altas mobilidades de cargas não podem ser atingidas devido à necessidade de uma energia de ativação. Quando nanopartículas de AZO são adicionadas ao PVK, essa energia de ativação diminui, aumentando a mobilidade das cargas e facilitando a sua injeção no interior da camada ativa [65].

Figura 61 - Curva J x V e fotografias dos dispositivos contendo (a) PVK:AZO e (b) PVK como camada ativa e suas respectivas tensões de limiar.

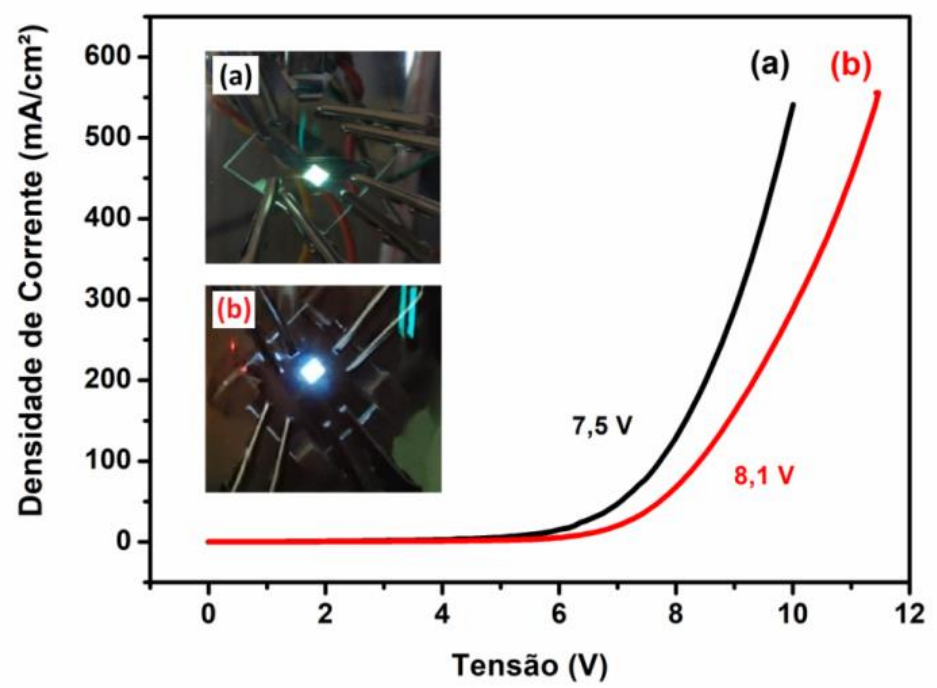

Fonte: Autoria própria. 
Os gráficos da luminância e da eficiência de corrente em função da tensão aplicada ilustrados na Figura 62 mostram que a adição de AZO no PVK melhorou as propriedades ópticas dos PLEDs a base de PVK:AZO. A máxima luminância passou de $5,86 \mathrm{~cd} / \mathrm{m}^{2}(10,5 \mathrm{~V})$ para $18,69 \mathrm{~cd} / \mathrm{m}^{2}(10 \mathrm{~V})$ o que equivale a um aumento de $68,6 \%$ enquanto que a máxima eficiência de corrente teve um aumentou de $69,6 \%$, de $0,14 \mathrm{~cd} / \mathrm{A}(9,5 \mathrm{~V})$ para $0,46 \mathrm{~cd} / \mathrm{A}(10 \mathrm{~V})$. Este comportamento é observado devido a maior facilidade de injeção de carga no interior da camada emissiva do sistema híbrido, conforme mostrado na Figura 61, aumentado a probabilidade de recombinação em seu interior. Além disso, sabe-se que para se obter PLEDs eficientes é necessário que exista um balanço de cargas negativas e positivas injetadas pelos seus respectivos eletrodos. Assim, como em materiais inorgânicos a mobilidade de elétrons é superior à mobilidade de lacunas enquanto que nos materiais orgânicos, no geral, a mobilidade de lacunas é maior que a mobilidade de elétrons, quando se misturam estes dois tipos de materiais, o desbalanço de cargas diminui e, por consequência, a probabilidade de ocorrer a recombinação aumenta, melhorando-se as propriedades ópticas dos dispositivos híbridos [64].

Destaca-se também que para os PLEDs contendo PVK:AZO como camada emissora a luminância aumenta significativamente a partir de $8,5 \mathrm{~V}$, enquanto que para o PLED a base de PVK, este aumento ocorre a partir de $9 \mathrm{~V}$ o que é condizente com o observado na curva $\mathrm{J} \times \mathrm{V}$ apresentado na Figura 61. Como a injeção de cargas é facilitada em sistemas contendo misturas de PVK e AZO, a probabilidade de ocorrer a recombinação entre cargas em tensões menores aumenta.

Figura 62 - Luminância e eficiência de corrente em função da tensão aplicada dos dispositivos contendo PVK e PVK:AZO como camada ativa.
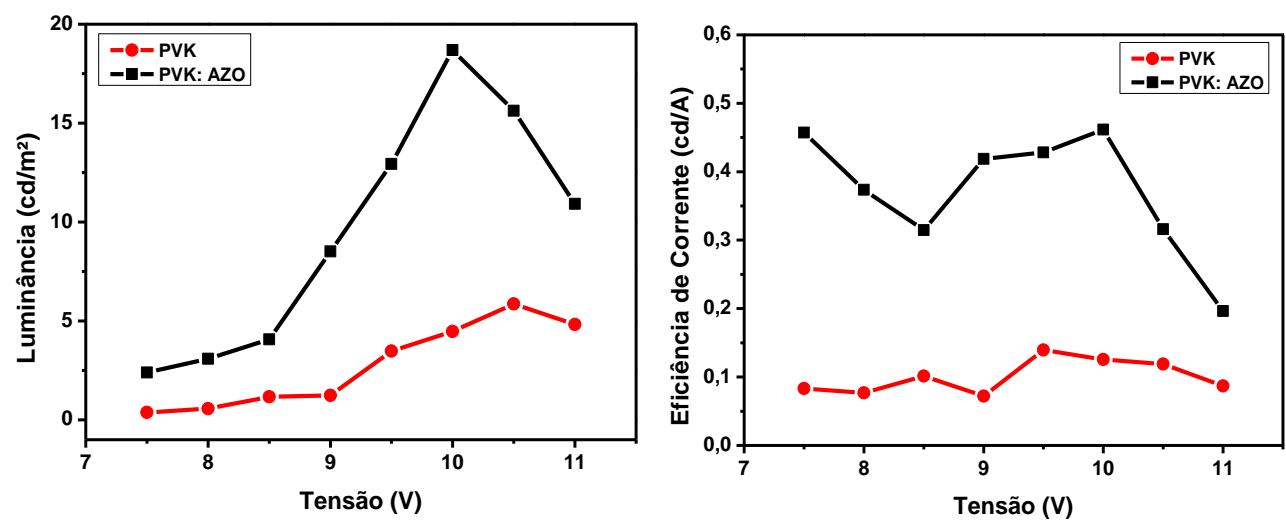

Fonte: Autoria própria. 
Os espectros de eletroluminescência normalizados e o diagrama de cromaticidade CIE 1931 em polarização constante a $10 \mathrm{~V}$ estão ilustrados na Figura 63. Ambos dispositivos apresentaram bandas largas de emissão na região do visível com três picos de emissão. Entretanto, o dispositivo contendo PVK puro apresentou picos em $433 \mathrm{~nm}$ e $474 \mathrm{~nm}$, que estão relacionados ao decaimento do excímero formado no estado $S_{1}$, e $601 \mathrm{~nm}$, que corresponde à emissão de eletrômeros formados durante a polarização do dispositivo [47]. Por outro lado, quando se adiciona nanopartículas de AZO, os picos sofrem um redshift para 504 nm, 583 nm e $700 \mathrm{~nm}$.

Figura 63 - Espectro de eletroluminescência normalizado e o diagrama de cromaticidade CIE 1931 dos dispositivos a base de PVK e PVK:AZO a $10 \mathrm{~V}$.

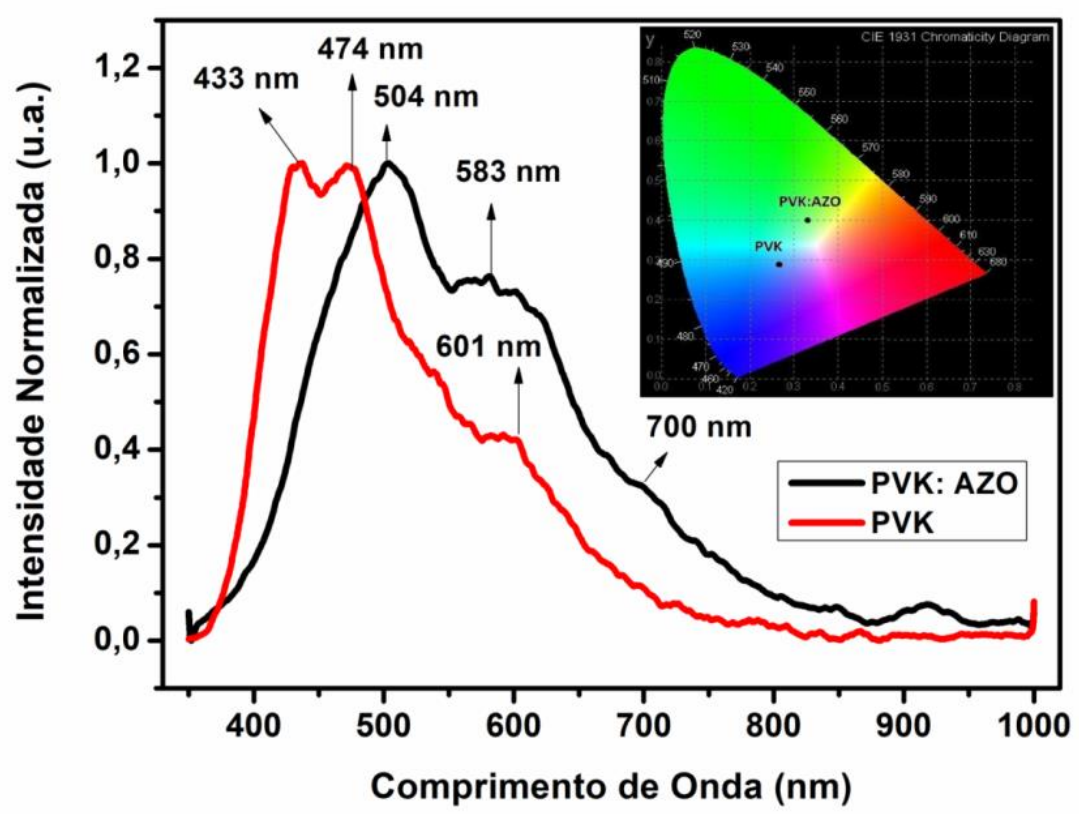

Fonte: Autoria própria.

Para se observar as diferentes emissões dos dispositivos à base de PVK e PVK:AZO os espetros de eletroluminescência a $10 \mathrm{~V}$ foram deconvoluídos em componentes gaussianos conforme mostrado na Figura 64. O PVK apresentou três componentes em 420 nm, 466 nm e 556 nm, cujas emissões correspondem à região azul-verde do espectro eletromagnético, enquanto que o sistema híbrido apresentou quatro componentes em $470 \mathrm{~nm}, 511 \mathrm{~nm}, 582 \mathrm{~nm}$ e $702 \mathrm{~nm}$, abrangendo toda a região do visível. Portanto, a adição de $\mathrm{AZO}$ provocou o desaparecimento do 
componente de Gauss em 420 nm do PVK e também, o surgimento de novas emissões aumentando a eletroluminescência na região azul-vermelho do espectro eletromagnético, sugerindo que transferência de energia do PVK para o AZO e emissão de luz por defeitos (intrínsecos e extrínsecos) das nanopartículas sejam responsáveis por estes fenômenos e pelo aumento do desempenho dos PLEDs híbridos.

Figura 64 - Espectros de eletroluminescência a $10 \mathrm{~V}$ normalizados e respectivas componentes de Gauss para: a) PVK e b) PVK:AZO.
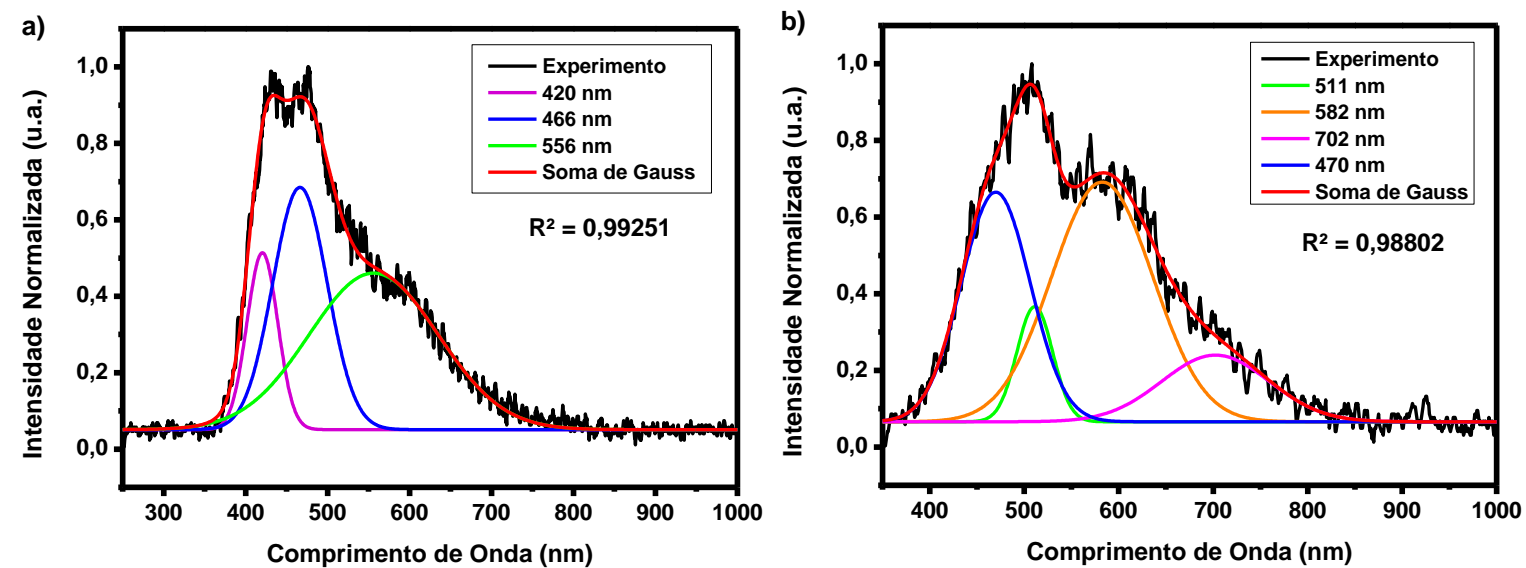

Fonte: Autoria própria.

O cálculo da pureza e a determinação do comprimento de onda dominante foram feitos em relação ao iluminante cuja coordenada de cromaticidade é $(0,33$; 0,33). A pureza e o comprimento de onda dominante a $10 \mathrm{~V}$ do PLED de PVK puro foram de 0,24 e $483 \mathrm{~nm}$, respectivamente, enquanto que para o PLED híbrido, de 0,19 e $552 \mathrm{~nm}$, respectivamente. Assim, a adição de AZO na camada emissora aumentou a sensação da cor branca uma vez que o valor da pureza diminuiu, entretanto, a percepção da cor emitida variou do azul (483 nm) para verde (552 nm) o que corrobora com os espectros eletromagnéticos (Figura 63) e com as fotografias obtidas (Figura 61).

\subsection{Espectros de Absorção e Fotoluminescência do AZO}

Com o intuito e se estudar as propriedades ópticas do AZO, espectros de absorção e de fotoluminescência em diferentes excitações foram obtidos. 
A Figura 65 mostra o espectro de absorção do AZO diluído em clorofórmio. Apesar do $\lambda_{\text {onset }}$ obtido ser de $377 \mathrm{~nm}$, foi possível observar que as nanopartículas apresentaram absorção a partir de $550 \mathrm{~nm}$ devido à existência de defeitos que criam estados no interior de seu band gap.

Figura 65 - Espectro de absorção da solução de AZO diluído em clorofórmio contendo a curva ampliada entre $325 \mathrm{~nm}$ e $550 \mathrm{~nm}$.

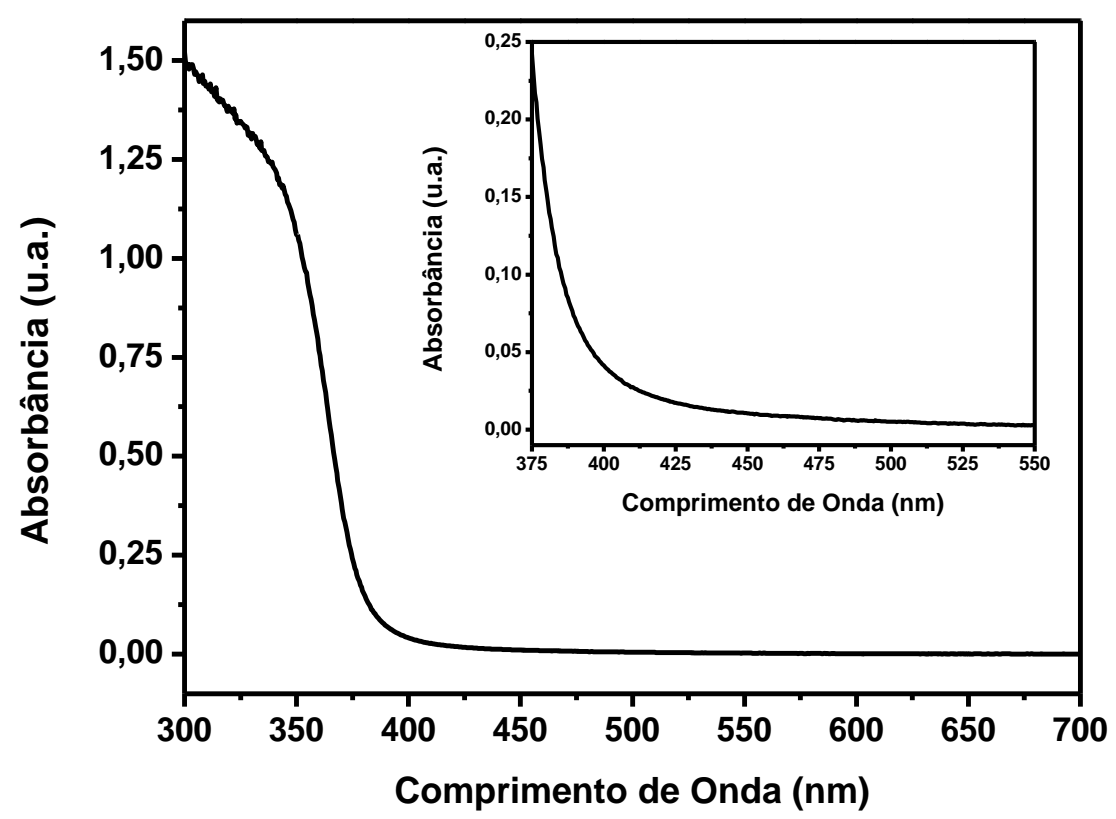

Fonte: Autoria própria.

A Figura 66 mostra o espectro de fotoluminescência do AZO disperso em clorofórmio, excitado em $320 \mathrm{~nm}$ com auxílio de um filtro de $360 \mathrm{~nm}$. Podem-se observar duas bandas de emissão com picos em $377 \mathrm{~nm}$, que envolvem transições entre as bandas de condução e de valência do AZO (near band edge - NBE), e 580 $\mathrm{nm}$, que está relacionado à emissão devido à existência de defeitos [28]. Além disso, notou-se que a intensidade de emissão na região do UV foi quase oito vezes maior que a intensidade de emissão na região do visível. 
Figura 66 - Solução diluída de AZO em clorofórmio excitado em 320 nm (filtro de 360 nm).

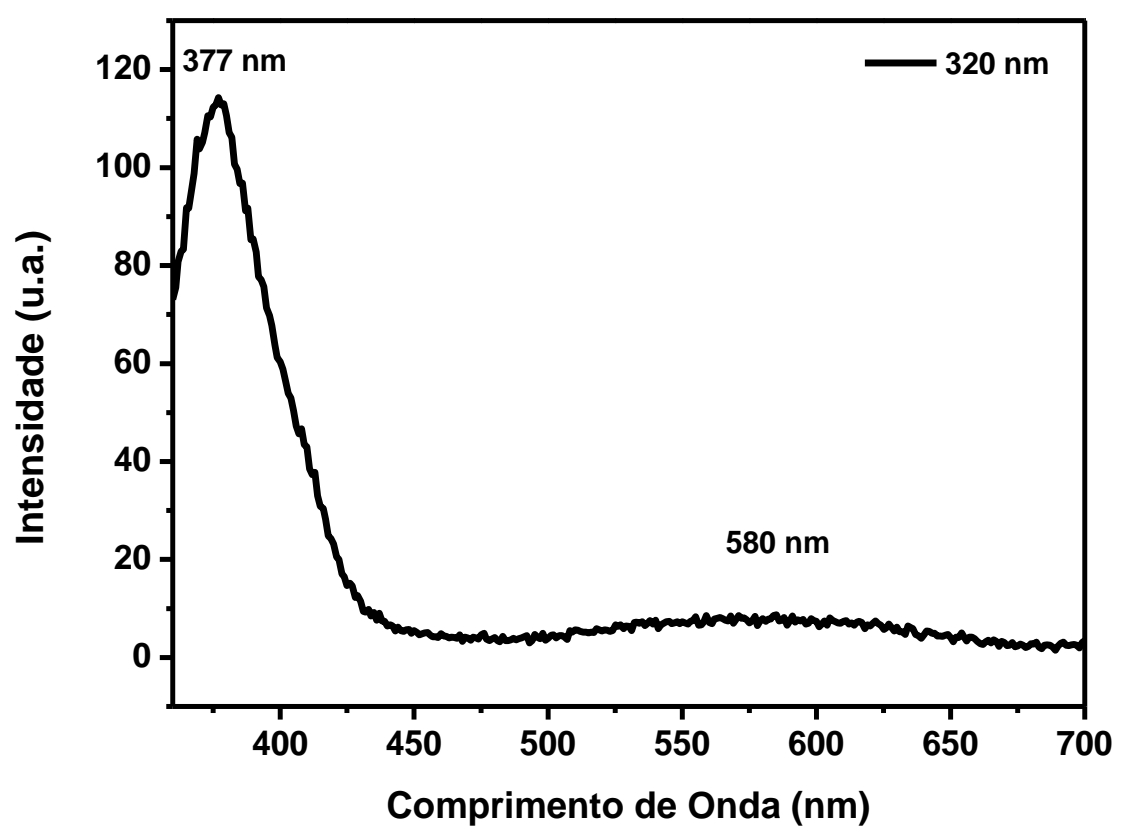

Fonte: Autoria própria.

A fim de se estudar a emissão de luz na região do visível, os espectros de fotoluminescência da dispersão de AZO puro concentrado e diluído em clorofórmio foram obtidos em diferentes excitações conforme mostrado na Figura 67. Nesta parte do trabalho, foram selecionados quatro comprimentos de onda distintos: menor que o $\lambda_{\text {onset }}(320 \mathrm{~nm})$, próximo ao $\lambda_{\text {onset }}(380 \mathrm{~nm})$ e maiores que $\lambda_{\text {onset }}(400 \mathrm{~nm}$ e 420 $\mathrm{nm}$ ) uma vez que o $\lambda_{\text {onset }}$ está relacionado com o band gap óptico do material.

Os espectros de fotoluminescência do AZO concentrado, quando excitados em $320 \mathrm{~nm}, 380 \mathrm{~nm}$ e $400 \mathrm{~nm}$ apresentaram perfis diferentes dos respectivos espectros de fotoluminescência do AZO diluído em clorofórmio, porém, quando excitado em $420 \mathrm{~nm}$, ambas as soluções apresentaram perfis e picos em posições similares, entretanto, os picos do AZO concentrado sofreram um deslocamento para a esquerda quando diluído, provavelmente, devido à diminuição das interações entre as nanopartículas. Pode-se destacar também que quando o AZO concentrado foi excitado em $320 \mathrm{~nm}$, não foi possível observar o pico relativo ao NBE em $377 \mathrm{~nm}$ conforme observado na Figura 73. Assim, sugere-se que estes fenômenos ocorreram devido ao fato de que sistemas concentrados favorecem a agregação de nanopartículas, aumentando as interações entre elas e favorecendo o processo de reabsorção. 
Observando-se o comportamento dos espectros de fotoluminescência quando o AZO concentrado foi excitado em diferentes comprimentos de onda, foi possível notar que o espectro varia conforme a excitação aplicada. Além disso, independentemente da excitação utilizada, o pico em $484 \mathrm{~nm}$ foi observado, sugerindo que esta emissão ocorreu no interior da nanopartícula [59]. Quando a excitação selecionada foi inferior ao $\lambda_{\text {onset, }}$ a intensidade de emissão dos defeitos foi baixa em relação às outras excitações e ainda, três picos na região azul e um pico na região vermelha foram observados. Quando a excitação foi feita próxima ao $\lambda_{\text {onset, }}$ a intensidade de emissão aumentou e também, novos picos na região azul-amarelo surgiram enquanto que a emissão no vermelho em $700 \mathrm{~nm}$ desapareceu. Diminuindo-se a energia de excitação para valores abaixo da energia do band gap ainda foi possível observar a emissão na região azul-amarelo e a emissão na região vermelha também se manteve suprimida, o que pode indicar que a emissão na região azul-amarela ocorreu devido aos defeitos com maior facilidade de ionização enquanto que os defeitos responsáveis pela emissão na região vermelha possuem maior energia de ionização e, portanto, são defeitos que criam deep levels no band gap, como por exemplo, vacâncias e oxigênio intersticial que são geralmente observados em sistemas ricos em oxigênio [66].

Estes comportamentos também se repetiram quando a solução diluída foi excitada nos mesmos comprimentos de onda que a solução concentrada, porém os perfis dos espectros, praticamente, mantiveram-se inalterados com três picos de emissão pertencentes à região azul-verde do espectro eletromagnético e com apenas pequenos deslocamentos entre os picos, exceto em $\lambda_{\text {exc }}=320 \mathrm{~nm}$ em que foi observada uma emissão larga de baixa intensidade na região azul-vermelho com dois picos (450 nm e $575 \mathrm{~nm}$ ).

Assim, foi possível observar que energias inferiores à energia do band gap do AZO são capazes de excitá-lo, mostrando a existência de estados no interior de seu band gap, que são responsáveis pela fotoluminescência em diferentes comprimento de onda. 
Figura 67 - Espectros de fotoluminescência das soluções de AZO: a) concentrado e b) diluído em clorofórmio excitado em diferentes comprimentos de onda.
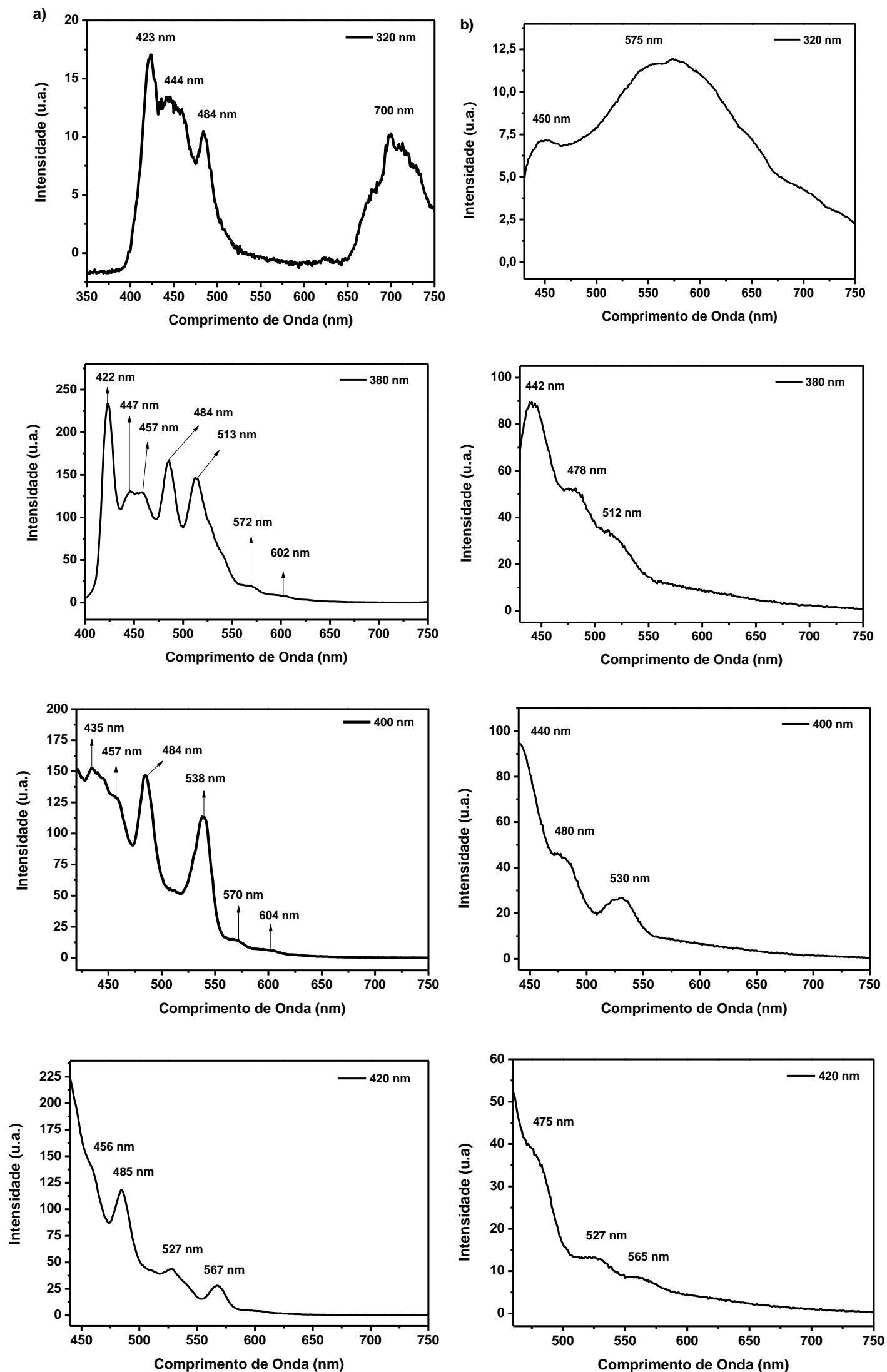

Fonte: Autoria própria. 
Com o intuito de identificar a origem das emissões, os espectros de fotoluminescência do AZO diluído em clorofórmio e excitados em 320 nm e $380 \mathrm{~nm}$ foram deconvoluídos em componentes Gaussianos (Figura 68) uma vez que em sistemas diluídos, as interações entre as nanopartículas são bem menores e, por consequência, processos de reabsorção são minimizados.

Figura 68 - Espectros de fotoluminescência do AZO diluído em clorofórmio deconvoluídos em componentes Gaussianos excitados em: a) $320 \mathrm{~nm}$ e b) $380 \mathrm{~nm}$.
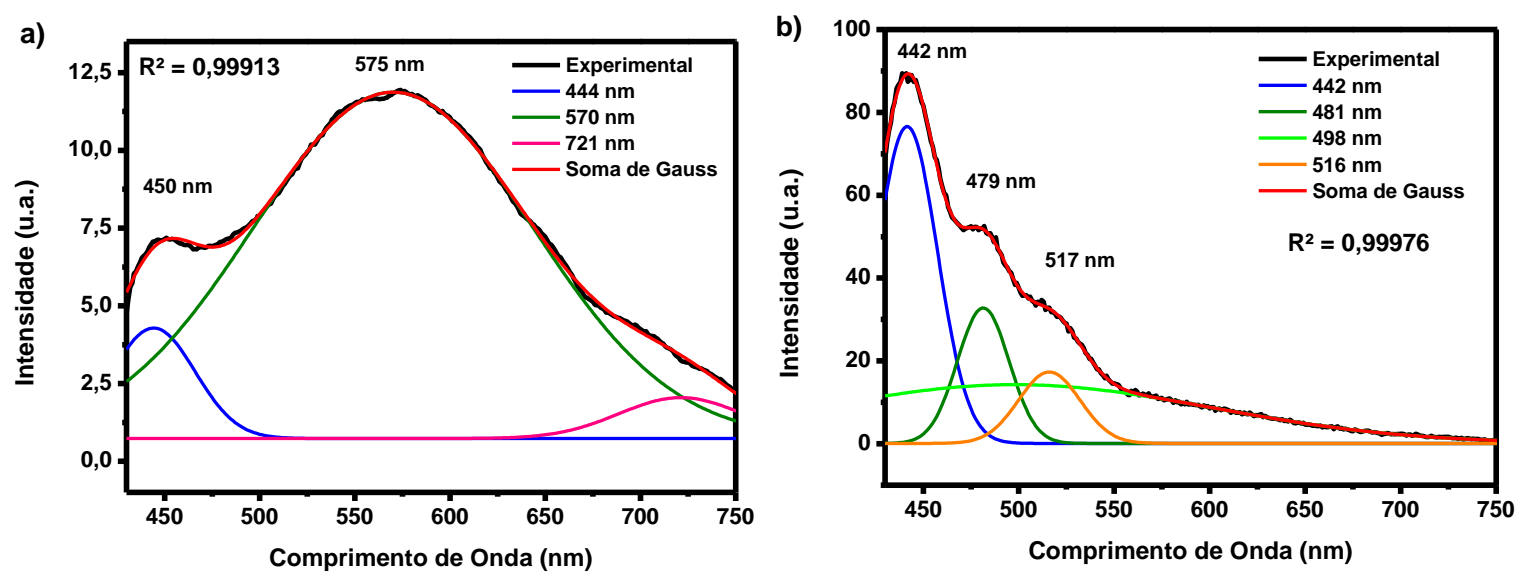

Fonte: Autoria própria.

Deconvoluindo-se o espectro de fotoluminescência do AZO diluído em clorofórmio quando $\lambda_{\mathrm{exc}}=320 \mathrm{~nm}$, foi possível observar três componentes Gaussianos em $444 \mathrm{~nm}, 570 \mathrm{~nm}$ e $721 \mathrm{~nm}$ enquanto que quatro componentes em $442 \mathrm{~nm}, 481 \mathrm{~nm}, 498 \mathrm{~nm}$ e $516 \mathrm{~nm}$ foram observados quando $\lambda_{\mathrm{exc}}=380 \mathrm{~nm}$.

As emissões na região violeta-azul são atribuídos à $V_{Z n}$ [67], $Z n_{i}$ [24] e estados $Z n_{i}$ estendidos [68]. Na literatura, as emissões em $442 \mathrm{~nm}(\sim 2,8 \mathrm{eV})$ e 444 $\mathrm{nm}(\sim 2,8 \mathrm{eV})$, geralmente, estão relacionadas às transições entre estados estendidos do $Z n_{i}\left(Z n_{i}^{-}\right.$e $\left.Z n_{i}^{2-}\right)$ e a banda de valência [24, 54]. O componente Gaussiano em $481 \mathrm{~nm}(\sim 2,6 \mathrm{eV})$ pode ser atribuído à transição eletrônica do estado de energia do $Z n_{i}$ para $V_{Z n}$ [22]. Conforme discutido na Seção 5.2, a emissão na região verde do espectro eletromagnético ainda é bastante controverso, entretanto, as emissões em $498 \mathrm{~nm}(\sim 2,5 \mathrm{eV})$ e $516 \mathrm{~nm}(\sim 2,4 \mathrm{eV})$, que é frequentemente observado pelos pesquisadores, foram atribuídos à transição de elétron no estado $V_{0}$ para a banda de valência pelos grupos de Ding [22] e Lin [69]. A emissão em 570 $\mathrm{nm}(\sim 2,2 \mathrm{e} \mathrm{V})$ foi atribuído aos defeitos superficiais em nanopartículas de $\mathrm{ZnO}$ pelo 
grupo de Theresa [70] e à transição entre a banda de condução e o estado $\mathrm{O}_{z n}$ pelo grupo de Kondal [59]. Por fim, a emissão próxima ao infra-vermelho é raramente observado, geralmente, a emissão no vermelho ocorre entre 600 e $690 \mathrm{~nm}$ e são atribuídos às transições envolvendo $O_{i} e$, portanto, ainda é muito controverso, pois existem modelos teóricos que conseguem prever o pico relacionado à emissão e seu respectivo nível de energia, entretanto, o defeito responsável pela emissão é instável, com baixa probabilidade de formação, sendo inconsistente com o observado experimentalmente. Na literatura, geralmente esta emissão está relacionada com as vacâncias de oxigênio, assim como observado na emissão verde. Estes defeitos ocorrem em três estados de carga: vacância de oxigênio neutro, vacância de oxigênio monovalente e vacância de oxigênio bivalente, sendo que a vacância de oxigênio monovalente é termodinamicamente instável e, por consequência, vacância de oxigênio bivalente dificilmente é formada [23, 71-72]. Apesar disso, existem estudos que afirmam que a existência de vacâncias de oxigênio monovalentes e bivalente provocam a emissão na região vermelha do espectro eletromagnético [71-72]. Singh e colaboradores acreditam que transições eletrônicas entre $\mathrm{V}_{0}^{+}$e a banda de valência sejam responsáveis pela emissão em $721 \mathrm{~nm}(\sim 1,7 \mathrm{eV})$ [73].

Assim, a partir dos dados experimentais e da literatura, montou-se o diagrama apresentado na Figura 69 com os mecanismos sugeridos para cada emissão.

Figura 69 - Diagrama sugerido dos mecanismos das emissões observadas experimentalmente.

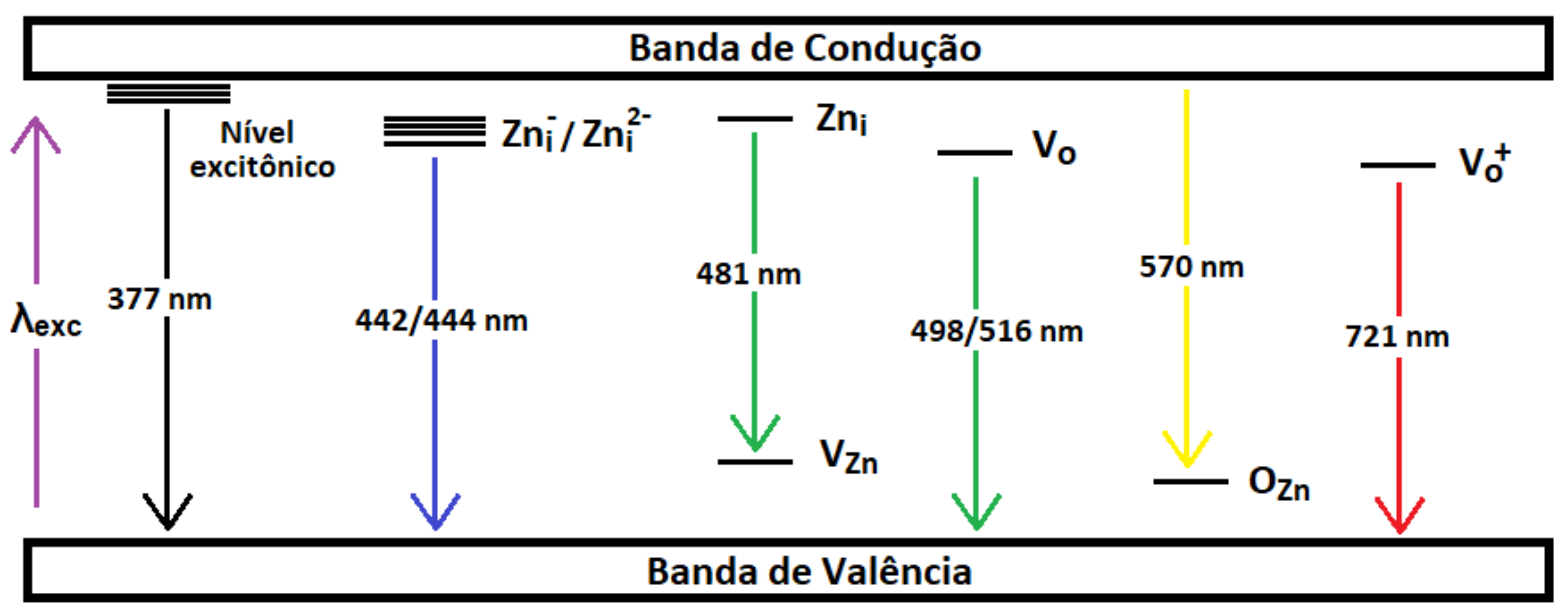

Fonte: Autoria própria. 


\subsection{UV-Vis e Fluorescência do sistema PVK:AZO}

Com o objetivo de se entender as propriedades ópticas (Figura 63) e as interações entre o PVK e o AZO, espectros de absorção e de fluorescência foram obtidas em soluções diluídas em clorofórmio.

A Figura 70 mostra os espectros de absorção das soluções diluídas de PVK, AZO e PVK:AZO em clorofórmio. Assim, os $\lambda_{\text {onset }}$ foram de $377 \mathrm{~nm}$, para o AZO e $352 \mathrm{~nm}$ tanto para o PVK quanto para o PVK:AZO. O PVK apresentou dois picos característicos em $330 \mathrm{~nm}$ e $345 \mathrm{~nm}$, derivados da absorção $\pi-\pi^{*}$ do grupo carbazol [74]. A adição de AZO provocou um aumento na absorção do sistema PVK:AZO, mantendo-se o perfil de absorção e os máximos locais do polímero puro. Portanto, sugere-se que existem interações entre os dois materiais, porém sem modificação aparente no comprimento das ligações do PVK [75-76]. Sonone [75] e seus colaboradores estudaram as propriedades estruturais e eletroluminescentes do PVK puro e sistemas contendo $\mathrm{TiO}_{2}$ em seu interior. Neste trabalho, a adição de $\mathrm{TiO}_{2}$ provocou um translado no pico de absorção (redshift) do polímero devido à expansão da banda C-N, que reduz as interações intermoleculares entre as cadeias poliméricas.

Figura 70 - Espectro de absorção na região UV-Vis do AZO, PVK e PVK:AZO diluídos em clorofórmio.

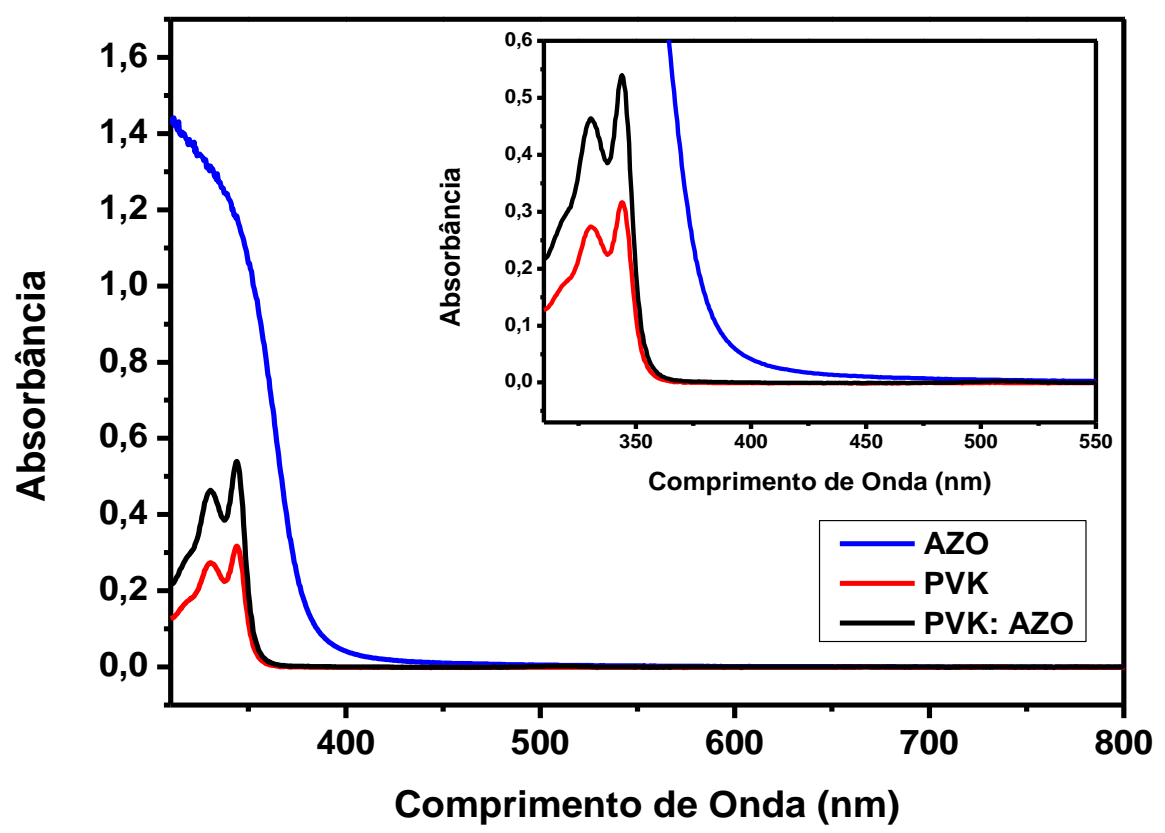

Fonte: Autoria própria. 
A Figura 72 mostra os espectros de fotoluminescência (original e normalizada) das soluções diluídas de PVK, AZO e PVK:AZO em clorofórmio excitados em $320 \mathrm{~nm}, 370 \mathrm{~nm}$ e $400 \mathrm{~nm}$. Os slits de emissão e excitação utilizados neste trabalho foram de $10 \mathrm{~nm}$ e $10 \mathrm{~nm}$ para o PVK e para o sistema híbrido, enquanto que para o AZO, de $20 \mathrm{~nm}$ e $20 \mathrm{~nm}$. As escolhas dos comprimentos de onda de excitação foram feitas de acordo com os Aonset do PVK e do AZO determinados a partir dos espectros de absorção da Figura 70. Assim, excitando-se o sistema híbrido em 320 nm, a emissão observada corresponderá à excitação dos elétrons do HOMO para o LUMO tanto do PVK quanto do AZO uma vez que este comprimento de onda é inferior aos $\lambda_{\text {onset }}$ destes materiais e, por consequência, possui energia suficiente para que os elétrons ultrapassem o band gap. Excitando-se o sistema PVK:AZO em 370 nm, as transições eletrônicas ocorrerão preferencialmente entre o HOMO e LUMO do AZO uma vez que este comprimento de onda é maior que o $\lambda_{\text {onset }}$ do PVK e menor que o $\lambda_{\text {onset }}$ do AZO. Por fim, a excitação em 400 nm não é capaz de provocar transições entre HOMO e LUMO do PVK e nem do AZO, entretanto, transições entre estados criados pelos defeitos do AZO podem ser estimulados conforme observado na Seção 5.4. A Figura 71 ilustra o processo de excitação nos três comprimentos de onda citados anteriormente.

Figura 71 - Esquematização do processo de excitação em 320 nm, 370 nm e 400 nm do sistema híbrido PVK:AZO.

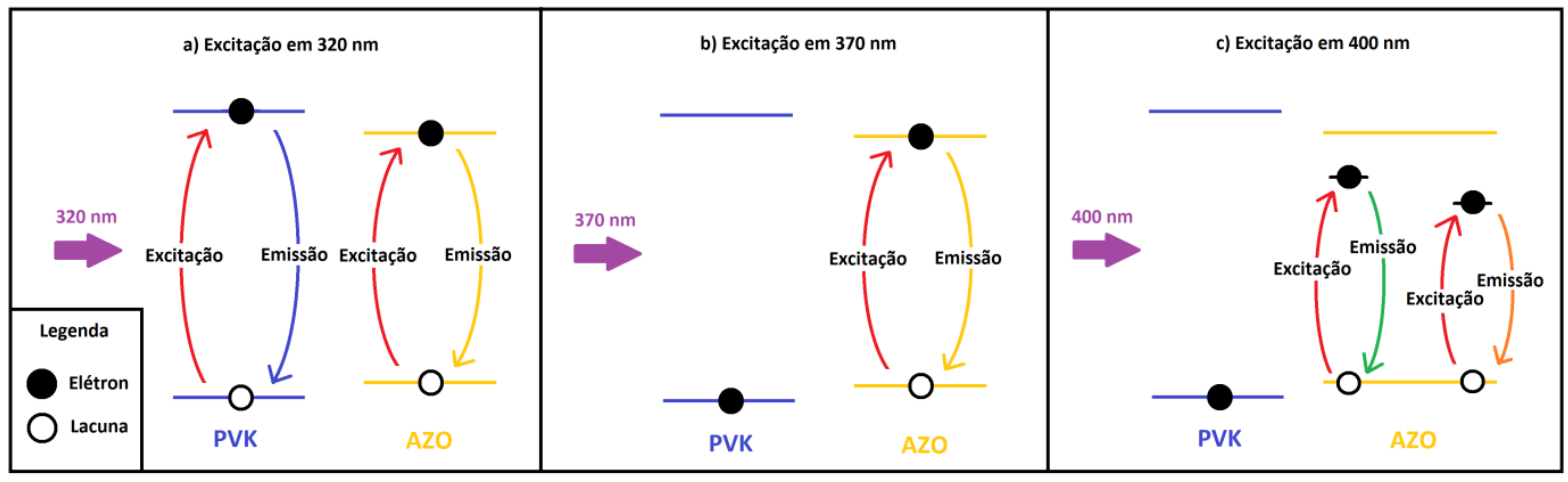

Fonte: Autoria própria.

Segundo a Figura 72 (a), o PVK apresentou uma banda larga de emissão entre $430 \mathrm{~nm}$ e $500 \mathrm{~nm}$ com pico em $377 \mathrm{~nm}$ enquanto que o AZO, apresentou um 
pico estreito em 377 nm e uma banda de emissão de baixa intensidade na região do visível centrada em $580 \mathrm{~nm}$ quando excitados em $320 \mathrm{~nm}$. O sistema híbrido apresentou intensidade de emissão quase duas vezes a intensidade de emissão do PVK puro, sendo que o seu pico apresentou um pequeno blueshift de $377 \mathrm{~nm}$ para $374 \mathrm{~nm}$, sugerindo a ocorrência da transferência de energia entre o AZO e o polímero hospedeiro. Pode-se destacar também que a banda em $580 \mathrm{~nm}$ do AZO puro desapareceu no sistema híbrido e foi possível observar um aumento na intensidade da banda de emissão na região entre $450 \mathrm{~nm}$ e $550 \mathrm{~nm}$. Como a excitação em $320 \mathrm{~nm}$ promove transições eletrônicas tanto no PVK quanto no AZO, não é possível identificar o sentido da transferência de energia.

Quando a excitação foi de 370 nm, o PVK apresentou uma banda de emissão larga entre $430 \mathrm{~nm}$ e $550 \mathrm{~nm}$, sendo que o seu pico ocorreu em comprimentos de onda inferior à $430 \mathrm{~nm}$ e ainda, a intensidade de emissão do PVK diminuiu em relação à excitação em $320 \mathrm{~nm}$ devido ao fato de que o PVK possui baixa absorção neste comprimento de onda conforme observado na Figura 70. Por outro lado, 0 AZO apresentou três máximos em 440 nm, 482 nm e 530 nm com uma banda larga entre $430 \mathrm{~nm}$ e $700 \mathrm{~nm}$, cobrindo a região visível do espectro eletromagnético. Observou-se também que a intensidade de emissão dos defeitos aumentou nesta excitação. A adição de $A Z O$ na matriz polimérica provocou um redshift do pico de emissão do PVK para $440 \mathrm{~nm}$, um aumento da sua intensidade de emissão em quase três vezes e também aumentos na intensidade de emissão correspondentes às bandas entre $430 \mathrm{~nm}$ e $550 \mathrm{~nm}$, sugerindo uma transferência de energia do PVK para o AZO e a ativação dos defeitos nos sistemas híbridos quando excitados em $380 \mathrm{~nm}$.

Por fim, quando a excitação foi de 400 nm, o PVK apresentou um pico de emissão em $440 \mathrm{~nm}$ de baixa intensidade e o AZO apresentou três picos em 440 $\mathrm{nm}, 476 \mathrm{~nm}$ e $530 \mathrm{~nm}$ intensos. Por outro lado, para o sistema híbrido, o ponto de máximo ocorreu em $442 \mathrm{~nm}$, sofrendo, por tanto, um pequeno redshift em relação ao polímero puro com aumento de sua intensidade de emissão em duas vezes. Assim, excitações nos níveis dos defeitos do AZO são suficientes para aumentar a fotoluminescência do sistema híbrido, entretanto, a emissão de seus defeitos é inibido. 
Portanto, com estes resultados é possível inferir que o aumento da intensidade de emissão do sistema híbrido ocorre devido à transferência de energia entre o PVK e o AZO, principalmente, quando excitado em $320 \mathrm{~nm}$.

Figura 72 - Espectro de fotoluminescência (original e normalizada) à temperatura ambiente das soluções diluídas de PVK, AZO e PVK:AZO em clorofórmio excitados em: a) 320 nm, b) 370 nm e c) $400 \mathrm{~nm}$.
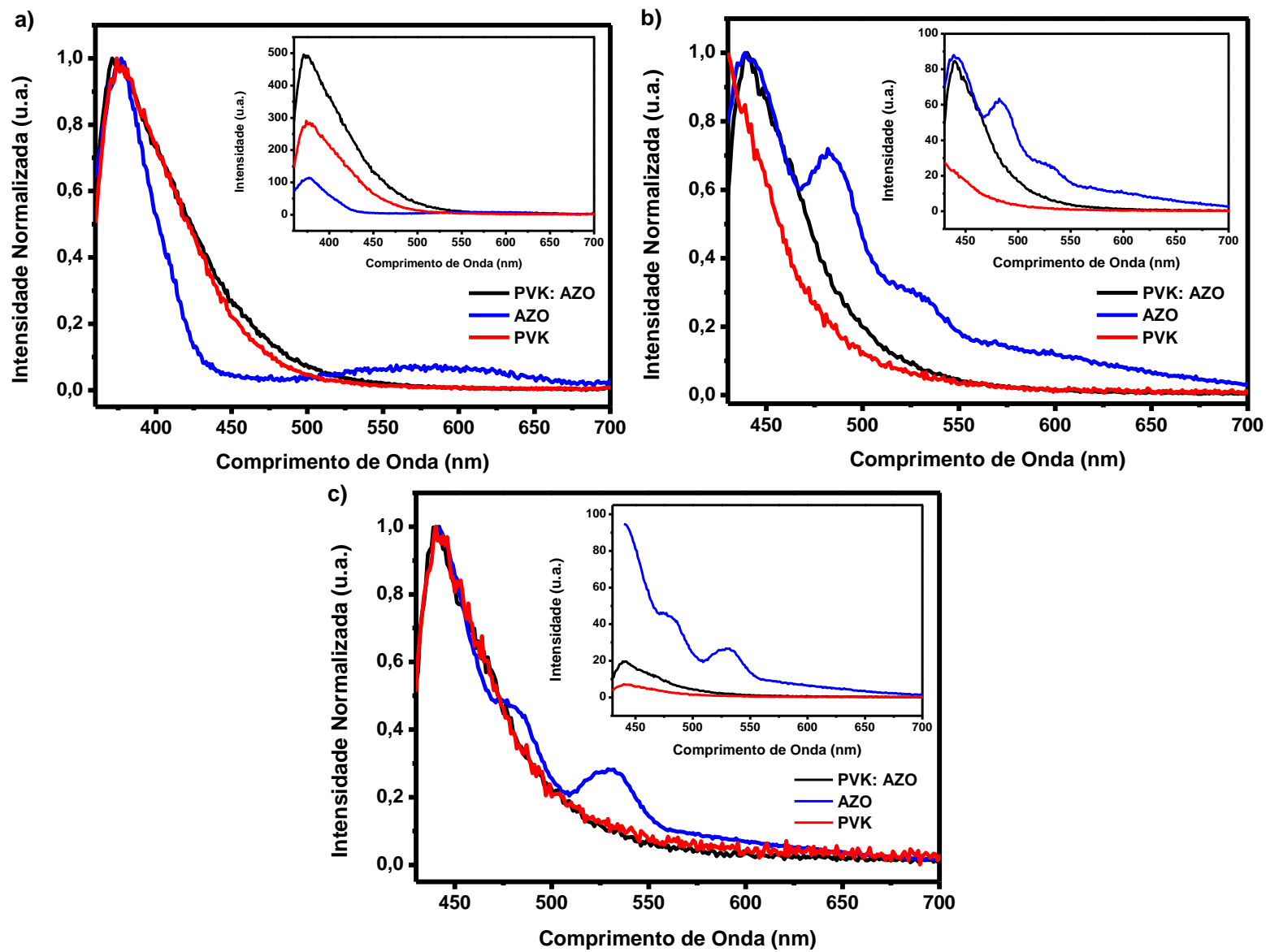

Fonte: Autoria própria.

Assim, com o objetivo de se observar o sentido da transferência de energia via Föster, espectros de absorção do AZO e de fotoluminescência do PVK excitado em $320 \mathrm{~nm}$ foram obtidos e apresentados na Figura 73 (a) enquanto que os espectros de absorção do PVK e de fotoluminescência do AZO excitado em $320 \mathrm{~nm}$ estão apresentados na Figura 73 (b). Conforme observado na Figura 73 (a), 0 espectro de emissão do AZO e o espectro de absorção do PVK, praticamente, não apresentaram sobreposição. Por outro lado, observando-se a Figura 73 (b), a sobreposição entre os espectros de absorção do AZO e de emissão do PVK foram 
maiores. $O \lambda_{\text {onset }}$ do AZO foi de $380 \mathrm{~nm}$. Assim, nos comprimentos de onda menores que este valor, o AZO começa apresentar absorção significativa. Como o PVK apresenta um pico de emissão em 337 nm, este comprimento de onda é absorvido pelo $A Z O$, sugerindo que a transferência de Föster possa ter ocorrido do PVK para o AZO, justificando o aumento no desempenho do dispositivo híbrido e da fotoluminescência da solução PVK:AZO.

Figura 73 - (a) Espectros de absorção do PVK diluído em clorofórmio e de fotoluminescência da solução diluída de $A Z O$ em clorofórmio excitado em $320 \mathrm{~nm}$. (b) Espectros de absorção do AZO diluído em clorofórmio e de fotoluminescência da solução diluída de PVK em clorofórmio excitado em $320 \mathrm{~nm}$
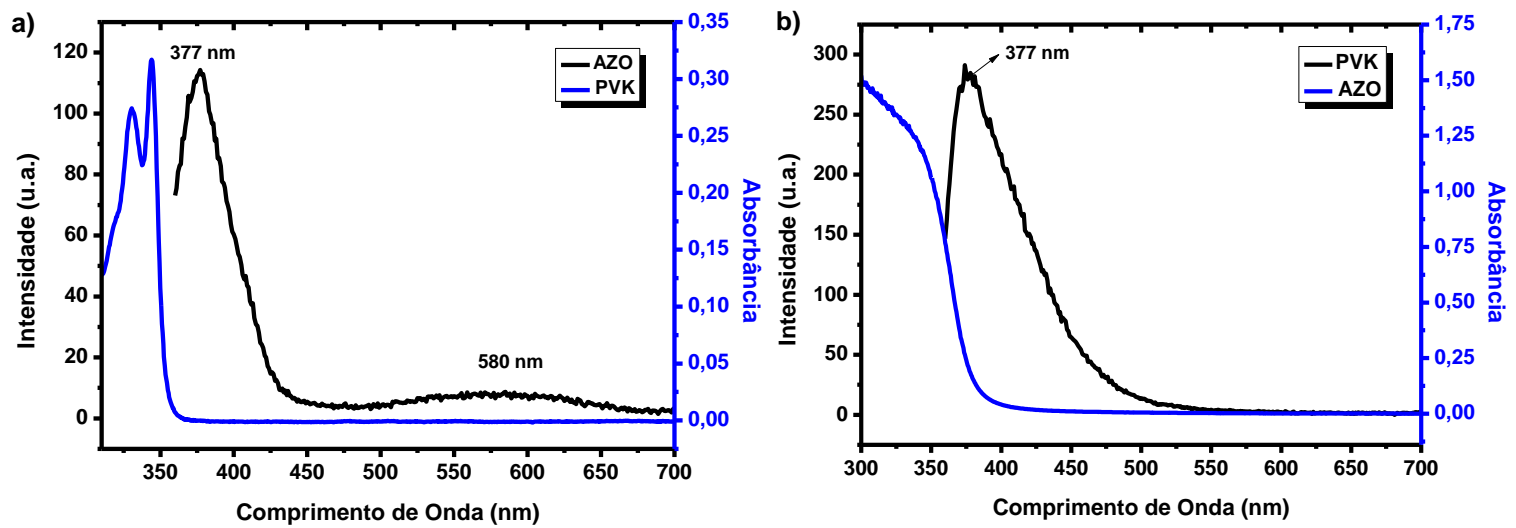

Fonte: Autoria própria.

Assim, o mecanismo sugerido para a transferência de energia entre o PVK e o AZO está esquematizado na Figura 74. Quando o sistema PVK:AZO é excitado em 320 nm, transições entre elétrons do HOMO e LUMO do PVK ocorrem com transferência de energia via Föster para o AZO e, por consequência, transições entre estados criados pelos defeitos no interior do bad gap do AZO ocorrem seguido de emissão de luz. 
Figura 74 - Esquematização do mecanismo sugerido para a transferência de energia entre PVK e AZO.

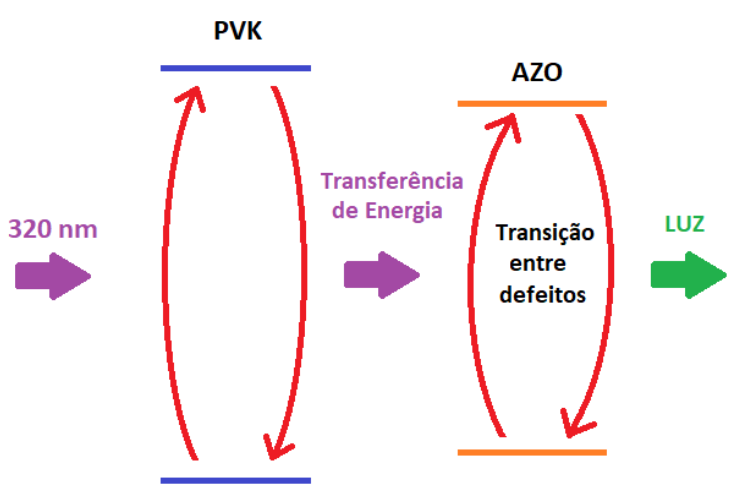

Fonte: Autoria própria.

\subsection{Eletroluminescência do sistema PVK:AZO}

A Figura 75 e a Figura 76 mostram as fotografias dos dispositivos distintos acesos separadamente que estão contidos na mesma lâmina. Conforme se pode observar, apesar da camada emissora ser composta por nanopartículas de AZO dispersas em uma matriz de PVK, a emissão de luz foi homogênea, cobrindo totalmente a área da camada emissora, indicando uma boa dispersão das nanopartículas na matriz polimérica. Entretanto, ocorreram variações na cor da luz emitida (azul, verde e branco) apesar dos dispositivos pertencerem à mesma lâmina conforme observados na Figura 75 e na Figura 76.

Figura 75 - Fotografias de diferentes dispositivos PVK:AZO acesos na mesma lâmina 1 durante a polarização.

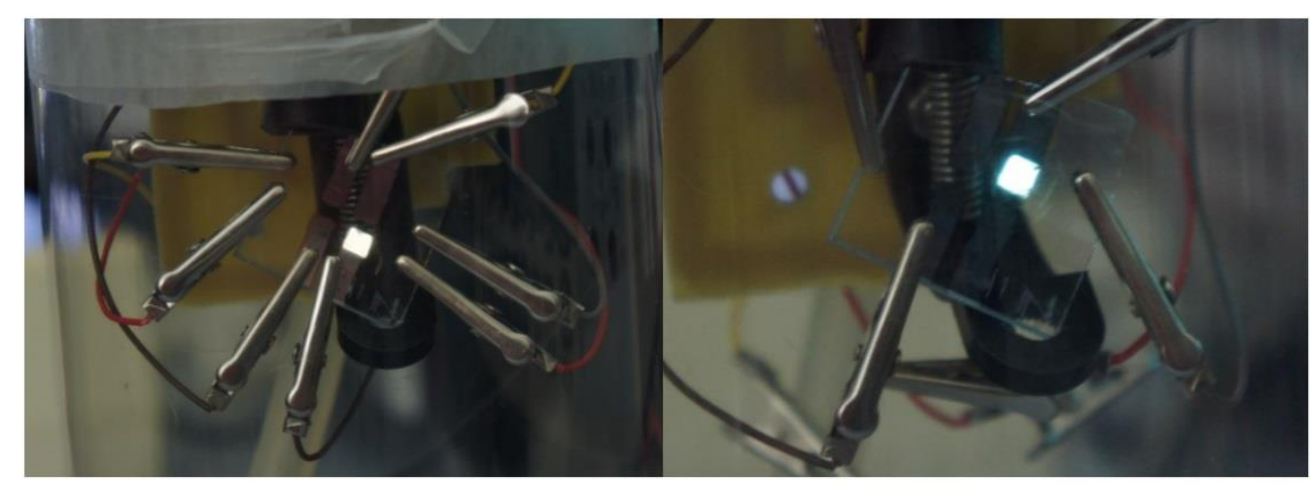

Fonte: Autoria própria. 
Figura 76 - Fotografias de diferentes dispositivos PVK:AZO acesos na mesma lâmina 2 durante a polarização.
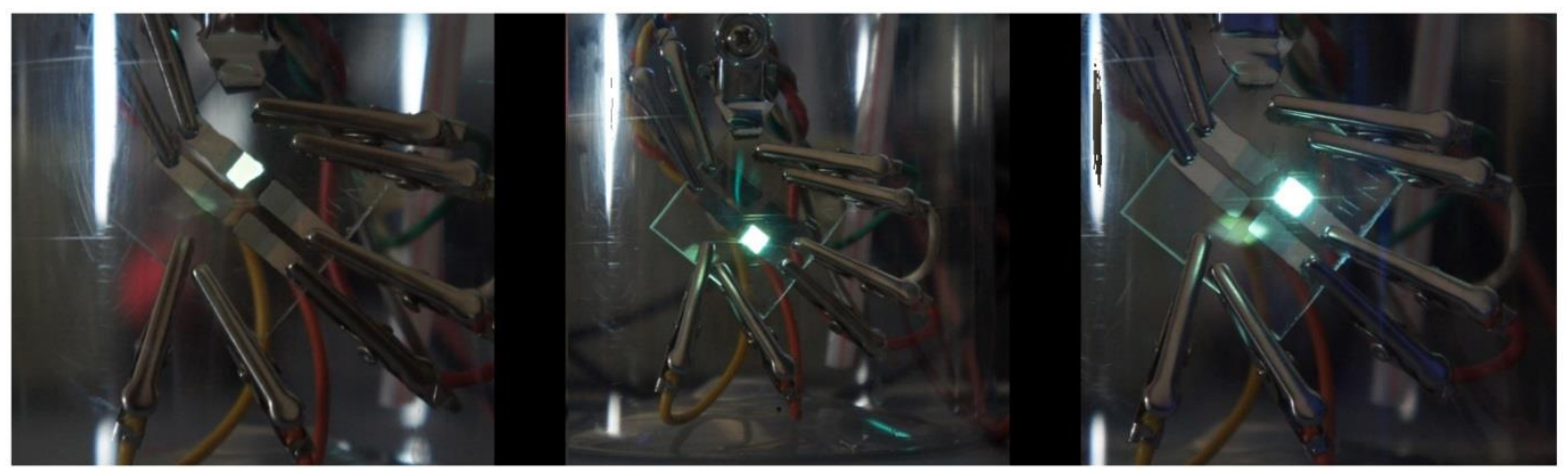

Fonte: Autoria própria.

A Figura 77 mostra os espectros de eletroluminescência obtidos para 0 mesmo dispositivo de PVK:AZO pertencentes às lâminas 1 e 2, respectivamente, em diferentes tensões. Pode-se observar que os espectro de eletroluminescência do PLED pertencente tanto à lâmina 1 quanto à lâmina 2 apresentaram uma banda de emissão entre $400 \mathrm{~nm}$ a $750 \mathrm{~nm}$. Entretanto, foi possível observar a existência de 3 picos ( $496 \mathrm{~nm}, 551 \mathrm{~nm}$ e $625 \mathrm{~nm}$ ) no espectro do PLED pertencente à lâmina 1 e, na lâmina 2, observou-se apenas 2 picos de emissão em 540 nm e 610 nm. Adicionalmente, o aumento na tensão aplicada não provocou "redshift" nos pontos de máximos dos espectros o que sugere que os éxcitons formados na camada emissora são constantes e as emissões resultantes bastante estáveis com o aumento da tensão aplicada.

Pode-se observar também que a intensidade relativa a maior emissão nos comprimento de onda 625 nm (lâmina 1) e 610 nm (lâmina 2) aumentou com o aumento da tensão. Entretanto, nos comprimentos de onda 496 nm (lâmina 1) e, 540 nm (lâmina 2) as variações foram insignificantes. Assim, sugere-se que os defeitos responsáveis pela emissão na região laranja-vermelho do espectro eletromagnético necessitam de maior energia para serem ativados, ao contrário das emissões nas regiões azul-verde conforme foi possível observar nos espectros de fotoluminescência excitados em diferentes comprimentos de onda apresentados na Seção 5.4 . 
Figura 77 - Influência da tensão aplicada no espectro de eletroluminescência no mesmo dispositivo da: a) lâmina 1 e b) lâmina 2.
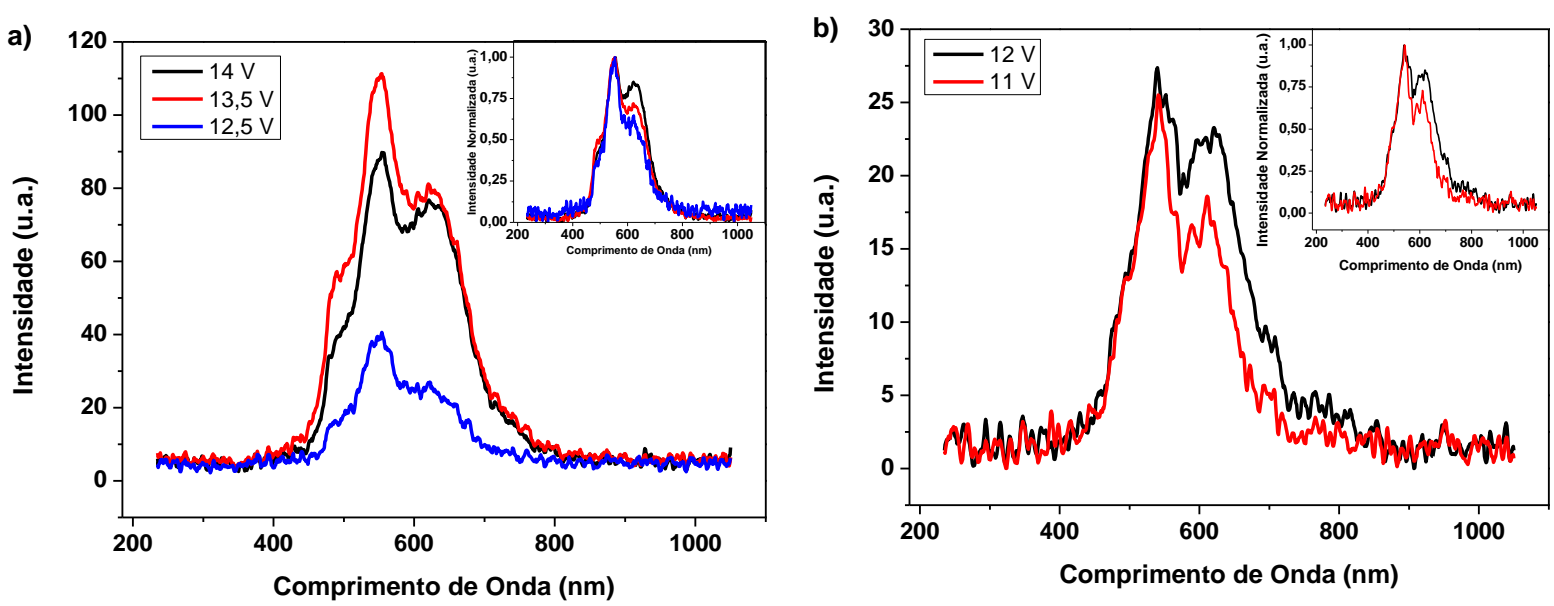

Fonte: Autoria própria.

Com o objetivo de identificar a origem das emissões eletroluminescentes obtidas experimentalmente, fez-se a deconvolução Gaussiana dos espectros coletados conforme apresentadas na Figura 78 e Figura 79.

Os espectros eletromagnéticos obtidos do dispositivo pertencente à lâmina 1 apresentaram cinco bandas de emissão nas três tensões aplicadas em $432 \mathrm{~nm}$ $440 \mathrm{~nm}$ (violeta-azul), $489 \mathrm{~nm}$ - $491 \mathrm{~nm}$ (azul-verde), $545 \mathrm{~nm}$ (verde-amarelo), 619 $\mathrm{nm}-626 \mathrm{~nm}$ (amarelo-laranja) e $740 \mathrm{~nm}-742 \mathrm{~nm}$ (vermelho). Enquanto que o dispositivo da lâmina 2 apresentou três bandas em 538 nm, 618 nm e 665 nm quando a tensão aplicada foi de $11 \mathrm{~V}$ e quatro bandas em $545 \mathrm{~nm}, 623 \mathrm{~nm}, 673 \mathrm{~nm}$ e $780 \mathrm{~nm}$ quando a tensão passou para $12 \mathrm{~V}$.

Nas duas lâminas produzidas, tanto a emissão em $420 \mathrm{~nm}$ correspondente ao PVK quanto o pico correspondente à transição entre a banda de condução e a banda de valência do AZO na região do UV não foram observados. Assim, a banda larga deve-se às transição entre os estados dos defeitos e as Tabela 20 e Tabela 21 foram montadas levando em consideração o comprimento de onda obtido pela deconvolução Gaussiana e as emissões observadas na literatura e suas respectivas origens.

Comparando-se os componentes Gaussianos obtidos nas lâminas 1 e 2 com os componentes dos espectros de fotoluminescência da solução diluída de AZO excitado em 320 e 380 nm (Figura 68), pode-se observar que as bandas de emissão 
são diferentes, sugerindo que os mecanismos de emissão de luz pelos defeitos envolvidos na eletroluminescência são diferentes dos mecanismos envolvidos na fotoluminescência.

Analisando-se os espectros deconvoluídos da lâmina 1, pode-se observar que os componentes Gaussianos para as três tensões aplicadas, praticamente, não sofreram alterações, exceto a banda em $619 \mathrm{~nm}$ que sofreu um deslocamento para $626 \mathrm{~nm}$ quando a tensão aplicada passou de $12,5 \mathrm{~V}$ para $13,5 \mathrm{~V}$ e $14 \mathrm{~V}$. Assim, sugere-se que o mecanismo envolvido na emissão na região laranja (619 nm) é modificada quando a tensão aplicada aumenta conforme pode ser observada na Tabela 20.

Figura 78 - Deconvolução dos espectros de eletroluminescência a: a) $12,5 \mathrm{~V}$; b) $13,5 \mathrm{~V}$ e c) $14 \mathrm{~V}$ para o mesmo dispositivo da lâmina 1.
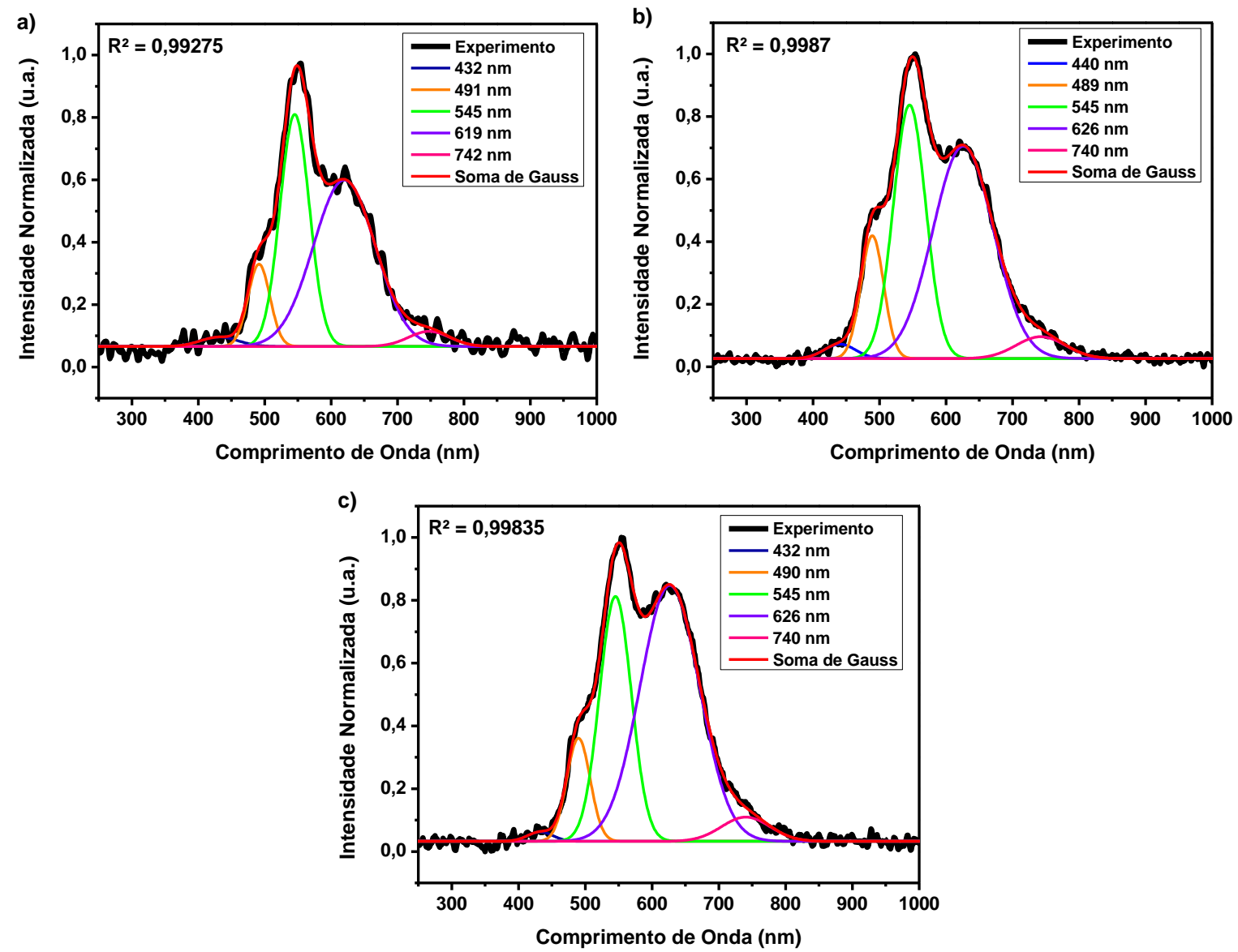

Fonte: Autoria própria. 
Tabela 20 - Origem sugerido para cada componente Gaussiano observado na lâmina 1.

\begin{tabular}{ccccc}
\hline $\begin{array}{c}\text { Componente } \\
\text { Gaussiano } \\
(\mathbf{n m})\end{array}$ & Estado Inicial & Estado final & Rota & Referência \\
\hline 432,440 & $\begin{array}{c}\text { Estados } \\
\text { estendidos do } \\
\mathrm{Zn}_{\mathrm{i}}\end{array}$ & $\mathrm{BV}$ & $\mathrm{B}$ & {$[77]$} \\
$489,490,491$ & $\mathrm{~V}_{\mathrm{o}}$ & $\mathrm{BV}$ & $\mathrm{B}$ & {$[26]$} \\
545 & $\mathrm{CB}$ & $\mathrm{O}_{\mathrm{i}}$ & $\mathrm{C}$ & {$[26]$} \\
619 & $\mathrm{Zn}$ & $\mathrm{O}$ & {$[55]$} \\
626 & $\mathrm{CB}$ & $\mathrm{O}_{\mathrm{i}}$ & $\mathrm{O}$ & {$[55]$} \\
740,742 & $\mathrm{~V}_{0}$ & $\mathrm{BV}$ & $\mathrm{B}$ & {$[73]$} \\
\hline
\end{tabular}

Fonte: Autoria própria.

Por outro lado, analisando-se os espectros deconvoluídos da lâmina 2, podese observar que os componentes Gaussianos variam significativamente com a tensão aplicada, indicando que o aumento da tensão ativa novos centros de recombinação, principalmente na região vermelha do espectro eletromagnético, fazendo com que uma banda em $780 \mathrm{~nm}$, na região do infra-vermelho próximo, aparecesse. Entretanto, na literatura, emissões fotoluminescentes nesta região não são observadas no ZnO. Assim, esta emissão pode ter se desenvolvido devido ao fato de que os mecanismos de emissão envolvidos na fotoluminescência e na eletroluminescência são diferentes conforme mencionado anteriormente. Portanto, a emissão em $780 \mathrm{~nm}$ foi atribuído à transição eletrônica entre $\mathrm{V}_{0}^{+}$para a banda de valência, que são responsáveis pela emissão no infra-vermelho próximo, fotoluminescência observada por $\mathrm{Xu}$ e colaboradores [71], e por Arya e colaboradores em $765 \mathrm{~nm}$ [78]. 
Figura 79 - Deconvolução dos espectros de eletroluminescência a: a) $11 \mathrm{~V}$ e b) $12 \mathrm{~V}$ para o mesmo dispositivo da lâmina 2.
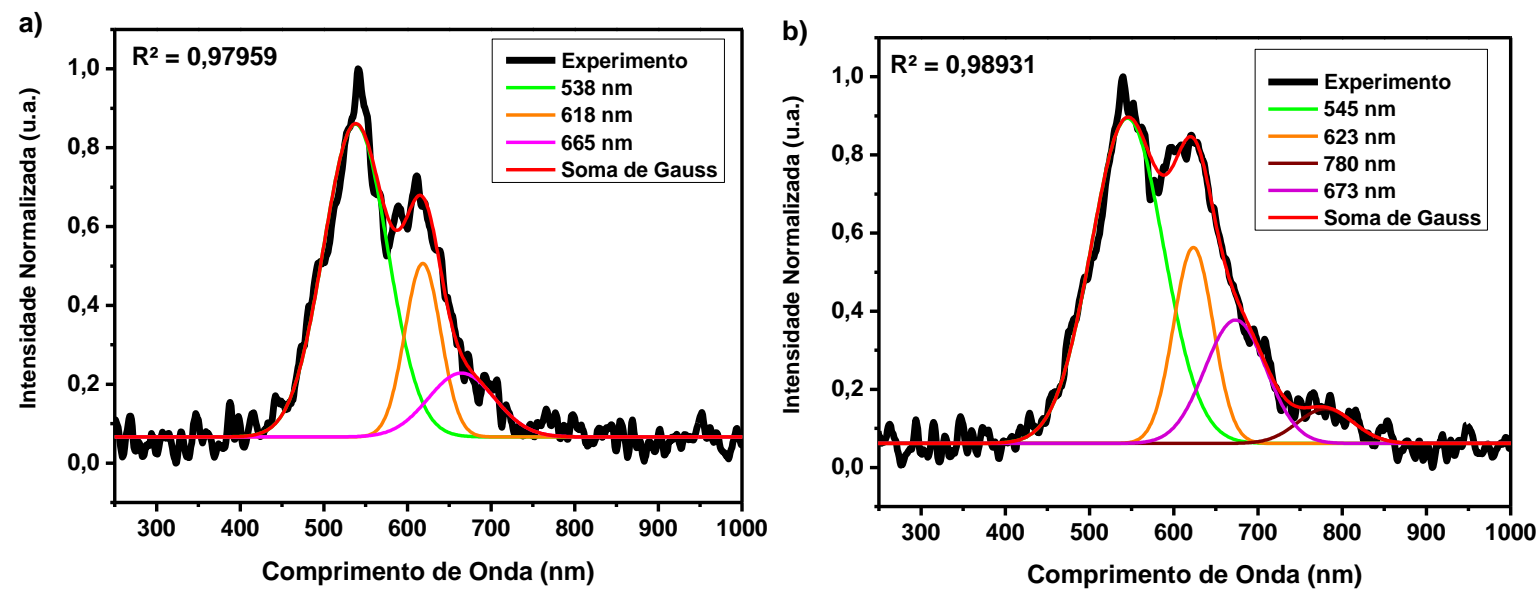

Fonte: Autoria própria.

Tabela 21 - Origem sugerido para cada componente Gaussiano observado na lâmina 2.

\begin{tabular}{ccccc}
\hline $\begin{array}{c}\text { Componente } \\
\text { Gaussiano (nm) }\end{array}$ & Estado Inicial & Estado final & Rota & Referência \\
\hline 538 & $\mathrm{~V}_{\mathrm{o}} \mathrm{Zn}_{\mathrm{i}}$ & $\mathrm{BV}$ & $\mathrm{B}$ & {$[62]$} \\
545 & $\mathrm{CB}$ & $\mathrm{O}_{\mathrm{i}}$ & $\mathrm{C}$ & {$[26]$} \\
545 & $\mathrm{Zn}_{\mathrm{i}}$ & $\mathrm{V}_{\mathrm{o}}$ & $\mathrm{D}$ & {$[55]$} \\
618 & $\mathrm{Zn}_{\mathrm{i}}$ & $\mathrm{O}_{\mathrm{i}}$ & $\mathrm{D}$ & {$[55]$} \\
$623,665,673$ & $\mathrm{CB}$ & $\mathrm{O}_{\mathrm{i}}$ & $\mathrm{C}$ & {$[55]$} \\
780 & $\mathrm{~V}_{\mathrm{o}}^{+}$ & $\mathrm{BV}$ & $\mathrm{B}$ & {$[26][55]$} \\
\hline
\end{tabular}

Fonte: Autoria própria.

Portanto, o mecanismo de emissão de luz proposto para os dispositivos contendo PVK:AZO como camada emissora está esquematizada na Figura 80 e cada rota descrita nesta esquematização, foi relacionada aos mecanismos da Tabela 20 e Tabela 21.

Quando se aplica uma diferença de potencial no PLED, os elétrons são facilmente injetados no LUMO do AZO e se eles tiverem energia suficiente para ultrapassar a barreira de 2,1 eV, serão injetados no LUMO do PVK. Por outro lado, as lacunas podem ser injetadas no HOMO do PVK ou diretamente nos estados 
criados pelos defeitos aceitadores, devido à menor barreira energética, ou no HOMO do AZO. Na rota (a), a recombinação ocorre no PVK e a energia é transferida do PVK para o AZO, provocando a inibição de sua emissão e o aumento da luminância do dispositivo híbrido conforme mostrado na Seção 5.3. Quando as cargas são injetadas no $\mathrm{AZO}$, a recombinação pode ocorrer entre um elétron capturado pelos defeitos doadores e uma lacuna na banda de valência (b) e/ou um elétron da banda de condução e uma lacuna injetada/capturada pelos defeitos aceitadores (c) e/ou um elétron capturado pelos defeitos doadores e uma lacuna injetada/capturada pelos defeitos aceitadores. Os comprimentos de ondas emitidos dependem dos tipos de defeitos que existem no interior do material e dos níveis das transições eletrônicas.

Figura 80 - Esquematização dos níveis de energia e do mecanismo de eletroluminescência dos dispositivos de PVK:AZO.

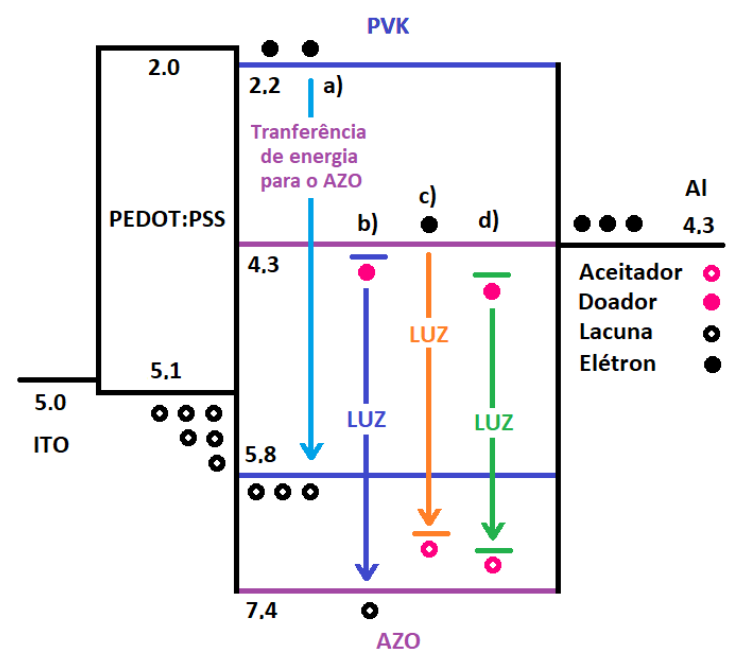

Fonte: Autoria própria.

\subsection{Dispositivos PMMA:AZO}

Com o objetivo de confinar cargas no AZO para se observar a sua emissão, dispositivos contendo PMMA:AZO como camada emissora foram produzidos. A Figura 81 mostra a curva $\mathrm{J} \times \mathrm{V}$ obtida para a quarta polarização e a fotografia do PLED aceso, sendo que a tensão de limiar foi de 1,6 V. Apesar da camada emissora do dispositivo produzido conter um polímero isolante (PMMA), o PLED apresentou emissão heterogênea na cor branca devido à agregação de nanopartículas de AZO. A eletroluminescência na cor branca foi observada porque o filme de PMMA formado 
era fino o suficiente para que cargas sofressem tunelamento e a recombinação entre elétrons e lacunas ocorressem nas partículas de AZO. Entretanto, este dispositivo se mostrou instável e com pouca luminância (não foi detectado pelo equipamento). Assim, pode-se inferir que nos dispositivos PVK:AZO, o PVK atuou também como injetor de lacunas, fazendo com que o balanceamento de cargas fosse melhorado.

Figura 81 - Curva $\mathrm{J}$ x V da quarta polarização e fotografia obtida do dispositivo aceso contendo PMMA:AZO como camada emissora.

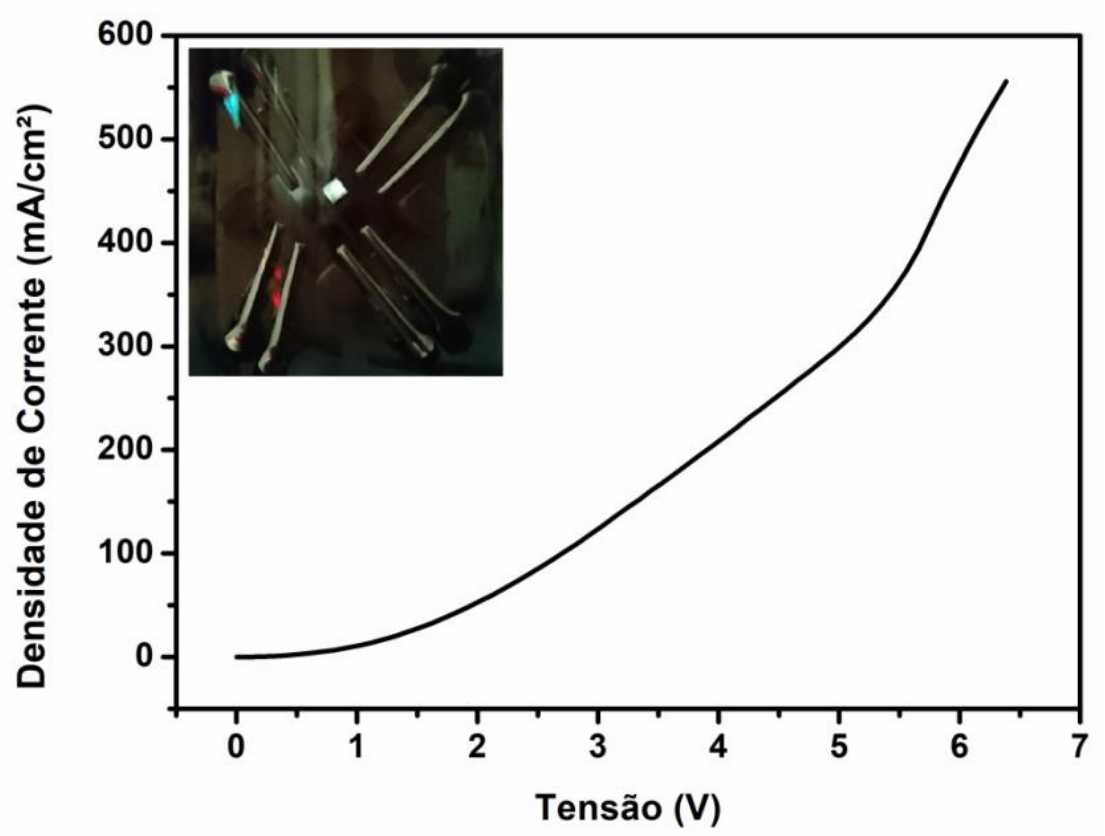

Fonte: Autoria própria.

Assim, a Figura 82 mostra a esquematização dos níveis de energia e do mecanismo sugerido para o processo de eletroluminescência dos PLEDs a base de PMMA:AZO. Conforme discutido em seções anteriores, o AZO, assim como o ZnO possui defeitos na sua estrutura cristalina, que podem possuir caráter doador ou aceitador de elétrons e criam estados de energia no interior de seu band gap. Quando cargas são injetadas respectivamente pelos seus eletrodos no interior da camada emissora, elétrons e lacunas podem ser capturados por estes estados, recombinarem e emitir luz em diferentes comprimentos de ondas de acordo com a origem destes defeitos. Na rota (a), o elétron é capturado por um defeito doador e este recombina com uma lacuna pertencente à banda de valência; em (b) uma lacuna é capturada por um defeito aceitador e se recombina com um elétron da 
banda de condução e, por fim, um defeito doador e um defeito aceitador podem capturar um elétron e uma lacuna das bandas de condução e de valência, respectivamente, e estas cargas capturadas podem se recombinar e emitir luz.

Assim, foi possível demonstrar que filmes contendo AZO podem ser depositados por spin-coating e originar dispositivos eletroluminescentes. Neste estudo, PLEDs híbridos a base de PVK:AZO foram obtidos e mostraram-se com as propriedades essenciais dos diodos emissores de luz.

Figura 82 - Esquematização dos níveis de energia e do mecanismo de eletroluminescência dos dispositivos de PMMA:AZO.

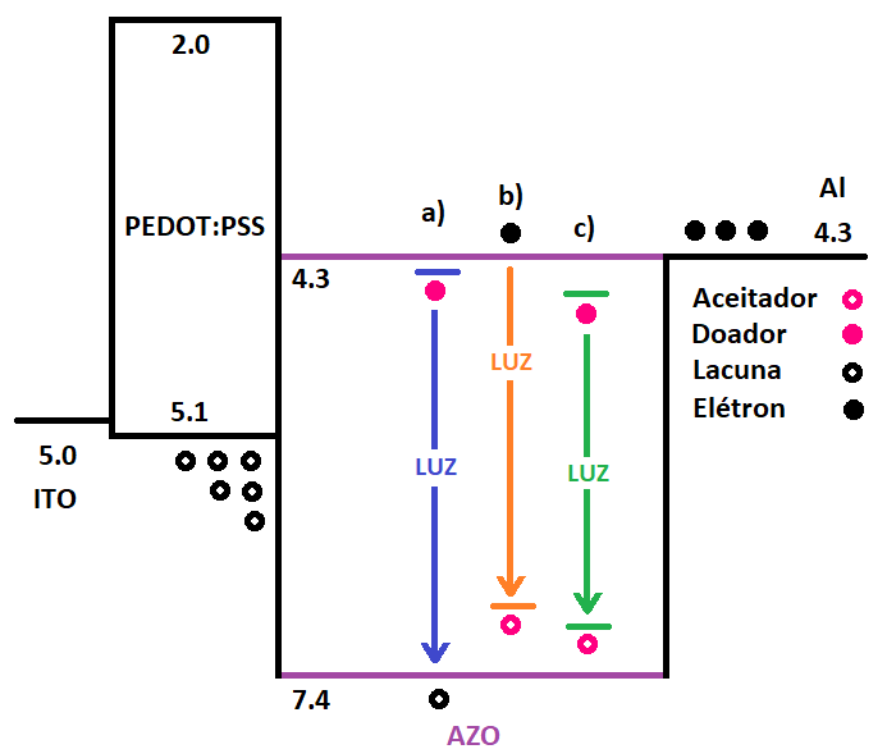

Fonte: Autoria própria. 


\section{Conclusões}

A partir do estudo envolvendo polímeros azuis dopados com $\operatorname{Ir}(\mathrm{ppy})_{3}$, pode-se concluir que tanto as curvas $\mathrm{J} \times \mathrm{V}$ quanto as tensões de limiar dos dispositivos produzidos praticamente não sofreram variações a partir da terceira polarização. $E$ ainda, as tensões de limiar de todos os dispositivos com a camada emissora dopada apresentaram tensões de limiar inferiores ao polímero puro. A adição de $\operatorname{Ir}(\mathrm{ppy})_{3}$ provocou a diminuição na densidade de corrente e nas tensões de limiar dos dispositivos à base de PVK, sugerindo que o dopante se comportou como centros de recombinações. Entretanto, para os dispositivos à base de $\mathrm{PFO}$ e $\mathrm{PF}_{\mathrm{PF}}$, este comportamento não foi observado, uma vez que a densidade de corrente não sofreu variações significativas para os PLEDs de PFO com a dopagem, enquanto que, para os PLEDs de PF $F_{P F}$ houve um aumento significativo na densidade de corrente.

A maior máxima luminância de $648,13 \mathrm{~cd} / \mathrm{m}^{2}(13 \mathrm{~V})$ foi obtida para 0 dispositivo à base de PFO dopado com $4 \%$ em massa de $\operatorname{Ir}(\mathrm{ppy})_{3}$ e ainda as maiores eficiências de corrente e de potência luminosa também foram obtidas para estes OLEDs, atingindo-se os valores máximos em 13,5 cd/A (7,5 V) e 5,6 Im/W (7 V). Entretanto, esperava-se que as maiores eficiências fossem obtidas nos dispositivos de PVK dopados, sugerindo-se um desbalanceamento de cargas na estrutura utilizada neste trabalho. Foi observado que a adição do complexo de Ir provocou um aumento nas eficiências, tanto de corrente quanto de potência luminosa, para os dispositivos de PVK e de PFO, entretanto, isso não foi observado para os dispositivos de PF PF. Para os dispositivos de PVK, a máxima luminância foi atingida com adição de $15 \%$ em massa de $\operatorname{Ir}(\mathrm{ppy})_{3}$, sendo o seu valor de $37,9 \mathrm{~cd} / \mathrm{A}$ $(9 \mathrm{~V})$. Entretanto, as maiores eficiências de corrente e de potência luminosa $(2,6$ $\mathrm{cd} / \mathrm{A}$ e $0,81 \mathrm{~lm} / \mathrm{W}$ a $10 \mathrm{~V}$ ) foram obtidas quando foi adicionado $5 \%$ em massa de dopante. Isso se deve ao fato de que grande quantidade de $\operatorname{Ir}(\mathrm{ppy})_{3}$ leva à formação de agregados e, por consequência, os processos de extinção de éxciton são favorecidos. Para os dispositivos baseados em $\mathrm{PF}_{\mathrm{PF}}$, a máxima luminância de 196,36 cd/A (10 V) foi obtida quando se adicionou $7 \%$ em massa de complexo de Ir. Contudo, as maiores eficiências de corrente e de potência luminosa $(8,2 \mathrm{~cd} / \mathrm{A}$ e 2,1 Im/W a $12,5 \mathrm{~V}$ ) foram obtidas para o polímero puro.

Conforme observado no diagrama de cromaticidade, todos os dispositivos emitiram luz na região verde do espectro eletromagnético, incluindo os PLEDs de 
PVK puro o que não foi condizente com o observado na literatura cuja emissão ocorre na região azul. As maiores purezas de cor foram obtidas nos PLEDs de PVK, sendo que o maior valor obtido foi de 0,87 quando se adicionou $10 \%$ em massa de $\operatorname{Ir}(\mathrm{ppy})_{3}(10 \mathrm{~V})$ enquanto que os dispositivos baseados em PFO e PF $F_{\mathrm{PF}}$ apresentaram, em média, pureza de 0,20 (7 V, $10 \mathrm{~V}$ e $13 \mathrm{~V})$. E ainda, observou-se que a tensão aplicada influencia significativamente na pureza da cor emitida, podendo ocorrer variações de até $103 \%$ (de $7 \mathrm{~V}$ para $13 \mathrm{~V}$ ) quando se adicionou 5 $\%$ em massa de dopante. Observou-se também que quanto maior a quantidade de $\operatorname{lr}(\mathrm{ppy})_{3}$, maior foi o redshift sofrido pelo comprimento de onda dominante, aproximando-se cada vez mais da região amarela do espectro eletromagnético. Para os dispositivos de PFO, o aumento da tensão provocou o aumento sucessivo na pureza de todos os PLEDs e um redshift do comprimento de onda dominante. Entretanto, este aumento foi tímido em relação aos dispositivos de PVK, obtendo-se variações de até $37,5 \%$ quando se adicionou $2 \%$ em massa de dopante (de $7 \mathrm{~V}$ para $13 \mathrm{~V}$ ). Além disso, o aumento da dopagem provocou a redução na pureza, atingindo-se uma redução de 56 \% com adição de 4 \% em massa de dopante, e o comprimento de onda dominante sofreu um redshift em relação ao PFO não dopado. Por fim, os dispositivos de $\mathrm{PF}_{\mathrm{PF}}$, quando dopado, apresentaram redução na pureza conforme o aumento da tensão aplicada, entretanto, os comprimento de onda sofreram um redshift. E ainda, conforme o aumento da proporção de $\operatorname{Ir}(\mathrm{ppy})_{3}$, os comprimentos de onda dominantes sofreram um blueshift para todas as tensões aplicadas.

Por fim, para os dispositivos baseados no PVK puro, o espectro de eletroluminescência apresentou uma banda larga entre $470 \mathrm{~nm}$ e $720 \mathrm{~nm}$ com um pico em torno de $530 \mathrm{~nm}$ a 6 V. A deconvolução Gaussiana possibilitou a observação de uma componente de baixa intensidade em $441 \mathrm{~nm}$, assim, a principal sugestão foi que a emissão do PVK ocorreu concomitantemente com a camada injetora e, por consequência, enfatizando o desbalanceamento de cargas neste tipo de estrutura. A adição de $\operatorname{Ir}(\mathrm{ppy})_{3}$ provocou o aparecimento de dois picos em torno de $510 \mathrm{~nm}$ e $540 \mathrm{~nm}$, emissão característica do dopante fosforescente utilizado e ainda, observou-se o estreitamento do espectro eletromagnético quando se adicionou $15 \%$ em massa de dopante para a mesma tensão aplicada. O espectro de eletroluminescência obtido a $6 \mathrm{~V}$ para o dispositivo de PFO puro apresentou 
quatro picos (425 nm, $445 \mathrm{~nm}, 495 \mathrm{~nm}$ e $558 \mathrm{~nm}$ ) característicos observados na literatura. A adição de $\operatorname{Ir}(\mathrm{ppy})_{3}$ provocou a diminuição nas intensidades relativas à maior intensidade relativos aos comprimentos de onda $425 \mathrm{~nm}$ e $445 \mathrm{~nm}$ e aumento nos comprimentos de onda $558 \mathrm{~nm}$ para a mesma tensão aplicada. A deconvolução permitiu a observação de um componente em torno de $511 \mathrm{~nm}$ para os dispositivos dopados, o que sugere a emissão do $\operatorname{Ir}(\mathrm{ppy})_{3}$ e que a transferência de energia entre o polímero e o dopante não foi eficiente. Para os dispositivos à base de $P_{P F}, 0$ espectro de eletroluminescência a $7 \mathrm{~V}$ apresentou quatro picos (425 nm, $438 \mathrm{~nm}$, $490 \mathrm{~nm}$ e $543 \mathrm{~nm}$ ). A adição do dopante fosforescente provocou a diminuição nas intensidades relativas à maior intensidade nos comprimentos de onda $425 \mathrm{~nm}$ e 438 $\mathrm{nm}$ e o aumento nos comprimentos de onda $543 \mathrm{~nm}$ para a mesma tensão aplicada. A partir da deconvolução Gaussiana, não foi possível observar nenhum componente que fosse compatível à emissão do $\operatorname{Ir}(\mathrm{ppy})_{3}$ para os dispositivos contendo a camada emissora dopada, entretanto, como foi possível observar a emissão nos comprimentos de ondas pertencentes ao $\mathrm{PF}_{\mathrm{PF}}$ independentemente da dopagem, então, sugere-se que a transferência de energia foi ineficiente.

Estudos da influência da massa molar média do PVK utilizado para a montagem do dispositivo mostram que o desbalanceamento de cargas se mantém, fazendo com que cargas sejam injetadas no AZO e provocando a sua emissão.

Dispositivos baseados no PVK puro apresentaram tensão de limiar em 8,1 V. $\mathrm{A}$ adição de $\mathrm{AZO}$ diminuiu este valor para $7,5 \mathrm{~V}$ devido ao fato de que as nanopartículas facilitam a injeção de carga no interior da camada emissiva. Além disso, o desempenho dos dispositivos híbridos foram superiores ao desempenho do dispositivo baseado no polímero puro, sendo que a máxima luminância e eficiência de corrente aumentaram de $5,86 \mathrm{~cd} / \mathrm{m}^{2}(10,5 \mathrm{~V})$ e $0,14 \mathrm{~cd} / \mathrm{A}(9,5 \mathrm{~V})$ para $18,69 \mathrm{~cd} / \mathrm{m}^{2}$ $(10 \mathrm{~V})$ e $0,46 \mathrm{~cd} / \mathrm{A}(10 \mathrm{~V})$, respectivamente. Os espectros de eletroluminescência dos dispositivos híbridos mostraram que a emissão larga na região do visível ocorreu devido à existência de defeitos no interior do AZO o que, por consequência, diminuiu a pureza da cor emitida de 0,24 para 0,19, aproximando-se do branco puro.

Os espectros de absorção e de fotoluminescência de PVK, AZO e PVK:AZO diluídos em clorofórmio mostraram que interações entre PVK e AZO com transferência de energia são responsáveis pelo aumento da eficiência dos dispositivos híbridos e da fotoluminescência da solução PVK:AZO. Além disso, foi 
possível observar a fotoluminescência do $\mathrm{AZO}$ na região do visível quando excitados em comprimentos de ondas superiores ao comprimento de onda de onset devido à formação de estados no interior de seu band gap criados defeitos pontuais intrínsecos e extrínsecos.

A partir dos resultados obtidos, mecanismos para a eletroluminescência dos defeitos do AZO foram sugeridos. Defeitos pontuais criam estados de energia no interior do band gap com caráter aceitador ou doador. Estes defeitos capturam elétrons e lacunas das bandas de condução e de valência, respectivamente, e recombinação pode ocorrer tanto nos níveis dos defeitos ou nas bandas de condução e de valência. Cada transição é responsável pela emissão em diferentes comprimentos de onda na região do visível (violeta ao vermelho próximo ao infravermelho).

Dispositivos de PMMA:AZO mostraram que o AZO possui propriedades eletroluminescentes, entretanto, de baixa eficiência e que o PVK funcionou como um injetor de lacunas no dispositivo híbrido PVK:AZO, aumentando o balanceamento de cargas e do desempenho do PLED.

Assim, o controle dos defeitos e a seleção da matriz polimérica são essenciais para o desenvolvimento de WPLEDs eficientes. 


\section{Referências}

[1] REINEKE, S. et al. White organic light-emitting diodes: Status and perspective. 2013.

[2] THEJO KALYANI, N.; DHOBLE, S. J. Organic light emitting diodes: Energy saving lighting technology -A review. Renewable and Sustainable Energy Reviews, v. 16, n. 5, p. 2696-2723, 2012.

[3] THEJOKALYANI, N.; DHOBLE, S. J. Novel approaches for energy efficient solid state lighting by RGB OLEDs - A review. Renewable and Sustainable Energy Reviews, v. 32, p. 448-467, 2014.

[4] FRIEND, R. H. et al. Electroluminescence in conjugated polymers. Nature, v. 397, n. 6715 , p. 121-128, 1999.

[5] CPD LED Course Notes LED Technology, Lifetime, Efficiency and Comparison. Disponível em: <https://www.cibse.org/getmedia/c41eb4e0-0c894b50-995c-d5d81ace1622/CPD-LED-Course-Hand-Out-Chris-B-Kris.pdf.aspx>. Acesso em: 11 dez. 2018.

[6] GEFFROY, B.; LE ROY, P.; PRAT, C. Organic light-emitting diode (OLED) technology: Materials, devices and display technologies. Polymer International, $v$. 55, n. 6, p. 572-582, 2006.

[7] WANG, J. et al. Key issues and recent progress of high efficient organic lightemitting diodes. Journal of Photochemistry and Photobiology C, v. 17, p. 69-104, 2013.

[8] CARTER, C. M. et al. Cost, energy and emissions assessment of organic polymer light-emitting device architectures. Journal of Cleaner Production, v. 137, p. 14181431, 2016.

[9] XU, F. et al. Progress and perspective of iridium-containing phosphorescent polymers for light-emitting diodes. Progress in Polymer Science, v. 47, p. 92-121, 2015.

[10] GEOGHEGAN, M.; HADZIIOANNOU, G. Polymer Eletronics. 1. ed. Croydon: Oxford University Press, 2013.

[11] ATKINS, P.; JONES, L. Princípios de Química: Questionando a Vida Moderna e o Maio Ambiente. 3. ed. São Paulo: Bookman, 2006.

[12] LOUDON, M. G. Organic Chemistry. 4. ed. [s.I.] Oxford University Press, 2002.

[13] BANERJI, A.; TAUSCH, M. W.; SCHERF, U. Classroom Experiments and Teaching Materials on OLEDs with Semiconducting Polymers. Educación Química, v. 24, n. 1, p. 17-22, 2013.

[14] STREetMAN, B. G.; BANERJEE, S. K. Solid State Electronic Devices. 6. ed. New Jersey: Pearson Prentice Hall, 2006.

[15] Chapter 7 Electrons in Atoms. - ppt download. Disponível em: $<$ http://slideplayer.com/slide/3369219/>. Acesso em: 11 dez. 2018.

[16] LAKOWICZ, J. R. Principles of Fluorescence Spectroscopy. 2 nd ed. New York: Kluwer Academic / Plenum Publishers, 1999. 
[17] BRÜTTING, W.; BERLEB, S.; MÜCKL, A. G. Device physics of organic lightemitting diodes based on molecular materials. Organic Electronics, v. 2, n. 1, p. 136, 2001.

[18] MENG, H.-F. Polymers Electronics. [s.I.] Pan Stanford Publishing, 2013.

[19] DIOUF, B. et al. Efficiency control in iridium complex-based phosphorescent light-emitting diodes. Advances in Materials Science and Engineering, v. 2012, 2012.

[20] YERSIN, H. Highly Efficient OLEDs with Phosphorescent Materials. Weinheim: Wiley-VCH, 2008.

[21] AIMABLE, A. et al. Comparison of two innovative precipitation systems for ZnO and Al-doped $\mathrm{ZnO}$ nanoparticle synthesis. Processing and Application of Ceramics, v. 4, n. 3, p. 107-114, 2010.

[22] DING, J. J.; CHEN, H. X.; MA, S. Y. The Al-doping and post-annealing treatment effects on the structural and optical properties of $\mathrm{ZnO}: \mathrm{Al}$ thin films deposited on $\mathrm{Si}$ substrate. Applied Surface Science, v. 256, n. 13, p. 4304-4309, 2010.

[23] JANOTTI, A.; VAN DE WALLE, C. G. Fundamentals of zinc oxide as a semiconductor. Reports on Progress in Physics, v. 72, n. 12, 2009.

[24] ZENG, H. et al. Blue luminescence of $\mathrm{ZnO}$ nanoparticles based on nonequilibrium processes: Defect origins and emission controls. Advanced Functional Materials, v. 20, n. 4, p. 561-572, 2010.

[25] DJURIIĆ, A. B.; NG, A. M. C.; CHEN, X. Y. ZnO nanostructures for optoelectronics: Material properties and device applications. Progress in Quantum Electronics, 2010.

[26] XU, X. et al. DEFECT-ORIGIN AND STABILITY OF VISIBLE EMISSION IN ZnO NANOPILLARS. Functional Materials Letters, v. 5, n. 3, p. 1240001, 2012.

[27] KARS DURUKAN, I. et al. Effects of annealing and deposition temperature on the structural and optical properties of AZO thin films. Journal of Materials Science: Materials in Electronics, v. 24, n. 1, p. 142-147, 2013.

[28] SANDEEP, K. M.; BHAT, S.; DHARMAPRAKASH, S. M. Structural defects and photoluminescence studies of sol-gel prepared $\mathrm{ZnO}$ and Al-doped $\mathrm{ZnO}$ films. Applied Physics A: Materials Science and Processing, v. 122, n. 11, p. 1-9, 2016.

[29] DAVENPORT, K. et al. Characterization of charge accumulation on multiple interfaces in phosphorescent organic light-emitting diodes. Organic Electronics: physics, materials, applications, v. 46, p. 166-172, 2017.

[30] LIANG, W. et al. A novel host material with high thermal stability for green electrophosphorescent device. Tetrahedron, v. 72, n. 11, p. 1505-1510, 2016.

[31] SONG, M. et al. High efficiency, solution-processed, red phosphorescent organic light-emitting diodes from a polymer doped with iridium complexes. Organic Electronics: physics, materials, applications, v. 10, n. 7, p. 1412-1415, 2009.

[32] HASSAN, M. U. et al. Charge trap assisted high efficiency in new polymer-blend based light emitting diodes. Nano Energy, v. 21, p. 62-70, 2016. 
[33] HOU, Q.; MENG, F.; SUN, J. Electrical and optical properties of Al-doped ZnO and $\mathrm{ZnAl} 2 \mathrm{O} 4$ films prepared by atomic layer deposition. Nanoscale Research Letters, v. 8, n. 1, p. 1-8, 2013.

[34] How to do a sol-gel coating using spin-coating technique? Disponível em: $<$ https://www.spincoating.com/en/featured-items/how-to-do-a-sol-gel-coating-usingspin-coating-technique/205/>. Acesso em: 25 dez. 2017.

[35] Keithley 2400 SourceMeter SMU Instruments | Tektronix. Disponível em: $<$ https://www.tek.com/keithley-source-measure-units/keithley-smu-2400-seriessourcemeter>. Acesso em: 11 dez. 2018.

[36] Introduction - KONICA MINOLTA Europe. Disponível em: $<$ https://www.konicaminolta.eu/en/measuring-instruments/products/light-displaymeasurement/luminance-colour-meters/cs-200/introduction.html>. Acesso em: 11 dez. 2018.

[37] CHEN, F. C. et al. Energy transfer and triplet exciton confinement in polymeric electrophosphorescent devices. Journal of Polymer Science, Part B: Polymer Physics, v. 41, n. 21, p. 2681-2690, 2003.

[38] File:CIExy1931.svg - Wikipedia.

Disponível em:

<https://en.wikipedia.org/wiki/File:ClExy1931.svg\#filehistory>. Acesso em: $11 \mathrm{dez}$. 2018.

[39] BEN, M. et al. Hole injection and transport in ITO / PEDOT / PVK / Al diodes. Materials Science, v. 21, p. 277-282, 2002.

[40] Luzchem. Disponível em:

$<$ https://www.luzchem.com/ProductDetails.php?product_line_ID=5\&product_ID=20>. Acesso em: 11 dez. 2018.

[41] SCHERF, U.; NEHER, D. Advances in Polymer Science: Polyfluorenes. New York: Springer, 2008.

[42] GAO, Z. et al. Carrier transfer and luminescence characteristics of concentrationdependent phosphorescent $\operatorname{Ir}(\mathrm{ppy}) 3$ doped CBP film. Optics and Laser Technology, v. 56, p. 20-24, 2014.

[43] DUMUR, F. Carbazole-based polymers as hosts for solution-processed organic light-emitting diodes: Simplicity, efficacy. Organic Electronics: physics, materials, applications, v. 25, p. 345-361, 2015.

[44] efg's Chromaticity Diagrams Lab Report. Disponível em:

<http://www.efg2.com/Lab/Graphics/Colors/Chromaticity.htm>. Acesso em: $11 \mathrm{dez}$. 2018.

[45] KANG, M. K.; MOON, D. G. Highly efficient phosphorescent white organic lightemitting devices with a poly( $\mathrm{N}$-vinylcarbazole) host layer. Transactions on Electrical and Electronic Materials, v. 12, n. 2, p. 80-83, 2011.

[46] YE, T.; CHEN, J.; MA, D. Electroluminescence of poly(N-vinylcarbazole) films: fluorescence, phosphorescence and electromers. Physical Chemistry Chemical Physics, v. 12, n. 47, p. 15410-15413, 2010. 
[47] TU, M.-L. et al. Violet electroluminescence from poly( $\mathrm{N}$-vinylcarbazole $) / \mathrm{ZnO}$ nanorod composite polymer light-emitting diode. Synthetic Metals, v. 161, p. 450454, 2011.

[48] ARAUJO, K. A. S. et al. Avoiding trap states in poly(n-vinylcarbazole) thin films. Organic Electronics, v. 13, p. 2843-2849, 2012.

[49] QIAN, L.; BERA, D.; HOLLOWAY, P. H. Electrophosphorescence from triplet excimers in poly-(N-vinylcarbazole). Applied Physics Letters, 2007.

[50] XU, X. et al. Achievement of complete electromer emission in organic lightemitting diodes. Journal of Luminescence, v. 136, p. 208-211, 2013.

[51] SOON-KI, K. et al. The efficient green emitting iridium ( III ) complexes and phosphorescent organic light emitting diode characteristics. In: MAZZEO, M. (Ed.). . Organic Light Emitting Diode. [s.I.] InTech, 2010. p. 25-42.

[52] LEE, C. Y. et al. White light electroluminescence from ZnO nanorods polyfluorene by solution based growth. Nanotechnology, v. 20, p. 1-5, 2009.

[53] SCHERF, U.; LIST, E. J. W. Semiconducting polyfluorenes - Towards reliable structure-property relationships. Advanced Materials, v. 14, n. 7, p. 477-487, 2002.

[54] VEMPATI, S.; MITRA, J.; DAWSON, P. One-step synthesis of ZnO nanosheets: a blue-white fluorophore. Nanoscale Research Letters, v. 7, p. 470, 2012.

[55] ALVI, N. H. et al. The origin of the red emission in n-zno nanotubes/p-gan white light emitting diodes. Nanoscale Research Letters, v. 6, n. 1, p. 130, 2011.

[56] CHANDRINOU, C. et al. PL study of oxygen defect formation in ZnO nanorods. Microelectronics Journal, v. 40, n. 2, p. 296-298, 2009.

[57] LIU, D. et al. Defect-related photoluminescence and photocatalytic properties of porous ZnO nanosheets. Journal of Materials Chemistry A, v. 2, n. 37, p. 15377, 2014.

[58] CHAN, Y. F. et al. Electroluminescence from ZnO-nanofilm/Si-micropillar heterostructure arrays. Optics Express, v. 20, n. 22, p. 24280, 2012.

[59] KONDAL, N.; TIWARI, S. K. Origin of polychromatic emission and defect distribution within annealed $\mathrm{ZnO}$ nanoparticles. Materials Research Bulletin, v. 88, p.156-165, 2017.

[60] AMIRUDDIN, R.; KUMAR, M. C. S. Epitaxial growth of vertically aligned highly conducting $\mathrm{ZnO}$ nanowires by modified aqueous chemical growth process. Ceramics International, v. 40, n. 7, p. 11283-11290, 2014.

[61] LEUNG, Y. H. et al. Green emission in ZnO nanostructures - Examination of the roles of oxygen and zinc vacancies. Applied Surface Science, v. 271, p. 202-209, 2013.

[62] SRINATHA, N. et al. Spin-coated Al-doped ZnO thin films for optical applications: Structural, micro-structural, optical and luminescence studies. Journal of Alloys and Compounds, v. 722, p. 888-895, 2017.

[63] SPADONI, A.; ADDONIZIO, M. L. Effect of the RF sputtering power on microstructural, optical and electrical properties of Al doped $\mathrm{ZnO}$ thin films. Thin Solid Films, v. 589, p. 514-520, 2015. 
[64] NGUYEN, T. P. Polymer-based nanocomposites for organic optoelectronic devices. A review. Surface and Coatings Technology, v. 206, n. 4, p. 742-752, 2011.

[65] MADHAVA RAO, M. V. et al. Electroluminescent characteristics of DBPPV-ZnO nanocomposite polymer light emitting devices. Nanoscale Research Letters, v. 4, n. 5, p. 485-490, 2009.

[66] KUMAR, V. et al. Origin of the red emission in zinc oxide nanophosphors. Materials Letters, v. 101, p. 57-60, 2013.

[67] KURBANOV, S. S. et al. Effect of ambient conditions on a violet emission band from ZnO nanorods. Journal of Luminescence, v. 197, p. 159-163, 2018.

[68] KUMARI, C.; PANDEY, A.; DIXIT, A. Zn interstitial defects and their contribution as efficient light blue emitters in $\mathrm{Zn}$ rich $\mathrm{ZnO}$ thin films. Journal of Alloys and Compounds, v. 735, p. 2318-2323, 2018.

[69] LIN, L. et al. Correlation between native defects and morphological, structural and optical properties of $\mathrm{ZnO}$ nanostructures. Journal of Alloys and Compounds, v. 695 , p. 1523-1527, 2017.

[70] P R, C.; THERESA JOHN, T. The influence of vacuum and annealing on the visible luminescence in $\mathrm{ZnO}$ nanoparticles. Journal of Luminescence, v. 185, p. 212-218, 2017.

[71] XU, L. et al. Stable co-emission of UV, green and red light in $\mathrm{ZnO}$ thin films with rapid annealing treatment. Optik, v. 127, n. 15, p. 5942-5949, 2016.

[72] CUI, L. et al. Effect of annealing temperature and annealing atmosphere on the structure and optical properties of $\mathrm{ZnO}$ thin films on sapphire $\left(\begin{array}{llll}0 & 0 & 0 & 1\end{array}\right)$ substrates by magnetron sputtering. Applied Surface Science, v. 258, n. 7, p. 2479-2485, 2012.

[73] SINGH, C. C.; PANDA, E. Zinc interstitial threshold in Al-doped ZnO film: Effect on microstructure and optoelectronic properties. Journal of Applied Physics, v. 123, n. 16, 2018.

[74] CHOI, S. S. et al. High photo- and electroluminescence efficiencies of ladder-like structured polysilsesquioxane with carbazole groups. Journal of Materials Chemistry, v. 20, n. 44, p. 9852-9854, 2010.

[75] SONONE, R. S.; RAUT, V. M.; MURHEKAR, G. H. Structural and Electroluminescence Properties of Pure PVK and Doped Tio 2 polymer Thin Films. International Journal of Advanced Research in Chemical Science, v. 1, n. 1, p. 87-94, 2014.

[76] BELHAJ, M.; DRIDI, C.; ELHOUICHET, H. PFE: ZnO hybrid nanocomposites for OLED applications: Fabrication and photophysical properties. Journal of Luminescence, v. 157, p. 53-57, 2015.

[77] SANDEEP, K. M.; BHAT, S.; DHARMAPRAKASH, S. M. Structural , optical , and LED characteristics of $\mathrm{ZnO}$ and $\mathrm{Al}$ doped $\mathrm{ZnO}$ thin films. Journal of Physical and Chemistry of Solids, v. 104, p. 36-44, 2017.

[78] ARYA, S. K. et al. Effect of Variable Oxidation States of Vanadium on the Structural, Optical, and Dielectric Properties of $\mathrm{B}_{2} \mathrm{O}_{3}-\mathrm{Li}_{2} \mathrm{O}-\mathrm{ZnO}-\mathrm{V}_{2} \mathrm{O}_{5}$ Glasses. Journal of Physical Chemistry B, v. 120, p. 12168-12176, 2016. 


\section{Anexos}

\subsection{Curvas $\mathrm{J} \times \mathrm{V}$ para diferentes números de polarizações}

Figura 83 - Influência da polarização na curva J x V do dispositivo de PVK com adição de 5 \% em massa de dopante.

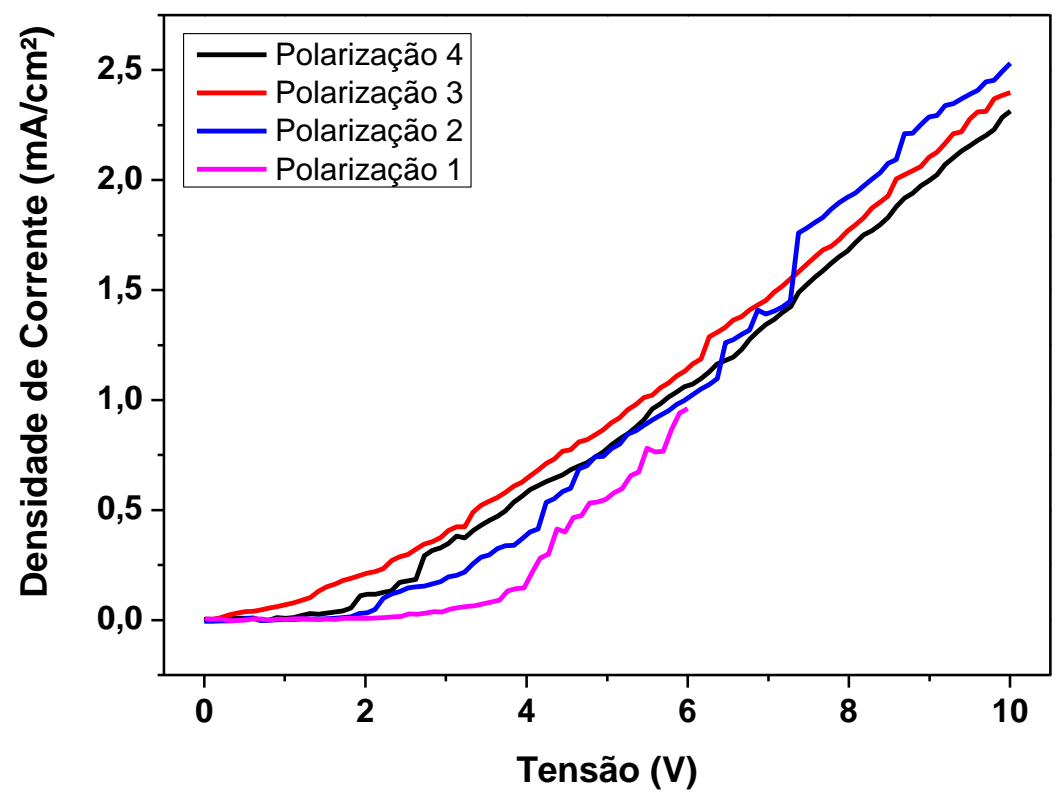

Fonte: Autoria própria.

Figura 84 - Influência da polarização na curva J x V do dispositivo de PVK com adição de 10 \% em massa de dopante.

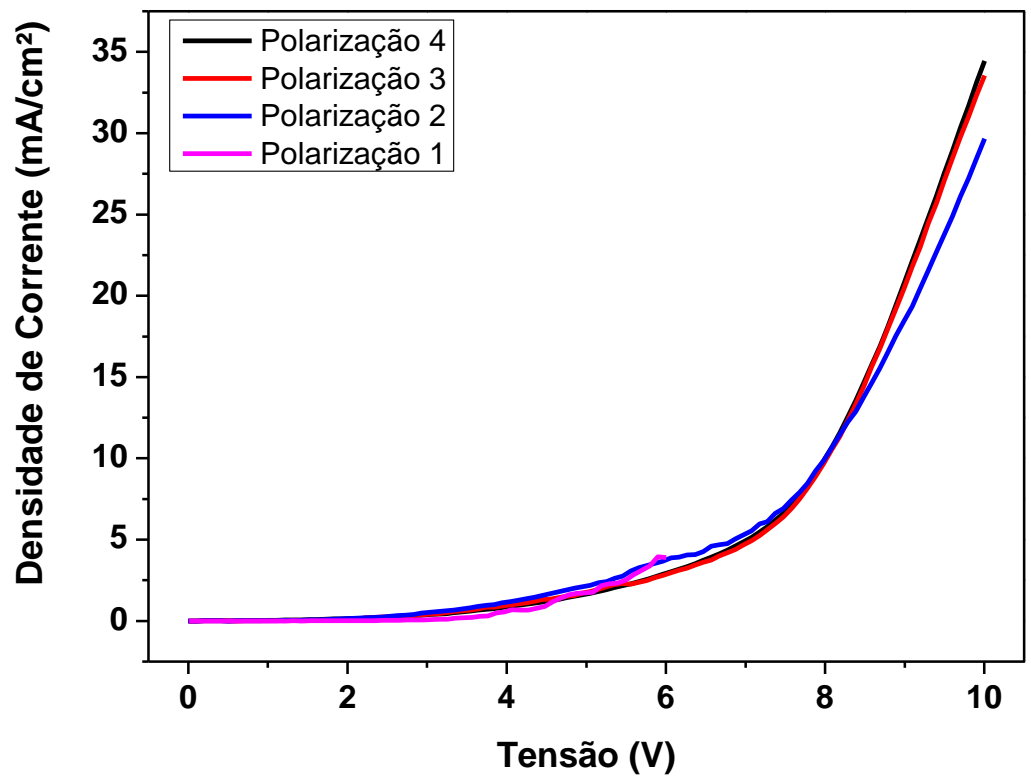

Fonte: Autoria própria. 
Figura 85 - Influência da polarização na curva J x V do dispositivo de PVK com adição de 15 \% em massa de dopante.

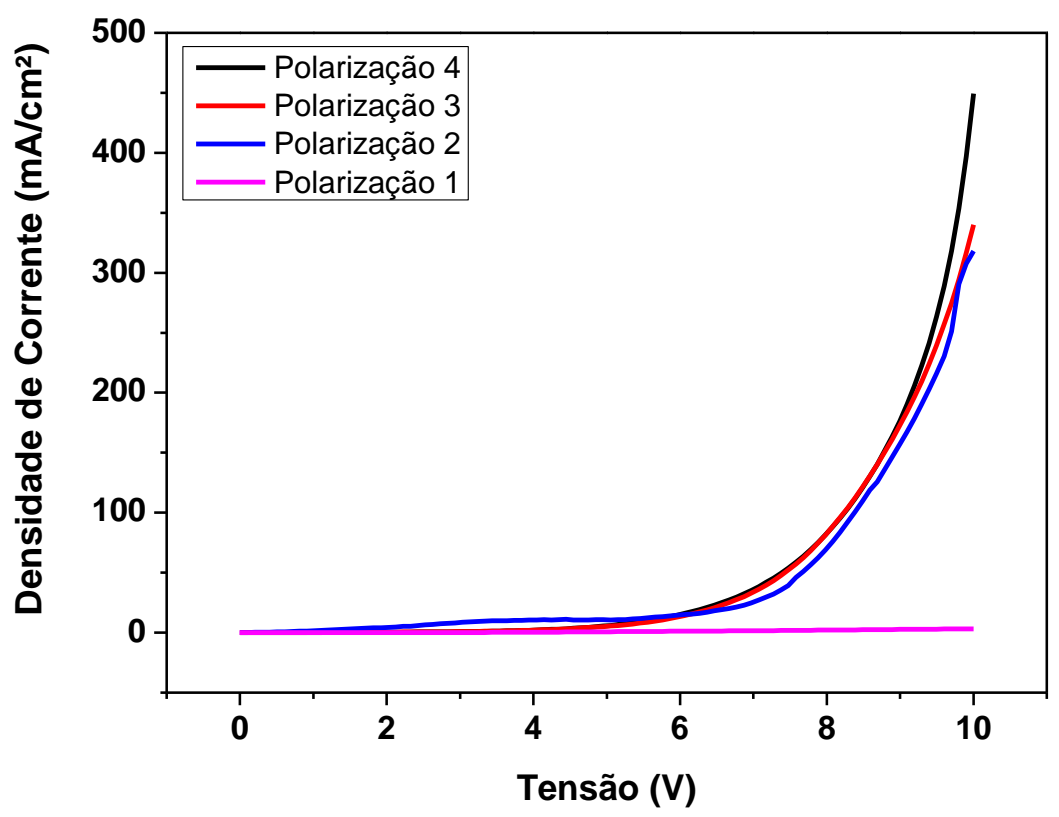

Fonte: Autoria própria.

Tabela 22 - Influência da polarização na tensão de limiar dos dispositivos de PVK.

Tensão de Limiar (V)

\begin{tabular}{ccccc} 
PVK:Ir(ppy) & Polarização 1 & Polarização 2 & Polarização 3 & Polarização 4 \\
\hline 95:5 & 3,7 & 2,7 & 2,3 & 2,3 \\
90:10 & 4,0 & 7,2 & 7,5 & 7,4 \\
85:15 & 3,4 & 7,4 & 7,4 & 7,4 \\
\hline
\end{tabular}

Fonte: Autoria própria. 
Figura 86 - Influência da polarização na curva $\mathrm{J}$ x $\mathrm{V}$ do dispositivo de PFO com adição de 2 \% em massa de dopante.

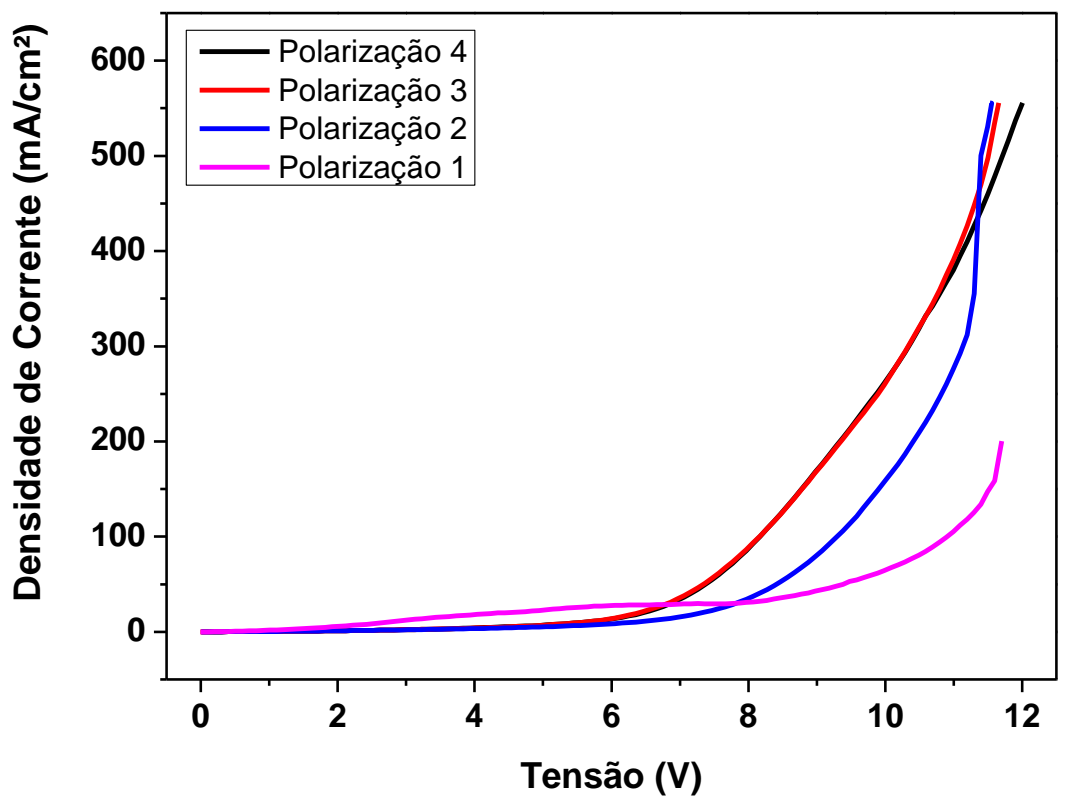

Fonte: Autoria própria.

Figura 87 - Influência da polarização na curva $\mathrm{J}$ x $\mathrm{V}$ do dispositivo de PFO com adição de 4 \% em massa de dopante.

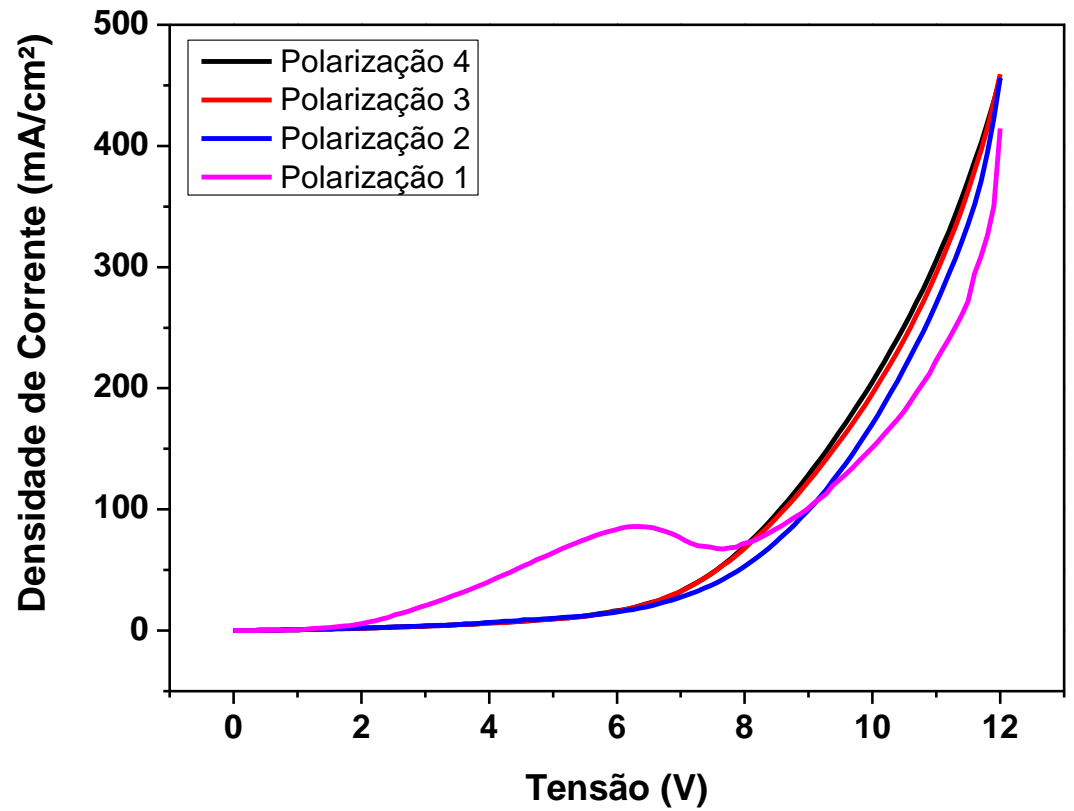

Fonte: Autoria própria. 
Figura 88 - Influência da polarização na curva J x V do dispositivo de PFO com adição de 7 \% em massa de dopante.

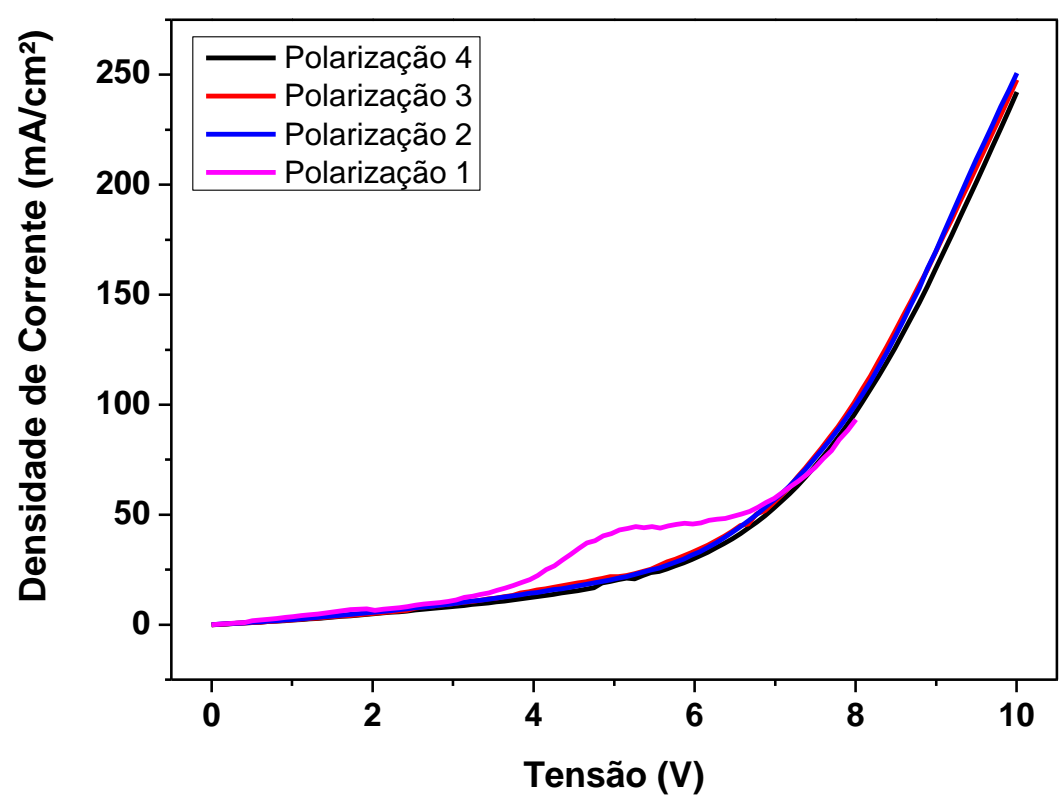

Fonte: Autoria própria.

Tabela 23 - Influência da polarização na tensão de limiar dos dispositivos de PFO.

Tensão de Limiar (V)

\begin{tabular}{ccccc}
\hline PFO:Ir(ppy) & Polarização 1 & Polarização 2 & Polarização 3 & Polarização 4 \\
\hline $\mathbf{9 8 : 2}$ & 9,9 & 8,3 & 7,1 & 7,1 \\
$96: 4$ & 9,2 & 8,3 & 7,2 & 7,1 \\
$93: 7$ & 5,7 & 7,1 & 6,8 & 6,7 \\
\hline
\end{tabular}

Fonte: Autoria própria. 
Figura 89 - Influência da polarização na curva $\mathrm{J}$ x $\mathrm{V}$ do dispositivo de $\mathrm{PF}_{\mathrm{PF}}$ com adição de 2 \% em massa de dopante.

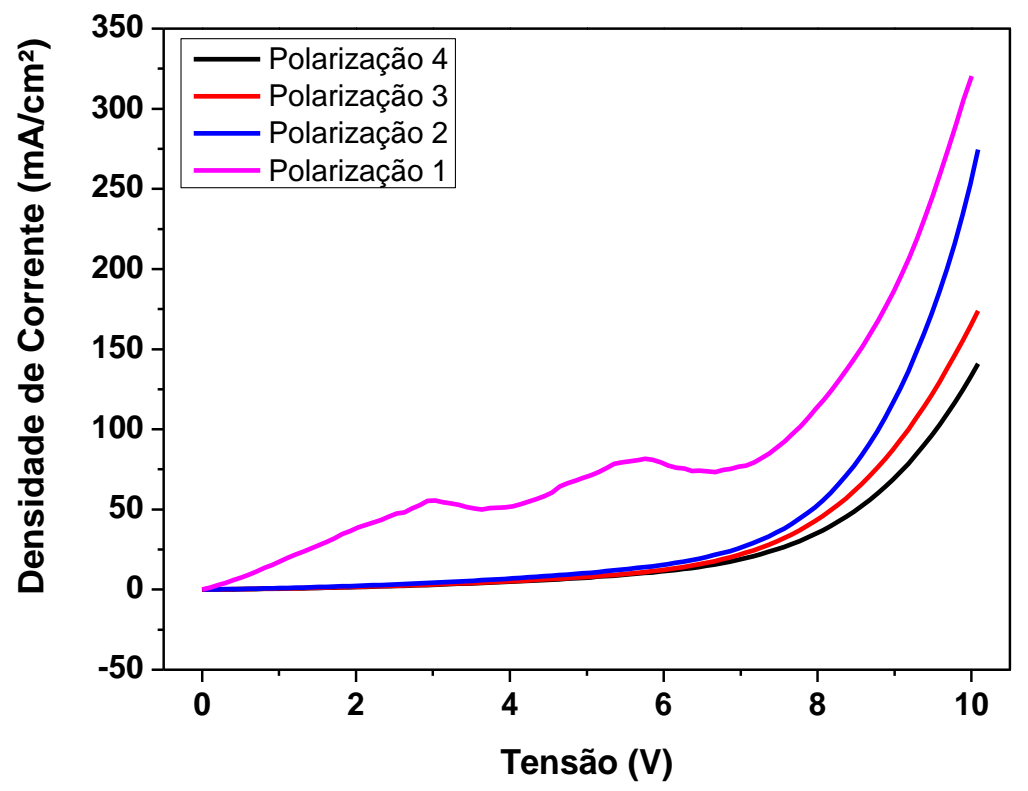

Fonte: Autoria própria.

Figura 90 - Influência da polarização na curva $\mathrm{J} \times \mathrm{V}$ do dispositivo de $\mathrm{PF}_{\mathrm{PF}}$ com adição de 4 \% em massa de dopante.

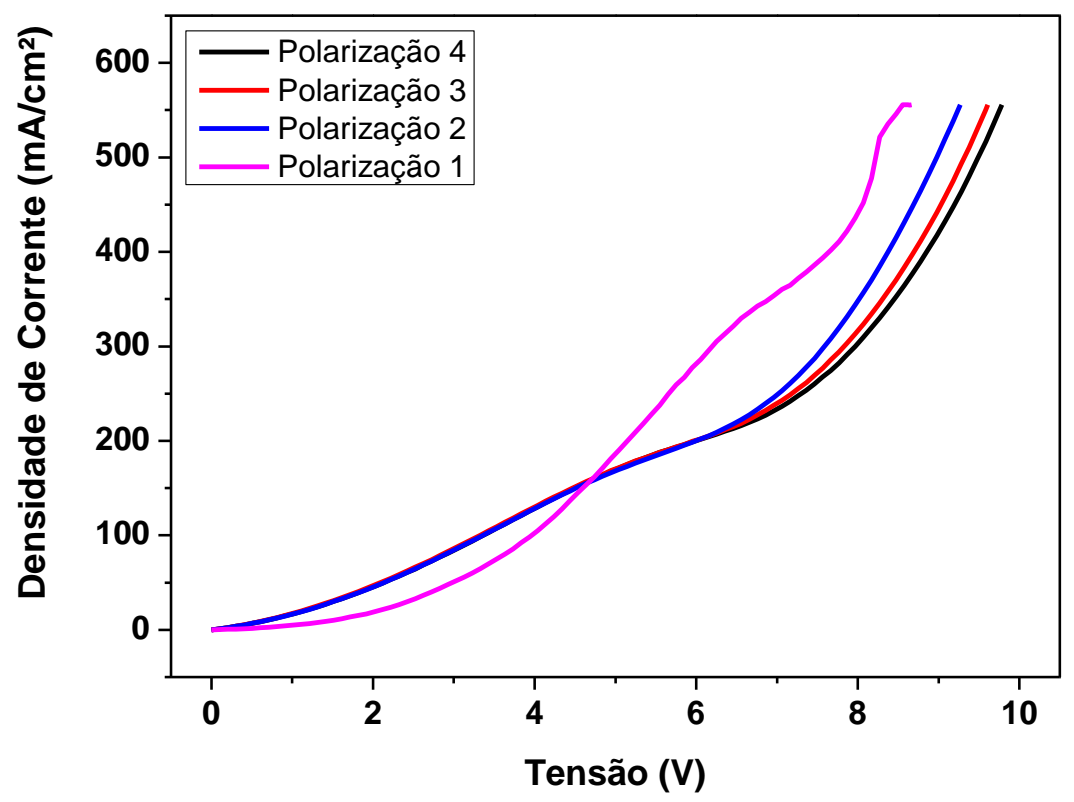

Fonte: Autoria própria. 
Figura 91 - Influência da polarização na curva $\mathrm{J}$ x $\mathrm{V}$ do dispositivo de $\mathrm{PF}_{\mathrm{PF}}$ com adição de 7 \% em massa de dopante.

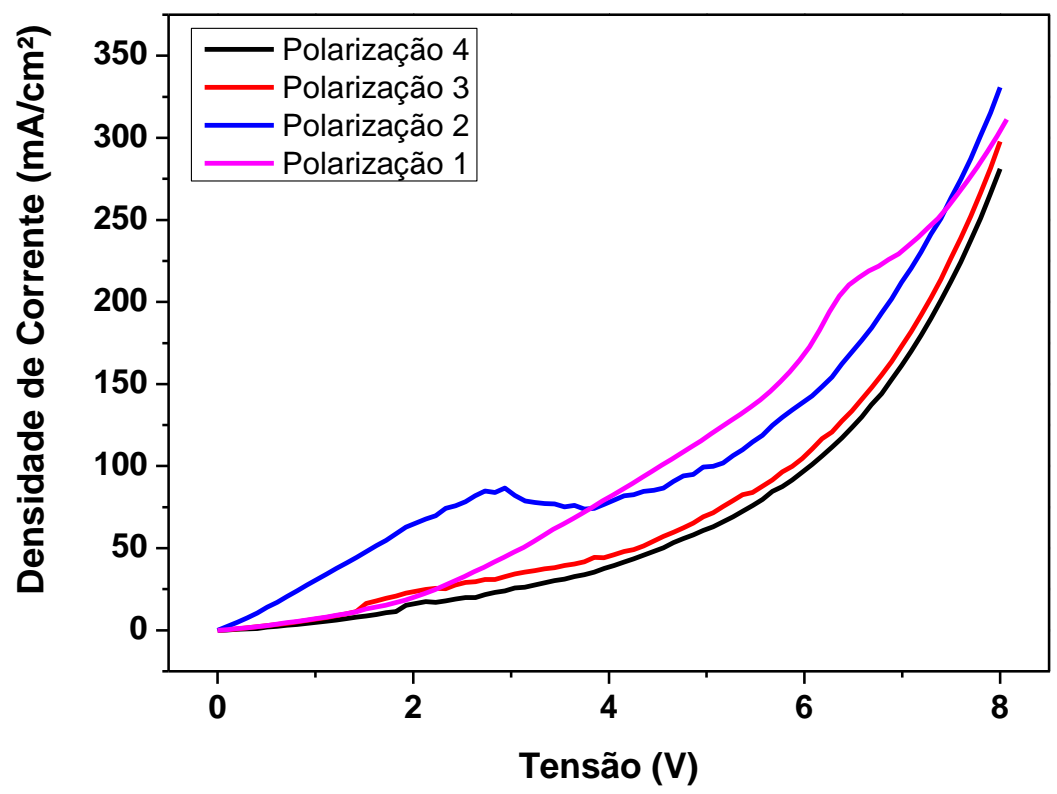

Fonte: Autoria própria.

Tabela 24 - Influência da polarização na tensão de limiar dos dispositivos de $\mathrm{PF}_{\mathrm{PF}}$.

Tensão de Limiar (V)

\begin{tabular}{ccccc} 
PFFF $_{\mathrm{PF}}$ Ir(ppy) & Polarização 1 & Polarização 2 & Polarização 3 & Polarização 4 \\
\hline $\mathbf{9 8 : 2}$ & 7,5 & 7,8 & 7,8 & 7,8 \\
$\mathbf{9 6 : 4}$ & 3,4 & 7,2 & 7,6 & 7,6 \\
$\mathbf{9 3 : 7}$ & 5,1 & 6,0 & 6,3 & 6,3 \\
\hline
\end{tabular}

Fonte: Autoria própria. 
Figura 92 - Influência da polarização na curva $\mathrm{J}$ x $\mathrm{V}$ do dispositivo de TI.

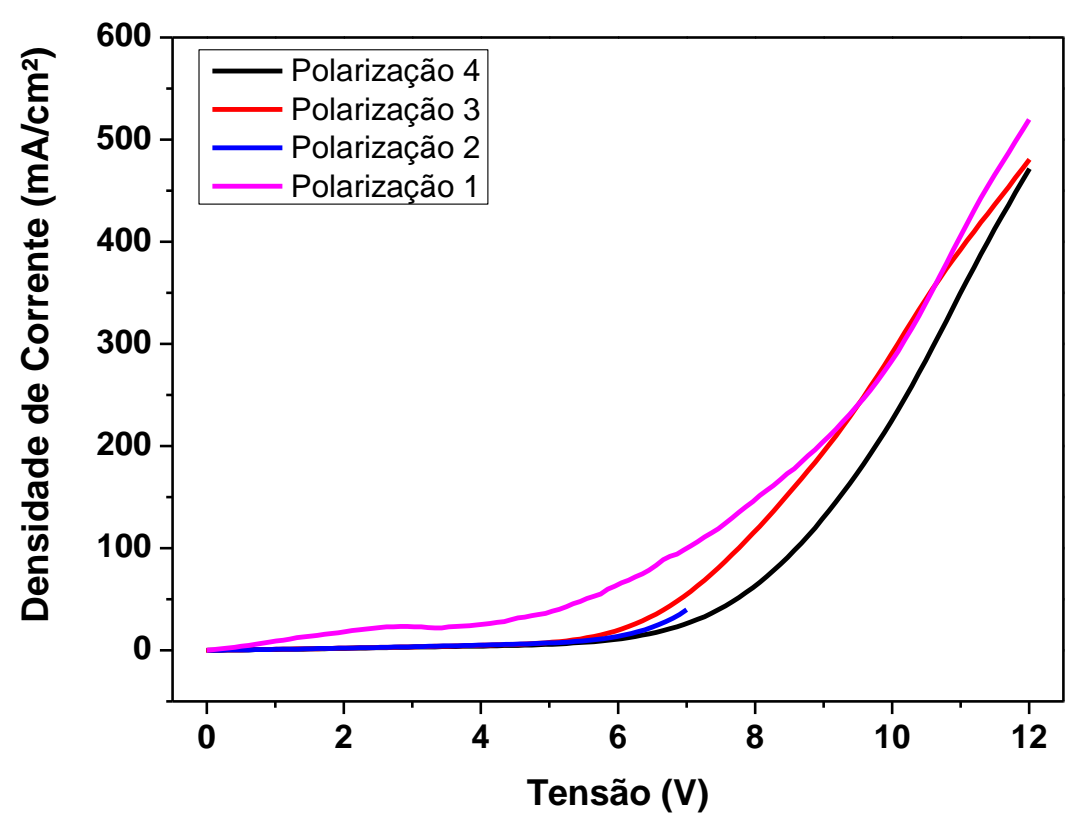

Fonte: Autoria própria.

Figura 93 - Influência da polarização na curva J x V do dispositivo TII.

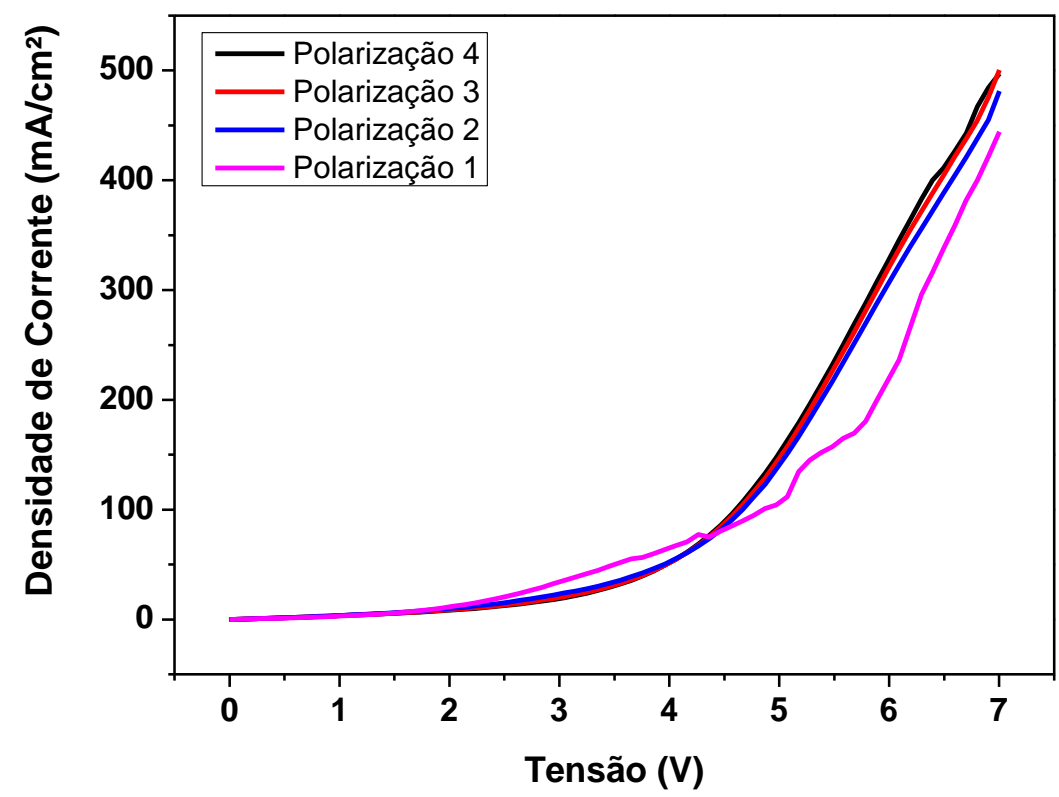

Fonte: Autoria própria. 
Figura 94 - Influência da polarização na curva J x V do dispositivo TIII.

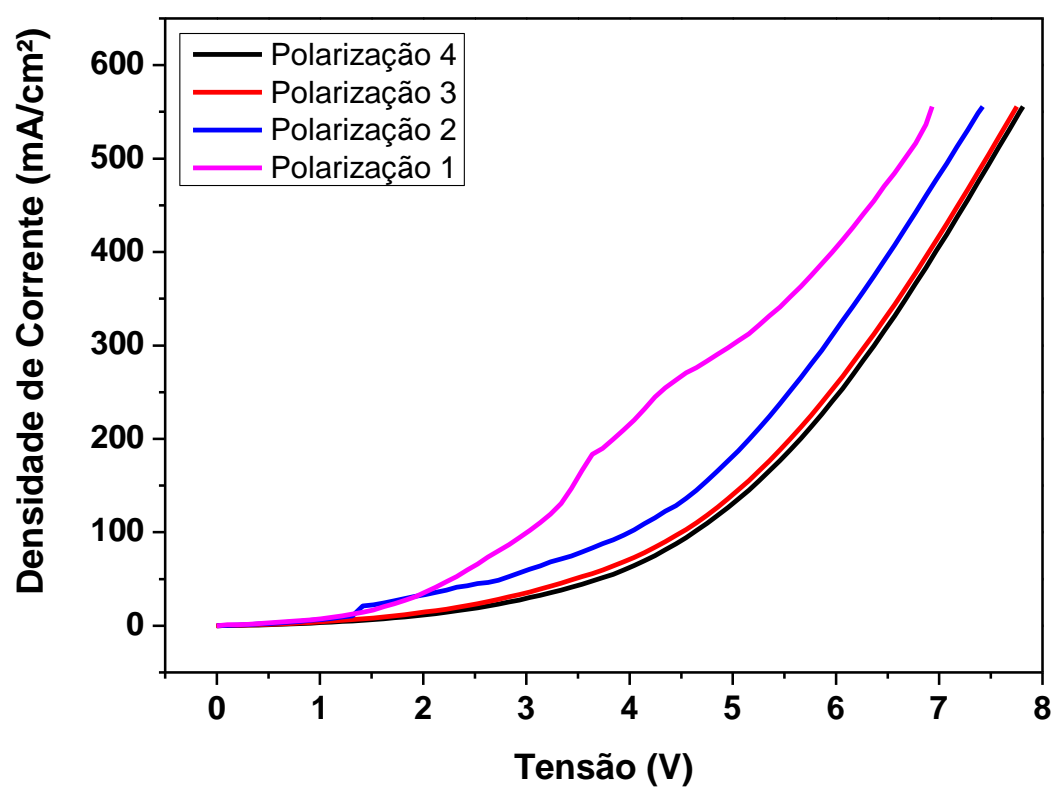

Fonte: Autoria própria.

Tabela 25 - Influência da polarização na tensão de limiar dos dispositivos de PVK puro (TI, TII e TIII).

\section{Tensão de Limiar (V)}

\begin{tabular}{ccccc} 
Dispositivo & Polarização 1 & Polarização 2 & Polarização 3 & Polarização 4 \\
TI & 8 & 6,1 & 7 & 8,2 \\
TII & 4,9 & 4,3 & 4,2 & 4,2 \\
TIII & 3,1 & 4,3 & 4,7 & 4,7 \\
\hline
\end{tabular}

Fonte: Autoria própria. 
Figura 95 - Influência da polarização na curva $\mathrm{J}$ x V do dispositivo PVK:AZO.

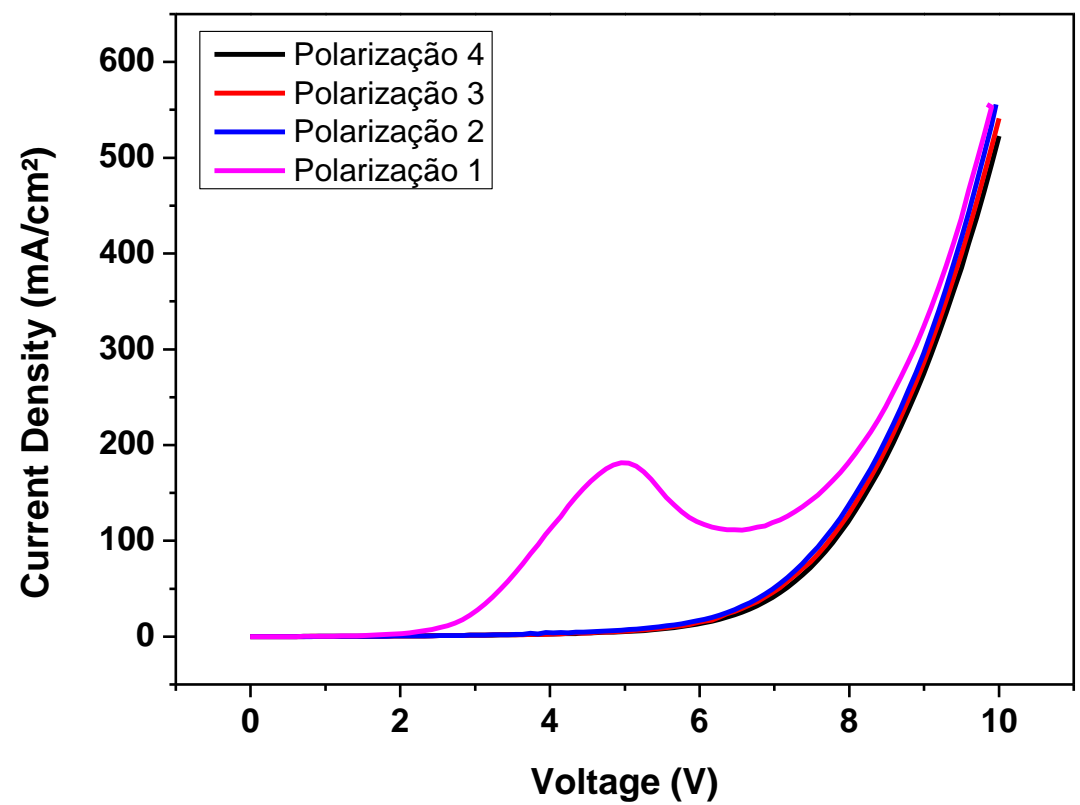

Fonte: Autoria própria. 